\title{
Climatic effects on rapid chemical and physical denudation rates measured with cosmogenic nuclides in the Ōhau catchment, New Zealand
}

Maia Fern Bellingham
A thesis submitted to Victoria University of Wellington in partial fulfilment of requirements for the degree of
Master of Science
in

Physical Geography
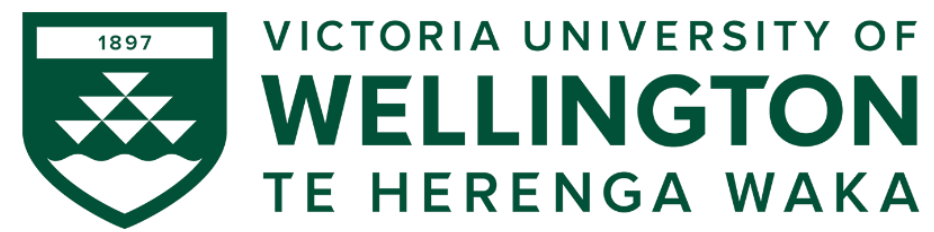

TE HERENGA WAKA

School of Geography, Environment and Earth Sciences

Victoria University of Wellington

2020 
This thesis is dedicated to my Mum, Alison Davis 


\begin{abstract}
Understanding how active mountain landscapes contribute to carbon dioxide cycling and influences on long-term climate stability requires measurement of weathering fluxes from these landscapes. The few measured chemical weathering rates in the Southern Alps are an order of magnitude greater than in the rest of the world. Rapid tectonic uplift coupled with extreme orographic precipitation is driving exceptionally fast chemical and physical denudation. These rates suggest that weathering in landscapes such as the Southern Alps could play a significant role in carbon dioxide cycling. However, the relative importance of climate and tectonics driving these fast rates remains poorly understood.

To address this gap, in situ ${ }^{10} \mathrm{Be}$ derived catchment-averaged denudation rates were measured in the Ōhau catchment, Canterbury, New Zealand. Denudation rates in the Dobson Valley within the Ōhau catchment, varied from $474-7,570 \mathrm{~m} \mathrm{Myr}^{-1}$, aside from one sub-catchment in the upper Dobson Valley that had a denudation rate of $12,142 \mathrm{~m}$ $\mathrm{Myr}^{-1}$. The Dobson and Hopkins Rivers had denudation rates of 1,660 and 4,400 $\mathrm{m} \mathrm{Myr}^{-}$ ${ }^{1}$ respectively, in these catchments. Dobson Valley denudation rates show a moderate correlation with mean annual precipitation $\left(\mathrm{R}^{2}=0.459\right)$. This correlation supports a similar trend identified at local and regional scales, and at high rates of precipitation this may be an important driver of erosion and weathering.
\end{abstract}

Sampling of four grain sizes $(0.125$ to $>8 \mathrm{~mm})$ at one site in the Dobson Valley resulted in variability in ${ }^{10} \mathrm{Be}$ concentrations up to a factor of 2.5 , which may be a result of each grain size recording different erosional processes. These observations demonstrate the importance of assessing potential variability and the need to sample consistent grain sizes across catchments.

Chemical depletion fractions measured within soil pits in the upper Dobson Valley indicate chemical weathering contributes $30 \%$ of total denudation, and that physical erosion is driving rapid total denudation. Chemical weathering appears to surpass any proposed weathering speed limit and suggests total weathering may not be limited by weathering kinetics. This research adds to the paucity of research in New Zealand, and for the first time presents ${ }^{10} \mathrm{Be}$ derived denudation rates from the eastern Southern Alps, with estimates of the long-term weathering flux. High weathering fluxes in the Southern Alps uphold the hypothesis that mountain landscapes play an important role in carbon dioxide cycling and long-term climate stability. 


\section{Acknowledgements}

Endeavouring on this research has been the most incredible adventure that I have been lucky enough to share with many wonderful people. Firstly, the greatest thank you to my two supervisors, Claire Lukens and Kevin Norton. There is no way I would have completed this without the both of you. To Claire, thank you for being by my side every step of the way, helping me in the lab whenever I needed and reading my thesis time and time again. To Kevin, thank you for the constant positivity and encouragement at the times I really needed it, and for reading my thesis many times. I have immense gratitude to both of you for allowing me to be a part of this project and for funding our amazing field work and lab work. I would also like to thank Luisa Ashworth, Jane Chewings and all others involved in the cosmo group at VUW for helping me through my outrageously long laboratory journey, particularly during physical sample preparation when the times were trying. I would also like to acknowledge Eron Raines for being part of the most amazing field work down to the Dobson Valley, soil pits and a helicopter ride I will never forget. Special thanks to Alan Hidy at the Lawrence Livermore National Laboratory (LLNL) centre for Accelerator Mass Spectrometry (CAMS) for processing my samples.

Thanks to my office mates in CO421 for always making it a fun time with perhaps to many games of cards and for encouraging me through the many difficult times. To my friends and flatmates, particularly Lauren thank you for being so supportive and understanding especially in these final few weeks. Finally, to my family, Mum, Dad and Finn thank you for everything you have done for me and for encouraging me throughout my whole life to achieve whatever I set my mind to. I would also like to especially thank my Mum, you have been my rock over the past 6 years at university. I will never be able to express the immense gratitude I have for you and will never forget how much you supported me as you went through your hardest times. 


\section{Table of Contents}

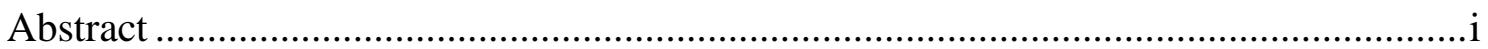

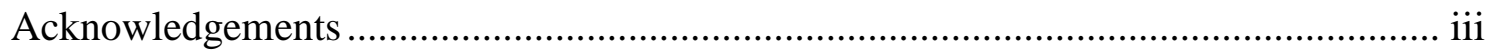

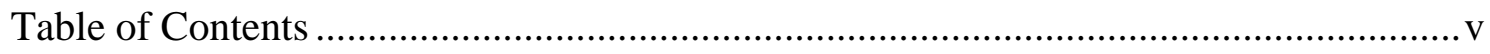

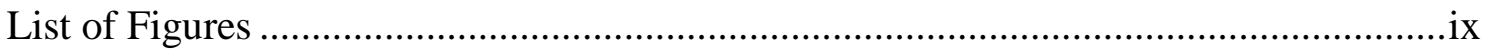

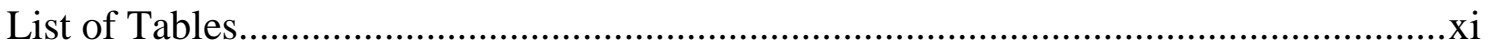

Chapter 1. Introduction and background............................................................ 1

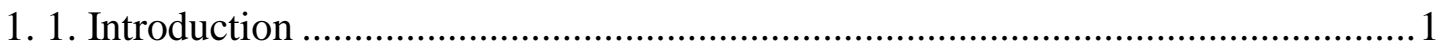

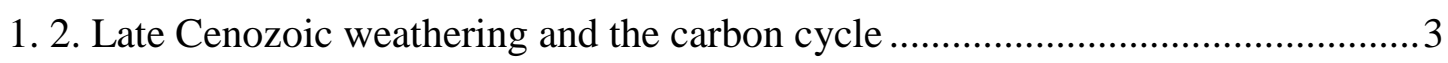

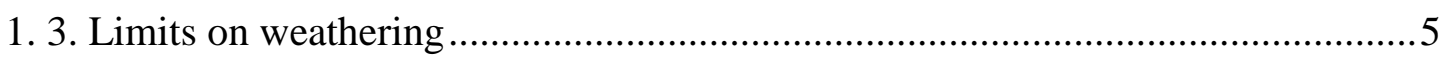

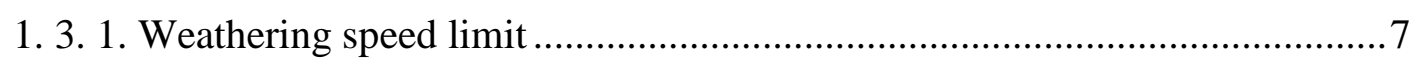

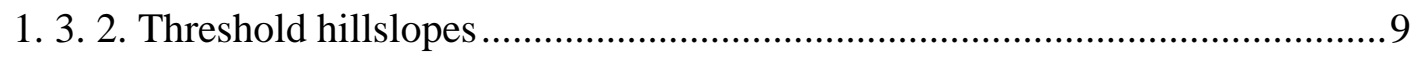

1. 4. Physical erosion and chemical weathering calculations...................................... 10

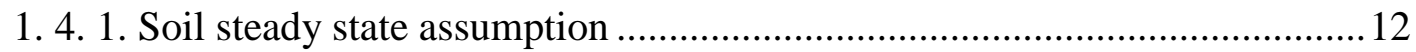

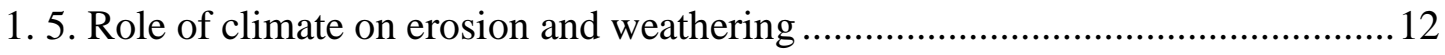

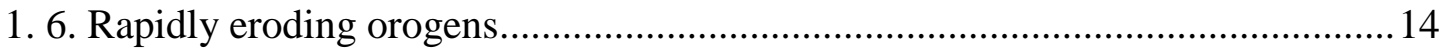

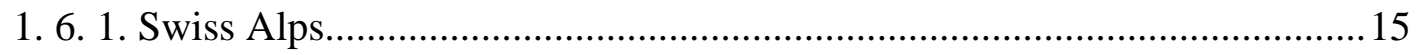

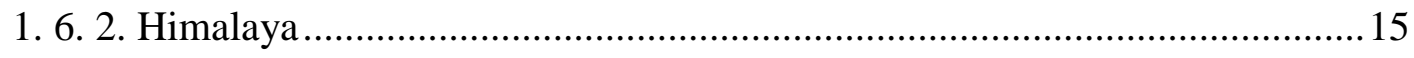

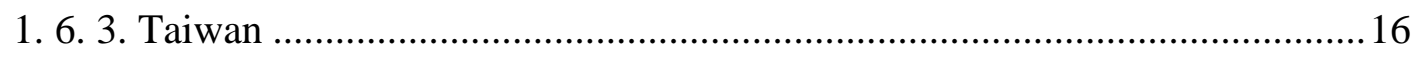

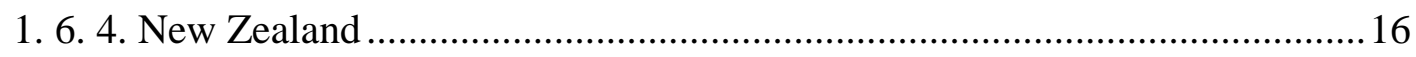

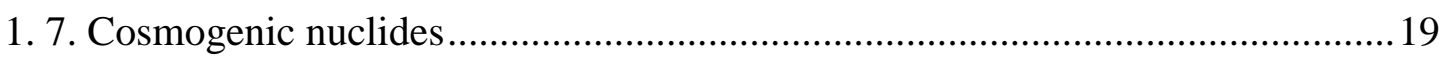

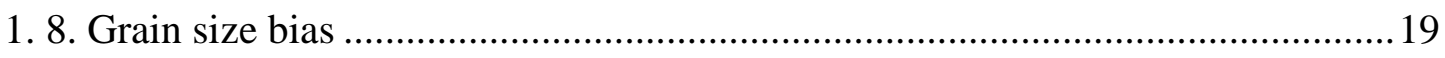

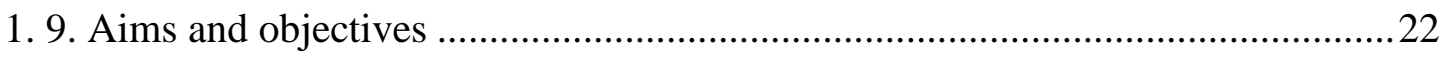

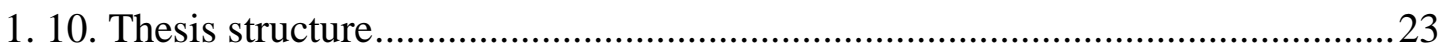

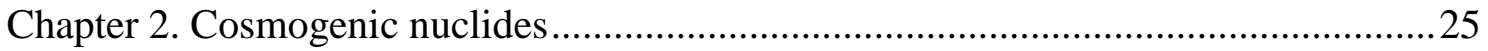

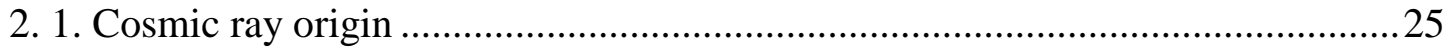

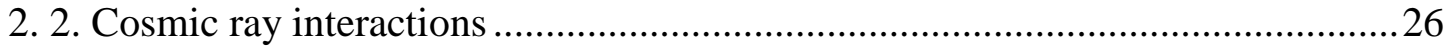




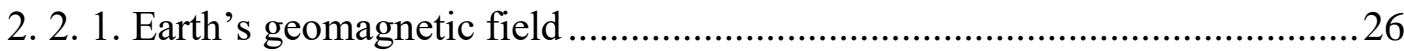

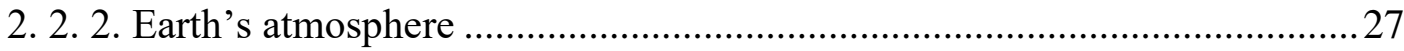

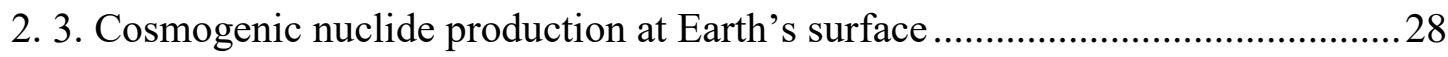

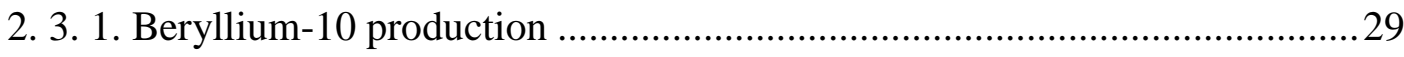

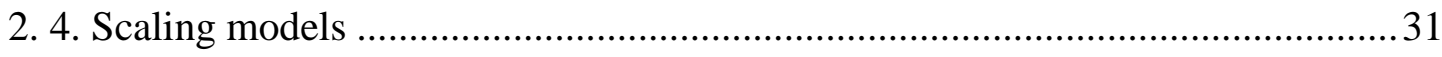

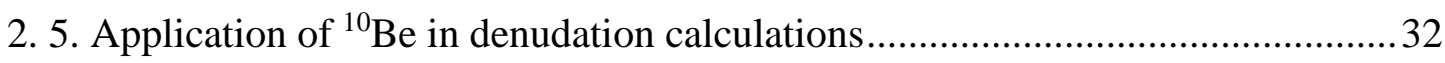

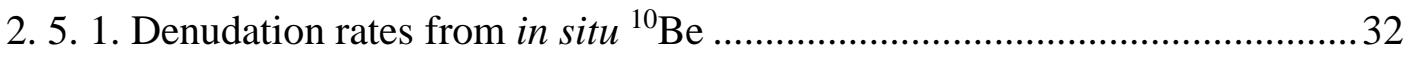

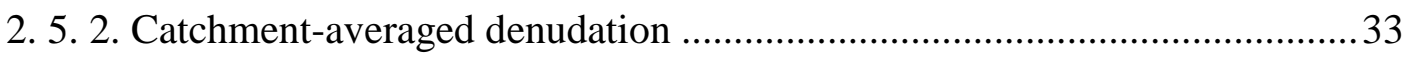

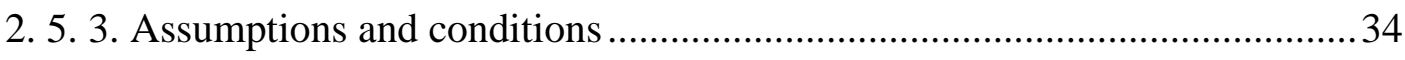

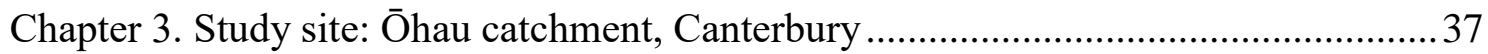

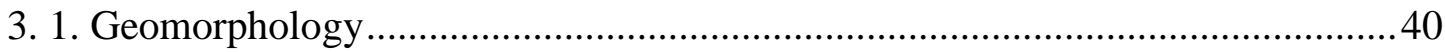

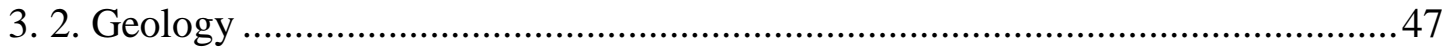

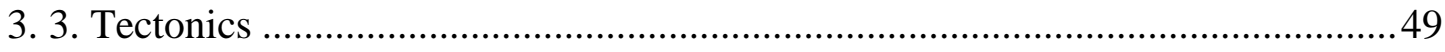

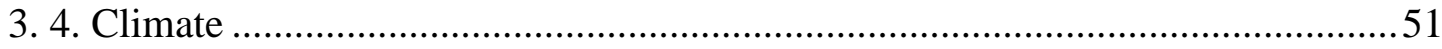

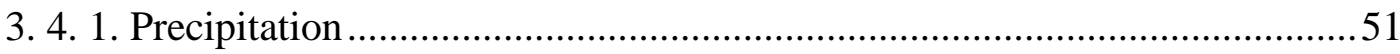

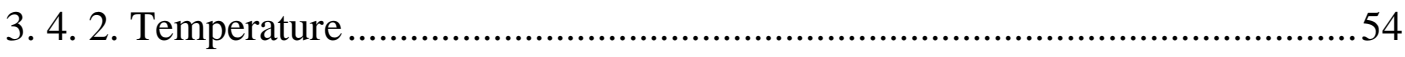

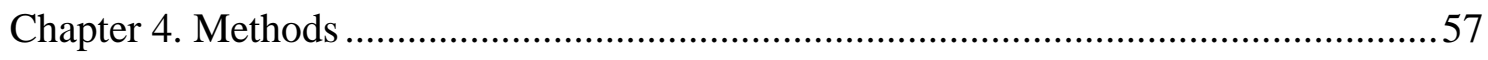

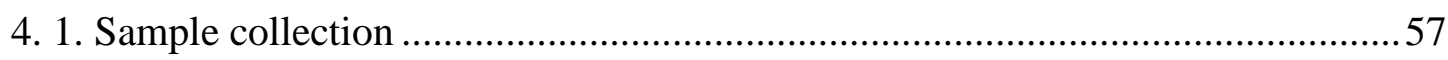

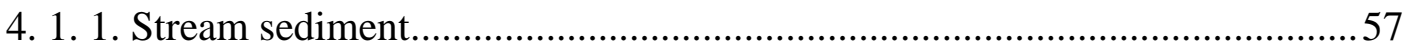

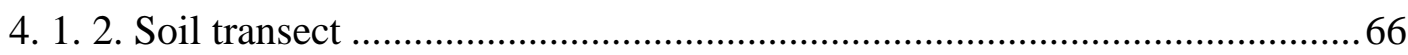

4. 2. Beryllium-10 laboratory procedures ........................................................ 70

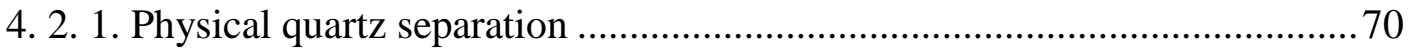

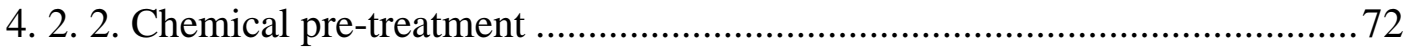

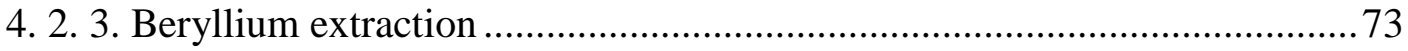

4. 2. 4. Accelerator Mass Spectrometer ............................................................. 75

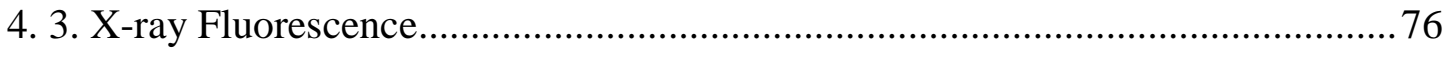

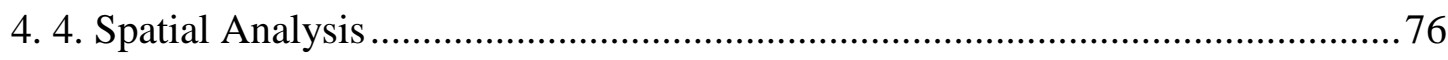




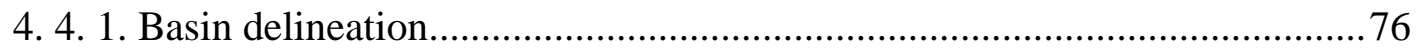

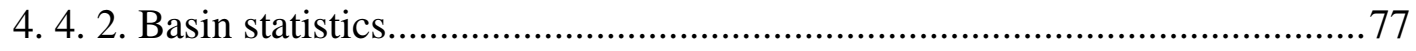

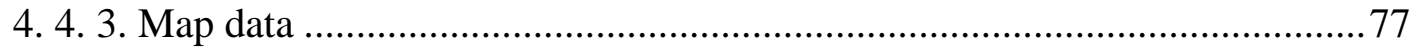

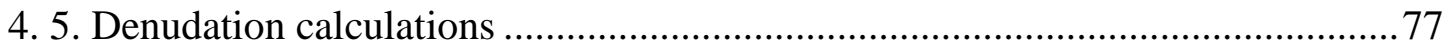

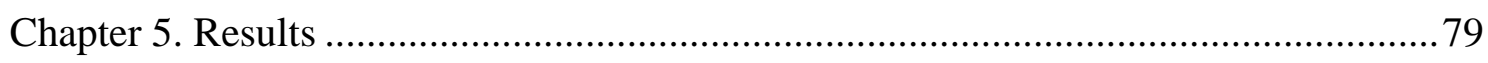

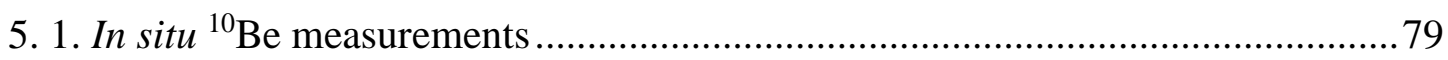

5. 1. 1. ${ }^{10}$ Be derived catchment-averaged denudation rates .................................. 79

5. 2. Zirconium concentrations from X-ray Fluorescence...................................... 90

5. 2. 1. Chemical depletion fractions ........................................................... 90

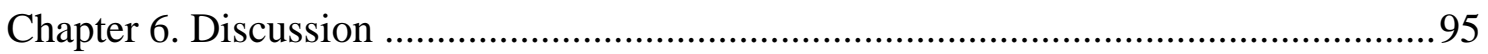

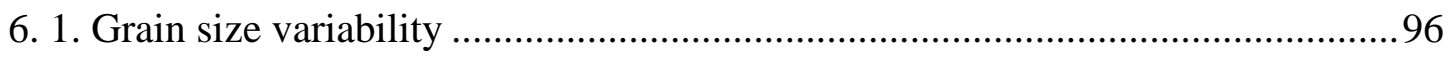

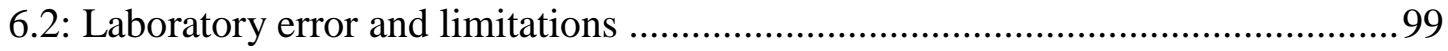

6. 3. Trends in Ōhau catchment denudation with topography, lithology and climate 100

6. 3. 1. Dobson Valley sub-catchment denudation rate variability .......................100

6. 3. 2. Controls on denudation rates in the Dobson Valley ..................................101

6. 3. 3. New Zealand cosmogenic nuclide production rates ............................... 103

6. 3. 4. Dobson River and Hopkin River denudation rates .................................. 104

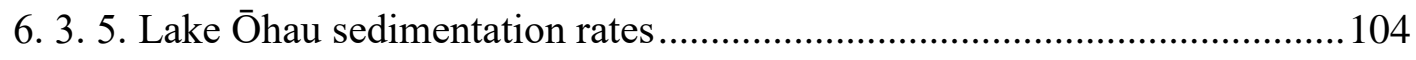

6. 4. Denudation rates across New Zealand ......................................................... 107

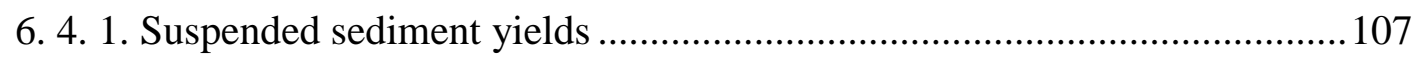

6. 4. 2. Cosmogenic nuclide derived long-term denudation rates.........................109

6. 5. Chemical weathering and physical erosion of total denudation .......................112

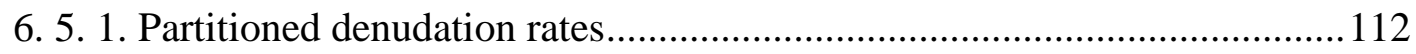

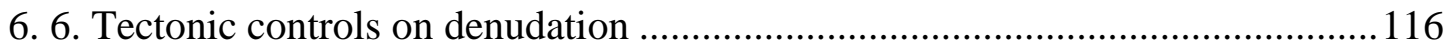

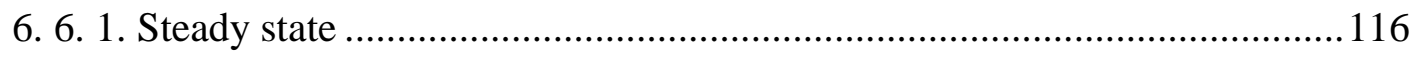

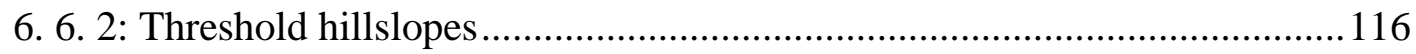

6. 6. 3. Tectonic activity on the Alpine Fault, Southern Alps ............................118 
6. 6. 4. Active and passive margin denudation rates 118

6. 7. Erosion, weathering and atmospheric $\mathrm{CO}_{2}$ consumption 120

6. 8: Future directions and recommendations 121

Conclusions 123

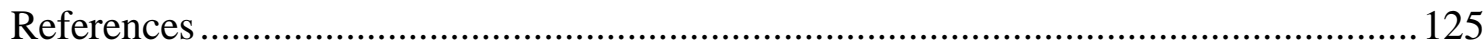

Appendix A. CRONUS-online Earth calculator V. 2.3 denudation rate results ........... 139 Appendix B. Analytical calibration curve and corrected $\mathrm{Zr}$ concentrations .................141 Appendix C. New Zealand catchments denudation rate results from Norton (unpublished) 143 


\section{List of Figures}

Figure 1.1. Geochemical carbon cycle 3

Figure 1.2. Soil mass balance in a steadily eroding landscape 6

Figure 1.3. Supply and kinetic limitations on physical erosion .8

Figure 1.4. Variations in chemical weathering rates in a landscape with periodic

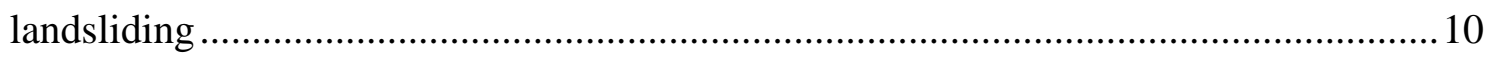

Figure 2.1. Cosmic ray interactions in Earth's atmosphere ........................................26

Figure 2.2. Incoming primary cosmic ray interactions with Earth's geomagnetic field. 27

Figure 2.3. Production of ${ }^{10} \mathrm{Be}$ with depth from the surface .......................................29

Figure 2.4. Meteoric and insitu ${ }^{10} \mathrm{Be}$ interactions at Earth's surface ................................. 30

Figure 2.5. Schematic of the principles of "let nature do the averaging" ....................... 34

Figure 3.1. Map of Te Waipounamu showing the Ōhau catchment, Canterbury ............38

Figure 3.2. Map of Ōhau catchment, Canterbury with the two main tributaries: Hopkins and Dobson Rivers .39

Figure 3.3. Lateral moraines and glacial benches in the upper Dobson Valley..............40

Figure 3.4. Geomorphology map of the Ōhau catchment, Canterbury ...........................42

Figure 3.5. Alluvial fans in the upper Dobson Valley .................................................. 43

Figure 3.6. Dobson River in flood January 19th 2019 ................................................ 44

Figure 3.7. Example of an upper Dobson Valley sub-catchment .................................45

Figure 3.8. Scree slopes in Stewart Stream, Lower Dobson Valley .............................. 46

Figure 3.9. Geology and tectonic map of the Ōhau catchment, Canterbury ....................48

Figure 3.10. Map of active and inactive faults of Te Waipounamu..............................50

Figure 3.11. Mean annual precipitation of Te Waipounamu, New Zealand...................52

Figure 3.12. Mean annual precipitation of the Ōhau catchment, Canterbury.................53

Figure 3.13. Mean annual temperature map of Ōhau catchment, Canterbury .................54

Figure 3.14. Image of perennial snow in Dobson Valley headwaters ............................55

Figure 4.1. Map of stream sediment sample locations and the corresponding catchment

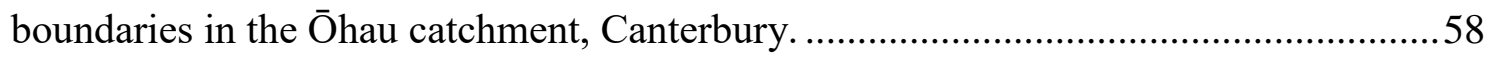

Figure 4.2. Map of stream sediment sample locations in the upper Dobson Valley,

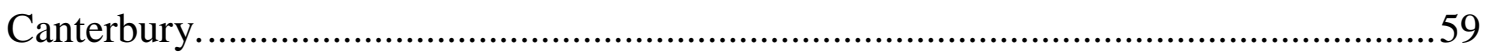

Figure 4.3. Map of stream sediment sample locations in the lower Dobson Valley,

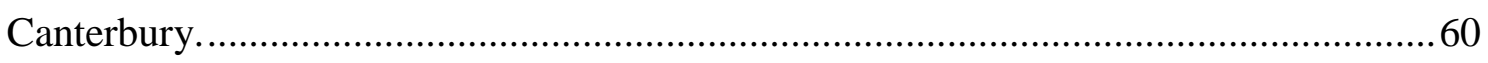

Figure 4.4. Sediment sampling sites in the upper Dobson Valley, Canterbury .............. 64 
Figure 4.5. Sediment sampling sites in the lower Dobson Valley, Canterbury 65

Figure 4.6. Map of soil transect, adjacent to the DOB19-08 sub-catchment in the upper

Dobson Valley, Canterbury..... 67

Figure 4.7. Soil pits dug along the crest of a ridge in the upper Dobson Valley ..... 69

Figure 5.1. Upper Dobson Valley catchment-averaged denudation rates...................... 81

Figure 5.2. Lower Dobson Valley catchment-averaged denudation rates 82

Figure 5.3 Catchment area plotted against denudation rate for sub-catchments in the Dobson Valley..... .87

Figure 5.4. Mean elevation plotted against denudation rate for sub-catchments in the Dobson Valley..... 87

Figure 5.5. Mean slope angle plotted against denudation rate for sub-catchments in the Dobson Valley. .88

Figure 5.6. Mean aspect plotted against denudation rate for sub-catchments in the Dobson Valley .88

Figure 5.7. Mean annual precipitation plotted against denudation rate .89

Figure 5.8. Mean annual temperatureplotted against denudation rate for sub-catchments in the Dobson Valley..... 89

Figure 5.9. DOB19-11 chemical depletion fraction plotted against depth below surface. .93

Figure 5.10. DOB19-12 chemical depletion fraction plotted against depth below surface .93

Figure 5.11. DOB19-15 chemical depletion fraction plotted against depth below surface 94

Figure 6.1. Photo of the Hopkins River showing past aggradation within the lifetime of a Matagouri tree in the Ōhau catchment, New Zealand 107

Figure 6.2. Plot of western Southern Alps and eastern Southern Alps suspended sediment loads and ${ }^{10} \mathrm{Be}$ derived denudation rates with rates from the Ōhau catchment. 109

Figure 6.3. Schematic of linkages between climate, tectonics, biological processes, carbon dioxide and weathering fluxes

Figure 6.4. Plot of denudation rates and mean annual precipitation for active and passive margins worldwide. 


\section{List of Tables}

Table 2.1. Summary of the five most common scaling models 32

Table 4.1. Summarised catchment characteristics for sampling locations in the Ōhau catchment, Canterbury.

Table 5.1. ${ }^{10} \mathrm{Be} /{ }^{9} \mathrm{Be}$ ratios, ${ }^{10} \mathrm{Be}$ concentrations and additional information associated with calculating catchment-averaged denudation rates. 83

Table 5.2. ${ }^{10} \mathrm{Be} /{ }^{9} \mathrm{Be}$ ratios, ${ }^{10} \mathrm{Be}$ concentrations and additional information associated with laboratory process blanks 84

Table 5.3. Results of catchment-averaged denudation rates calculated by the online earth calculator (version 3)

Table 5.4. Results for DOB19-04 catchment-averaged denudation rate 86

Table 5.5. Zirconium concentration results from XRF for soils and saprolites within pits along the soil transect

Table 5.6. Chemical depletion fraction results calculated using zirconium concentrations of soils and saprolites

Table 6.1. Partitioned chemical weathering and physical erosion components of total average denudation using DOB19_08 sub-catchment denudation rate. 112 Table 6.2. Partitioned chemical weathering and physical erosion components of total average denudation for the Dobson River catchment 



\section{Chapter 1. Introduction and background}

\section{1. Introduction}

There is currently little consensus on the role physical erosion and chemical weathering play on carbon cycling and thus long-term climate change in tectonically active landscapes (Berner, Lasaga, \& Garrels, 1983; Gabet \& Mudd, 2009; Molnar \& England, 1990; Raymo \& Ruddiman, 1992). A paucity of chemical weathering and physical erosion measurements from rapidly eroding mountains has contributed to this lack of a consensus. Here, I define chemical weathering as the disintegration of rock through geochemical reactions, through the alteration of rock and by removal of solutes. Physical erosion is the process of the mechanical break up and removal of rock. Denudation is the combination of both chemical weathering and physical erosion in a landscape. Together, these processes play an important role in the global carbon cycle through the sequestration and storage of carbon dioxide over geologic timescales.

Tectonically active mountain landscapes such as the Southern Alps, New Zealand have long been thought to be rapidly eroding based on fast uplift rates, high precipitation, and large historical river suspended sediment yields (Adams, 1980; Griffiths, 1979; Hicks et al., 2011). The Southern Alps have been converging and uplifting for the past $~ 8 \mathrm{Myr}$ at a rate up to $2.8 \mathrm{~mm} \mathrm{yr}^{-1}$ (Tippett \& Kamp, 1993). Rates of tectonic uplift, coupled with precipitation rates exceeding $10,000 \mathrm{~mm} \mathrm{yr}^{-1}$ (Macara, 2016b) have contributed to exceptionally high denudation rates. Historic short-term river suspended sediment yields from the western Southern Alps have been measured up to $37,000 \mathrm{t} \mathrm{km}^{-2} \mathrm{yr}^{-1}$ (Adams, 1980). Western Southern Alps suspended sediment yields are substantially higher than other global river yield measurements (Milliman \& Syvitski, 1992). New Zealand contributes $1.7 \%$ of the global sediment yield to the oceans making it a significant global sediment contributor (Hicks et al., 2011). Recent erosion and soil production measurements from cosmogenic nuclides across the western Southern Alps are up to 9 $\mathrm{mm} \mathrm{yr}^{-1}$ and $2.5 \mathrm{~mm} \mathrm{yr}^{-1}$ respectively (Larsen et al., 2014). These results have affirmed that denudation rates from the Southern Alps are amongst the highest on Earth.

Chemical weathering plays a key role in the long-term climate cycle through the sequestration of carbon dioxide (Berner et al., 1983) and it is accepted that the processes are coupled, however to what extent has not been widely concluded (Riebe, Kirchner, \& 
Finkel, 2004b). The relationship between physical erosion and chemical weathering processes is critical in understanding long-term effects on the global carbon cycle as physical erosion regulates chemical weathering. Chemical weathering is often limited by the supply of fresh minerals in the weathering zone by uplift (Ferrier, Riebe, \& Hahm, 2016; Hilley et al., 2010). Through the mechanical break up of rock, physical erosion leads to a supply of fresh minerals. When chemical reactions slow, physical erosion may accelerate denudation rates from the influence of tectonic activity (Hilley et al., 2010). Physical erosion may drive weathering in places where it may otherwise not be high through the influence of tectonic uplift.

Quantifying denudation rates in rapidly eroding mountain ranges allows for further understanding of how carbon cycling may change in the future and how it may influence long-term climate stability. New Zealand has some of the highest measured physical erosion and soil production rates, but very few studies exist to document these fast rates particularly outside the western Southern Alps (Jacobson \& Blum, 2003; Larsen et al., 2014). With exceptionally high erosion rates, chemical weathering should also increase with the supply of fresh minerals. In the work presented here, I used established methods to measure chemical weathering and physical erosion rates in the Southern Alps, which documents rapid rates in New Zealand. This research contributes to the current debate on the control and limits on weathering and its role in the long-term global carbon cycle. 


\section{2. Late Cenozoic weathering and the carbon cycle}

Rates of denudation rapidly accelerated throughout the Late Cenozoic from the Late Pliocene to the Quaternary (Molnar, 2004a). During that time period, increased rates of denudation are often attributed to changes in climate. Throughout the Late Cenozoic, frequency and amplitude of climate change have both increased (Zachos et al., 2001b). On long time scales, chemical weathering of silicate minerals is consequential as weathering sequesters carbon dioxide $\left(\mathrm{CO}_{2}\right)$. Sequestration of $\mathrm{CO}_{2}$ from the atmosphere through weathering ultimately leads to a balance of atmospheric $\mathrm{CO}_{2}$ on geological timescales.

Chemical weathering is the break-up of rock through chemical processes and is characterised by the break-up of the cleavage of bonds in the mineral lattice by water with the presence of a secondary weathering agent such as carbonic acid (Brault, Matthews, \& Mysak, 2017). Weathering is a major component of the geochemical cycle (Fig. 1. 1) which dictates the climate and life cycles on Earth. Among other ions, weathering products include calcium $\left(\mathrm{Ca}^{2+}\right)$ and bicarbonate $\left(\mathrm{HCO}_{3}^{-}\right)$which can be carried in runoff to rivers, eventually into the ocean. Weathering of silicate rock into silicic acid or $\mathrm{SiO}_{2}$ consumes one more molecule of $\mathrm{CO}_{2}$ than weathering of carbonate minerals even though the same amount of $\mathrm{Ca}^{2+}$ and $\mathrm{HCO}_{3}{ }^{-}$is produced (Brault et al., 2017). Weathering through hydrolysis of silicate minerals is much slower than dissolution of carbonate minerals which results in the effect of atmospheric $\mathrm{CO}_{2}$ uptake through silicate weathering to be a significant sink on geologic timescales upward of $10^{5}$ years (Brault et al., 2017).

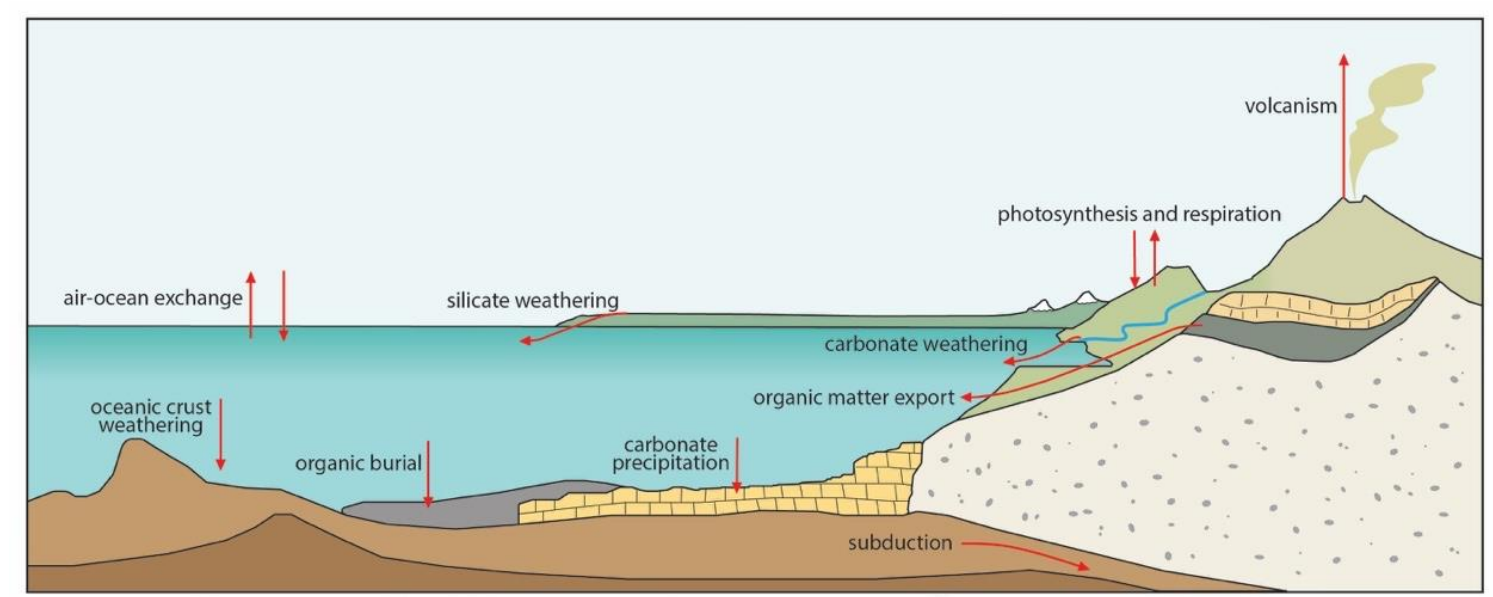

Figure 1.1. Geochemical carbon cycle adapted from Gaillardet and Galy (2008). 
As $\mathrm{CO}_{2}$ concentrations rise, temperature and precipitation increase, which promotes more weathering (Goudie \& Viles, 2012; Zachos et al., 2001a). This negative weatheringclimate feedback removes $\mathrm{CO}_{2}$ and ultimately leads to cooling. Together with other processes in the geochemical cycle such as oxidation and the burial of carbon, levels of $\mathrm{CO}_{2}$ are reduced. These mechanisms maintain Earth's climate within a habitable range (Zachos et al., 2001b).

There has long been a consensus that there is a link between the carbon cycle and chemical weathering. Although this link is agreed on throughout the literature (Berner \& Raiswell, 1983; Kump, Brantley, \& Arthur, 2000; Raymo, Ruddiman, \& Froelich, 1988; Stallard, 1998) there is much debate as to whether increased $\mathrm{CO}_{2}$ led to higher temperatures resulting in an increase in weathering (Molnar \& England, 1990) or that mountain uplift led to an increase in rates of weathering (Raymo \& Ruddiman, 1992). In either case the increase in weathering throughout eroding landscapes has resulted in removal of $\mathrm{CO}_{2}$ from the atmosphere on long term geologic time scales.

The debate regarding the impact of climatic cooling on erosion and whether cooling has then led to further increases in sediment flux and erosion was presented in a series of review papers (Herman \& Champagnac, 2016; Norton \& Schlunegger, 2017; Willenbring \& Jerolmack, 2016). There is agreement that a cooling trend occurred during the Late Cenozoic, beginning at $50 \mathrm{Ma}$ and ultimately resulting in Northern Hemisphere Glaciation that began 2-3 Ma (Ruddiman, 2010). There is however significant debate as to whether sedimentation rates increased 2-4 Myr ago and whether this increased erosion (and weathering) lead to climatic cooling. The more widely accepted consensus is that climatic cooling led to increased glaciation that then resulted in an acceleration of weathering and erosion (Herman \& Champagnac, 2016; Molnar, 2004b; Molnar \& England, 1990; Norton \& Schlunegger, 2017). The alternate hypothesis is that weathering and erosion rates have in fact not increased in the past $10 \mathrm{Ma}$ or only increased due to tectonic uplift in the Himalayas, and therefore did not act as a primary driver to climatic cooling (Raymo \& Ruddiman, 1992; Willenbring \& Jerolmack, 2016; Willenbring \& von Blanckenburg, 2010a).

The controversy creating this disagreement comes in part from a potential erosion measurement bias in the sedimentary record. Sedimentary records include long term 
periods of sedimentation and also hiatuses in sedimentation with the latter potentially creating a bias showing rates that increase toward modern times (Herman \& Champagnac, 2016; Norton \& Schlunegger, 2017; Sadler, 1999; Willenbring \& Jerolmack, 2016). This bias is important and based on the interpretation of geological, geomorphological and thermochronological data, although interpretation shows there is still an increase in erosion rate even in the presence of a bias (Herman \& Champagnac, 2016).

An alternative scenario was presented whereby either a non-linear trend or a significant contribution from non-silicate rock caused the effect of accelerated erosion rates to be minimised when only assessing chemical weathering rates (Norton \& Schlunegger, 2017). Although there may be a lack of a chemical weathering signal that does not exclude a concurrent increase in physical erosion rates. Coupling of chemical weathering and physical erosion rates across landscapes thus becomes a relationship of increasing significance in order to establish a consensus across the literature.

\section{3. Limits on weathering}

Physical erosion and chemical weathering have long been thought to be tightly coupled and therefore increase linearly together (Riebe, Kirchner, \& Finkel, 2004a; Stallard \& Edmond, 1983; White \& Blum, 1995). In the recent years however it is been shown that there may be limits to this relationship and at the highest rates of erosion this relationship may decouple (Ferrier \& Kirchner, 2008; Norton \& von Blanckenburg, 2010; West, Galy, $\&$ Bickle, 2005). Physical erosion regulates the rate of chemical weathering through two main processes: replenishment of fresh minerals and an increase in surface area (Dixon \& von Blanckenburg, 2012; Riebe et al., 2004b; West et al., 2005). Firstly, the breakup of regolith through physical erosion replenishes fresh minerals from below the regolith. Secondly, erosion increases the surface area available for weathering. Chemical weathering accelerates physical erosion through the weakening of rock (Dixon \& von Blanckenburg, 2012). Regolith is generally defined as weathered material at Earth's surface. Regolith may include weathered rock (saprolite), that is chemically weathered but not physically mixed, and soil, which is both weathered and mixed (Fig. 1. 2). The regolith is the boundary between Earth's lithosphere, biosphere and atmosphere (Dixon \& von Blanckenburg, 2012). This layer of regolith is maintained through chemical weathering, either keeping pace with or outpacing physical erosion, which removes material from the landscape. 


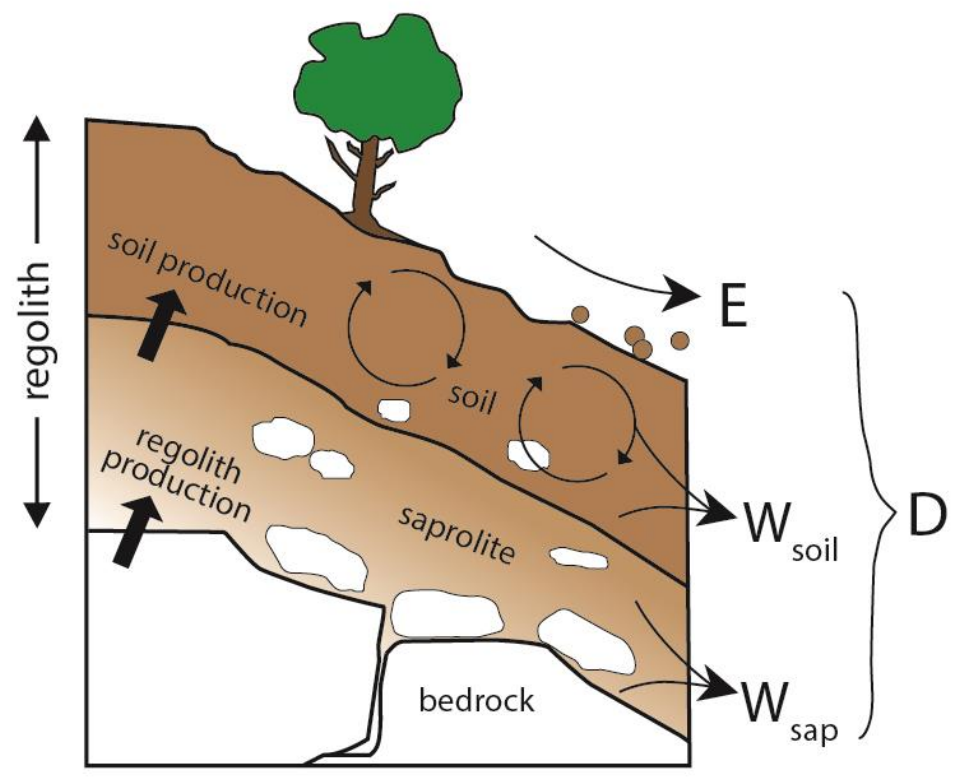

Figure 1.2. Soil mass balance in a steadily eroding landscape. Adapted from Dixon et al. (2012).

Interactions between physical erosion and chemical weathering are determined by rates of sediment supply and rates of mineral reactions (West et al., 2005). This leads to two potential end members. Landscapes can be described as having supply or kinetic limitations, depending on climatic and tectonic conditions. Supply limited weathering is where there is a greater supply of water and acids than the availability of fresh minerals. Minerals are near complete alteration before removal off a hillslope; therefore complete leaching can be reached. Chemical weathering rates are thus directly proportional to the availability of fresh minerals (Dixon et al., 2012; Ferrier et al., 2016; Gabet \& Mudd, 2009; Hilley et al., 2010; Riebe et al., 2004a, 2004b; West et al., 2005). Supply limited slopes have high rates of rock to soil conversion and movement downslope is controlled by the pace of soil formation, eventually the soil production rate and transport rate will match. Soil production is the combination of both physical erosion and chemical weathering as bedrock turns into soil. Supply limited hillslopes theoretically have a thicker soil mantle as they have time to accumulate.

Contrary to supply limited landscapes, in kinetically limited landscapes the supply of regolith outpaces the reaction rate of minerals. In kinetically limited landscapes, rates of chemical weathering do not necessarily change with the supply of minerals. Landscapes can be described as being kinetically limited based on whether chemical weathering is being constrained by mineral dissolution kinetics (Brantley \& White, 2009; Ferrier et al., 
2016; West et al., 2005). Chemical weathering in kinetically limited landscapes is dependent on factors that influence the rate of mineral dissolution including temperature, precipitation and runoff, and vegetation. Kinetically limited landscapes typically have a thin soil mantle, steep slopes and are in dry, cold climates.

A compilation of a global dataset of chemical weathering and total denudation rates show that at lower physical erosion rates landscapes are supply limited compared to landscapes at the highest erosion rates that are kinetically limited (West et al., 2005). Landscapes can be defined as being supply limited by the regolith showing similar chemical depletion as the parent rock (Ferrier et al., 2016). In these catchments physical erosion (supply of fresh minerals) and chemical weathering rates are tightly coupled (West et al., 2005). This tight coupling shows there to be an insensitivity to climate thus showing a weak feedback between denudation and climate (Ferrier et al., 2016; Gabet \& Mudd, 2009; West, 2012). As physical erosion rates increase the relationship with chemical weathering decouples and landscapes become kinetically limited by rates of mineral dissolution. In kinetically limited landscapes it is thought tectonics rather than climate may exert a stronger influence on regulating chemical weathering rates (Ferrier et al., 2016; Gabet \& Mudd, 2009). As increases in uplift enhance physical erosion rates, the non-linear relationship of chemical weathering with increasing physical erosion rates is important for landscapes at the highest erosion rates such as in New Zealand and the Himalayas. Rapidly eroding landscapes that maintain a soil mantle may be significant for increased $\mathrm{CO}_{2}$ sequestration. Soil mantled hillslopes have the greatest solute fluxes and are also where most denudation is taking place (Gabet \& Mudd, 2009; Hilley et al., 2010; West, 2012).

\section{3. 1. Weathering speed limit}

As previously discussed above, the weathering-erosion relationship is non-linear and at the highest physical erosion rates, chemical weathering decouples. This relationship should not increase indefinitely as at high rates of physical erosion there may been a loss of soil cover (Dixon \& von Blanckenburg, 2012; Heimsath, DiBiase, \& Whipple, 2012; Norton \& von Blanckenburg, 2010). If regolith production is limited by the rate of physical erosion then there will be an upper limit on chemical weathering, as observed in the San Gabriel Mountains (Dixon et al., 2012). Chemical weathering becomes kinetically limited at high erosion rates, however in rapidly eroding landscapes the 
regolith is often thin and although the weathering is high per unit volume, the rate per unit area decreases (Gabet \& Mudd, 2009).

Modelling by Ferrier and Kirchner (2008) concluded that chemical weathering rates should approach zero in two scenarios; firstly when physical erosion rates approach zero and secondly, when physical erosion reaches maximum soil production rates (Fig. 1. 3). The second reason is due to soil thickness approaching zero, thus chemical weathering rates are limited by $\mathrm{pH}$, temperature, mineralogy, the availability of water and the time in the reaction zone. Modelled rates of chemical weathering peaked at intermediate levels of physical erosion rates (Ferrier \& Kirchner, 2008). Exceptionally high erosion rates thus may not lead to equally high rates of chemical weathering (Fig. 1. 3).

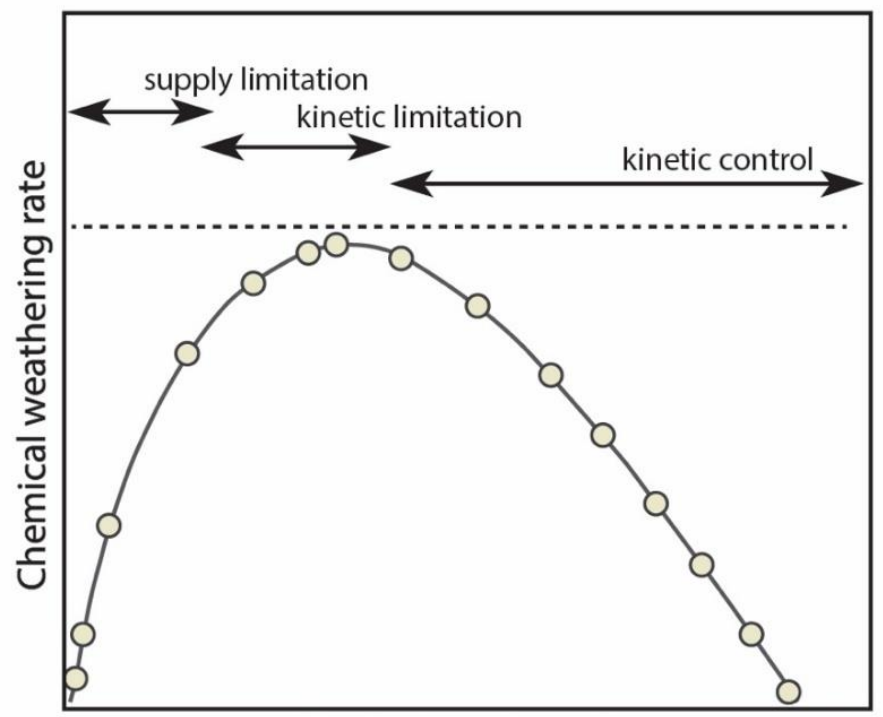

Physical erosion rate

Figure 1.3. Supply and kinetic limitations on physical erosion and chemical weathering. Adapted from Dixon and von Blanckenburg (2012).

Production of regolith in the Southern Alps, New Zealand appears to be much higher than previously measured elsewhere in the world, with rates up to $2.5 \mathrm{~mm} \mathrm{yr}^{-1}$ (Larsen et al., 2014). These results from the Southern Alps demonstrate that if there is a proposed weathering speed limit (Dixon \& von Blanckenburg, 2012; Ferrier \& Kirchner, 2008), this limit may be dependent on tectonic uplift and climatic variables such as precipitation and temperature. 


\section{3. 2. Threshold hillslopes}

In order for hillslopes to remain soil-mantled the rate of weathering and thus formation of soil must be equal to or exceed that of removal off the hillslope through erosional processes (Heimsath et al., 1997). Soil-mantled hillslopes have increased $\mathrm{CO}_{2}$ sequestration relative to bare hillslopes (Gabet \& Mudd, 2009; Hilley et al., 2010; West, 2012). The morphology of a hillslope is constrained by the interactions of diffusive and landsliding processes that are influenced by climate and tectonics (Roering, 2008; Roering et al., 2004; Roering, Kirchner, \& Dietrich, 1999, 2001).

In steep soil-mantled landscapes, shallow landsliding frequently shapes the hillslope. Landscape characteristics such as lithology, climate, topography and tectonics influence the mechanisms and frequency of landsliding. In mountainous regions both shallow and deep landsliding are common mechanisms that regulate the rate of sediment removal off a landscape.

Threshold landscapes are those in which hillslopes are nearing the angle at which landslides will occur (Binnie et al., 2007). These types of hillslopes need to be treated independently to denudation rates as once the threshold is reached further erosion will be due to slope failure rather than slope steepening through physical erosion (Binnie et al., 2007; Burbank et al., 1996; Clarke \& Burbank, 2011). When this threshold slope angle is reached, a hillslope will periodically have landsliding thus, clearing sediment and vegetation. During a landslide, surface material uncovers fresh mineral surfaces and a pulse in chemical weathering may occur on a short time scale (Fig 1.4) (Gabet, 2007). Over long timescales these pulses in chemical weathering become encompassed in the overall denudation rate on a landscape. 


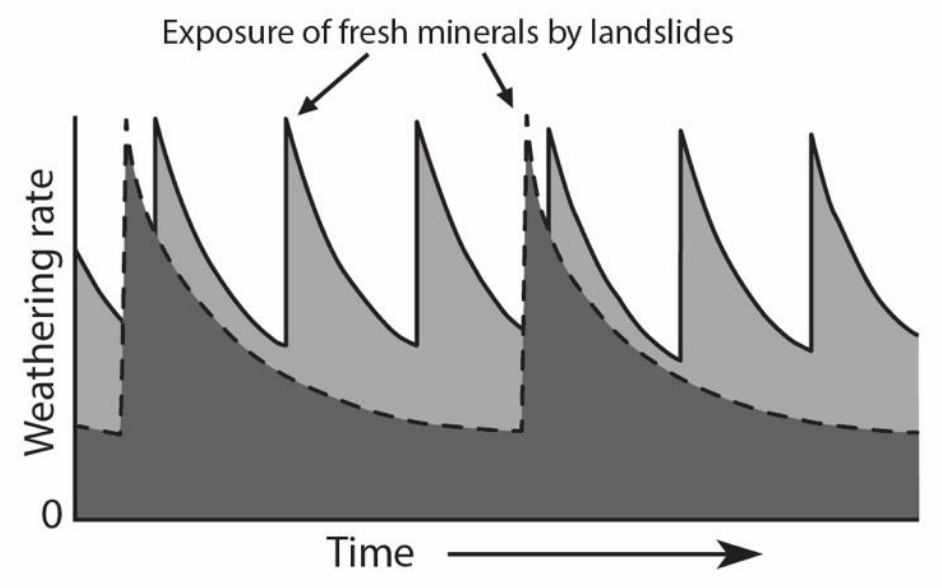

Figure 1.4. Variations in chemical weathering rates in a landscape with periodic landsliding. Figure adapted from (Gabet, 2007).

\section{3. 2. 1. Bedrock erodibility}

In landscapes where rates of physical erosion outpace the rate of soil formation, a bedrock dominated hillslope develops. Bedrock dominated hillslopes are affected by how fractured bedrock is. Highly fractured rock will lead to slope failure at lower slope angles. Bedrock strength in mountainous settings limits hillslope relief and sets the threshold slope angle at which landsliding will occur (Burbank et al., 1996; Clarke \& Burbank, 2011; Montgomery, 2001; Schmidt \& Montgomery, 1995). Weakening of bedrock continually occurs in the subsurface through weathering processes. Weakening of bedrock plays a significant role in physical erosion in the Southern Alps, with tectonic activity in the region leading to fracturing of bedrock (Clarke \& Burbank, 2011). The Southern Alps are dominated by tectonically fractured bedrock that is unstable, resulting in frequent landsliding across the landscape (Clarke \& Burbank, 2011).

\section{4. Physical erosion and chemical weathering calculations}

Long-term chemical weathering rates can be measured using a soil mass-balance approach (Kirchner, Granger, \& Riebe, 1997; Riebe, Kirchner, \& Finkel, 2003; Riebe et al., 2004a, 2004b; Riebe et al., 2001b). Long-term denudation and soil production rates are measured using cosmogenic nuclides, and the fraction of total denudation attributable to chemical weathering is calculated using the enrichment of insoluble elements from rock to soil (Riebe et al., 2003). 
With a measured total denudation flux, the partition of chemical weathering versus physical erosion can be calculated by comparing zirconium in the regolith and zirconium in a given soil horizon. This approach was first developed by Kirchner et al. (1997), then further developed by Riebe et al. (2003); Riebe et al. (2001a); and Riebe et al. (2004a). As mobile elements are removed during chemical weathering through dissolution, immobile elements such as zirconium become enriched (Riebe et al., 2003).

Partitioning of chemical weathering (Eq. 1) and physical erosion (Eq. 2) can be determined using the following equations where, $\mathrm{W}$ is weathering, $\mathrm{E}$ is erosion, $\mathrm{D}$ is total denudation, $[\mathrm{Zr}]_{\text {rock }}$ is the zirconium concentration of the rock and $[\mathrm{Zr}]_{\text {soil }}$ is the zirconium concentration of the soil:

$$
\begin{gathered}
W=D\left(1-\frac{[\mathrm{Zr}]_{\text {rock }}}{[\mathrm{Zr}]_{\text {soil }}}\right) \\
E=D\left(\frac{[\mathrm{Zr}]_{\text {rock }}}{[\mathrm{Zr}]_{\text {soil }}}\right)
\end{gathered}
$$

Eq. 1.1

Eq. 1.2

Equation 1 can then be rearranged to find the chemical depletion fraction (CDF) which describes the intensity of chemical weathering from zero to one, with one being completely weathered (Eq. 3) (Riebe et al., 2003).

$$
\frac{W}{D}=\left(1-\frac{[\mathrm{Zr}]_{\text {rock }}}{[\mathrm{Zr}]_{\text {soil }}}\right)=\mathrm{CDF}
$$

Eq. 1.3

This technique of using a combination of cosmogenic nuclide derived denudation rates and zirconium concentrations to partition chemical weathering and physical erosion rates has shown to have reliability across a diverse range of landscapes (Dixon et al., 2012; Dixon et al., 2009; Ferrier \& Kirchner, 2008; Larsen et al., 2014; Norton \& von Blanckenburg, 2010; Riebe et al., 2003, 2004a, 2004b). 
Using these equations, several assumptions must be made (Ferrier \& Kirchner, 2008):

1. The supply of minerals is entirely from bedrock beneath the soil

2. Sampling is indicative of soil on the hillslope;

3. Both the parent rock and the soil contain an immobile element (such as zirconium)

4. Soil thickness on the hillslope is in steady state (soil production is roughly equal to soil removal).

\section{4. 1. Soil steady state assumption}

A key assumption when partitioning chemical weathering and physical erosion is that the soil mantle is in steady state (Fig 1. 3). Soil can be described as being in steady state when the rate of soil production is roughly equal to the rate of soil removal off a hillslope (Ferrier \& Kirchner, 2008; Riebe et al., 2004a, 2004b; Riebe et al., 2001b). If a hillslope is in steady state, the rate of denudation at one point on the slope should then be equal across the landscape (Roering et al., 1999). Strongly convex hillslopes exhibit thinner soils than weakly convex hillslopes and can be sensitive to biogenic disturbances (Heimsath et al., 1997). Local short term disruptions in the soil mantle such as biogenic and cyclic wet/dry disturbances have little long term effect on soil steady state as diffusion dominated slopes return to steady state within a few thousand years (Dietrich et al., 1995). Landsliding can result in disturbances to the soil mantle through stripping of the soil mantle and accelerating soil production rates by a rapid supply of fresh minerals. This increase in the supply of fresh minerals then replenishes the soil mantle. As hillslopes steepen, increases in the sediment flux become limited as the slope threshold is reached thus creating slope over steepening (Roering et al., 2001). Rapid soil production mean that even in landscapes with steep slopes and frequent landsliding, the landscape can return to steady state thickness over relatively short time periods.

\section{5. Role of climate on erosion and weathering}

Climatic factors such as temperature and precipitation have long been thought to influence chemical weathering rates by effecting the thermodynamics and kinetic reactions of minerals (Dixon, Chadwick, \& Vitousek, 2016; Dixon et al., 2009; Riebe et al., 2004a; White \& Blum, 1995; White \& Brantley, 2003). Temperature plays a significant role on chemical weathering rates and intensity through the effect on mineral kinetics. First applied to chemical weathering by White and Blum (1995), the Arrhenius 
formula (Eq 1. 4) describes the effects of temperature on the dissolution of silicate minerals.

$$
r_{\mathrm{T}}=A e^{\left(-E_{a} / R T\right)}
$$

Eq. 1.4

Where $r_{\mathrm{T}}$ is the chemical weathering response to temperature, $A$ is the pre-exponential factor that links surface area and reactivity, $E_{\mathrm{a}}$ is activation energy for the weathering reaction, $R$ is the gas constant and $T$ is temperature in Kelvin (K). The Arrhenius formula shows a linear correlation at a given temperature with chemical weathering (White \& Blum, 1995).

Recent research has shown a strong relationship between temperature and chemical weathering across a diverse range of landscapes (Dixon et al., 2016; Dixon et al., 2009; Dixon \& von Blanckenburg, 2012; Norton \& von Blanckenburg, 2010; Riebe et al., 2004b; White \& Blum, 1995). Altitude is frequently used as the indicator of temperature change due to the lapse rate of decreasing temperature with increasing elevation. A global dataset of solute concentrations and fluxes established that chemical weathering accelerated in catchments that are warm and have high rates of precipitation (White \& Blum, 1995). Modelling on the effects of climatic variables on chemical weathering suggested temperature exerted the greatest influence, showing an exponential increase compared to precipitation (White \& Blum, 1995). Rates of chemical weathering in the Santa Rosa Mountains decreased significantly with increasing altitude to near zero at the top of the transect (Riebe et al., 2004b). Although along the transect, temperature exhibited a strong influence on weathering rates, other factors such as snow cover and vegetation may have played a role in weathering processes in the Santa Rosa Mountains. Temperature shows a dominant control on chemical weathering rates, with weathering decreasing significantly with increases in elevation both in the Sierra Nevada (Dixon et al., 2009) and the Swiss Alps (Norton \& von Blanckenburg, 2010).

Although temperature has a strong influence on chemical weathering rates, precipitation also plays an important role in weathering processes (Dixon et al., 2016; Rasmussen et al., 2011). Chemical weathering rates can accelerate with increased precipitation affecting the unsaturated soil zone thus, increasing the wetted surface area of minerals (White $\&$ Blum, 1995). Weathering can also accelerate with increases in soil moisture as the 
porewaters that are immobile in dry conditions become hydrologically connected leading to more reactive porewaters. Chemical weathering may become accelerated in landscapes with high rates of precipitation such as the Southern Alps, New Zealand. Indeed the high annual precipitation in the Southern Alps and increased leaching is thought to contribute to rapid physical erosion and chemical weathering rates (Larsen et al., 2014). On the West Coast (South Island, New Zealand) soil production rates were equal or greater than those of slowly eroding watersheds; however, associated weathering only makes up a very small fraction of overall denudation (Larsen et al., 2014). Another important finding was that hillslopes in the Southern Alps remain soil mantled even when rates of physical erosion are exceptionally high, thus allowing for on-going chemical weathering processes (Larsen et al., 2014).

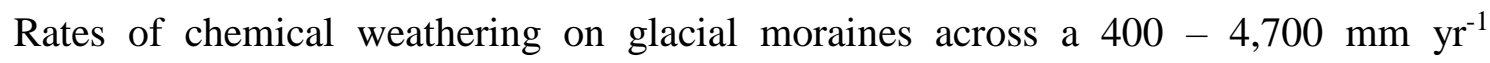
precipitation gradient in the Southern Alps were heavily influenced by precipitation (Dixon et al., 2016). Moisture availability along the western side of Lake Pukaki and extending up toward Mount Cook had the strongest control on weathering, suggesting that the study area in the Southern Alps is kinetically limited. An important pedogenic threshold occurred at a precipitation rate of $800 \mathrm{~mm} \mathrm{yr}^{-1}$ (Dixon et al., 2016). Pedogenic thresholds are defined as where soil morphology changes rapidly and stability of the soil is affected. This threshold coincided with the transition between a positive water balance and a water deficit, thus showing non-linear controls on weathering are being driven by soil moisture and leaching intensity. The pedogenic threshold may demonstrate a

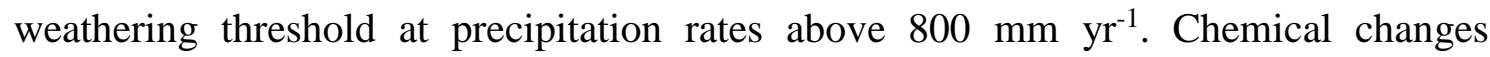
observed in this research indicated a weathering 'switch' with chemical changes occurring with very small changes in precipitation (Dixon et al., 2016). Research in areas with narrow climate gradients may miss this important weathering 'switch'.

\section{6. Rapidly eroding orogens}

Mountainous landscapes including the Swiss Alps, Himalayas, Andes and Southern Alps, New Zealand have some of the fastest weathering rates on Earth (Burbank et al., 1996; Larsen et al., 2014; Norton \& von Blanckenburg, 2010). Convergence of tectonic plates and faulting activity has led to mountain building processes. These mountainous regions tend toward steady-state erosion as mountain building and total denudation balance (Willett \& Brandon, 2002; Willett, Slingerland, \& Hovius, 2001). Increases in tectonic 
uplift and changes in climate toward a more greenhouse state should accelerate chemical weathering in rapidly uplifting mountain belts (Raymo \& Ruddiman, 1992; Raymo et al., 1988). Passive continental settings such as Australia and eastern USA have denudation rates measured an order of magnitude lower than in tectonically active margins (Portenga \& Bierman, 2011). As described above in previous sections, with higher rates of chemical weathering, the potential amount of carbon dioxide sequestration also increases. Therefore, if chemical weathering can keep pace with physical erosion, weathering in mountainous landscapes could be important for the overall reduction of greenhouse gases such as carbon dioxide on geologic timescales (Larsen et al., 2014; Willenbring et al., 2014).

\section{6. 1. Swiss Alps}

The Swiss Alps are one of several large mountain belts on Earth where high denudation rates have been observed (Champagnac et al., 2007; Champagnac et al., 2009; Norton, von Blanckenburg, \& Kubik, 2010; Wittmann et al., 2007). Tectonic activity is at a slower rate in the Swiss Alps compared to actively converging mountain belts, and isostatic rebound is likely the current primary driver of long-term denudation. Denudation rates of $1.4 \mathrm{~mm} \mathrm{yr}^{-1}$ were measured in the upper Rhone Valley, where soils are generally in steady state but weathering is unable to keep pace with erosion thus, weathering is likely kinetically limited (Norton \& von Blanckenburg, 2010). Rates of denudation in the Swiss Alps are significantly higher than many areas of the world and may be attributed to widespread glaciation and isostatic rebound as topographic steady-state is reached.

\section{6. 2. Himalaya}

The Himalaya mountain belt has some of the highest rates of tectonic activity in the world due to the collisional nature of tectonic plates in the region. The Himalaya region has high tectonic convergence, up to $11 \mathrm{~mm} \mathrm{yr}^{-1}$ (Burbank et al., 1996; Wang et al., 2001), heavy precipitation greater than 3,000 $\mathrm{mm} \mathrm{yr}^{-1}$ (Gabet et al., 2004) and steep hillslopes (Puchol et al., 2014). Erosion rates in the Himalaya region are amongst the highest globally with the eastern Himalayas eroding at $2.9 \mathrm{~mm} \mathrm{yr}^{-1}$ (Galy \& France-Lanord, 2001). Total Himalaya erosion rate measurements are double that of measured annual specific suspended sediment loads from the Ganga and Brahmaputra Rivers (Galy \& FranceLanord, 2001). Discrepancy in denudation rates may be a result of differing measurement timescales and that suspended sediment loads do not capture the bedload component of 
river loads thus, physical erosion processes in the Himalayas likely exert strong controls on overall denudation rates.

Fast physical erosion rates throughout the Himalayas results in a high weathering flux of silicate minerals (Dalai, Krishnaswami, \& Sarin, 2002; Galy \& France-Lanord, 2001). High rates of weathering in the Himalaya are a result of fast eroding hillslopes, high precipitation and warm temperatures.

\section{6. 3. Taiwan}

Taiwan is an example of a tectonically active mountainous island that is rapidly denuding (Siame et al., 2011; Willett et al., 2003). Taiwan has been shown to have some of the highest physical erosion and chemical weathering rates globally. Despite being a relatively small area the output of sediment is exceptionally high (Siame et al., 2011). High uplift rates due to collisional plate tectonics and extreme precipitation events has led to Taiwan having such fast erosion and weathering rates. Millennial denudation rates of 2 - $7 \mathrm{~mm} \mathrm{yr}^{-1}$ were measured from cosmogenic nuclides across several catchments in Taiwan (Siame et al., 2011). Further, denudation rates calculated using thermochronometric data show rates of $4-6 \mathrm{~mm} \mathrm{yr}^{-1}$, over long-term timescales of 2 - 4 Ma (Willett et al., 2003). Using records of suspended sediment yields, short-term (annual) rates of denudation were $2-6 \mathrm{~mm} \mathrm{yr}^{-1}$ (Fuller et al., 2003). Silicate chemical weathering measured from suspended sediment loads in the Liwu catchment is weathering at $18 \mathrm{t} \mathrm{km}^{-}$ ${ }^{2} \mathrm{yr}^{-1}$ (Calmels et al., 2011). Rates of weathering in Taiwan are remarkably consistent across suspended sediment yield, cosmogenic nuclide and thermochronology measurements and are amongst the highest rates measured globally. High rates of tectonic activity and a wet-tropical climate has resulted in very high rates of weathering. Taiwan remains an important landscape for understanding the relationship between climate, tectonics and denudation.

\section{6. 4. New Zealand}

The Southern Alps of New Zealand have long been used in a range of geologic and geomorphic studies for their highly active tectonic setting, extreme orographic precipitation and local geology. The Southern Alps are located on a compressional plate boundary between the Pacific and Australian plates. This position on the plate boundary has led to an unusually high uplift rate of up to $12 \mathrm{~mm} \mathrm{yr}^{-1}$ (Tippett \& Kamp, 1993). The 
West Coast of the South Island experiences very high precipitation upward of 10,000 $\mathrm{mm}$ $\mathrm{yr}^{-1}$ due to north-south trending mountains with prevailing south-westerly winds (Macara, 2016b). The lithology in the Southern Alps are highly deformed and are composed mainly of schist and greywacke which have been altered through varying levels of metamorphism.

The earliest studies on erosion in New Zealand began in the late 1970's, although it was long presumed New Zealand has fast-paced erosion due to the geology and climate in the South Island. Early research includes work that measured denudation rates in the Cropp River, Southern Alps (Basher, Tonkin, \& McSaveney, 1988). The Cropp River has long been a popular location for research as there are exposed outcrops of the Alpine Fault and evidence of past glaciation. Landforms were dated in the Cropp River area using radiocarbon dating, dendrochronology and soil chronosequences (Basher et al., 1988). Due to widespread glaciation through the Pleistocene in New Zealand, the maximum age of land surfaces can be estimated at 10,250 BP (Basher et al., 1988). Soil removal in this region is frequent and of an episodic nature with few surfaces being over 1,000 years, with mean residence times more likely being 100-500 years old due to the presence of coarse, gravelly loam soils (Basher et al., 1988).

Chemical weathering and physical erosion rates have been measured using annual specific suspended sediment yields across New Zealand including within several catchments across the Southern Alps (Adams, 1979, 1980; Griffiths, 1979; Hicks, Gomez, \& Trustrum, 2000; Hicks et al., 2011; Jacobson \& Blum, 2003; Lyons et al., 2005). Early research used suspended sediment yields to quantify denudation rates in the Southern Alps with measurements from both the western and eastern Southern Alps. Western Southern Alp suspended sediment yields vary from $84-37,000 \mathrm{t} \mathrm{km}^{-2} \mathrm{yr}^{-1}$ (Adams, 1980; Griffiths, 1979; Griffiths \& Glasby, 1985) compared to the eastern Southern Alps that had yields varying from $100-3320 \mathrm{t} \mathrm{km}^{-2} \mathrm{yr}^{-1}$. More recent annual specific suspended sediment yield from 233 New Zealand rivers and subsequent GISbased modelling has reinforced the view that rivers in tectonically active mountainous regions are important for global sediment contributions (Hicks et al., 2011).

Research by Jacobson and Blum (2003) used suspended sediment yields to determine erosion and weathering in the Southern Alps. Suspended sediment yields from 12 rivers 
across the Southern Alps were measured by investigating concentrations of solutes to partition silicate and carbonate weathering. The western Southern Alps have 13-times the rate of physical erosion and 5-times the chemical weathering than the eastern side (Jacobson \& Blum, 2003). These rates of both erosion and weathering are amongst the highest measured in the world and are likely a result of the tectonic and climatic settings. As these rates of physical erosion increase so does chemical weathering which has led to there being 1.5-times higher $\mathrm{CO}_{2}$ drawdown than the global mean (Jacobson \& Blum, 2003). In areas of mountain building such as in the Southern Alps and the Himalayas, $\mathrm{CO}_{2}$ consumption has increased 2-fold compared to the global average.

The correlation of physical erosion and chemical weathering rates was again observed from suspended sediment yields in fifteen catchments in the Southern Alps (Lyons et al., 2005). High rates of chemical weathering requires fresh mineral surfaces through the rapid removal of sediment as previously discussed. Although in New Zealand it has been shown chemical weathering is relatively high, this is primarily due to the large amounts of physical erosion rather than the fraction of chemical weathering being particularly high (Gaillardet et al., 1999).

For one of the first times in New Zealand, catchment-averaged in situ beryllium-10 $\left({ }^{10} \mathrm{Be}\right)$ was used to measure erosion and weathering rates. Total denudation measured within

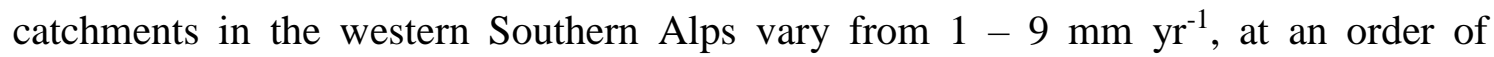
magnitude higher than other locations around the world (Larsen et al., 2014; Portenga \& Bierman, 2011; Willenbring et al., 2014). Soil production rates from the western Southern Alps of $0.1 \mathrm{~mm}$ y to $2.5 \mathrm{~mm} \mathrm{yr}^{-1}$ are amongst some of the highest in the world and demonstrate the Southern Alps are undergoing rapid landscape evolution. Rates of chemical weathering increased proportionally with physical erosion even when erosion measurements were highest (Larsen et al., 2014). Previous to this, research on chemical weathering fluxes in the Southern Alps used river solute loads (Jacobson \& Blum, 2003; Jacobson et al., 2003). River solute research may only capture part of the overall denudation as they do not capture river bedloads, which are an important component of river sediment transport in tectonically active landscapes. Measurements of denudation rates using river solute data is also over short timescales (annual) compared to ${ }^{10} \mathrm{Be}$ that averages over longer timescales $\left(10^{2}-10^{5}\right)$ and therefore excludes infrequent largemagnitude events such as earthquakes, storms and landslides. In the Southern Alps 
several environmental factors drive such high soil production rates including high annual precipitation and fractured bedrock which leads to fast rates of leaching, increased productivity of flora and root expansion throughout fractured rock.

\section{7. Cosmogenic nuclides}

Cosmogenic nuclides are used globally to measure long term catchment-averaged denudation rates (Bierman \& Steig, 1996; Brown et al., 1995; Granger, Kirchner, \& Finkel, 1996). Catchment-averaged denudation rates rely on the mixing of stream sediment that represents erosion from the entire catchment upstream of where it is sampled (Brown et al., 1995). Lal (1991) pioneered the first quantitative tools that allowed the use of nuclides to measure ages of meteorites, geomorphic change and landscapes. Further development of cosmogenic nuclides as a dating technique in geomorphic studies has led to a plethora of research. Because its production is relatively straightforward and well-understood, the cosmogenic nuclide ${ }^{10} \mathrm{Be}$ is most commonly used for denudation studies. The nuclide ${ }^{10} \mathrm{Be}$ is produced in quartz, which is a very common, stable silicate mineral; thus this method can be used in a variety of landscapes. When measuring catchment-averaged denudation there are several assumptions which must be met (outlined in Section 2. 5. 4). Long-term denudation rates calculated from

${ }^{10} \mathrm{Be}$ measurements range on timescales of $10^{2}$ to $10^{5}$ (Bierman \& Steig, 1996; Brown et al., 1995; Granger et al., 1996; Larsen et al., 2014; von Blanckenburg, 2005).

\section{8. Grain size bias}

The use of catchment-averaged denudation rates has allowed for development in geomorphic studies. The effects of a grain size bias have been outlined by several recent studies (Lukens et al., 2016; Riebe et al., 2015; Sklar et al., 2017; van Dongen et al., 2019). However, there is little consensus how a grain size bias may impact denudation rate results and what role slope, precipitation and high relief catchments play on a bias.

When sampling stream sediment the sand-sized fraction is commonly used for measuring catchment-averaged denudation rates. Slope angle, precipitation, temperature, vegetation and bioturbation all play a role in denudation leading to differences in grain size across catchments (Binnie et al., 2007; DiBiase \& Whipple, 2011; Riebe et al., 2004a; Roering et al., 2010). As parent rock is broken up through chemical and physical processes the resulting grain size can be highly variable. Grain size is not only dependent on how the 
parent rock is broken up but also by the regolith residence time. Regolith residence time is affected by thickness of the regolith and how quickly it is being removed (Sklar et al., 2017). Sampling only a narrow range of grain sizes leads to a potential bias if sediment size changes systematically with elevation (Lukens et al., 2016). There are a multitude of reasons as to why grain size may change across catchments, and this is an active area of research (Sklar et al., 2017).

Since 2015 there have been several studies into how using different grain sizes to measure catchment-averaged denudation may affect results. Both climate and topography play a role in the observed grain sizes at a particular part of a catchment (Riebe et al., 2015). In landscapes where denudation rates are fast such as those observed in the Southern Alps (Larsen et al., 2014) sediment will spend less time being weathered and, may lead to an overall coarser grain size. At Inyo Creek in the Sierra Nevada Mountains, California eroded sediment size is coupled with climate and topography due to effects on landscape denudation and sediment production (Riebe et al., 2015).

At Inyo Creek, California there is a measurable grain size bias of more than a factor of three (Lukens et al., 2016). Modelling suggests that a grain size bias should increase with high relief and in larger catchments (Lukens et al., 2016). In higher relief catchments grain size bias increases as sediment is generally coarser, thus is under-represented when sand sized sediment is sampled. Area of catchments also affects grain size bias as larger catchments have further distance for sediment to travel thus leading to a reduced grain size. In landscapes where sediment size varies substantially across slopes, sampling sand for catchment-averaged denudation using cosmogenic nuclides may introduce a significant grain size bias as the distribution from the hillslope may not be the fraction of stream sediment that is sampled, and care should be taken to understand which sediment size represents erosion and weathering processes in a particular catchment. Empirical research exhibited similar results to that of previous studies into the effects of a grain size bias when sampling stream sediment (van Dongen et al., 2019).

Transport downslope occurs through two processes: diffusive transport and deep-seated erosion. Diffusive transport occurs in slower eroding, soil mantled landscapes as sediment gradually moves downslope. In diffusive landscapes sediment size is generally finer as there is more time for grains to be broken up (Roering et al., 1999). Deep-seated erosion 
such as landsliding results in highly variable grain sizes being transported downslope. Landscapes that are both actively eroding and steep $\left(>25-30^{\circ}\right)$ are often dominated by deep-seated landsliding. Landsliding events result in mixing of sediment from depth with rock fragments (Casagli, Ermini, \& Rosati, 2003). Hillslope gradient showed the greatest effect on grain size bias, as slopes that have reached a threshold angle of 25-30 degrees have frequent landsliding events. In addition to landsliding, mixing a wide range of sediment sizes brought up from depth will affect the measured ${ }^{10} \mathrm{Be}$ concentrations. Sampling distance from source had a weak correlation with a grain size bias (van Dongen et al., 2019). If sufficient mixing of stream sediment has not been achieved, it is likely that the dominant grain size will be influenced by other sediment sources such as from landsliding or other deep-seated erosional processes.

Analysis of a compilation of global data including from the Chilean Coastal Cordillera concluded that mean annual precipitation may play a role in grain size bias (van Dongen et al., 2019). Grain size bias was greatest in the most humid catchments with precipitation above 2,000 $\mathrm{mm} \mathrm{yr}^{-1}$, however this may be a result of frequent landsliding occurring in catchments with higher precipitation (Gabet et al., 2004). Controls on grain size distribution across hillslopes were modelled showing systematic patterns (Sklar et al., 2017). Systematic patterns identified that sediment size varies with controls such as lithology, precipitation, temperature, topography and erosion. Results of the modelling were compared to data from Inyo Creek (Riebe et al., 2015). Modelling shows the controls on grain size in a given catchment may be predictable across a range of variables (Sklar et al., 2017). Further work on developing a geomorphic transport laws will enable constraints on the grain size bias in a given catchment. 


\subsection{Aims and objectives}

In tectonically active mountain belts such as the Southern Alps, New Zealand, physical erosion and chemical weathering rates have been measured at rates higher than the global average. These high rates of erosion and weathering have led to remarkably high rates of soil production on the West Coast, New Zealand where precipitation can exceed 10,000 $\mathrm{mm} \mathrm{yr}^{-1}$ (Larsen et al., 2014). High rates of erosion and weathering may be important for understanding global carbon cycling and the impact on long-term climate stability on geologic timescales. The Ōhau catchment, Canterbury is located in close proximity to the main west-east drainage divide in the Southern Alps. Steep actively eroding slopes make the Ōhau catchment a prime location to assess the impact of tectonic and climatic conditions on erosion and weathering rates.

The primary aim of this research is to quantify denudation rates in the Ōhau catchment, determine any influence of grain size variability on ${ }^{10} \mathrm{Be}$ concentrations and partition chemical weathering and physical erosion rates across climatic gradients in the rapidly eroding Dobson Valley.

To achieve these aims the following objectives were completed:

1) Quantify catchment-averaged denudation rates from sub-catchments within the Ōhau catchment, Canterbury using in situ cosmogenic ${ }^{10} \mathrm{Be}$.

2) Calculate chemical weathering and physical erosion components of total denudation in the Dobson Valley using zirconium concentrations in soil and bedrock.

3) Establish how grain size variability effects measured in situ ${ }^{10} \mathrm{Be}$ concentrations in the Dobson Valley.

4) Determine how denudation rates change across gradients in the Dobson Valley to assess the effects of precipitation and temperature.

While there is a general consensus that weathering of silicate minerals in mountain landscapes is important for global carbon dioxide cycles, the details and limits of these feedbacks are an active area of research. In particular, the role of climate in driving erosion and weathering in active landscapes is important for understanding long-term climate change. This research contributes to on-going research in active, fast eroding settings such as the Southern Alps, New Zealand. 


\section{10. Thesis structure}

Chapter two of this thesis discusses the theory of cosmogenic nuclides and the application

of in situ ${ }^{10} \mathrm{Be}$ measurements to catchment-averaged denudation rates. Chapter three details the study area, including detail on geomorphology, geology, tectonics and climate of the region. Chapter four describes the methodologies used for field sampling and laboratory procedures carried out for ${ }^{10} \mathrm{Be}$ analysis and zirconium measurements. Chapter five presents results of the ${ }^{10} \mathrm{Be}$ analysis, zirconium concentrations, and chemical depletion fractions for partitioning of chemical weathering and physical erosion. Chapter six provides a discussion of results and addresses the research aims and objectives. 
Introduction and background 


\section{Chapter 2. Cosmogenic nuclides}

\section{1. Cosmic ray origin}

Primary cosmic rays are fast moving, highly charged particles which originate either outside of the solar system (galactic) or in the sun (solar cosmic rays) (Gosse \& Phillips, 2001). Galactic cosmic rays have high energies on the order of $100 \mathrm{MeV}$ to $10 \mathrm{GeV}$ (Masarik \& Reedy, 1995), and are thought to originate from supernova explosions (Diehl et al., 2006). Cosmic rays produced through energetic events on the sun produce solar cosmic rays with lower energies of $1-100 \mathrm{MeV}$ (Masarik \& Reedy, 1995). Cosmic rays that reach the Earth's surface are made up of protons (87\%), alpha particles (12\%) and heavier nuclei (>1\%) (Dunai, 2010; Gosse \& Phillips, 2001; Masarik \& Reedy, 1995). In the past 10 Million years the cosmogenic flux has remained relatively constant and the production of cosmogenic rays has not been altered by either galactic or solar cosmic rays (Dunai, 2010). These primary cosmic rays constantly bombard the Earth's atmosphere (Fig. 2. 1) interacting with the nuclei of atoms to produce a cascade of particles and ongoing reactions in the atmosphere, and eventually at Earth's surface (Gosse \& Phillips, 2001). 
THE ATMOSPHERIC NUCLEAR CASCADE

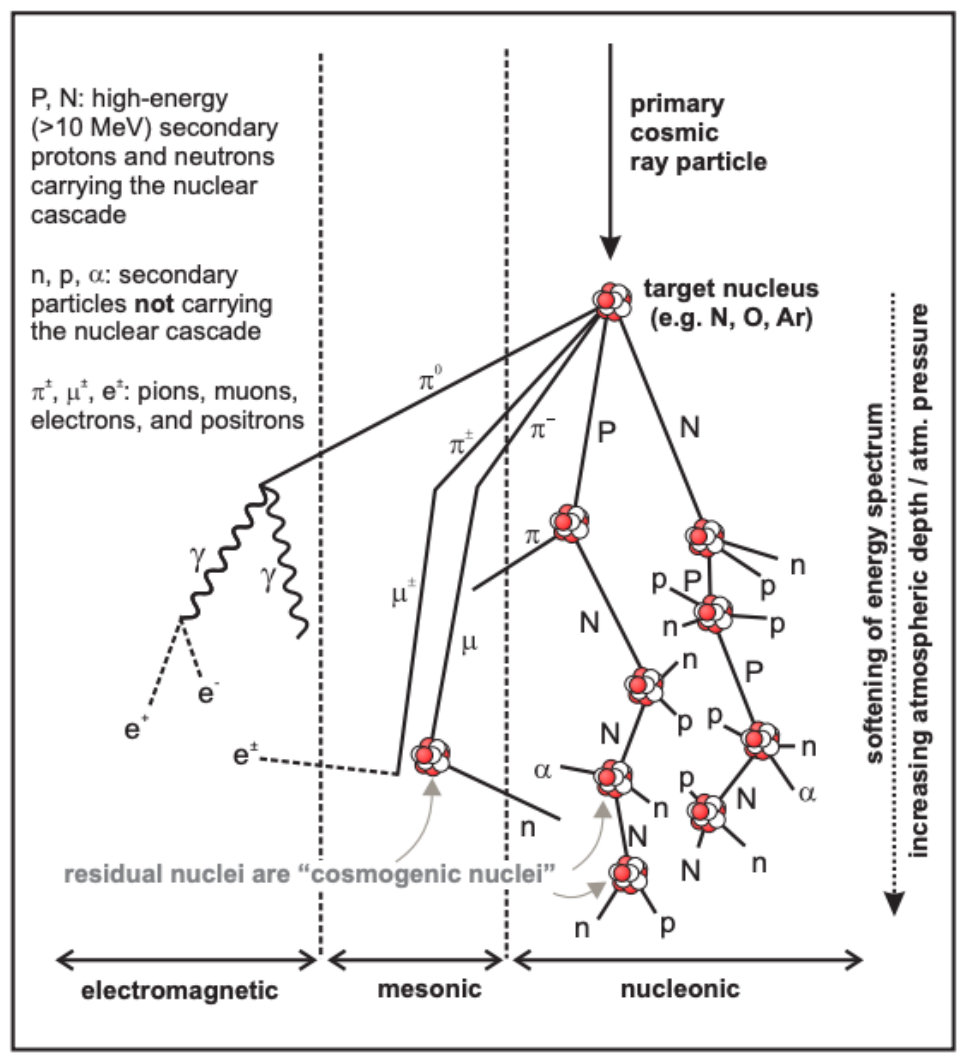

Figure 2.1. Primary cosmic rays enter Earth's atmosphere which bombard target nuclei. Atmospheric nuclides and secondary particles are produced, primarily made up of neutrons. (Dunai \& Lifton, 2014).

\section{2. Cosmic ray interactions}

\section{2. 1. Earth's geomagnetic field}

The Earth's geomagnetic field creates significant disturbance to cosmic rays as they enter the atmosphere. The geomagnetic field deflects the incoming cosmic rays and affects the intensity of secondary cascades of cosmic rays. The Earth's geomagnetic field is primarily a dipole field which influences cosmic ray trajectory. The influence of the geomagnetic field can be quantified by the cut-off rigidity (Dunai, 2010; Gosse \& Phillips, 2001; Masarik \& Reedy, 1995) which is defined as the minimum 'rigidity' (momentum per unit charge) a particle must have to enter the Earth's geomagnetic field (Dunai, 2010; Dunai \& Lifton, 2014).

Low energy particles are more likely to be deflected than high energy particles as the kinetic energy of higher energy particles reduces the effects from the geomagnetic field 
(Smart, Shea, \& Flückiger, 2000). Due to the shape of the magnetic field, primary rays approaching the geomagnetic equator travel perpendicular to the geomagnetic field compared to at the poles where primary rays travel parallel to the field (Dunai, 2010). The direction of movement and interaction with the geomagnetic field mean the cosmic ray flux at the poles is much higher than that at the equator (Fig. 2. 2) (Dunai, 2010; Dunai \& Lifton, 2014; Gosse \& Phillips, 2001; Masarik \& Reedy, 1995).

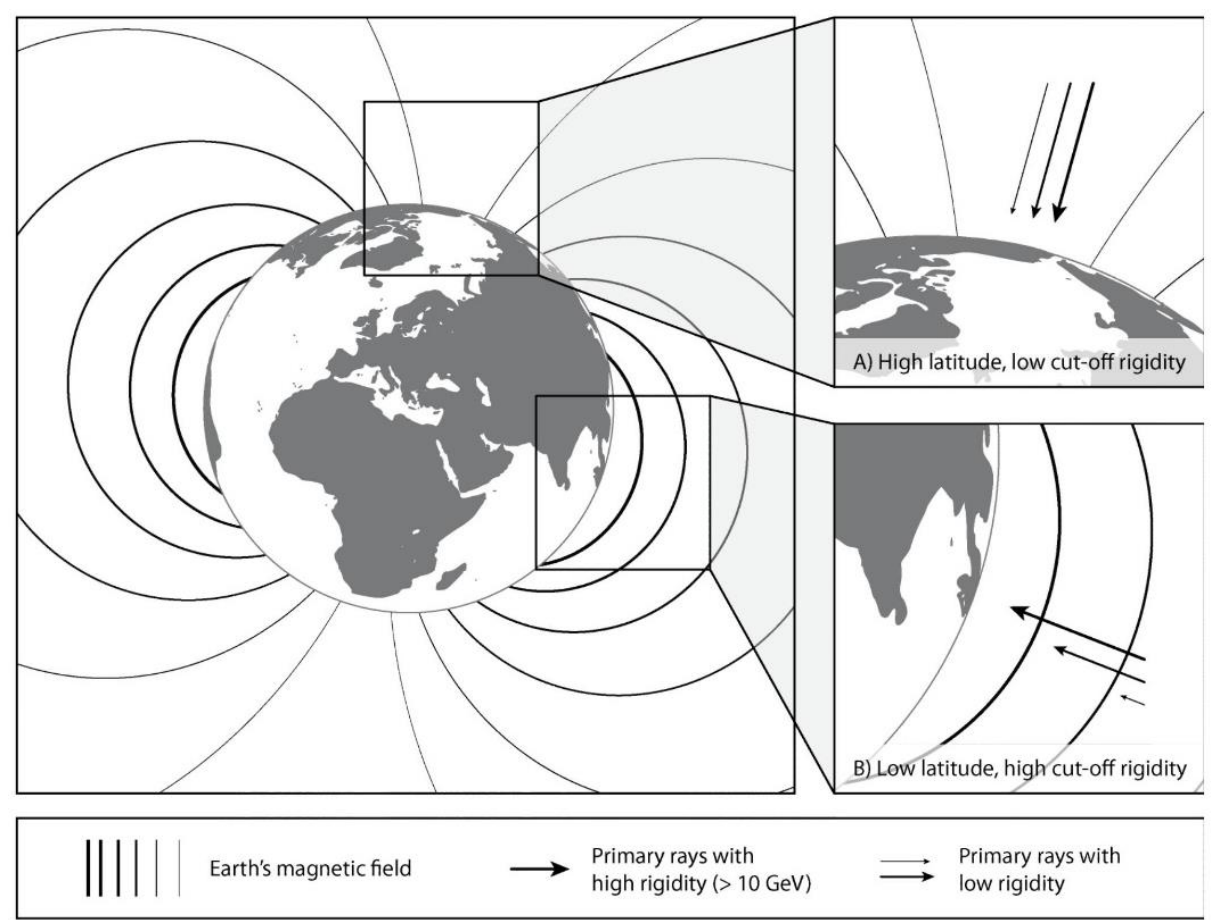

Figure 2.2. Incoming primary cosmic rays are effected by Earth's geomagnetic field. Cutoff rigidity must be met for particles to enter Earth's field. Towards the poles cut-off rigidity is low compared to that at the equator.(Darvill, 2013).

\section{2. 2. Earth's atmosphere}

As primary cosmic rays enter the Earth's atmosphere, spallation reactions among others occur, where primary cosmic rays break-up atomic nuclei (target nuclei) (Fig. 2. 1; (Dunai \& Lifton, 2014)). Three components make up a cosmic ray cascade, electromagnetic, mesonic and nucleonic components (Dunai, 2010; Gosse \& Phillips, 2001). Some of the secondary particles which are produced during spallation reactions are in the nucleonic component where spallation reactions continue onto other target nuclei, thus creating a cascade of reactions (Gosse \& Phillips, 2001). 
During the spallation reaction, protons and neutrons sputter off creating a cascade, propagating into the atmosphere and several meters into the Earth's surface (Fig. 2. 1; (Dunai \& Lifton, 2014)). This cascade creates the composition of particles near the top of the atmosphere dominated by protons and becomes neutron dominated closer to Earth's surface. The process of high-energy spallation reactions involving fast neutrons is the primary way cosmogenic isotopes are produced (Dunai, 2010). Other mechanisms of producing cosmogenic isotopes include thermal neutron capture and muon induced nuclear disintegration are described below (Lal, 1988).

As secondary particles cascade through Earth's atmosphere, particles decrease exponentially both in intensity and number (Cerling \& Craig, 1994b; Gosse \& Phillips, 2001; Stone, 2000). The decrease in intensity is termed attenuation and varies with the density of material that is passed through (Darvill, 2013). At higher surface elevations cosmogenic nuclide production is greater (Balco et al., 2008) and is described by (Dunai, 2010) in the following equation:

$$
N(d)=N_{o} e^{-d / \Lambda}
$$

Eq. 2. 1

Where $\mathrm{N}$ is number of nucleons, $\mathrm{N}_{0}$ is the number of nucleons at the top of the atmosphere, $\mathrm{d}$ is atmospheric depth $\left(\mathrm{g} \mathrm{cm}^{-2}\right)$ and $\Lambda$ is attenuation length $\left(\mathrm{g} \mathrm{cm}^{-2}\right)$. Attenuation length is a function of geomagnetic latitude, magnetic field inclination, cutoff rigidity and altitude (Dunai, 2010; Gosse \& Phillips, 2001). Thus, cosmogenic nuclide production on Earth's surface is dependent on both latitude and altitude.

\section{3. Cosmogenic nuclide production at Earth's surface}

The change of the atomic mass of nuclei through spallation produces cosmogenic nuclides in both the atmosphere (meteoric) and in the lithosphere (terrestrial in situ cosmogenic nuclides) (Gosse \& Phillips, 2001). Spallation reactions occur most commonly in the upper 2-3m of rock and decrease exponentially with depth (Dunai, 2010; Gosse \& Phillips, 2001; Masarik \& Reedy, 1995).

Cosmogenic nuclides are also produced through negative muon capture which creates muogenic reactions. Muons are produced during the nuclear cascade in the atmosphere, where muons descend until they decay or are captured by a target nucleus. At this point one proton is neutralised which produces a cosmogenic nuclide (Gosse \& Phillips, 2001). 
Interaction of matter with muons is weak therefore only a small number of cosmogenic nuclides are produced. Their low mass and high energy results in muons being able to penetrate down several 10's of meters into rock (Dunai \& Lifton, 2014; Gosse \& Phillips, 2001), where they are responsible for a larger fraction of cosmogenic nuclide production (Fig. 2. 3).

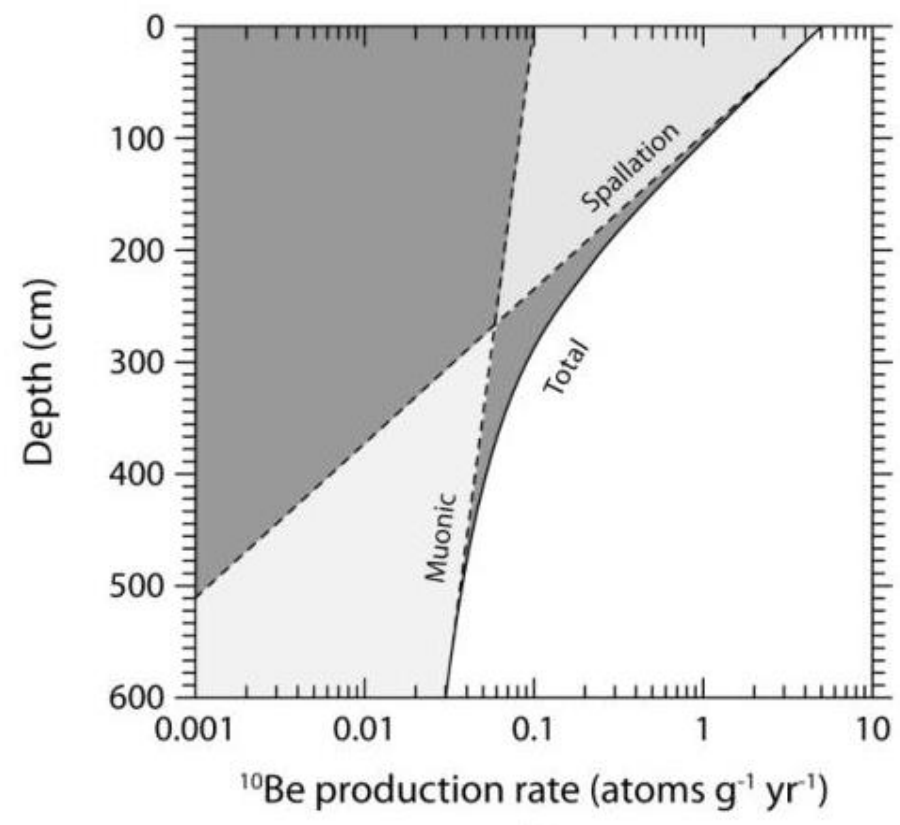

Figure 2.3. Production rates of ${ }^{10} \mathrm{Be}$ are inversely related with depth from the surface. Spallation reactions play at greater role near the surface. As depth increases the component of muonic reactions increase.(Darvill, 2013).

Many types of nuclides are produced in the atmosphere and on Earth's surface that have variable, yet predictable production rates. These nuclides which are 'useful' for Earthscience applications are categorised as stable, rare gases or as radio-nuclides (Dunai, 2010). The useful stable rare gases include ${ }^{3} \mathrm{He},{ }^{21} \mathrm{Ne}$ and ${ }^{22} \mathrm{Ne}$, and the radio-nuclides include ${ }^{10} \mathrm{Be},{ }^{26} \mathrm{Al}$ and ${ }^{36} \mathrm{Cl}$ (Gosse \& Phillips, 2001).

\section{3. 1. Beryllium-10 production}

Beryllium-10 $\left({ }^{10} \mathrm{Be}\right)$ produced in quartz $\left(\mathrm{SiO}_{2}\right)$ is one of the most commonly-used nuclides in Earth surface applications. Beryllium has one stable nuclide, ${ }^{9} \mathrm{Be}$ and two radio nuclides: ${ }^{7} \mathrm{Be}$ and ${ }^{10} \mathrm{Be}$. The most appropriate to use for Earth-surface applications is ${ }^{10} \mathrm{Be}$ due to a longer half-life than ${ }^{7} \mathrm{Be} .{ }^{10} \mathrm{Be}$ undergoes radioactive decay with a halflife of 1.36 \pm 0.07 Ma versus 53 days for ${ }^{7} \mathrm{Be}$ (Chmeleff et al., 2010; Korschinek et al., 2010; Nishiizumi et al., 2007). Radioactive decay means that in most cases there is no ${ }^{10} \mathrm{Be}$ present in rock prior to exposure to the atmosphere; thus knowing the half-life allows 
for calculation of age of exposure to the atmosphere. In situ ${ }^{10} \mathrm{Be}$ is produced primarily through spallation reactions $(96.4 \%)$ and a smaller amount through muon reactions (3.6\%) with oxygen and nitrogen (Dunai, 2010). Meteoric ${ }^{10} \mathrm{Be}$ is also produced at much higher rates in the atmosphere than in situ ${ }^{10} \mathrm{Be}$ (Gosse \& Phillips, 2001). For in situ studies, meteoric ${ }^{10} \mathrm{Be}$ is effectively a contaminant, as it is deposited in aerosols that precipitate down and are absorbed into surface rock and sediment (Fig. 2. 4). Meteoric ${ }^{10} \mathrm{Be}$ contamination must therefore be removed when measuring in situ ${ }^{10} \mathrm{Be}$ otherwise an older apparent age or equivalent slower erosion rate will be calculated (Dunai, 2010).

In situ ${ }^{10} \mathrm{Be}$ is suitable for measuring catchment-averaged denudation on time scales of $10^{2}$ to $10^{5}$ years (Bierman \& Steig, 1996; Brown et al., 1995; Granger et al., 1996; von Blanckenburg, 2005). In situ cosmogenic nuclides give long term denudation rates which are insensitive to short pulses of denudation. The frequent use of ${ }^{10} \mathrm{Be}$ is due to its long half-life and availability in the mineral quartz. Quartz is a very common silicate mineral in a variety of rock types and is resistant to loss of numerous cosmogenic nuclides and to chemical weathering (von Blanckenburg, 2005).

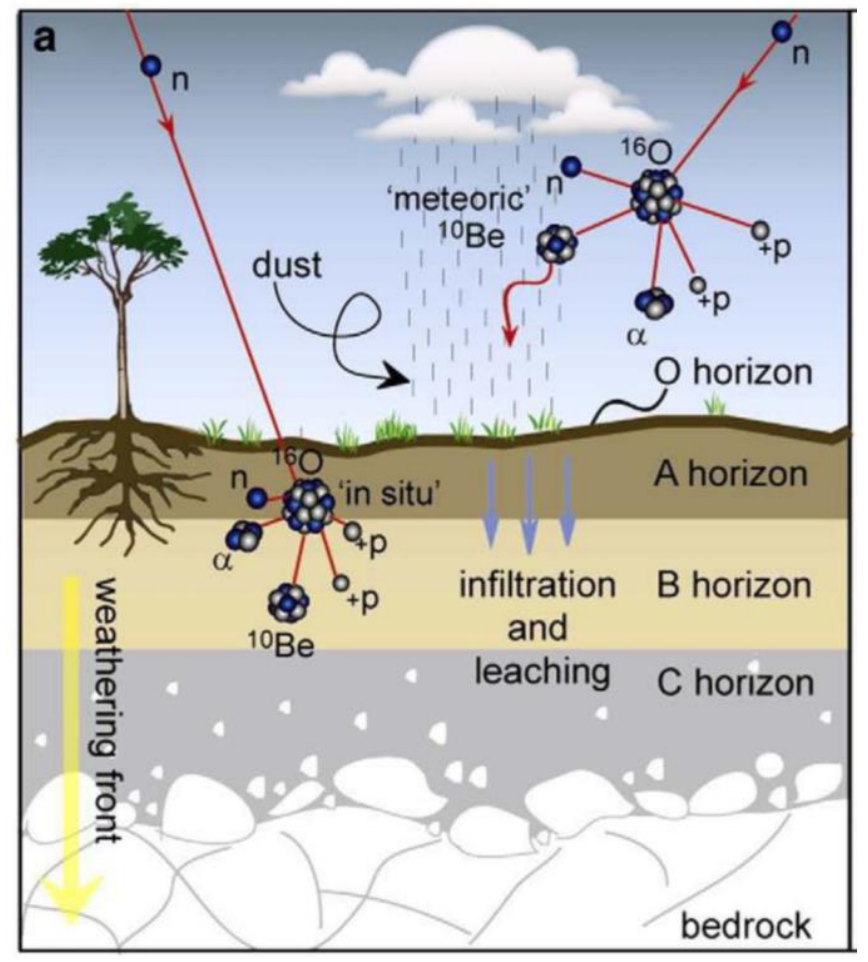

Figure 2.4. ${ }^{10}$ Be is incorporated into the soil profile in several ways. Weathering follows a downward pattern with the movement of percolating water from atmospheric precipitation. (Willenbring \& von Blanckenburg, 2010b). 
Production of in situ ${ }^{10} \mathrm{Be}$ can be calculated by measuring the nuclide concentration at sites where independent geological calibration has occurred (Balco et al., 2008; Putnam et al., 2010; Stone, 2000). These sites must have a land surface of an independentlyknown age such as landslide scarps, glacially polished bedrock, lava flows, moraines or wave cut shore platforms (Cerling \& Craig, 1994a; Ivy-Ochs \& Kober, 2008; Ivy-Ochs et al., 2004; Nishiizumi et al., 1989). Independent dating these surfaces may include luminescence, dendrochronology or radiocarbon dating (Gosse \& Phillips, 2001). The cosmogenic nuclide production rate can then be calculated by dividing a measured nuclide concentration by the independent age.

The majority of calibration sites for calculating the production rate of ${ }^{10} \mathrm{Be}$ have been located in the Northern Hemisphere. Thus, cosmogenic nuclide production rates for the Southern Hemisphere have typically been extrapolated from the Northern Hemisphere using scaling models (discussed in Section 2. 4). Production rates have been calculated in New Zealand for the first time (Putnam et al., 2010). The production rate of ${ }^{10} \mathrm{Be}$ was estimated using radiocarbon ages from a debris flow of buried soil and vegetation in the Macaulay Valley in the Central Southern Alps, this age can be used to estimate the production rate of ${ }^{10} \mathrm{Be}$ in New Zealand. Production rates ranging from 3.74 atoms $\mathrm{g}^{-1} \mathrm{yr}^{-}$ ${ }^{1}$ to 4.15 atoms $\mathrm{g}^{-1} \mathrm{yr}^{-1}$ were calculated for the Macaulay Valley (Putnam et al., 2010). The range of values comes from different scaling models being applied to the initial production rate. Production rates of ${ }^{10} \mathrm{Be}$ reported by Putnam et al. (2010) are referenced to sea-level high latitude (SLHL) and the latitude and elevation of the sample location. Production rates in New Zealand are 12-14\% lower than those from a global calibrated dataset (Balco et al., 2008; Putnam et al., 2010). This discrepancy between the values by Balco et al. (2008) and Putnam et al. (2010) suggests previous production rates used in New Zealand research have likely been underestimated.

\section{4. Scaling models}

Cosmogenic nuclide production rates on Earth's surface have both spatial and temporal variability. This variability has led to scaling models being developed to adjust local production rates to any location and through time. Scaling is used to adjust for latitude and altitude attenuation, and changes in the magnetic field through time at a particular position on Earth. Spatial scaling takes into account the variability of production rates at different locations (both altitude and latitude). The first scaling model took into account 
elevation and latitude variability (Lal, 1991). Since the first scaling model there have been developments with newer models taking into account the temporal changes in the geomagnetic field, cut-off rigidity and solar modulation. The five different scaling models are summarised below (Table 2. 1,(Balco et al., 2008)).

Table 2.1. Summary of the five most common scaling models adapted from Balco et al. (2008).

\begin{tabular}{cll}
\hline ID & References & Description \\
\hline St & Lal (1991), Stone (2000) & $\begin{array}{l}\text { The scaling factor is a function of latitude and atmospheric pressure, not accounting } \\
\text { for magnetic field variations. Nuclide production rates are constant over time. }\end{array}$ \\
De & Desilets, Zreda, and Prabu (2006) & $\begin{array}{l}\text { The scaling factor is a function of cut-off rigidity and atmospheric pressure. } \\
\text { Production rates vary with changes in magnetic field over time. }\end{array}$ \\
Du $\quad$ Dunai (2001) & $\begin{array}{l}\text { The scaling factor is a function of cut-off rigidity and atmospheric pressure. } \\
\text { Production rates vary with changes in magnetic field over time. }\end{array}$ \\
& Lifton et al. (2005) & $\begin{array}{l}\text { Scaling factor is a function of cut-off rigidity, atmospheric pressure, and solar } \\
\text { modulation. Production rate is variable with change in solar output and the } \\
\text { geomagnetic field. }\end{array}$ \\
Lm & Lal (1991), Stone (2000), Nishiizumi et & $\begin{array}{l}\text { Adaptation from Lal (1991) now accommodating for paleomagnetic corrections by } \\
\text { Nishiizumi et al. (1989). Production rates are variable with changes in Earth's } \\
\text { magnetic field. }\end{array}$ \\
\hline
\end{tabular}

These scaling models normalise production rates to the sea level at high latitude (SLHL). When normalised, production rates may be directly compared to other localities.

The online Earth calculator (formerly CRONUS) uses the five scaling models to calculate exposure and erosion rates from ${ }^{10} \mathrm{Be}$ and ${ }^{26} \mathrm{Al}$ concentrations (Balco et al., 2008). This online calculator uses ${ }^{10} \mathrm{Be}$ and/or ${ }^{26} \mathrm{Al}$ concentrations and latitude, longitude and elevation data from each sample location to determine either denudation rates or exposure ages.

\section{5. Application of ${ }^{10} \mathrm{Be}$ in denudation calculations}

2. 5. 1. Denudation rates from in situ ${ }^{10} \mathrm{Be}$

As surfaces erode the underlying material (rock and sediment) becomes gradually exposed to the atmosphere and nuclides begin to accumulate. Cosmogenic nuclide concentrations in a given rock are dependent on three factors; exposure age, erosion rate and the number of inherited nuclides. With the assumption of a constant nuclide 
production rate, Eq. 2. 2 was developed for calculating denudation rates from a nuclide concentration at a given depth (z) (Lal, 1991):

$$
N(x, t)=N(x, 0) e^{-\lambda t}+\frac{P(O)}{\lambda \frac{\rho \varepsilon}{\Lambda}} e^{-z p} \frac{1}{\Lambda} \times\left(1-e^{-\left(\lambda+\frac{\rho \varepsilon}{\Lambda}\right) t}\right)
$$

Eq. 2.2

$N(t)$ represents nuclide concentration at present, $N(x, 0)$ is inherited nuclide concentration, $P(0)$ is production rate, $\lambda$ is the nuclide half-life, $\rho$ is rock density, $\varepsilon$ is denudation and $\Lambda$ is attenuation length. Inheritance is not usually relevant when considering an eroding landscape, thus it can be excluded from the equation. Denudation is occurring at the surface meaning the value $\mathrm{z}$ is zero. These considerations mean the above equation simplifies to:

$$
N(t)=\frac{P(O)}{\lambda \frac{\rho \varepsilon}{\Lambda}} \times\left(1-e^{-\left(\lambda+\frac{\rho \varepsilon}{\Lambda}\right) t}\right)
$$

Eq. 2.3

If a landscape has been undergoing steady erosion over a longer timespan than the erosional timescale $\left(t \gg \lambda+\frac{\rho \varepsilon}{\Lambda}\right)$. At this point, the nuclide concentration can be calculated using the following equation (Granger et al., 1996; Lal, 1991);

$$
N(t)=\frac{P_{0}}{\lambda+\frac{\varepsilon}{Z^{*}}}
$$

Eq. 2.4

Where $N(t)$ is the cosmogenic nuclide concentration, $P_{o}$ is nuclide production at the surface, $\lambda$ is the decay constant of the given nuclide, $\varepsilon$ is denudation rate and $z *$ is attenuation depth $(\Lambda$ divided by $\rho)$.

\section{5. 2. Catchment-averaged denudation}

As material is removed from the landscape and is transported down through a catchment, mixing occurs and sediment is thoroughly mixed in rivers during transport downstream. Mixing of sediment means sampling at a particular point in a stream is taking into consideration the entire catchment above that point (Bierman \& Steig, 1996; Brown et al., 1995; Granger et al., 1996; von Blanckenburg, 2005). Sampling for catchment- 
averaged denudation rates should be taken from a point downstream that has had sufficient mixing. Cosmogenic nuclides measured in the sample collected then represents an average of the catchment including all side streams above a confluence (Fig. 2. 5).

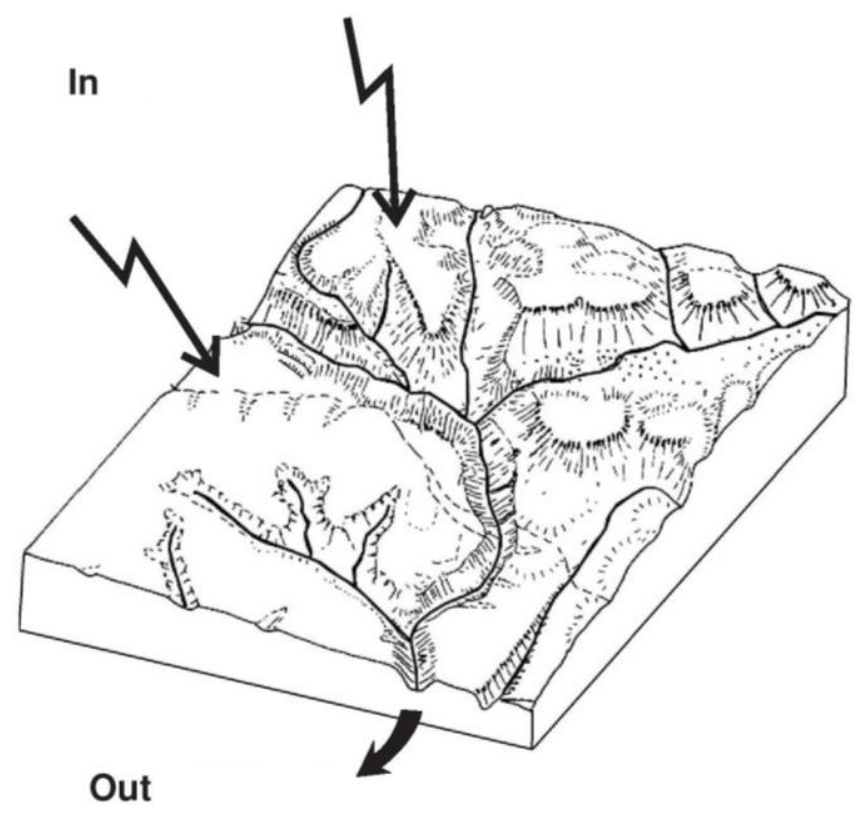

Figure 2.5. Schematic of the principles of "let nature do the averaging". Denudation rates are averaged over the wider catchment when samples are taken from the "out" location. Cosmogenic nuclides are mixed in the catchment between "in" and "out" (von Blanckenburg, 2005).

Given a long enough time period of erosion in catchment-averaged samples measuring erosion rate, time drops out of the equation. Catchment-averaged denudation rates are averaged by the time taken to remove one attenuation length (von Blanckenburg, 2005). The time taken to remove one attenuation length is dependent on bedrock density with one attenuation length typically being $\sim 60 \mathrm{~cm}$. When new material is exposed to cosmic rays, the rate of denudation in a catchment is inversely related to the accumulation of in situ cosmogenic nuclide concentrations at Earth's surface (Bierman \& Steig, 1996). Catchment-averaged denudation rates average out different parts of the same landscape that may locally have high or low rates, resulting in an average for the whole landscape.

\section{5. 3. Assumptions and conditions}

Several key assumptions must be made in order to use the method of catchment-averaged denudation. Firstly, denudation in a catchment over time must be constant which can be 
affected by mass-movement such as landsliding (Niemi et al., 2005; Yanites, Tucker, \& Anderson, 2009). Sampling from a large catchment area as to dampen the effect from landsliding and avoiding sampling from obvious past-landsliding this assumption may be met (Dunai, 2010; Matmon et al., 2005; Niemi et al., 2005; von Blanckenburg, 2005; Yanites et al., 2009). Lithologies must represent the entire catchment including both mineralogy and grain size. If there are differing lithologies there may be denudation resistance and a bias may arise (Brown et al., 1995). Mass loss should be primarily through surface lowering (physical erosion) rather than from deep in the landscape (chemical weathering) (Bierman \& Steig, 1996). Corrections have been developed using zirconium to account for the amount of chemical weathering (Riebe et al., 2003). Transport of sediment through a catchment must be short enough to reflect the current denudation rates and sediment storage must be minimal.

Advances in isotope measurement techniques such as accelerator mass spectrometry led the way for development of in situ cosmogenic nuclide research (Lal, 1991; Nishiizumi et al., 1989). Applications to earth surface processes including erosion rate measurements have rapidly expanded since the development of in situ cosmogenic nuclide techniques (Bierman \& Steig, 1996; Brown et al., 1995; Granger et al., 1996). These techniques are the most ubiquitous way to measure long term erosion rates across the world in a variety of erosional settings as to investigate the relationship between Earth's surface, climate and tectonics. Development of the online Earth calculators (Balco et al., 2008; Codilean, 2006; Marrero et al., 2016; Mudd et al., 2016) has allowed for the community to stay abreast new developments, scaling schemes and production rates. In this thesis, I used in situ ${ }^{10} \mathrm{Be}$ in the steep landscapes of the Ōhau catchment, New Zealand which I describe in the following chapters. 


\section{Chapter 3. Study site: Ōhau catchment, Canterbury}

Te Waipounamu (South Island), New Zealand (Fig. 3. 1) is situated on the obliquely converging plate boundary between the Pacific and Australian plates. Tectonic activity along the plate boundary resulted in the rise of the north-east/south-west trending Southern Alps at a maximum elevation of 3,754m. Prevailing westerly winds bring high orographic precipitation, exceeding $10,000 \mathrm{~mm} \mathrm{yr}^{-1}$ to western regions of New Zealand. The combination of high uplift rates of over $10 \mathrm{~mm} \mathrm{yr}^{-1}$ and very high orographic precipitation makes the Southern Alps an ideal landscape to study fast eroding orogens. The Ōhau catchment, Canterbury (Fig. 3. 2) was selected as the study site due to the considerable climatic gradients, proximity to the Alpine Fault and the locality of Lake Ōhau. The Dobson Valley $\left(43.95^{\circ} \mathrm{S}, 169.95^{\circ} \mathrm{E}\right)$ was the focus of the research. The Dobson Valley has evident precipitation and temperature gradients within the catchment from the highest elevations in the headwaters of the valley (>2600 m asl) down to Lake Ōhau (520 $\mathrm{m}$ asl). The underlying lithology of interbedded sandstone, siltstone and mudstone that has undergone metamorphism is relatively quartz rich. The abundance of quartz was crucial for selecting the Ōhau catchment as it was the target mineral used for measurements of in situ ${ }^{10} \mathrm{Be}$ analysis. This chapter will discuss the geomorphology, geology, tectonics, climate of the Ōhau catchment, Canterbury. 
Study site: Ōhau catchment, Canterbury

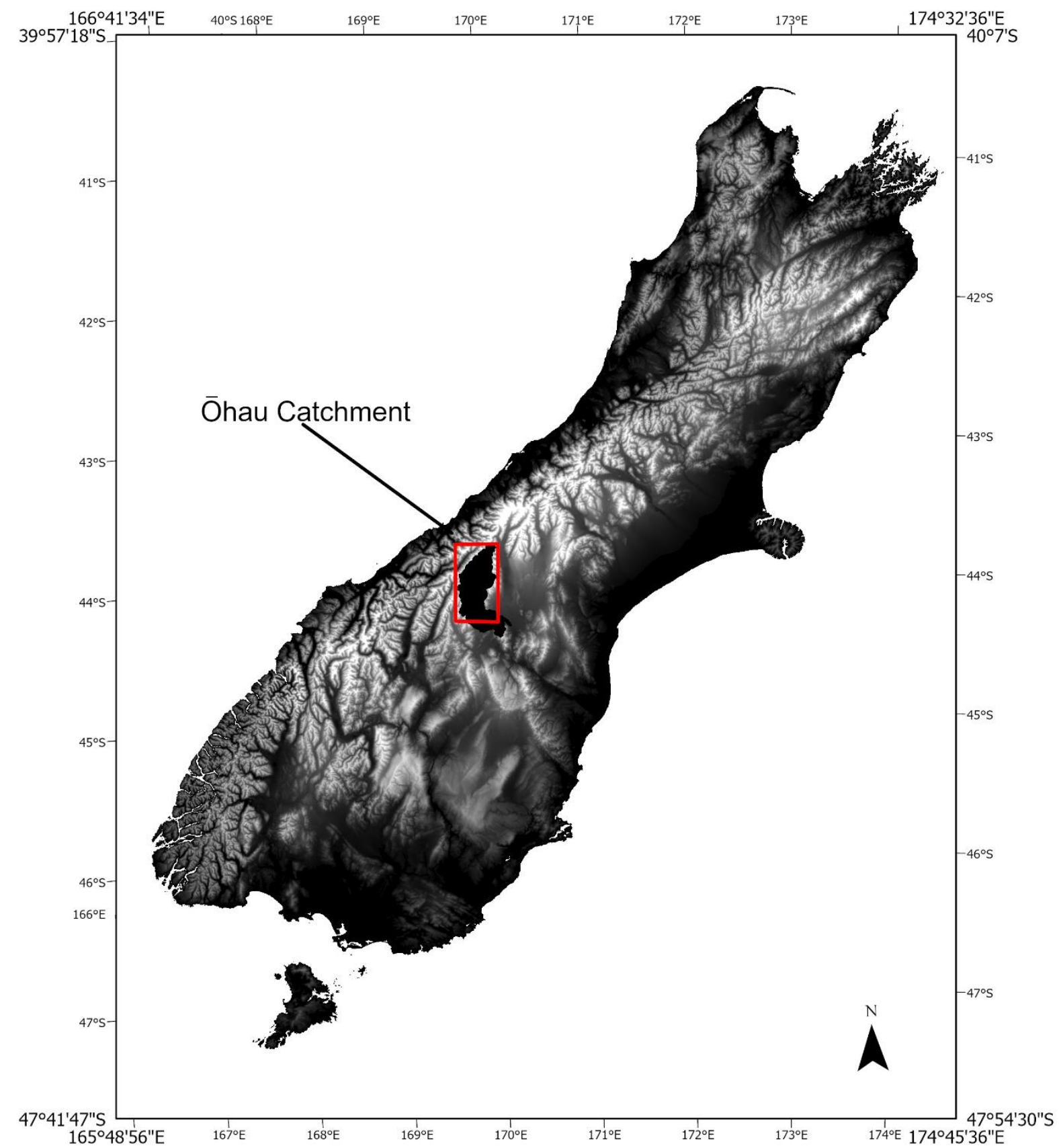

Figure 3.1. Map of Te Waipounamu showing the Ōhau catchment, Canterbury. 


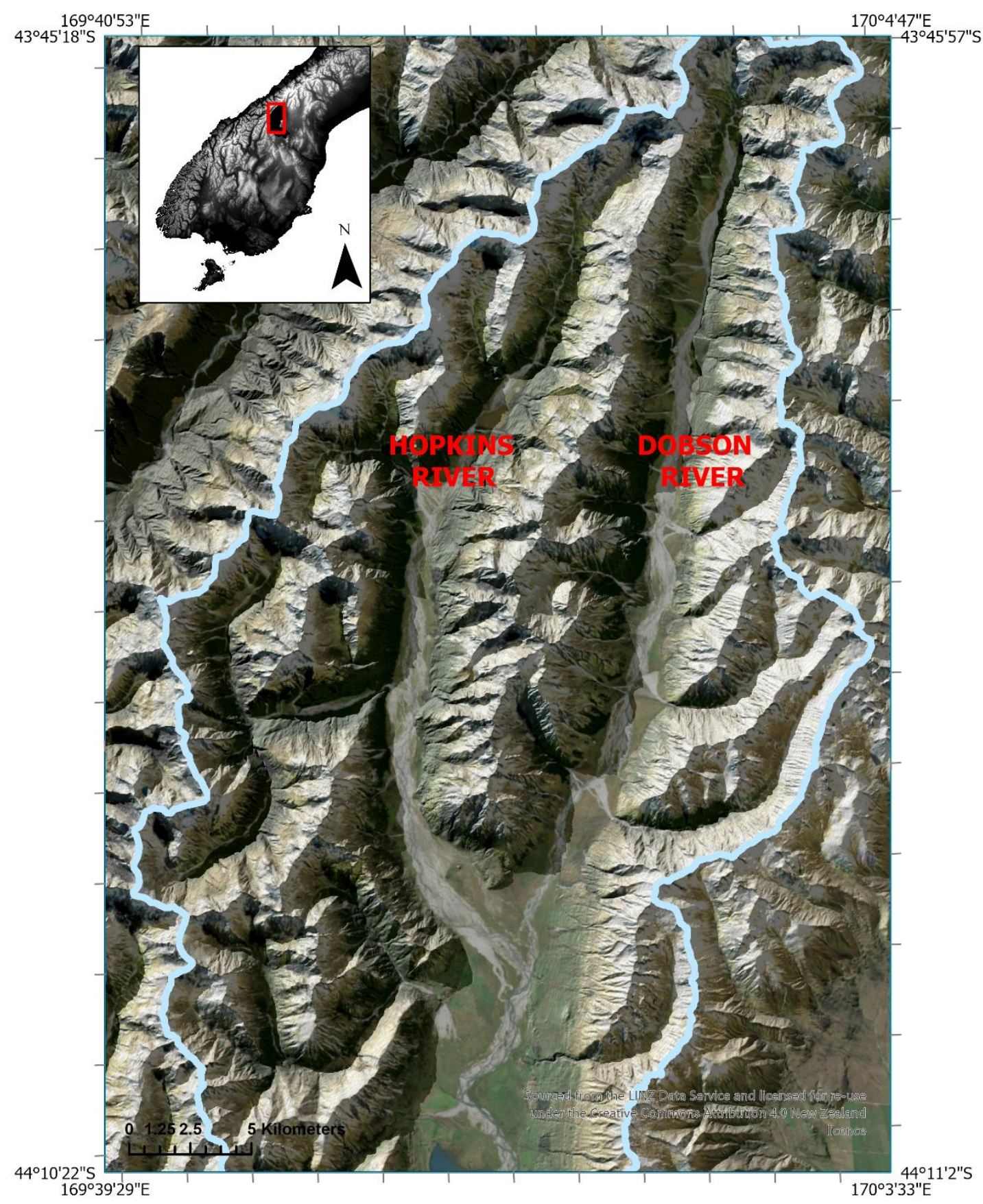

Figure 3.2. Map of Ōhau catchment, Canterbury with the two main tributaries: Hopkins and Dobson Rivers. 


\section{1. Geomorphology}

The Southern Alps exhibit a history of widespread glaciation throughout the Quaternary. Throughout the Southern Alps, large previously glaciated valleys are evident with widespread lateral and terminal moraines. The last glacial maximum (LGM) in New Zealand is thought to have been reached approximately 32,500 yrs ago with several glacial advances occurring until the glacial recession began (Barrell, 2011; Putnam et al., 2013). Dating of lateral moraines along Lake Pukaki show recession of the Ōhau and Pukaki glaciers began 18,000 yrs ago (Putnam et al., 2013). Throughout the Dobson Valley and surrounding Lake Ōhau there is evidence of prior glaciation. Lateral and terminal moraines are located around Lake Ōhau, and in the Dobson Valley hanging valleys are present (Fig. 3.3).

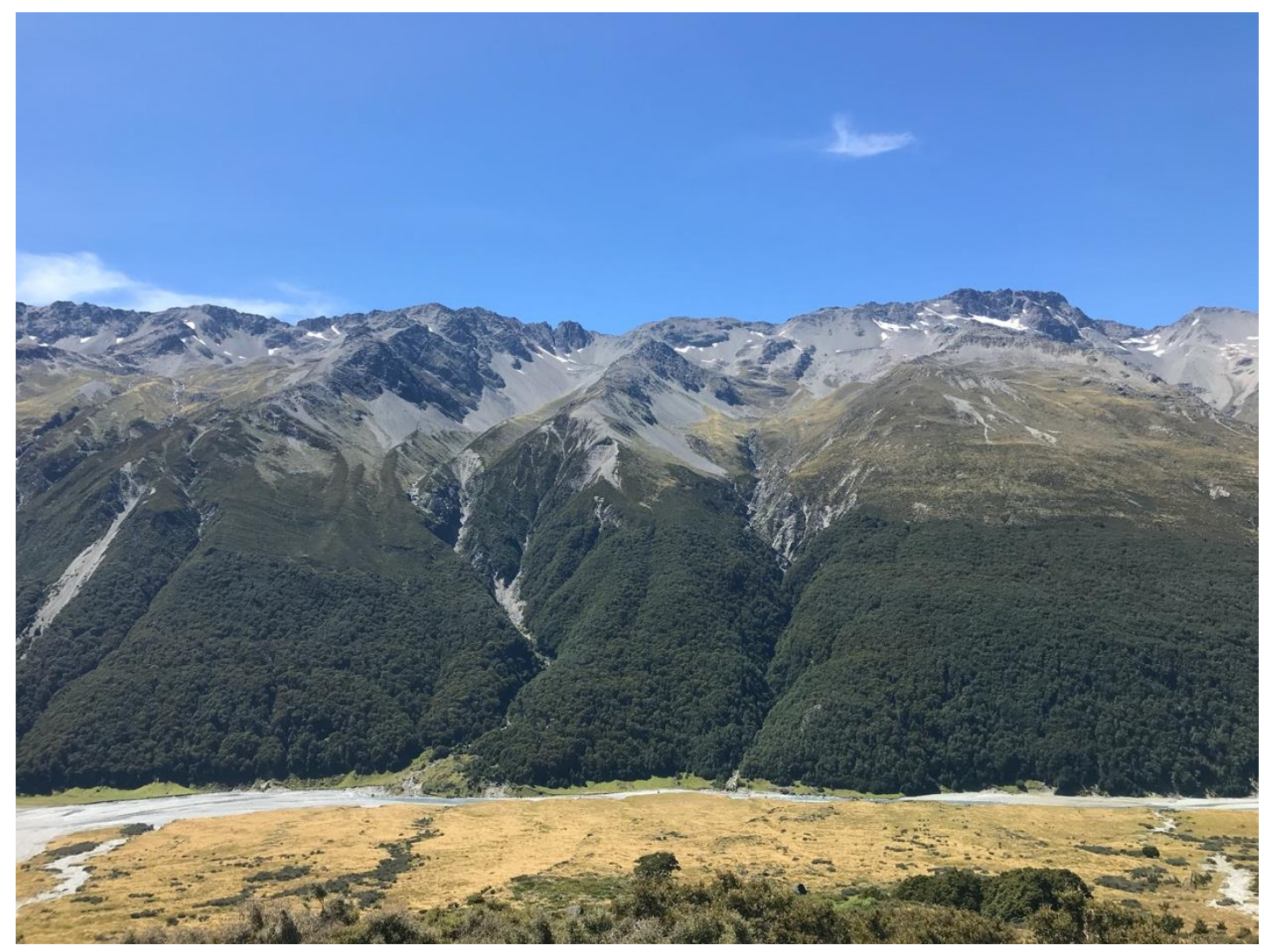

Figure 3.3. Lateral moraines and glacial benches on the eastern side of the upper Dobson Valley. Photo taken by Maia Bellingham. 
The Southern Alps experience frequent landsliding events as a result of tectonic activity along the Pacific and Australia plates. Coseismic rock fall and landsliding events are common with Alpine Fault rupturing. Ruptures on the Alpine Fault are approximately every 260 years with the last >7.6Mw rupture occurring in 1717 (Bull, 1996; Howarth et al., 2012; Sutherland, Berryman, \& Norris, 2006). Tectonic activity on the Alpine Fault are thought to cause a three-fold increase in the sediment flux across the Southern Alps in the 50 years following an earthquake (Howarth et al., 2012).

Three geomorphological regions in the Southern Alps are defined as western, main divide and eastern (Whitehouse, 1988). The western Southern Alps have steep, dissected slopes which have been developed through intense fluvial erosion and debris avalanches. The main divide is primarily made up of glaciated mountains at high elevations (Whitehouse, 1988). The eastern Southern Alps where the Ōhau catchment is located has two subregions, the basin and range and the eastern front. The basin and range, which includes the Ōhau catchment, is made up of large braided fluvial systems and scree-covered slopes (Fig. 3. 4). The eastern range has large V-shaped valleys made up of greywacke and is of a lower elevation that the rest of the Southern Alps (Whitehouse, 1988).

The Ōhau catchment has two main tributary rivers, the Dobson and Hopkins Rivers. The confluence of the two rivers is $\sim 10 \mathrm{~km}$ above Lake Ōhau with the river channel becoming increasingly braided closer to the lake. This research is focused on the Dobson River Valley. Upstream from the confluence the Dobson River has numerous sub-catchments on the western and eastern side of the valley ranging from $0.7 \mathrm{~km}^{2}-37.6 \mathrm{~km}^{2}$. Alluvial fans dominate the landscape in the Dobson Valley and side catchments, and show significant removal of sediment off the landscape (Fig. 3. 5). Alluvial fans in the Dobson Valley are active with sediment being transported out onto the fans during periods of precipitation. Periods of intense precipitation are common in the Ōhau catchment due to the close proximity to the main divide and from incoming prevailing westerly winds bringing storms. 
Study site: Ōhau catchment, Canterbury

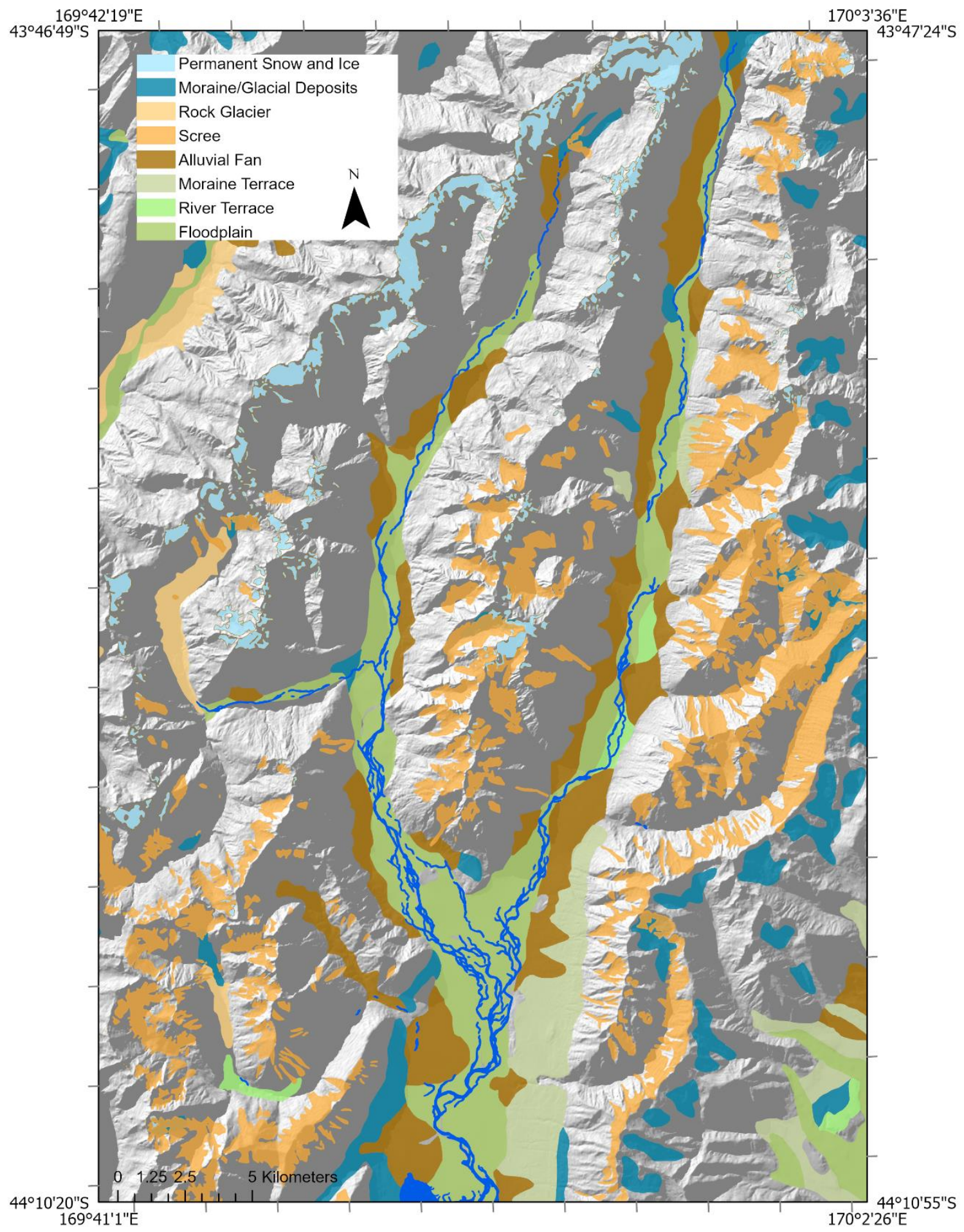

Figure 3.4. Geomorphology map of the Ōhau catchment, Canterbury. 


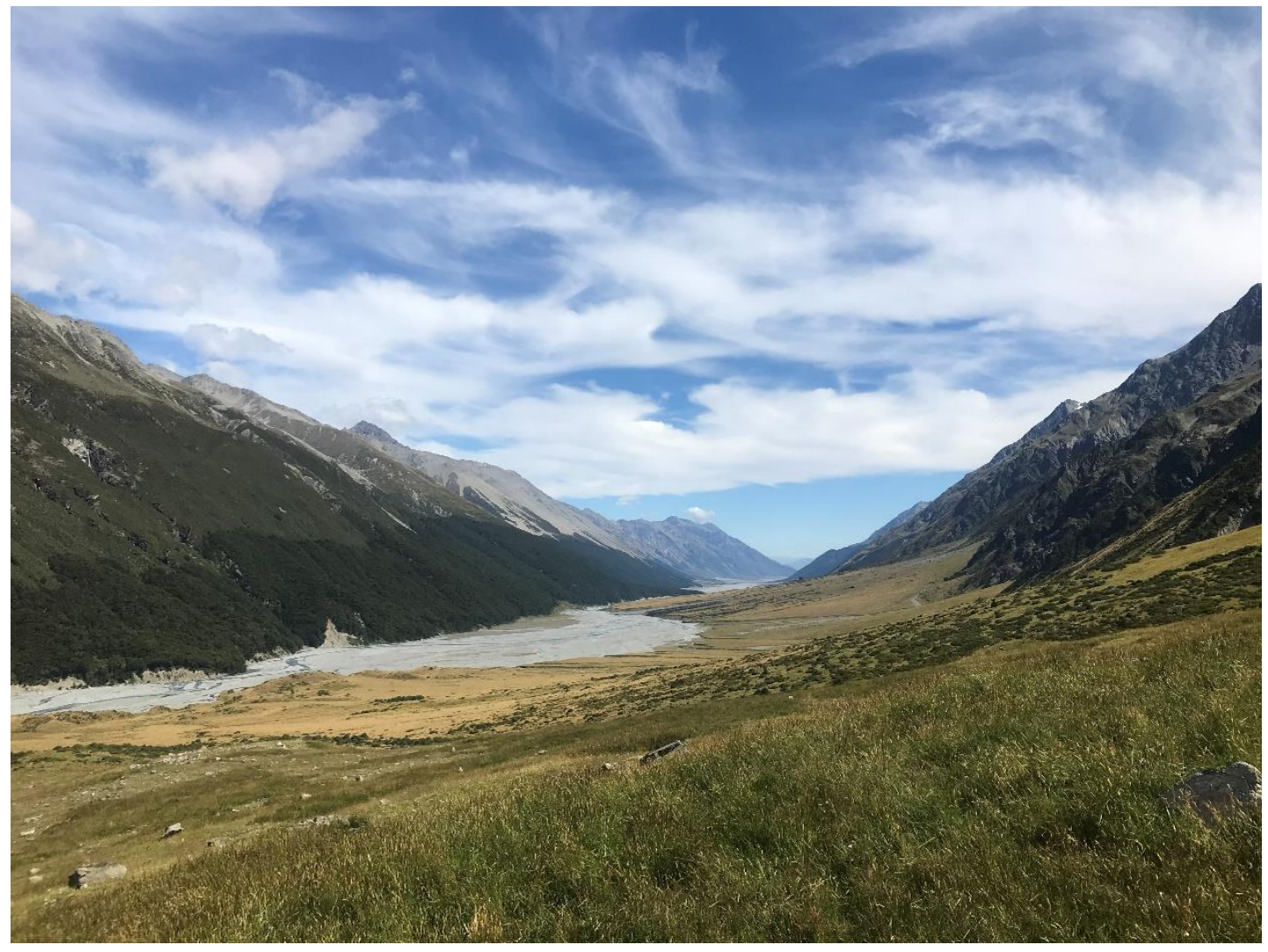

Figure 3.5. Alluvial fans in the upper Dobson Valley, looking south. Photo taken by Maia Bellingham.

Periods of intense precipitation in the Ōhau catchment and associated sub-catchments frequently result in widespread flooding (Fig. 3. 6). During flooding events, sediment transport increases resulting in modification of stream channels. Sediment transport in the Dobson Valley occurs frequently, particularly in the summer months, transporting significant amounts of sediment downstream. 


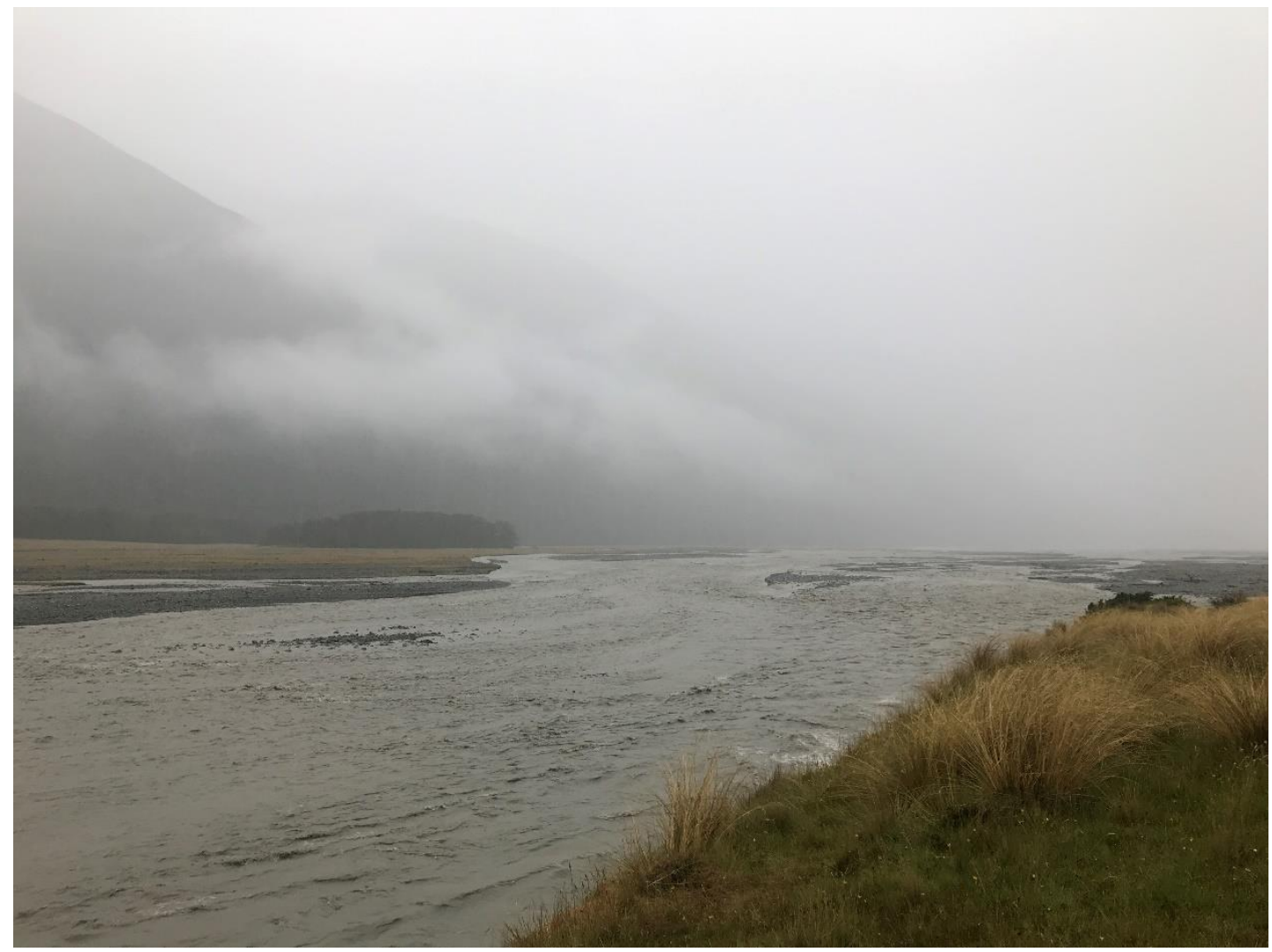

Figure 3.6. Dobson River in flood January 19th 2019, looking south, down river. Photo taken by Maia Bellingham.

Vegetation in the Dobson Valley is primarily sparse and covered in pasture in low lying areas, due to the area being actively farmed with sheep and cattle. Anthropogenic modification in the valley has been persistent over the past century. Vegetation on the western side of the main valley is sparse, particularly at higher elevations as the landscape becomes more heavily influenced by snow and ice. On the eastern side of the valley, however, slopes are covered in dense native forest (Fig. 3. 3) as the steep slopes limit the potential for grazing. In the upper Dobson Valley, sub-catchments are steep with exposed, highly fractured bedrock (Fig. 3. 7). Many of the sub-catchments in the upper Dobson Valley have persistent ice and snow cover resulting in permanent streams. During heavy precipitation numerous waterfalls emerge and flow through areas of fractured bedrock, accumulating flow during heavy precipitation. 


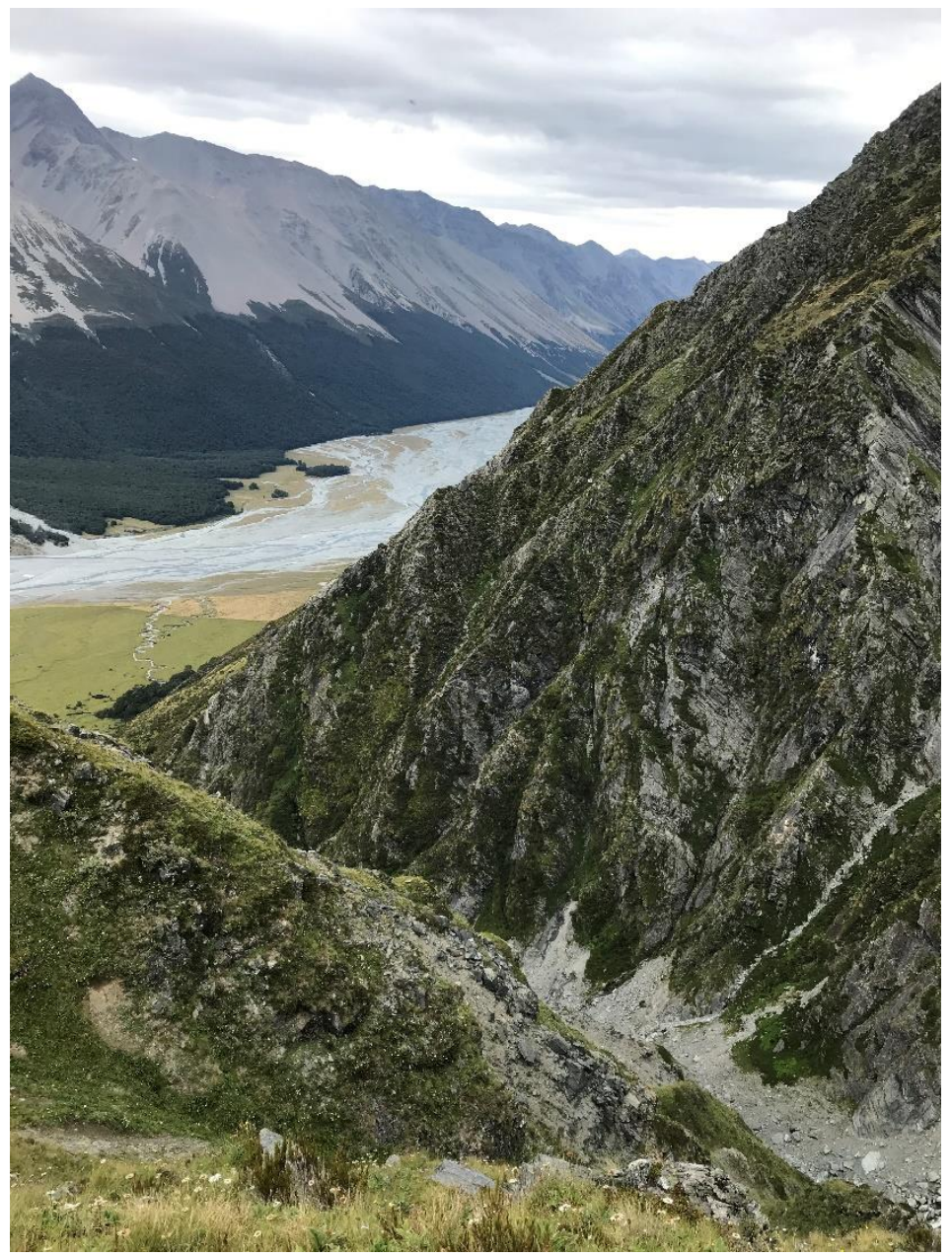

Figure 3.7. Example of an upper Dobson Valley sub-catchment, looking west. Photo taken by Maia Bellingham.

In the lower Dobson Valley, sub-catchments on the eastern side of the valley vary significantly from the upper and western side of the valley. Catchments on the eastern side of the valley are significantly larger ranging from $27.4 \mathrm{~km}^{2}$ to $37.6 \mathrm{~km}^{2}$ compared to the upper catchments that are as small as $0.7 \mathrm{~km}^{2}$. The lower valley sub-catchments have other small tributaries and are primarily covered in scree slopes with some native forest cover (Fig. 3. 8). 


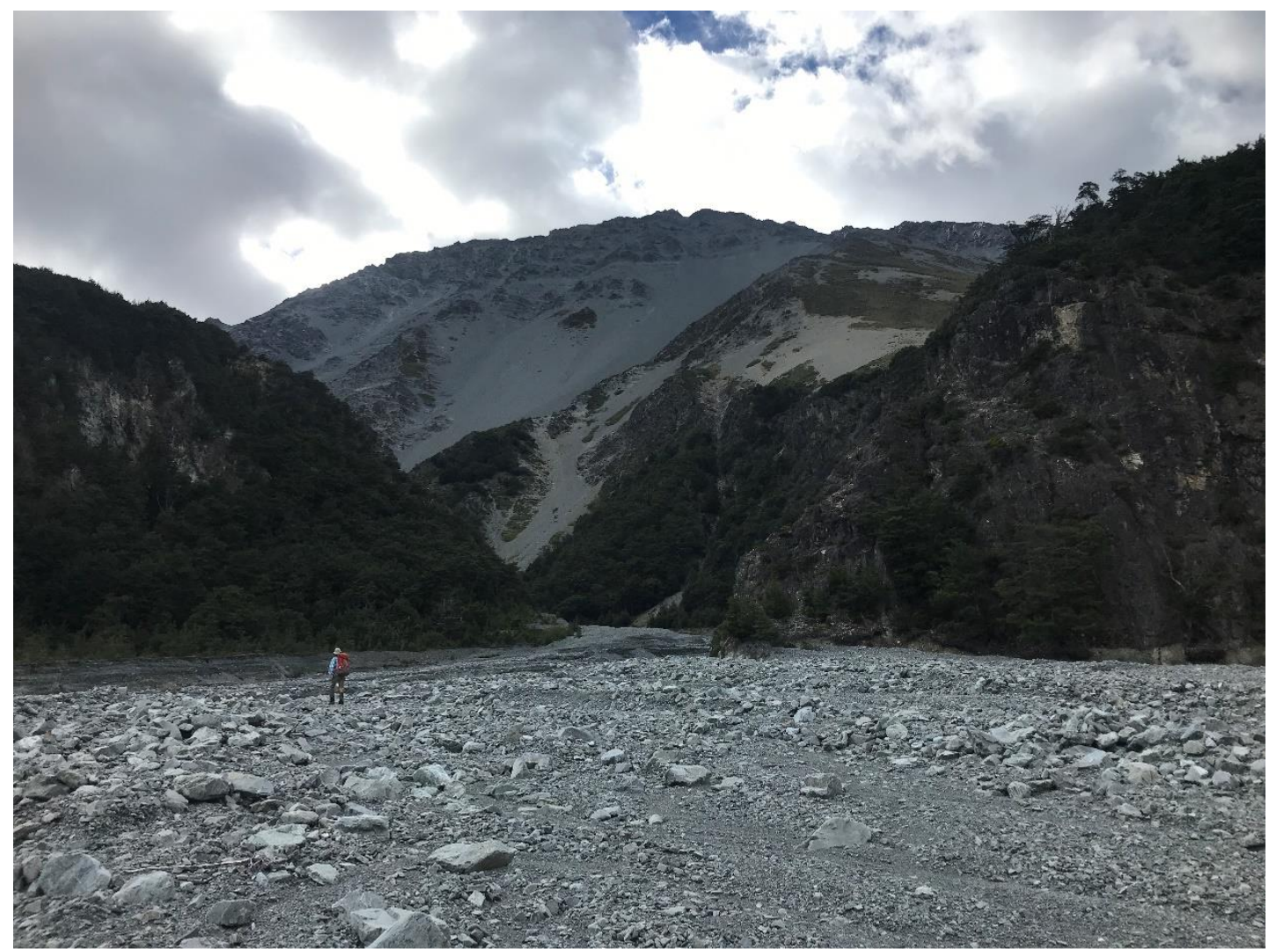

Figure 3.8. Scree slopes in Stewart Stream, Lower Dobson Valley. Photo taken by Maia Bellingham.

Soils of the Ōhau catchment include Brown, Podzol and Raw Soils (Hewitt, 2010). Brown Soil dominates the majority of the catchment, surrounding Lake Ōhau and covering much of the land at low elevations, including on moraines. At higher elevations in the catchment Podzol and Raw Soils become more common. Podzol Soils cover the Naumann Range, between the Dobson and Hopkins Rivers. The Podzol soil along the Naumann Range is acidic, strongly leached and is typical of areas of high precipitation (Hewitt, 2010). Raw Soil covers all other high elevations in the catchment and are indicative of young soils with minimal topsoil located in active alpine landscapes, with scree slopes that are highly erosive (Hewitt, 2010). Podzol and Raw soils are most common in alpine landscapes including across high elevations in the Southern Alps as precipitation is very high and slopes are under-going active erosion. 


\section{2. Geology}

The Southern Alps are composed of a variety of lithologies that have been offset by the Alpine Fault due to the oblique convergence of the Pacific and Australian plates. Lithologies vary from low-grade metamorphic rocks of the Torlesse group (greywacke/argillite) to low-medium grade schist. The Torlesse group is made up of mineral fragments derived from the erosion of schist, granites and gneiss that were deposited as part of the Rakaia Terrane during the Permian-Jurassic (Suggate, 1978). The Ōhau catchment is composed primarily of two lithologies from the Torlesse Group that formed during the Triassic: semischist and argillite/greywacke (Fig. 3. 9) (Cox \& Barrell, 2008). The argillite/greywacke of the Rakaia Terrane is an interbedded quartzofledspathic sandstone, siltstone and mudstone. Closer toward the Alpine Fault, lithologies become dominated by schists that have been metamorphosed from argillite/greywacke. Semi-schist becomes increasingly common toward the west as metamorphic grade increases across the Ōhau catchment (Cox \& Barrell, 2008). 
Study site: Ōhau catchment, Canterbury

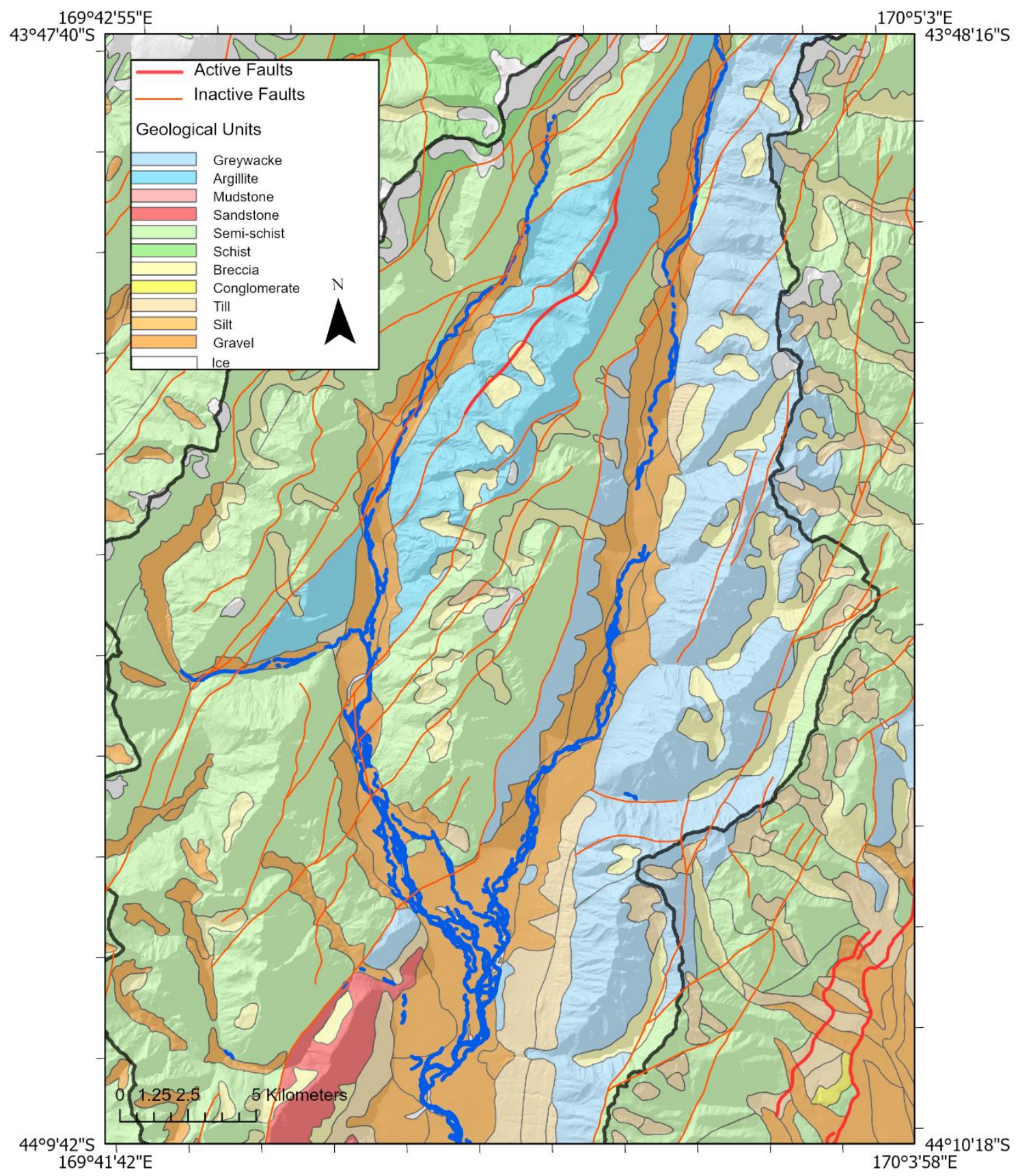

Figure 3.9. Geology and tectonic map of the Ōhau catchment, Canterbury. 


\section{3. Tectonics}

New Zealand is made up of varied geologic units which were deposited during three distinct orogens that are heavily faulted (Fig 3. 10). These include the Tuhua, Rangitata and Kaikoura orogenies. The Tuhua and Rangitata orogenies had significant deformation and uplift throughout Gondwana. The Kaikoura Orogeny is the most significant event to understand the modern day Southern Alps. During the Kaikoura Orogeny (24 Ma to now) the obliquely convergent plate boundary between the Pacific and Australian plates formed. The Alpine Fault is located along the plate boundary, trending northeastsouthwest, with surface uplift initiating between 4-5 Ma (Tippett \& Kamp, 1993). The Southern Alps have formed as a result of this tectonic activity during the Late Cenozoic. Total uplift along the Alpine Fault varies significantly from $19 \mathrm{~km}$ near Fox Glacier to only $3 \mathrm{~km}$ in the eastern most section of the fault (Tippett \& Kamp, 1993). There are several major faults in the Southern Alps with slip along the Alpine Fault being fastest. Along the Alpine Fault rates of slip have been measured as $27 \mathrm{~mm} \mathrm{yr}^{-1}$ (Norris \& Cooper, 2001; Sutherland et al., 2006). The Ōhau catchment lies $3 \mathrm{~km}$ to the east of the Alpine Fault. The close proximity to the Alpine Fault has also led to highly faulted and deformed, uplifted sedimentary rock that is orientated northeast-southwest. 
Study site: Ōhau catchment, Canterbury

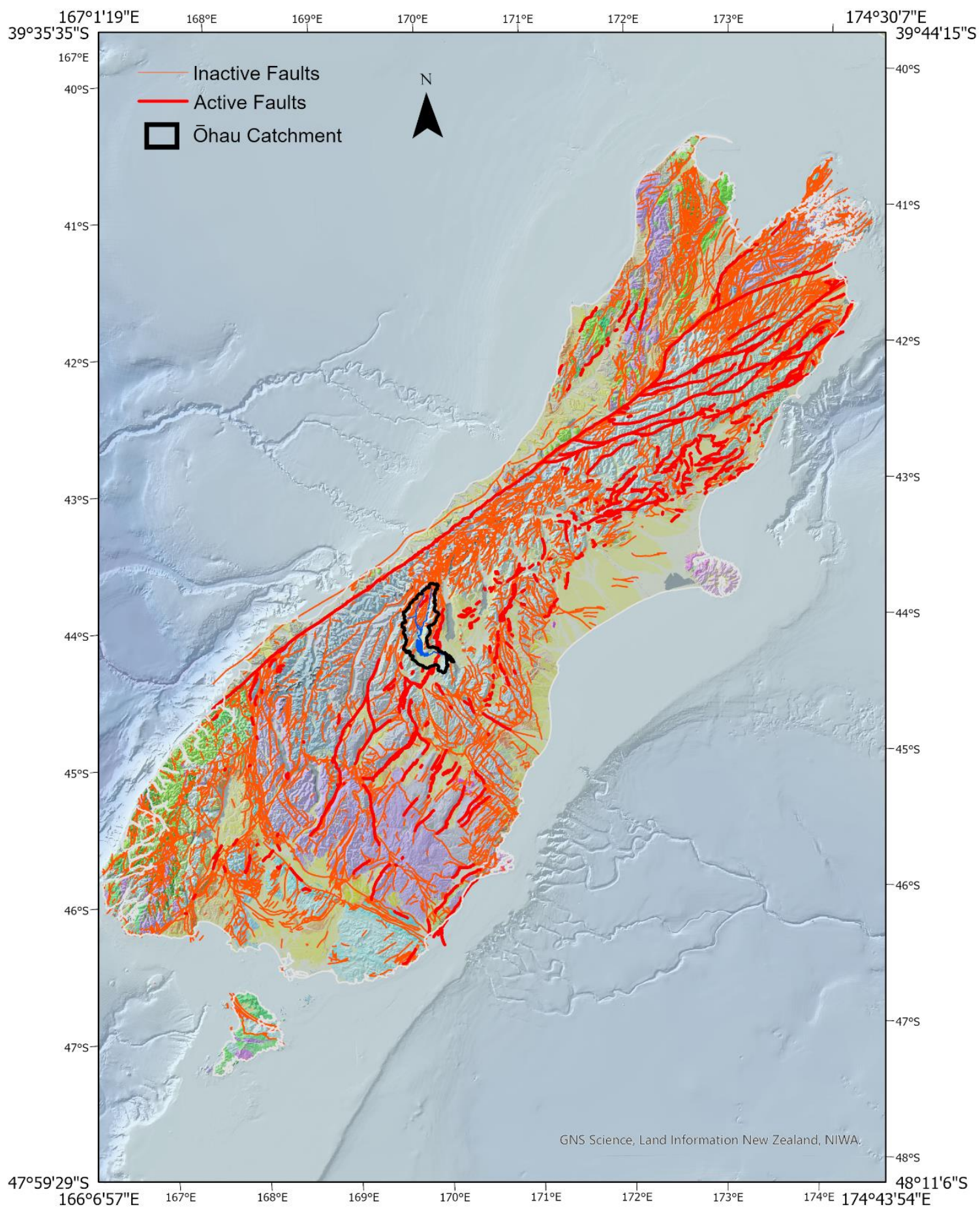

Figure 3.10. Map of active and inactive faults of Te Waipounamu. 


\section{4. Climate}

The location of New Zealand in the south Pacific results in a temperate maritime climate. Air moving down from the sub-tropics and up from the sub-Antarctic produces a westerly wind belt between $40^{\circ} \mathrm{S}$ and $50^{\circ} \mathrm{S}$. Te Waipounamu is strongly influenced by the circumpolar westerly winds, thus the climate on the west of the Southern Alps is vastly different to the east. Although New Zealand climate is impacted by large scale climate oscillations such as El Nino Southern Oscillation (ENSO) and Southern Annular Mode (SAM), Te Waipounamu is continuously impacted by the prevailing westerly winds.

\section{4. 1. Precipitation}

Prevailing westerly winds interacting with the Southern Alps creates a strong orographic effect across Te Waipounamu. The main drainage divide (main divide) that connects several $>2,500 \mathrm{~m}$ asl peaks creates a barrier which produces an orographic effect. Moisture-laden air moves across the Tasman Sea from the west. These air masses interact with the Southern Alps by being forced to rise over the western side of the Alps. When the air masses are forced to rise they cool rapidly resulting in high precipitation on the western side of the main divide. The further these air masses move from west to east the less moisture is available, thus there is evident decreases in precipitation in the eastern most extent of Te Waipounamu (Fig. 3. 11). Canterbury is located east of the central and northern main divide. Median annual precipitation in Canterbury exhibits a rain shadow effect with precipitation ranging from $4,642 \mathrm{~mm} \mathrm{yr}^{-1}$ at Arthurs Pass to $506 \mathrm{~mm} \mathrm{yr}^{-1}$ at Omarama (Macara, 2016a; Tait et al., 2006). The West Coast region is located to the west of the main divide. Precipitation is high both annually (>10,000 $\left.\mathrm{mm} \mathrm{yr}^{-1}\right)$ and in intensity.

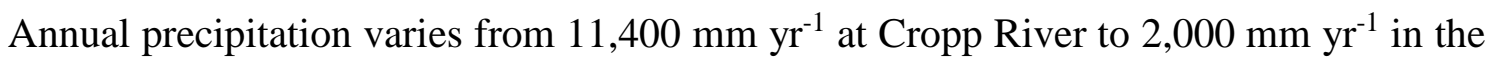
northern West Coast region (Macara, 2016b). 
Study site: Ōhau catchment, Canterbury

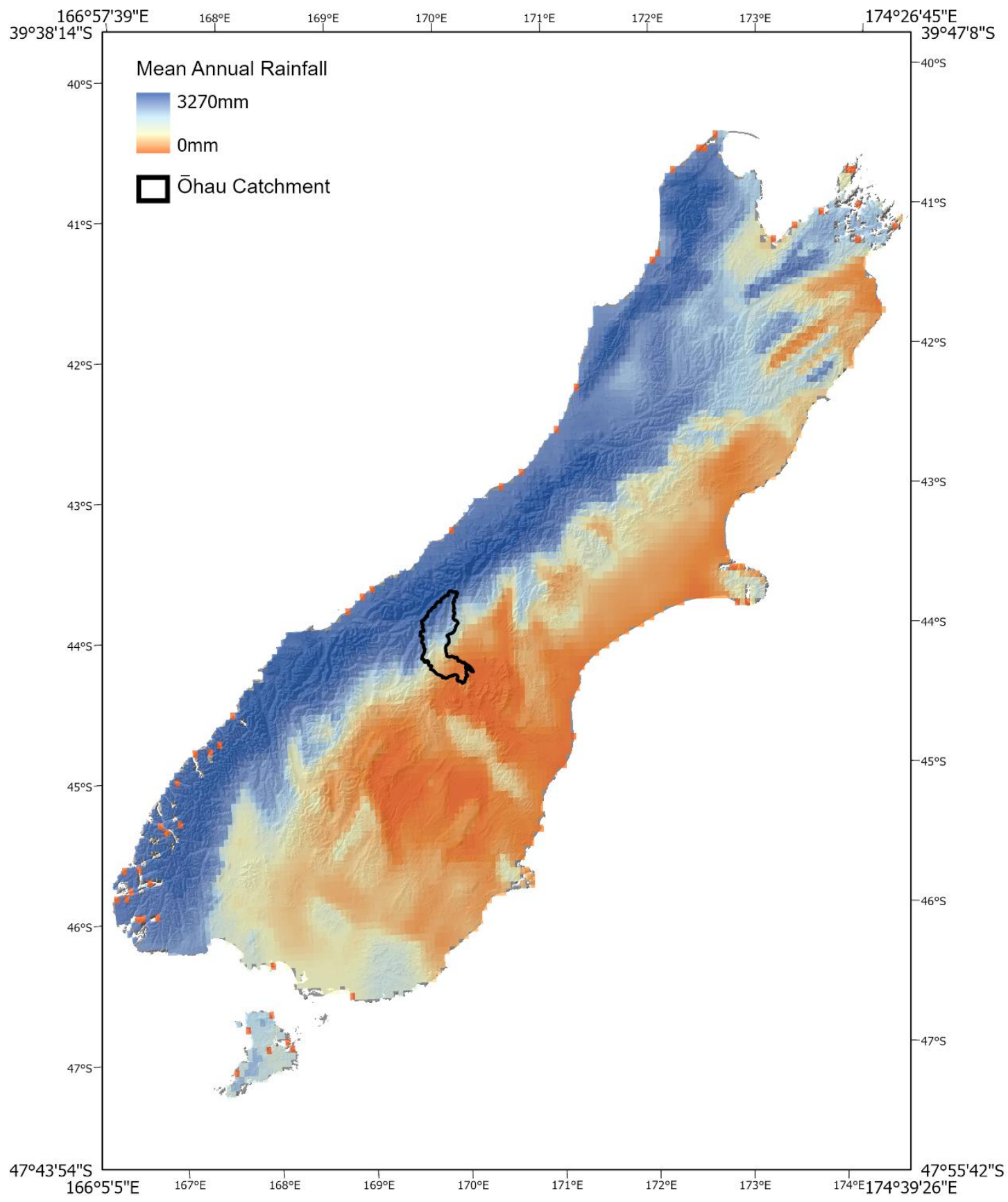

Figure 3.11. Mean annual precipitation of Te Waipounamu, New Zealand. 
The headwaters of the Ōhau catchment lies along the main divide and on the boundary of the West Coast and Canterbury regions. Precipitation in the headwaters of the catchment and peaks on the western side of the valley exceeds $4,000 \mathrm{~mm} \mathrm{yr}^{-1}$. There is a strong north-west to south-east precipitation gradient in the valley (Fig 3. 12). In the southeastern part of the valley annual precipitation is less than $1,500 \mathrm{~mm} \mathrm{yr}^{-1}$ (Macara, 2016a).

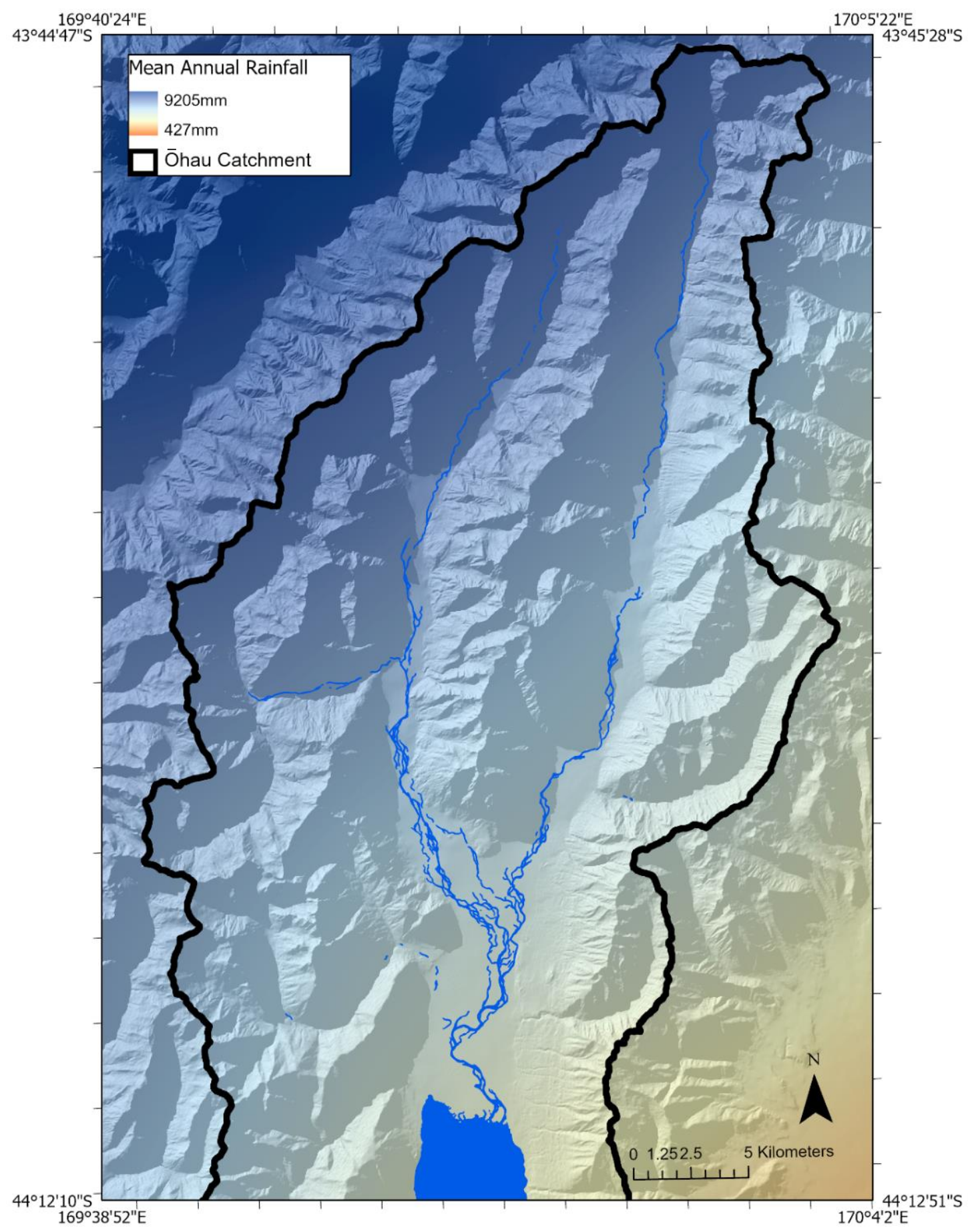

Figure 3.12. Mean annual precipitation of the Ōhau catchment, Canterbury. 


\section{4. 2. Temperature}

Similar to precipitation, there is a strong temperature gradient in the Ōhau catchment. Temperature across the Southern Alps is closely linked with elevation and this creates the gradient in the Dobson (Fig 3. 13). Median annual temperatures in the Ōhau catchment vary from $<2{ }^{\circ} \mathrm{C}$ to $8^{\circ} \mathrm{C}$ (Macara, 2016a). Temperatures are $<2{ }^{\circ} \mathrm{C}$ at the highest elevations in the Ōhau catchment which are areas that have evidence of perennial snow (Fig. 3. 14). In the lowest part of the Ōhau catchment median annual temperatures reach $8^{\circ} \mathrm{C}$ creating this temperature gradient.

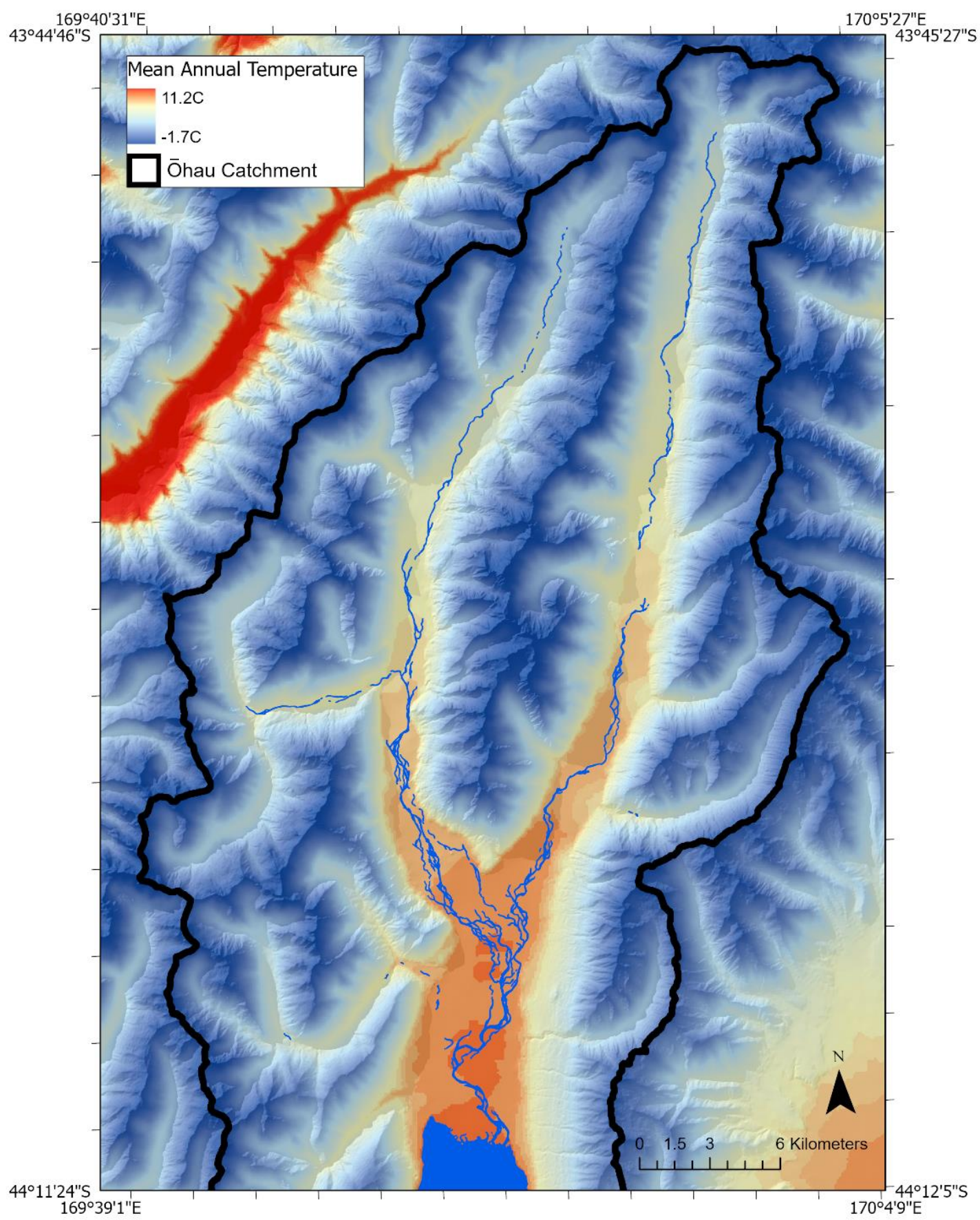

Figure 3.13. Mean annual temperature map of Ōhau catchment, Canterbury. 


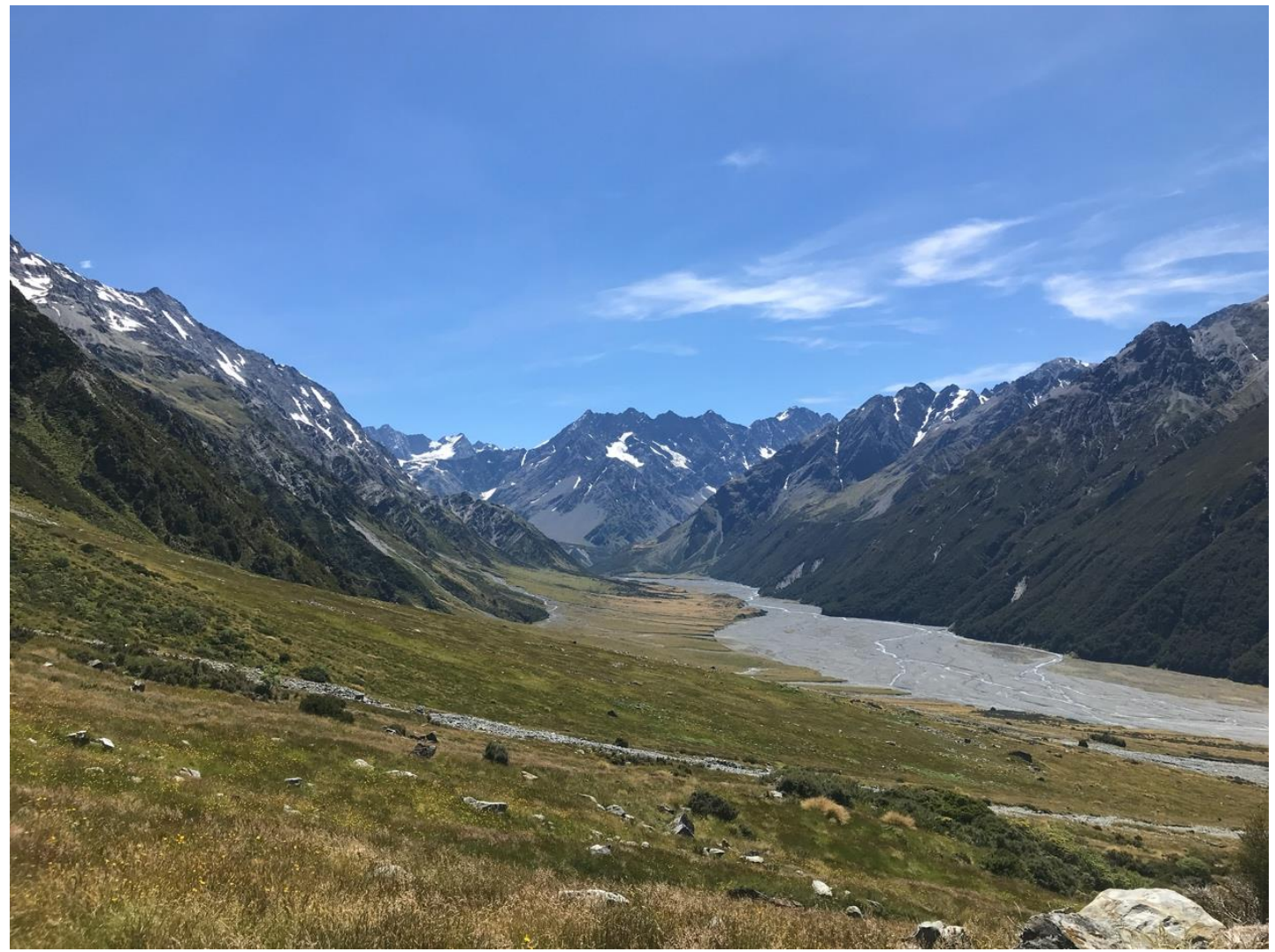

Figure 3.14. Image of perennial snow in Dobson Valley headwaters, looking north. Photo taken on January 16th 2019 by Maia Bellingham. 
Study site: Ōhau catchment, Canterbury 


\section{Chapter 4. Methods}

\section{1. Sample collection}

The Dobson and Hopkins Rivers are the two main tributary rivers draining into Lake Ōhau. Samples were collected along the Dobson River from near the headwaters down to the junction with the Hopkins River.

\section{1. 1. Stream sediment}

Stream sediment was collected for in situ ${ }^{10} \mathrm{Be}$ analysis. Sediment was collected from the main Dobson and Hopkins Rivers (Fig. 4. 1) and at six localities from within the stream bed of small tributaries of the Dobson River (Fig. 4. 2 \& Fig. 4. 3). Tributary streams were selected based on a sufficient geographic spread along the Dobson Valley and where there was a clear indication the sampling locality was above alluvial fan activity. Samples were taken directly above where alluvial fan activity ceases to avoid contributions from fan sediment, which might reflect previous climatic or erosional regimes in the valley. Sampling sediment from fan material may not reflect current erosion rates in the catchment. Sampling from above the alluvial fan was also to ensure sufficient mixing had occurred in the stream (Savi et al., 2017). Further sampling was completed in the main Dobson River and Hopkins River channels approximately $3 \mathrm{~km}$ upstream of the rivers confluence. Surface stream sediment was collected from an active area of the channel. Sediment was collected at random with a variety of grain sizes from silt to pebbles. Catchment characteristics are summarised in Table 4. 1 including for the main Dobson and Hopkins Rivers. 


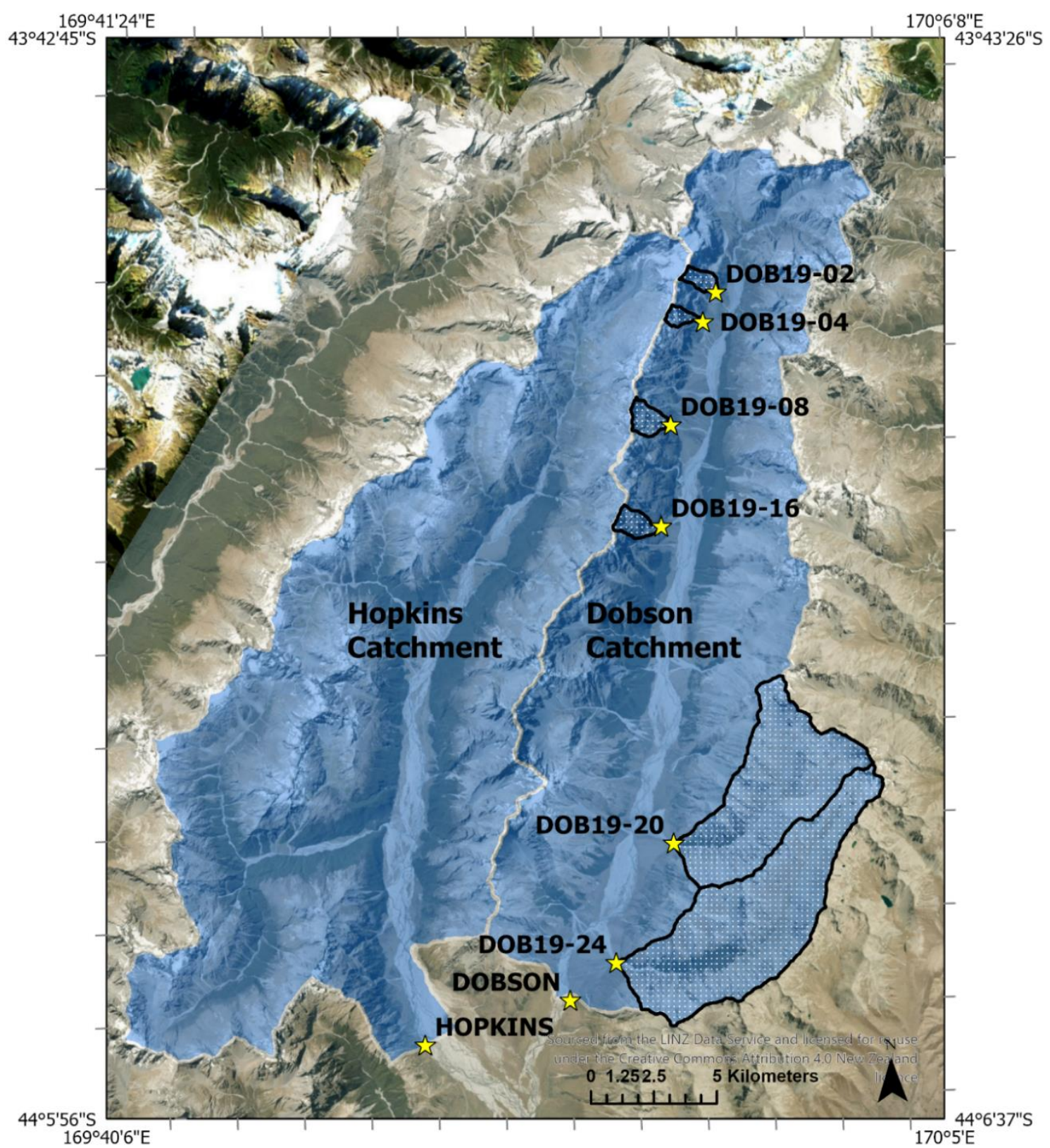

Figure 4.1. Map of stream sediment sample locations (yellow stars) and corresponding catchment boundaries in the Ōhau catchment, Canterbury. 


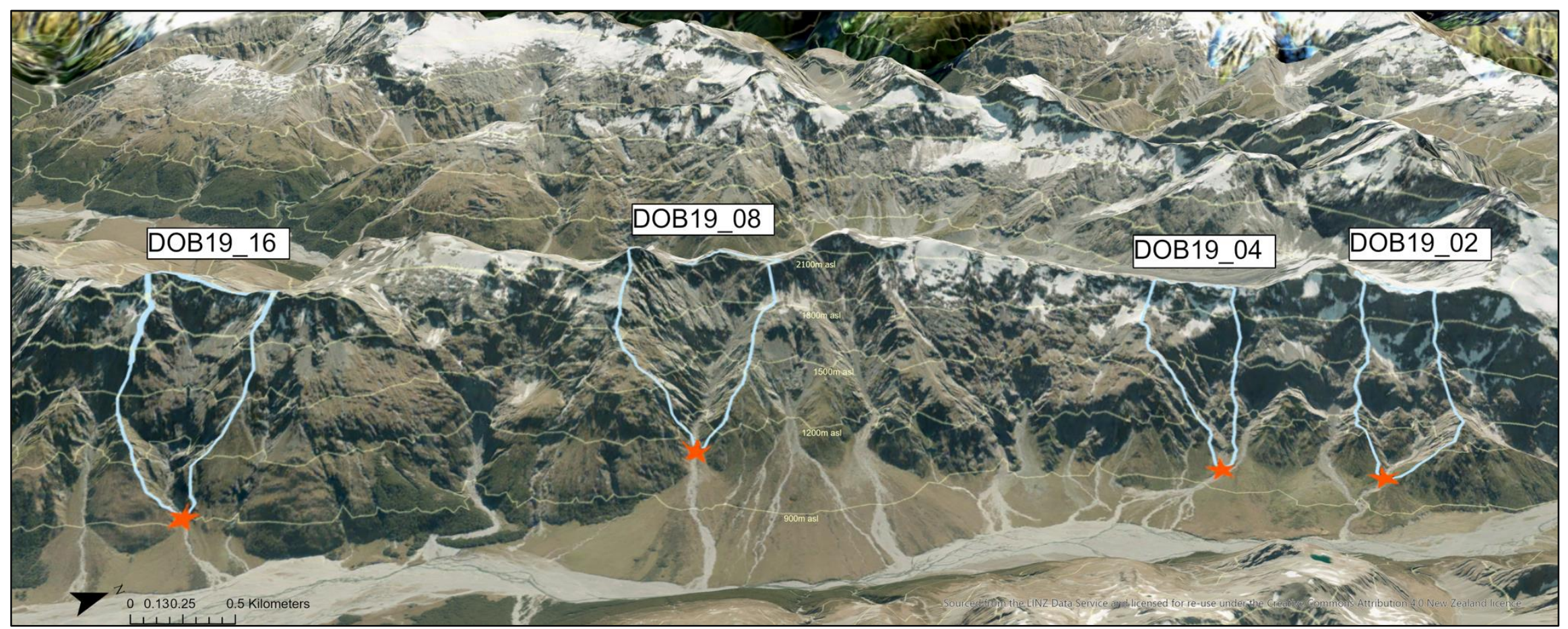

Figure 4.2. Map of stream sediment sample locations (red stars) in the upper Dobson Valley, Canterbury. 


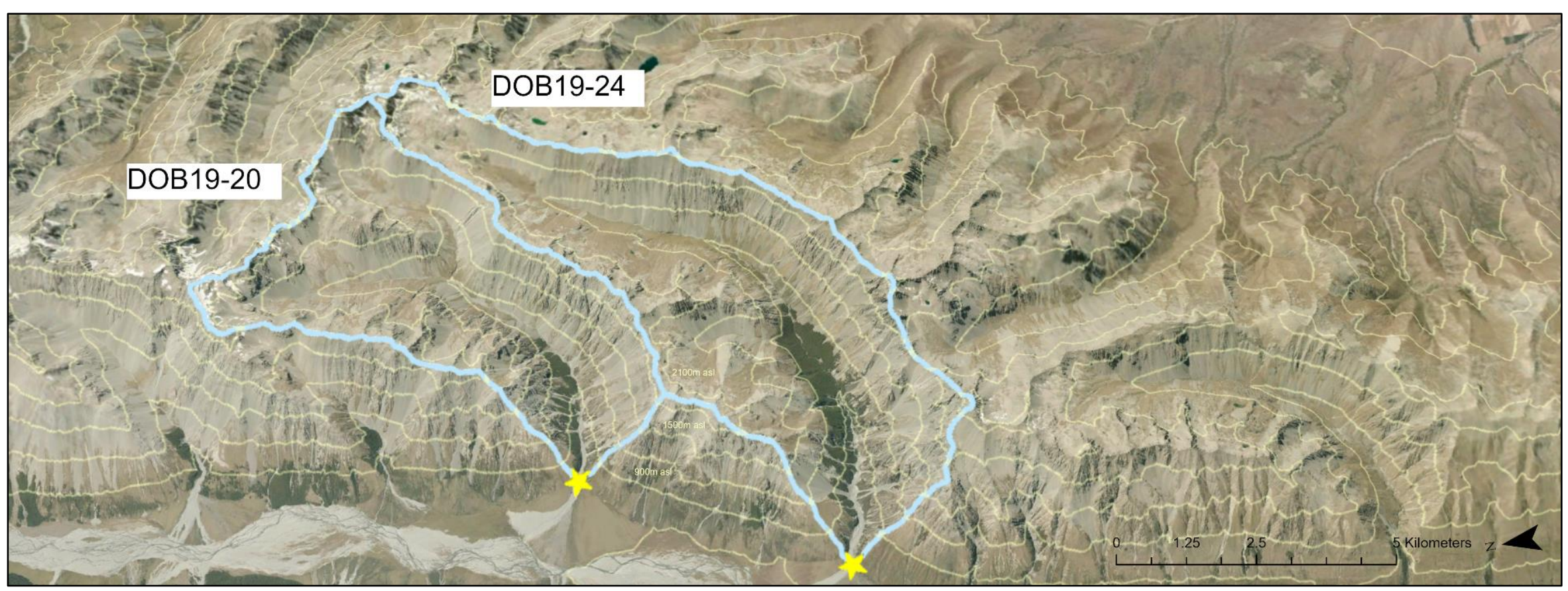

Figure 4.3. Map of stream sediment sample locations (yellow stars) in the lower Dobson Valley, Canterbury. 
Table 4.1. Summarised catchment characteristics for sampling locations in the Ōhau catchment, Canterbury.

\begin{tabular}{|c|c|c|c|c|c|c|c|c|}
\hline Sample ID & $\begin{array}{c}\text { Catchment } \\
\text { Area } \\
\left(\mathrm{km}^{2}\right)\end{array}$ & $\begin{array}{c}\text { Mean } \\
\text { Elevation } \\
(\mathrm{m} \text { asl) }\end{array}$ & $\begin{array}{l}\text { Maximum } \\
\text { Elevation } \\
\text { (m asl) }\end{array}$ & $\begin{array}{l}\text { Minimum } \\
\text { Elevation } \\
\text { (m asl) }\end{array}$ & $\begin{array}{c}\text { Mean Slope } \\
\text { Angle } \\
\left(^{\circ}\right)\end{array}$ & $\begin{array}{c}\text { Mean } \\
\text { Aspect } \\
\left(^{\circ}\right)\end{array}$ & $\begin{array}{l}\text { Mean Annual } \\
\text { Precipitation } \\
\text { (mm) }\end{array}$ & $\begin{array}{c}\text { Mean Annual } \\
\text { Temperature } \\
\left({ }^{\circ} \mathrm{C}\right)\end{array}$ \\
\hline DOB19-02 & 0.906 & 1436 & 2135 & 949 & 49.64 & 128 & 5887 & 5.02 \\
\hline DOB19-04 & 0.694 & 1562 & 2043 & 940 & 50.35 & 107 & 5665 & 4.32 \\
\hline DOB19-08 & 1.447 & 1706 & 2343 & 1040 & 50.32 & 98 & 4838 & 3.53 \\
\hline DOB19-16 & 1.392 & 1590 & 2282 & 885 & 51.03 & 113 & 3822 & 4.15 \\
\hline DOB19-20 & 27.37 & 1619 & 2427 & 698 & 41.2 & 209 & 1778 & 4.02 \\
\hline DOB19-24 & 37.60 & 1543 & 2375 & 644 & 38.4 & 209 & 1619 & 4.4 \\
\hline Dobson & 308.6 & 1371 & 2621 & 559 & 36.5 & 183 & 3009 & 5.26 \\
\hline Hopkins & 329.1 & 1379 & 2594 & 565 & 37.6 & 180 & 4441 & 5.19 \\
\hline
\end{tabular}


The sampling location for DOB19-02 was the furthest up the Dobson Valley (Fig. 4. 2). Sediment was sampled from the active stream channel, 100m downstream from a patch of snow (Fig. 4. 4A). The grain size of this sub-catchment varied from fine sand to $\sim 50 \mathrm{~cm}$ boulders.

The next sub-catchment sampled down-valley was DOB19-04. This sub-catchment was of similar characteristics to the previous catchment (DOB19-02). The grain size ranged from fine sand to boulders; however, the larger boulders above $40 \mathrm{~cm}$ were less common than at the DOB19-02 sampling location. The sampling location for this sub-catchment was within $100 \mathrm{~m}$ of a persistent snow patch with several waterfalls above draining into this catchment (Fig 4. 4B).

The sampling location for the DOB19-08 sub-catchment was located within the active stream channel however the channel was more active than previous sampling locations due to greater stream flow and a larger grain size. Grain size in this sub-catchment was significantly more varied (Fig. 4. 4C). Sediment was of a larger size in general however ranged from fine sand to boulders $(>2 \mathrm{~m})$. At higher elevations of this sub-catchment a large amount of snow was observed additional to some side streams and waterfalls draining into the main stream.

Sampling in the sub-catchment DOB19-16 was also located above where alluvial fan activity ceased and within the active stream channel. Grain size in this catchment was less varied than that of DOB19-08. Sediment varied from fine sand to boulders $(\sim 60 \mathrm{~cm})$ (Fig. 4. 4D).

In the lower Dobson Valley two sub-catchments were sampled on the eastern side of the valley: DOB19-20 and DOB19-24 (Fig 4. 3). These two catchments have a greater area than the previously sampled sub-catchments in the upper Dobson Valley and have permanent snow in the headwaters.

DOB19-20 was sampled within the active stream channel of Stony Stream directly above the alluvial fan. Similarly DOB19-24 was sampled in the active channel in Irishman stream above alluvial fan activity. Sediment from both Stony (4. 5A) and Irishman (4. 5B) streams consisted of sizes from sand to boulders up to $\sim 40 \mathrm{~cm}$ in diameter. 
The final two samples: Dobson and Hopkins were sampled from the main channel of the Dobson and Hopkins rivers respectively. Sampling for Dobson was within the active channel of the Dobson River, with the grain size ranging from sand to pebbles $(\sim 5 \mathrm{~cm})$. The Hopkins sample was taken in 2014 from the active main channel and had a similar grain size representation as Dobson from the Dobson River. Both Dobson and the Hopkins were sampled from approximately $3 \mathrm{~km}$ upstream of the confluence where the Dobson River joins the Hopkins and flows directly into Lake Ōhau. The river channel here is active and is braided with the river changing course very frequently. 


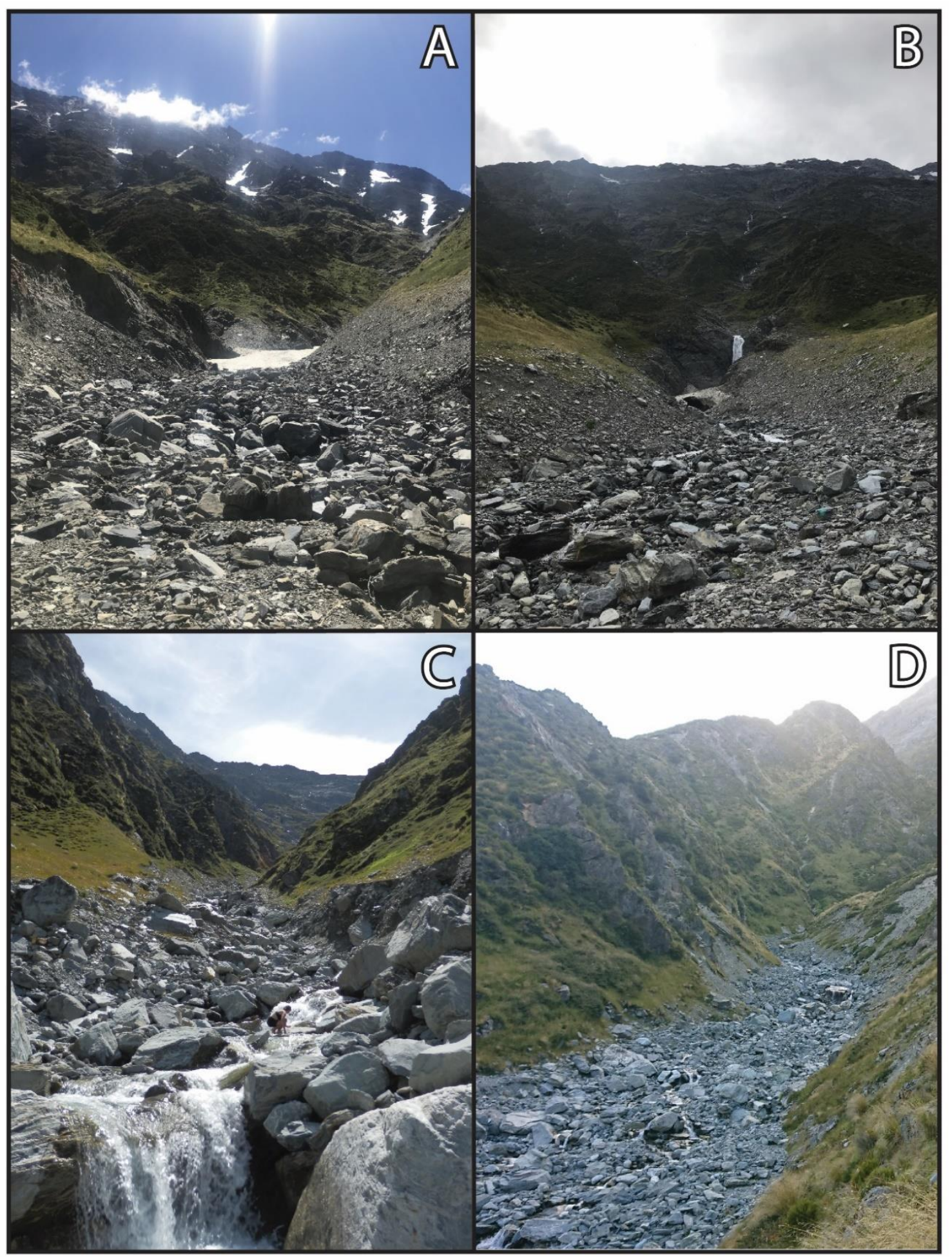

Figure 4.4. Images of sediment sampling sites in the upper Dobson Valley, Canterbury. (A) DOB19-02 sub-catchment looking north-west. (B) DOB19-04 sub-catchment looking west. (C) DOB19-08 sub-catchment looking west. (D) DOB19-16 sub-catchment looking west. Note figure for scale in Panel C. Images A\& B were taken by Maia Bellingham, image C by Claire Lukens and image D by Kevin Norton. 


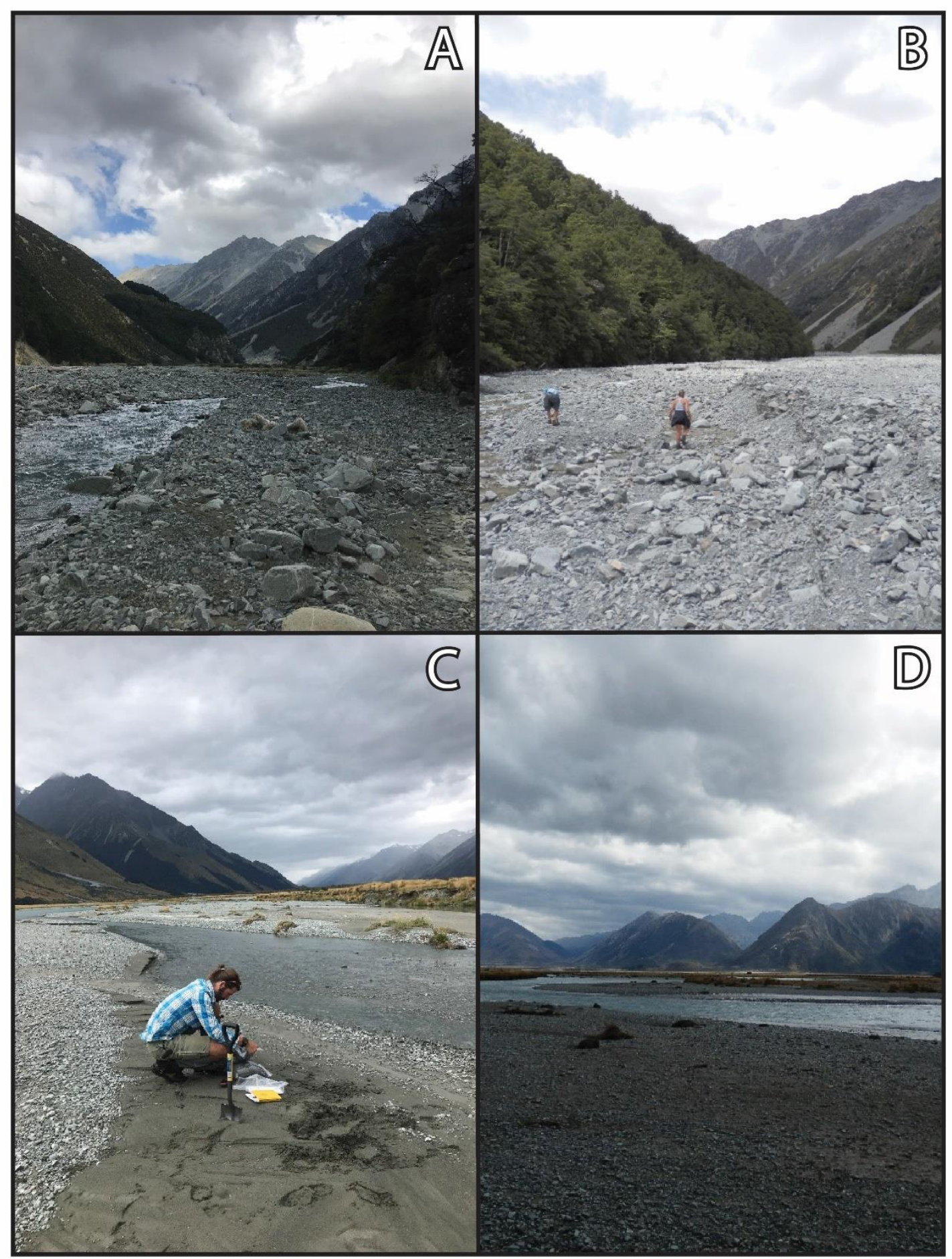

Figure 4.5. Images of sediment sampling sites in the lower Dobson Valley, Canterbury. (A) DOB19-20 sub-catchment looking east. (B) DOB19-24 sub-catchment looking east. (C) Dobson, Dobson River looking north. (D) Looking south-west toward the confluence of the Dobson and Hopkins Rivers. Note figures for scale in Panel $C \& D$. Images A, $C$ $\& D$ were taken by Maia Bellingham and image B was taken by Claire Lukens. 


\section{1. 2. Soil transect}

Soil pits were dug at regular intervals along the crest of a ridge above a tributary stream on the western side of the upper Dobson Valley. The crest or convex nose of a ridge is the most suitable location to minimise the contribution of any material not from the underlying bedrock and to avoid any glacial deposits. Soil depth to saprolite is likely to be least on a ridge as material is not easily accumulated there. The selected transect along the ridge had no evidence of recent deep seated landsliding. The western Dobson Valley also has a consistent lithology making anywhere on the ridge a suitable site to sample. Importantly processes on this ridge had evidence of diffusive processes such as soil creep.

Soil pits were dug approximately 100 meters uphill from each other (Fig. 4. 6). The soil pits were dug approximately $60 \mathrm{~cm}$ to $1 \mathrm{~m}$ wide. Depth of each pit was dependent on where the soil to saprolite boundary was located. Once dug one side of the pit was scraped down to expose a clean edge. Soils were then sampled from each soil horizon within the pit. At least $\sim 50 \mathrm{~g}$ of soil was sampled. Fragments of saprolite were also taken from the soil to the saprolite boundary and any other fragments located in the clean edge of the pit (depth recorded if not at boundary). 


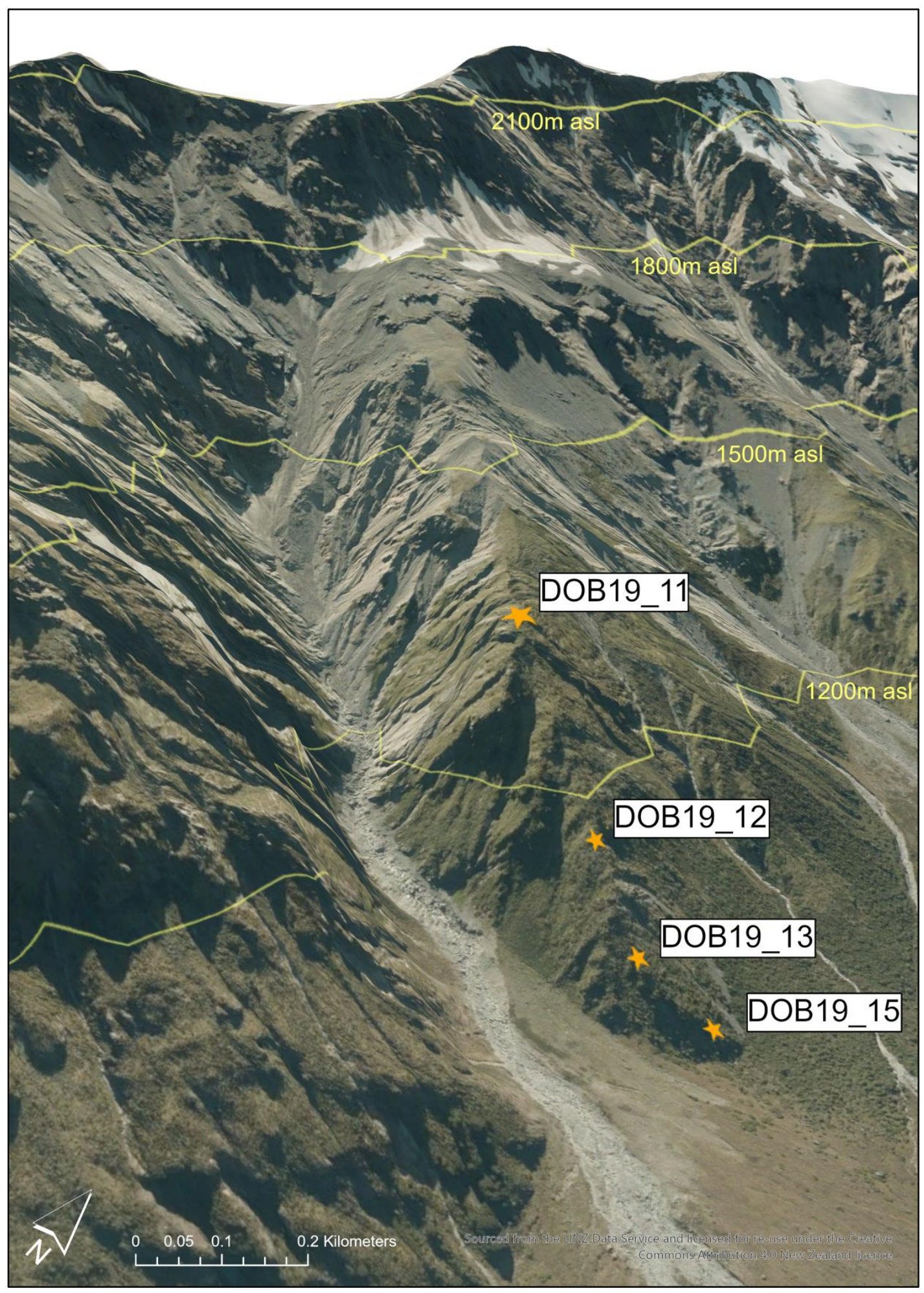

Figure 4.6. Map of soil transect, adjacent to the DOB19-08 sub-catchment in the upper Dobson Valley, Canterbury. 
The highest soil pit dug for the soil transect was DOB19-11. This soil pit was located on the crest of the main ridge. Vegetation at this pit was primarily grass and small shrubbery. The soil pit was $35 \mathrm{~cm}$ deep with a top soil and a sub-soil that both had pieces of saprolite throughout (Fig 4. 7A). The upper $10 \mathrm{~cm}$ of the soil pit had significant plant material such as roots.

The soil pit DOB19-12 was the shallowest soil pit at $22 \mathrm{~cm}$ depth. This pit was dug $1 \mathrm{~m}$ off the crest of the ridge. Vegetation was primarily tussocks, small shrubbery $(<1 \mathrm{~m})$ and grasses. Within the soil pit the topsoil, the subsoil and the saprolite were sampled. In the upper $15 \mathrm{~cm}$ of the soil pit there were abundant plant roots (Fig 4. 7B).

The soil pit DOB19-13 was on the crest of the ridge and was dug $50 \mathrm{~cm}$ deep. Soils were sampled down to $50 \mathrm{~cm}$ depth where saprolite was sampled (Fig 4. 7C). Roots were highly abundant throughout the soil pit down to the saprolite at $50 \mathrm{~cm}$. Vegetation surrounding the pit were grasses, tussock and shrubbery up to $60 \mathrm{~cm}$ high.

The soil pit at lowest elevation was DOB19-15. This pit was dug on the lower crest of the ridge and was dug to $60 \mathrm{~cm}$ depth. Soil in this pit appeared to be much more orange in colour compared to previously dug pits with clasts throughout (Fig 4. 7D). The topsoil, two further soil horizons and the saprolite were sampled from DOB19-15. Within the pit roots were less abundant than in the previous pits with roots only of higher abundance in the top $10 \mathrm{~cm}$. Vegetation in the surrounding area were mainly grasses, small tussocks $(<30 \mathrm{~cm})$ and trees and shrubs $(>1 \mathrm{~m})$. 


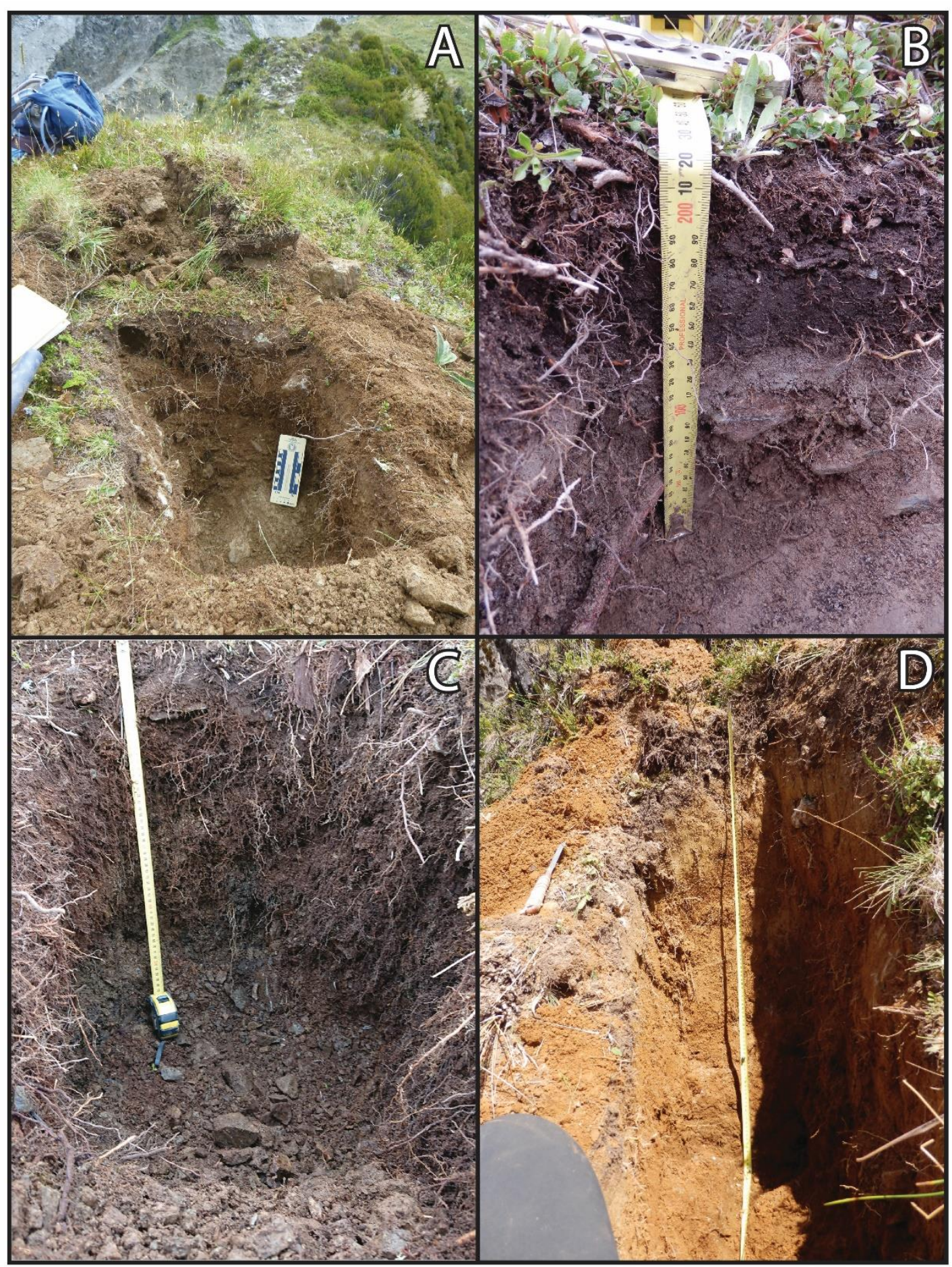

Figure 4.7. Soil pits dug along the crest of a ridge in the upper Dobson Valley. (A) DOB19-11. (B) DOB19-12. (C) DOB19-13. (D) DOB19-15. Image A was taken by Kevin Norton and images $B, C \& D$ were taken by Claire Lukens. 


\section{2. Beryllium-10 laboratory procedures}

Stream sediment and soil samples were brought back to Victoria University of Wellington (VUW). Standard laboratory physical and chemical processing was implemented for measuring catchment-averaged denudation using in situ ${ }^{10} \mathrm{Be}$. Stream sediment samples consisted of thirteen sites (four from previous sampling by Kevin Norton). Of the total thirteen stream sediment samples collected, eight had the $125 \mu \mathrm{m}-500 \mu \mathrm{m}$ fraction processed and one sampled site had the full grain size suite processed. A total of thirtysix soil samples were processed and measured for zirconium content through X-ray fluorescence. In situ ${ }^{10} \mathrm{Be}$ preparation in the soil and cosmogenic laboratories at VUW followed procedures adapted from Von Blanckenburg, Hewawasam, and Kubik (2004), von Blanckenburg, Belshaw, and O'Nions (1996) and Norton et al (2008).

\section{2. 1. Physical quartz separation}

Samples were dried at $105^{\circ} \mathrm{C}$ for at least twenty-four hours. Material was then dry sieved with a mechanical sieve shaker to the following fractions: $<125 \mu \mathrm{m}, 125-500 \mu \mathrm{m}, 500 \mu \mathrm{m}-$ $1 \mathrm{~mm}, 1 \mathrm{~mm}-8 \mathrm{~mm}$ and $>8 \mathrm{~mm}$. The $<125 \mu \mathrm{m}$ fraction was archived as it is too fine grained for later chemistry procedures. The $1 \mathrm{~mm}-8 \mathrm{~mm}$ and $>8 \mathrm{~mm}$ samples were crushed in the Boyd jaw-crusher and sieved to $<250 \mu \mathrm{m}$. Pulverising of samples occurred frequently even when the width of the plates in the jaw-crusher had not changed because of the platy and elongate nature of schist grains. To overcome fully pulverising samples they were crushed two to three times without moving the plates closer together in the crusher.

Samples were then divided into two batches for separate rounds of chemistry. Round one consisted of 125-500 $\mu \mathrm{m}$ for DOB19-02, DOB19-04 and DOB19-16 and all grain sizes except $<125 \mu \mathrm{m}$ for DOB19-08. The grain sizes $125-500 \mu \mathrm{m}$ for all samples and $500 \mu \mathrm{m}-$ $1 \mathrm{~mm}$ for DOB19-08 were crushed in the tungsten carbide ring mill to ensure grains were monomineralic and $<250 \mu \mathrm{m}$. Crushing using the ring mill resulted in pulverisation of samples after $\sim 5$ seconds due to the shape of schist grains being platy and elongate. All grain sizes for DOB19-08 were washed with distilled water then let to settle until only fine particulates were still suspended, at that point the suspended sediment was poured off. These samples were then oven dried at $50^{\circ} \mathrm{C}$ for twelve hours. Initially the DOB19$081 \mathrm{~mm}-8 \mathrm{~mm}$ and $>8 \mathrm{~mm}$ were not washed enough for the Frantz magnetic separator. All samples were then wet sieved through a $63 \mu \mathrm{m}$ sieve to wash any fine particulates then oven dried at $50^{\circ} \mathrm{C}$. 
Froth floatation was tested for DOB19-08 (>8mm). The sample was pre-treated with $8 \mathrm{ml}$ $1 \%$ hydrofluoric acid (HF) and $800 \mathrm{ml}$ deionised $\mathrm{H}_{2} \mathrm{O}$ then heated in a $50^{\circ} \mathrm{C}$ water bath for 1 hour. $1 \% \mathrm{HF}$ solution was decanted then 2-3 drops of eucalyptus oil was added. A pre-mixed solution of $1 \mathrm{ml}$ glacial acetic acid, $1 \mathrm{~g}$ lauryl amine and $1 \mathrm{~L}$ of deionised $\mathrm{H}_{2} \mathrm{O}$ was added to $10 \mathrm{~L}$ of $\mathrm{H}_{2} \mathrm{O}$ in a carbonator. The sample and froth floatation solution from the carbonator were then used to separate quartz and feldspar through the froth float technique. Through froth floatation there was not an adequate mass of quartz separated thus it was decided to separate minerals on a Frantz Isodynamic Magnetic Separator.

Samples DOB19-02, DOB19-08 (all grain sizes) and DOB19-16 (1/2 \& 2/2) were cleaned firstly by a hand magnet to remove highly magnetic grains. The sample DOB19-16 was split into two samples due to the initial mass. A Frantz Isodynamic Magnetic Separator was then used to separate magnetic and non-magnetic minerals. Magnetic separation was first run at a 1.0 amperage pass then again at 1.5 amperage. At this point upon visual inspection quartz primarily made up the non-magnetic fraction. The sample DOB19-04 was passed through an induced roll magnetic separator to separate non-magnetic and magnetic minerals. The non-magnetic fraction was then passed through the Frantz Isodynamic Magnetic Separator as above. By introducing the step using the induced roll magnetic separator the mass having to go through the secondary magnetic separator was significantly less. In addition to the mass being significantly reduced the induced roll magnetic separator processes minerals much faster than the Frantz Isodynamic Magnetic Separator.

The second round of samples included the grain size $125-500 \mu \mathrm{m}$ for DOB19-20, DOB1924, Dobson and Hopkins. Physical preparation of the second round of samples was the same as the first round. This included drying at $105^{\circ} \mathrm{C}$ and sieving into the following fractions; $<125 \mu \mathrm{m}, 125-500 \mu \mathrm{m}, 500 \mu \mathrm{m}-1 \mathrm{~mm}, 1 \mathrm{~mm}-8 \mathrm{~mm}$ and $>8 \mathrm{~mm}$. The $125-500 \mu \mathrm{m}$ fraction were then crushed using a disk mill pulveriser to ensure all grains were monomineralic and $<250 \mu \mathrm{m}$. A disk mill was decided on instead of using the tungsten carbide ring mill as in round one of sample processing as there was much less risk of powdering the sample which makes it unusable. Once crushed samples were washed once through a $63 \mu \mathrm{m}$ sieve then oven-dried at $105^{\circ} \mathrm{C}$. 
The 125-500 $\mu \mathrm{m}$ fraction for DOB19-20, DOB19-24, Dobson and Hopkins were then passed over with a hand magnet to remove any highly magnetic grains within each sample. As with the sample DOB19-04 the samples were then passed through an induced roll magnetic separator. This separated non-magnetic and magnetic minerals, with the non-magnetic fraction then being passed through the Frantz Isodynamic Magnetic Separator as above at 1.5 amperage. With the use of the disk mill and induced roll magnetic separator for the second round of physical sample preparation the timeframe was significantly reduced. Both pieces of equipment were unavailable to be used during the first round hence the late introduction of using both pieces of equipment. It was also decided against the use of froth floatation for any other samples due to the fine grain size across all samples as demonstrated by testing on DOB19-08.

\section{2. 2. Chemical pre-treatment}

The following chemical pre-treatment and chemistry steps were carried out in two rounds. The first round consisted of 125-500 $\mu \mathrm{m}$ for DOB19-02, DOB19-04 and DOB19-16, all grain sizes except $<125 \mu \mathrm{m}$ for DOB19-08 and one laboratory blank. The second round of chemistry consisted of the $125-500 \mu \mathrm{m}$ fraction for DOB19-20, DOB19-24, Dobson, Hopkins and two laboratory blanks.

For chemical pre-treatment samples of predominately quartz were added to a 1 L HDPE bottle per sample. To remove any remaining metal oxides, organic matter and carbonates $100 \mathrm{ml} \mathrm{10 \%} \mathrm{hydrochloric} \mathrm{acid}(\mathrm{HCl})$ was added slowly to each bottle. Once any reaction with the sample had subsided a further $700 \mathrm{ml} \mathrm{10 \%} \mathrm{HCl}$ was added. Bottles were placed in a $50^{\circ} \mathrm{C}$ water bath for at least 24 hours, after the first hour lids were tightened. Samples were agitated on a regular basis to ensure all grains were being exposed to the $\mathrm{HCl}$. The acid was then decanted and the samples were triple rinsed with deionised water. A similar process of leaching with HF was carried out four times to remove any remaining impurities on the quartz. For the first $\mathrm{HF}$ leach, $750 \mathrm{ml}$ of $5 \% \mathrm{HF}$ and $2 \%$ nitric acid $\left(\mathrm{HNO}_{3}\right)$ was added to each sample. The bottles were then placed in the $50^{\circ} \mathrm{C}$ water bath for 24 hours with regular agitating before decanting the acid and quadruple rinsing the samples with deionised $\mathrm{H}_{2} \mathrm{O}$. This was then repeated three further times with $1 \% \mathrm{HF}$ for 48 hours each time. Samples were again agitated regularly during these three $48 \mathrm{hr}$ periods. Between each round samples were rinsed four times with deionised water. After the final round of leaching the samples were rinsed until the $\mathrm{pH}$ was $\sim$ neutral and were 
then dried in a $50^{\circ} \mathrm{C}$ oven without lids. Samples then underwent a visual inspection using a microscope to determine the purity of the quartz. Mass loss at this point was over the required 15-20\% (Nishiizumi et al., 2007).

\section{2. 3. Beryllium extraction}

To remove meteoric ${ }^{10} \mathrm{Be}$ present in the samples there was a final quartz leach carried out. $350 \mathrm{ml}$ Teflon beakers were weighed without lids and labelled, that included the addition of a clean extra beaker. This clean extra beaker would not contain any sample and would be treated the same as all other samples to identify if there was any contamination during processing. The pure quartz ranging from $36 \mathrm{~g}$ to $65 \mathrm{~g}$ was then added to each beaker and weighed again. For the final quartz leach $7 \mathrm{M} \mathrm{HF}$ was added to each beaker ensuring each sample was covered by at least $5 \mathrm{~mm}$ in liquid. Beakers were capped and left on a $120^{\circ} \mathrm{C}$ hotplate for $\sim 1$ hour. Once cooled the HF was decanted and samples were rinsed four times in $18.0 \mathrm{M} \Omega$ milli-Q $\mathrm{H}_{2} \mathrm{O}$. To remove any remaining fluoride, aqua regia (per $1 \mathrm{~L}$, 15M HNO $3: 12 \mathrm{M} \mathrm{HCl}, \mathrm{N} 1: 3$ molar mixture) was then added to each sample with enough to cover each sample by $5 \mathrm{~mm}$. Beakers were left with lids off for 30 minutes for any off gassing before being capped and put on a $120^{\circ} \mathrm{C}$ hotplate for $\sim 2$ hours. Samples were then rinsed five times with milli-Q $\mathrm{H}_{2} \mathrm{O}$ and left to dry down uncapped on a $100^{\circ} \mathrm{C}$ hotplate.

Once dried down samples were precisely weighed. Each sample (including the blank) was spiked with $280 \mu \mathrm{L}$ of $1008.3 \mathrm{ppm}{ }^{9} \mathrm{Be}$ carrier. A ${ }^{9} \mathrm{Be}$ carrier is added to each sample to ensure there is adequate Be to measure through accelerator mass spectrometry (AMS).

Open beaker dissolution was initially used before moving to closed beaker dissolution due to the initial mass of the samples. Samples were completely dissolved over a five day period with concentrated 28M HF. For the initial open beaker dissolution 45ml 28M HF was added to each sample. Beakers were left uncapped on the hotplate at $100^{\circ} \mathrm{C}$ for 6 hours (until dry). Samples were carefully swirled several times to disrupt density stratification. A further $45 \mathrm{ml} 28 \mathrm{M} \mathrm{HF}$ was added to all samples and were gently swirled to break up any solids. Samples were then left on a $100^{\circ} \mathrm{C}$ hotplate for $\sim 2$ days. Samples were then of the desired volume for closed beaker dissolution. $185 \mathrm{ml} 28 \mathrm{M} \mathrm{HF}$ and $37 \mathrm{ml}$ $\mathrm{HNO}_{3}$ were added to each sample. Beakers were left off the heat with lids loose for $\sim 3.5$ hours. Lids were then tightened and the hotplate turned on to $60^{\circ} \mathrm{C}$ for 2 days ( 45 hours) until all quartz had dissolved. During this time samples were swirled several times. 
Samples were then uncapped and left on the hotplate at $100^{\circ} \mathrm{C}$ to evaporate, leaving a thin fluoride $\left(\mathrm{BeF}_{2}\right)$ cake in the bottom of each beaker.

\section{2. 3. 1. BeF 2 leaching}

As $\mathrm{BeF}_{2}$ is soluble in $\mathrm{H}_{2} \mathrm{O}$ compared to several other insoluble elements ( $\mathrm{Al}, \mathrm{Ca}, \mathrm{Fe}, \mathrm{Mg}$ and $\mathrm{Na}$ ) which are retained as solids (Stone, 2000). 10ml milli-Q $\mathrm{H}_{2} \mathrm{O}$ was added to each beaker, enough to cover the fluoride cake on the bottom of the beaker. Samples were left for $\sim 20$ minutes on a $50^{\circ} \mathrm{C}$ hotplate. Once cooled, samples were pipetted into $50 \mathrm{ml}$ centrifuge tubes. This was repeated with $5 \mathrm{ml}$ milli-Q $\mathrm{H}_{2} \mathrm{O}$ to rinse the beakers that was then also pipetted into the $50 \mathrm{ml}$ centrifuge tubes. The centrifuge tubes were mixed with a vortex mixer for 1 minute, let rest for 10 minutes then centrifuged for 5 minutes at 3000rpm. The supernate from each sample was poured off into the cleaned original beakers (wiped out with a kimwipe and rinse with milli-Q $\mathrm{H}_{2} \mathrm{O}$ three times). $15 \mathrm{ml}$ milli$\mathrm{Q} \mathrm{H}_{2} \mathrm{O}$ was added to each centrifuge tube which was vortexed, let sit for 10 minutes then centrifuged for 5 minutes at 3000rpm. The supernate was poured off into the same beakers as the previous step. This was repeated once more to ensure a maximum $\mathrm{BeF}_{2}$ yield. The samples now back in the beakers were heated overnight on a $120^{\circ} \mathrm{C}$ hotplate to evaporate the solution. Once evaporated, $10 \mathrm{ml} 6 \mathrm{M} \mathrm{HCl}$ was added to each sample and were transferred from the beakers into new, clean centrifuge tubes. The samples were centrifuged for 5 minutes at 3000rpm one more time to ensure no particulates remain, in preparation for the iron $(\mathrm{Fe})$ columns.

\section{2. 3. 2. Cation chemistry: Fe columns}

For removal of any remaining Fe samples were passed through $15 \mathrm{ml}$ Eichrom columns with 2ml Biorad AG1-X8 100-200 mesh (anion) resin. The resin was first cleaned with $5 \mathrm{ml}+5 \mathrm{ml} 0.3 \mathrm{M} \mathrm{HCl}$ then conditioned with $2 \mathrm{ml}+2 \mathrm{ml}+2 \mathrm{ml} 6 \mathrm{M} \mathrm{HCl}$. The samples in $10 \mathrm{ml} 6 \mathrm{M} \mathrm{HCl}$ were then added followed by $2 \mathrm{ml}+2 \mathrm{ml}+2 \mathrm{ml} 6 \mathrm{M} \mathrm{HCl}$ to elute the Be. The Be was collected in the original beakers. To clean the resin $5 \mathrm{ml}+5 \mathrm{ml} 0.3 \mathrm{M} \mathrm{HCl}$ was added to each column. Samples were then heated uncapped at $100^{\circ} \mathrm{C}$ overnight, until dry. To redissolve samples $20 \mathrm{ml} 0.4 \mathrm{M}$ oxalic acid was added and were warmed at $60^{\circ} \mathrm{C}$ with lids for $\sim 2$ hours. Samples were cooled for at least 30 minutes before being transferred into new, clean $15 \mathrm{ml}$ centrifuge tubes that were centrifuged for 5 minutes at $3000 \mathrm{rpm}$. 


\section{2. 3 3. Cation chemistry: Be columns}

For Be elution, 15ml Eichrom columns were used with 5ml Biorad AG50-X8 200-400 mesh (cation) resin. To clean the resin $5 \mathrm{ml}+10 \mathrm{ml} 5 \mathrm{M} \mathrm{HNO}_{3}$ was added, then to remove $\mathrm{HNO}_{3} 5 \mathrm{ml}+5 \mathrm{ml}$ milli-Q $\mathrm{H}_{2} \mathrm{O}$ was added. $5 \mathrm{ml}+10 \mathrm{ml} 0.4 \mathrm{M}$ oxalic acid was added to condition the resin. Next the samples were added which were now in $20 \mathrm{ml} 0.4 \mathrm{M}$ oxalic acid. To wash the sample down $5 \mathrm{ml}+5 \mathrm{ml} 0.4 \mathrm{M}$ oxalic acid was added. Fifty $\mathrm{ml} 0.4 \mathrm{M}$ oxalic acid was added to elute any Fe, $\mathrm{Al}$ and $\mathrm{Ti}$. Then $5 \mathrm{ml}+10 \mathrm{ml}$ milli-Q $\mathrm{H}_{2} \mathrm{O}$ was added to remove the oxalic acid. To elute $\mathrm{Na} 15 \mathrm{ml}+25 \mathrm{ml} 0.5 \mathrm{M} \mathrm{HNO}_{3}$ was added. For elution of Be $20 \mathrm{ml}+20 \mathrm{ml}+20 \mathrm{ml} 1 \mathrm{M} \mathrm{HNO}_{3}$ was used and collected in beakers. To clean resin $40 \mathrm{ml} 5 \mathrm{M} \mathrm{HNO}_{3}$ then $5 \mathrm{ml}+15 \mathrm{ml}$ milli-Q $\mathrm{H}_{2} \mathrm{O}$ was added. The beakers containing Be and $60 \mathrm{ml} 1 \mathrm{M} \mathrm{HNO}_{3}$ were then heated at $120^{\circ} \mathrm{C}$ to evaporate the solution.

\section{2. 3. 4. Be precipitation}

To redissolve the samples $5 \mathrm{ml} 1 \mathrm{M} \mathrm{HNO}_{3}$ was added to the beakers and were then transferred into new, clean centrifuge tubes. To form the $\mathrm{Be}(\mathrm{OH})_{2}$ precipitate the $\mathrm{pH}$ changed to $\sim 10$ by adding $0.550 \mathrm{ml} 25 \% \mathrm{NH}_{4} \mathrm{OH}$ to each sample. The samples were then vortexed until the precipitate began to form (small white specks) which took $\sim 10$ minutes. The samples were then centrifuged for 5 minutes at 3000rpm, during which a milky gel of $\mathrm{Be}(\mathrm{OH})_{2}$ formed at the bottom of each tube. Supernates were decanted into the centrifuge tubes from the previous step (Section 4. 2. 3. 3). Samples were redissolved by adding $5 \mathrm{ml} 1 \mathrm{M} \mathrm{HNO}_{3}$ then $0.550 \mathrm{ml}_{2} 25 \% \mathrm{NH}_{4} \mathrm{OH}$. Samples were vortexed, let sit for $\sim 10$ minutes, centrifuged for 5 minutes at $3000 \mathrm{rpm}$ then the supernate was decanted. Finally $3 \mathrm{ml}$ milli-Q $\mathrm{H}_{2} \mathrm{O}$ was added to each sample which were vortexed, centrifuged and decanted as the previous step.

\section{2. 4. Accelerator Mass Spectrometer}

Precipitate gels were pipetted into quartz crucibles and dried down on a $120^{\circ} \mathrm{C}$ hotplate overnight. The dried samples were calcined over an open Bunsen burner flame for $\sim 30$ seconds which oxidised $\mathrm{Be}(\mathrm{OH})_{2}$ into $\mathrm{BeO}$. The oxidised samples were then powdered using a metal spatula. Once powdered samples were mixed with $\mathrm{Nb}(\mathrm{N} 1: 3$ ratio of 1 part oxidised sample, 3 parts $\mathrm{Nb}$ ). The powdered mixture was then packed and pressed into acid-cleaned stainless steel AMS targets. Targets were sent to the Lawrence Livermore National Laboratory (LLNL) for final analysis. ${ }^{10} \mathrm{Be} /{ }^{9} \mathrm{Be}$ ratios were measured at the 
Centre for Accelerator Mass Spectrometry (CAMS) using the HVEC 10 MV Model FN Tandem Van de Graaff Accelerator.

\section{3. X-ray Fluorescence}

Samples were dried in a $105^{\circ} \mathrm{C}$ oven for $\sim 24$ hours (until dry) then precisely weighed. To measure Loss-on-ignition (LOI) samples were split into thirds to have a reliable data set. Crucibles were weighed (crucible weight), filled $3 / 4$ full with each sample and weighed again (dry weight). Samples were placed in a $550^{\circ} \mathrm{C}$ furnace for 4 hours, cooled in a desiccator to ensure no moisture reabsorption then weighed again (ash weight). Samples were then pulverised using a tungsten carbide ring mill pot for one to two, 30 second cycles in the mill. Pulverised samples were then transferred into plastic vials with $4 \mu \mathrm{m}$ polypropylene film tightly covering the opening of the vials. X-ray fluorescence was carried out at VUW using a portable Olympus Vanta XRF analyser. Seven standards of known compositions were measured three times each throughout the measurements. A calibration curve was then constructed using the results from measured known standards.

\section{4. Spatial Analysis}

\section{4. 1. Basin delineation}

In order to calculate catchment statistics for sub-catchments within the Dobson Valley, ArcGIS Pro V2.3.0 was used. The watershed tool within ArcGIS was used to determine the area of sub-catchments above the sampling locations by using a $15 \mathrm{~m}$ Digital Elevation Model (DEM) obtained from Land Information New Zealand. To delineate subcatchments the following tools were used: fill, flow direction, flow accumulation, snap pour point and watershed. To determine the contributing area of each catchment the direction of flow down a slope and the accumulation of flow were calculated. Snap pour point was then used to find the place with highest flow accumulation. Finally the watershed tool was used to determine the contributing area of drainage above each sampling location. Sub-catchments have been labelled according to the sample taken from each stream. The upper Dobson Valley consists of five sub-catchments which are considerably smaller in size than the two sub-catchments in the lower Dobson Valley (Fig 4. 1). 


\section{4. 2. Basin statistics}

To determine a range of statistics for each sub-catchment zonal statistics was used in ArcGIS. Zonal statistics was used to calculate the area $\left(\mathrm{m}^{2}\right)$, maximum and minimum elevation ( $\mathrm{m}$ asl) and the mean elevation ( $\mathrm{m}$ asl). These statistics were calculated for each sub-catchment by selecting the raster for each catchment as the input.

\section{4. 3. Map data}

All maps were produced using ArcGIS Pro 2.3.0. Base maps include aerial imagery from the Land Information New Zealand (LINZ) Data Service ${ }^{1}$ and the hill shade base map from the GNS Science Online Database ${ }^{2}$. Landcover classes are sourced from the Land Cover DataBase v5.0 (LCDB) ${ }^{3}$ on the LRIS portal as licensed by Landcare Research. $20 \mathrm{~m}$ contour data is sourced from the Topo50 map contour feature service from the LINZ Data Service ${ }^{1}$. Geomorphological data is sourced from a combination of the $\mathrm{LCDB}^{3}$, the Topo50 map vegetation and structure feature service from the LINZ Data Service ${ }^{1}$ and the River Environment Classification New Zealand (2010) feature service from the Ministry for the Environment (MFE) Data Service ${ }^{4}$. Geological units and fault data are sourced from the GNS Science Online Database ${ }^{2}$. Climate data is sourced from the NIWA Virtual Climate Station Network (VCSN) ${ }^{5}$.

\section{5. Denudation calculations}

In situ ${ }^{10} \mathrm{Be}$ denudation rates were calculated using the concentrations reported from the accelerator mass spectrometer (AMS) measurements. Initial AMS measurements are reported in ${ }^{10} \mathrm{Be} /{ }^{9} \mathrm{Be}$ ratios. Concentrations of ${ }^{10} \mathrm{Be}$ are calculated using the reported ${ }^{10} \mathrm{Be} /{ }^{9} \mathrm{Be}$ ratios, mass of quartz, mass of the ${ }^{9} \mathrm{Be}$ carrier and the ${ }^{9} \mathrm{Be}$ carrier in parts per million (ppm).

To calculate denudation rates the online Earth erosion rate calculator (formerly CRONUS) developed by Balco et al. (2008) was used. The measured ${ }^{10} \mathrm{Be} /{ }^{9} \mathrm{Be}$ ratios were normalised using 07KNSTD standard (Nishzumii et al, 2007) and were corrected for the respective laboratory blank. The number of ${ }^{10} \mathrm{Be}$ atoms were determined from the

\footnotetext{
${ }^{1}$ https://data.linz.govt.nz/

${ }^{2}$ https://data.gns.cri.nz/

${ }^{3}$ https://lris.scinfo.org.nz/

${ }^{4}$ https://data.mfe.govt.nz/

${ }^{5}$ https://data.niwa.co.nz/
} 
${ }^{10} \mathrm{Be} /{ }^{9} \mathrm{Be}$ ratio through the approach defined by Balco (2006). To simply calculate erosion rates from the reported ${ }^{10} \mathrm{Be}$ concentrations returned from LLNL AMS the version 3 of the online Earth erosion rate calculator was used. The version 3 calculator firstly derives the production rate then uses that to determine the erosion rate. The latitude, longitude, elevation and shielding factor for each sample location was used for the production rate calculation. Other inputs for the erosion rate calculations included density $\left(2.65 \mathrm{~g} \mathrm{~cm}^{-3}\right)$, thickness $(0.1 \mathrm{~cm}$, surface samples $)$, measured ${ }^{10} \mathrm{Be}$ concentrations and ${ }^{10} \mathrm{Be}$ uncertainties, and ${ }^{10} \mathrm{Be}$ standardisation (KNSTD). Built into the online calculator code is the ${ }^{10} \mathrm{Be}$ halflife $(\lambda=1.39 \mathrm{Myr})$, attenuation of ${ }^{10} \mathrm{Be}$ production from both spallation and muon pathways with depth and global surface production rates (incorporating New Zealand production rates (Putnam et al., 2010)). Built into the online Earth erosion rate calculator is also the use of several different production rate scaling schemes; St (Lal, 1991; Stone, 2000), De (Desilets, Zreda, \& Prabu, 2006), Du (Dunai, 2001), Li (Lifton et al., 2005) and Lm (Lal, 1991; Nishiizumi et al., 1989; Stone, 2000). Results from the St scaling scheme will be used in Chapter 6: Discussion, however full results from V2.3 will be presented in Appendix A for completeness. 


\section{Chapter 5. Results}

\section{1. In situ ${ }^{10} \mathrm{Be}$ measurements}

5. 1. $1 .{ }^{10} \mathrm{Be}$ derived catchment-averaged denudation rates

Results from in situ ${ }^{10} \mathrm{Be}$ concentrations measured through accelerator mass spectrometry from the Lawrence Livermore National Laboratory ranged from $0.905 \times 10^{3}-10.257 \mathrm{x}$ $10^{3}$ atoms $/ \mathrm{g}^{-1}$ (Table 5. 1). Analytical uncertainty for raw ${ }^{10} \mathrm{Be}$ concentrations ranged from $2.05 \%-4.75 \%$. Concentrations of processes blanks associated with in situ ${ }^{10} \mathrm{Be}$ measurements blanks indicate background ${ }^{10} \mathrm{Be}$ introduced during laboratory preparation. Process blank concentrations measured also through accelerator mass spectrometry from the Lawrence Livermore National Laboratory varied from $1.48 \times 10^{5}-4.94$ x $10^{5}$ (Table 5. 2). Analytical uncertainties for process blank raw ${ }^{10} \mathrm{Be}$ concentrations varied from $2.9 \%$ $-6.26 \%$.

Using the online erosion rate calculator version 3 (formerly the CRONUS-Earth erosion rate calculator), catchment-averaged denudation rates were calculated (Balco et al., 2008) (Table 5. 3). Concentrations measured were on the order of $10^{2}-10^{3}$, two orders of magnitude lower than typical concentrations $\left(10^{5}\right)$ for this type of analysis. Concentrations on the order of $10^{2}$ resulted in the lower bound of the standard error returned less-than-zero erosion rates with the updated version 3 online erosion calculator because the updated version now reflects new constraints on muogenic production, which is a relatively large component of the production for sites with rapid erosion. As a result of this version 2.3 of the online erosion calculator was used for DOB19-04 (Table 5. 4) as it returns a slightly lower erosion rate, and can be viewed as a minimum erosion rate compared to the other samples. All results calculated using version 2.3 are within 1-sigma error of concentrations calculated using version 3 (see Appendix A). Given the large errors on this sample, this discrepancy is a small fraction of the total error, thus it will not alter interpretation of this sample. Denudation rates ranged from 1,100 $\mathrm{m} \mathrm{Myr}^{-1}-12,153$ $\mathrm{m} \mathrm{Myr}^{-1}$ in the upper Dobson Valley (Fig 5.1) and were $474 \mathrm{~m} \mathrm{Myr}^{-1}$ and 2,700 $\mathrm{m} \mathrm{Myr}^{-1}$ in the lower Dobson Valley (Fig. 5. 2). The main Dobson and Hopkins Rivers had denudation rates of 1,660 $\mathrm{m} \mathrm{Myr}^{-1}$ and 3,340 $\mathrm{m} \mathrm{Myr}^{-1}$ respectively.

Four of the sub-catchments are located along the upper western Dobson Valley (Fig. 5. 1), where the underlying lithology is metamorphosed interbedded sandstone, siltstone and 
mudstone. These sub-catchments are small ranging from $0.6 \mathrm{~km}^{2}$ to $1.4 \mathrm{~km}^{2}$ all with a mean slope angle of $\sim 50^{\circ}$. Comparatively, the two sub-catchments on the eastern side of the lower Dobson Valley have interbedded sandstone, siltstone and mudstone that has not undergone metamorphism. Catchments in the lower Dobson Valley (Fig. 5. 2) are much greater in area at $27 \mathrm{~km}^{2}$ and $37 \mathrm{~km}^{2}$ and have a mean slope angle of $\sim 40^{\circ}$. Variability in sub-catchment characteristics such as precipitation, slope angle, aspect, lithology, geomorphology and area allow for comparison of denudation rates within the Dobson Valley.

Erosion rates were plotted against catchment area, mean elevation ( $\mathrm{m}$ asl), mean slope $\left({ }^{\circ}\right)$, mean aspect $\left({ }^{\circ}\right)$, mean annual precipitation $(\mathrm{mm})$ and mean annual temperature $\left({ }^{\circ} \mathrm{C}\right)$. Catchment area had a little correlation with erosion rate (Fig 5. 3). Mean elevation (m asl) also showed little correlation with erosion. Catchments varied from 1,437m-1,706m asl, thus having relatively similar mean elevation (Fig 5. 4). Mean slope angle (Fig 5. 5) and mean aspect (Fig 5.6) showed no correlation with erosion rate across the catchments. Slope angle is similar across the catchments ranging from $49^{\circ}-51^{\circ}$ as is the aspect which ranges from $98^{\circ}-128^{\circ}$. Mean annual precipitation $(\mathrm{mm})$ showed a moderate positive trend with a $\mathrm{R}^{2}$ value 0.459 (Fig 5. 7). Mean annual temperature $\left({ }^{\circ} \mathrm{C}\right.$ ) showed no correlation with erosion rates around the sub-catchments in the upper Dobson Valley (Fig. 5. 8). 


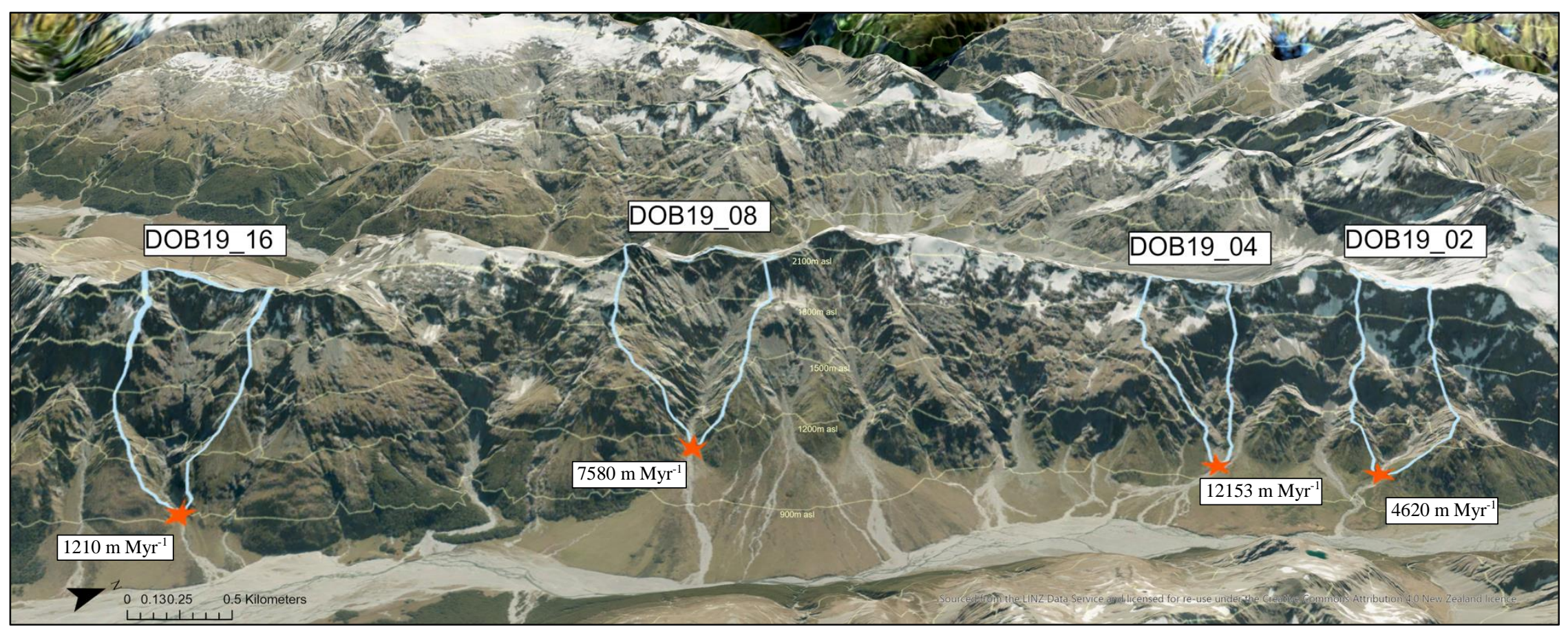

Figure 5.1. Upper Dobson Valley catchment-averaged denudation rates. In situ ${ }^{10}$ Be catchment-averaged denudation rates for the

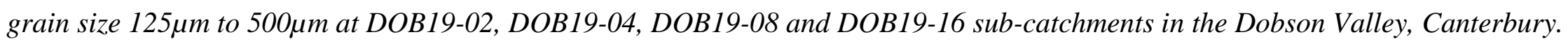




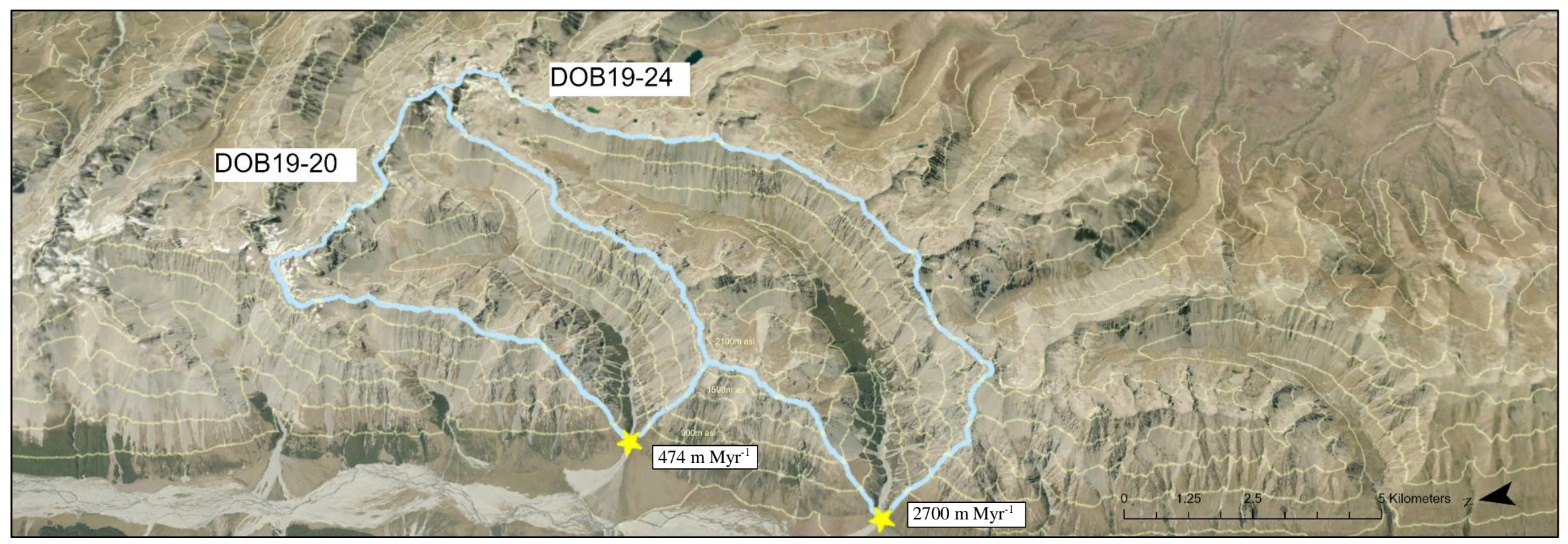

Figure 5.2. Lower Dobson Valley catchment-averaged denudation rates. In situ ${ }^{10}$ Be catchment-averaged denudation rates for the

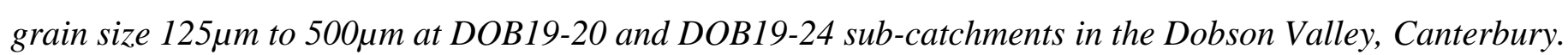


Table 5.1. ${ }^{10} \mathrm{Be}{ }^{\rho} \mathrm{Be}$ ratios, ${ }^{10} \mathrm{Be}$ concentrations and additional information associated with calculating catchment-averaged denudation rates. Catchment-averaged denudation rates were calculated using the online erosion rate calculator version 3 (Balco et al., 2008). Further values needed for calculation included sample density of $2.65 \mathrm{~g} \mathrm{~cm}^{-3}$, elevation/pressure flag 'std', thickness of $0.1 \mathrm{~cm}$ (surface concentrations) and the AMS standard for Be KNSTD (Nishiizumi et al., 2007).

\begin{tabular}{|c|c|c|c|c|c|c|c|c|c|c|}
\hline Sample ID & Latitude & Longitude & $\begin{array}{c}\text { Elevation } \\
\text { (m asl) }\end{array}$ & $\begin{array}{l}\text { Shielding } \\
\text { correction }\end{array}$ & $\begin{array}{c}\text { Quartz } \\
\text { mass } \\
(\mathrm{g})\end{array}$ & $\begin{array}{c}{ }^{9} \text { Be mass } \\
(\mu \mathrm{g})\end{array}$ & $\begin{array}{c}{ }^{10} \mathrm{Be} /{ }^{9} \mathrm{Be} \\
\left(10^{-14}\right)\end{array}$ & $\begin{array}{c}{ }^{10} \mathrm{Be} /{ }^{9} \mathrm{Be} \\
(1 \sigma)\left(10^{-14}\right)\end{array}$ & $\begin{array}{c}{ }^{10} \mathrm{Be} \\
\text { conc. } \\
\left(10^{3} \text { at }\right)\end{array}$ & $\begin{array}{l}{ }^{10} \text { Be conc. } \\
(1 \sigma)\left(10^{3} \mathrm{at}\right)\end{array}$ \\
\hline DOB19-02 & -43.8119 & -169.9852 & 1437 & 1 & 57.949 & 286.978 & 3.48 & 0.115 & 3.041 & 0.265 \\
\hline DOB19-04 & -43.8055 & -169.9783 & 1562 & 1 & 36.227 & 288.590 & 2.73 & 0.073 & 0.906 & 0.396 \\
\hline DOB19-08_1 & -43.8586 & -169.9605 & 1707 & 1 & 60.462 & 288.792 & 3.37 & 0.096 & 2.586 & 0.248 \\
\hline DOB19-08_2 & -43.8586 & -169.9605 & 1707 & 1 & 65.183 & 288.389 & 4.18 & 0.118 & 4.797 & 0.258 \\
\hline DOB19-16_1 & -43.8947 & -169.9538 & 1590 & 1 & 45.437 & 288.490 & 4.79 & 0.101 & 9.483 & 0.373 \\
\hline DOB19-16_2 & -43.8947 & -169.9538 & 1590 & 1 & 46.45 & 288.893 & 5.03 & 0.103 & 10.261 & 0.373 \\
\hline DOB19-20 & -44.0082 & -169.9544 & 1619 & 1 & 32.534 & 258.552 & 5.52 & 0.154 & 24.241 & 0.748 \\
\hline DOB19-24 & -44.0502 & -169.9238 & 1543 & 1 & 55.420 & 259.157 & 2.37 & 0.065 & 4.729 & 0.212 \\
\hline
\end{tabular}




\begin{tabular}{|c|c|c|c|c|c|}
\hline Process blank & $\begin{array}{c}{ }^{9} \text { Be mass } \\
(\mu \mathrm{g})\end{array}$ & $\begin{array}{c}{ }^{10} \mathrm{Be} /{ }^{9} \mathrm{Be} \\
\left(10^{-15}\right)\end{array}$ & $\begin{array}{c}{ }^{10} \mathrm{Be} /{ }^{9} \mathrm{Be} \\
(1 \sigma)\left(10^{-15}\right)\end{array}$ & $\begin{array}{c}{ }^{10} \text { Be conc. } \\
\left(10^{5} \text { at }\right)\end{array}$ & $\begin{array}{l}{ }^{10} \text { Be conc. } \\
(1 \sigma)\left(10^{5} \text { at }\right)\end{array}$ \\
\hline DOB19-B01 & 288.389 & 2.56 & 0.742 & 4.94 & 0.143 \\
\hline DOB19-B02 & 258.552 & 0.856 & 0.534 & 1.48 & 0.092 \\
\hline DOB19-B03 & 258.250 & 0.964 & 0.603 & 1.67 & 0.104 \\
\hline
\end{tabular}


Table 5.3. Results of catchment-averaged denudation rates (erosion rate) calculated by the online earth calculator (version 3) (Balco, 2017) for three scaling scheme; St (Stone, 2000), Lm (Balco et al., 2008) and LSDn (Lifton, Sato, \& Dunai, 2014). The process blank DOB19-B01 was used for DOB19-02, DOB19-04, all DOB19-08 and both DOB19-16 samples. The DOB19-B02 process blank was used for DOB19-24, Dobson and Hopkins and the DOB19-B03 process blank was used for DOB19-20.

\begin{tabular}{|c|c|c|c|c|c|c|c|c|c|c|c|c|c|}
\hline \multirow[b]{2}{*}{ Sample ID } & \multicolumn{4}{|c|}{ St } & \multicolumn{4}{|c|}{ Lm } & \multicolumn{4}{|c|}{ LSDn } & \multirow[b]{2}{*}{$\begin{array}{c}\text { Production } \\
\text { rate } \\
\text { (spallation) } \\
\left(\text { at }^{-1} \mathbf{y r}^{-1} \text { ) }\right.\end{array}$} \\
\hline & $\begin{array}{c}\text { Erosion rate } \\
\left(\mathrm{g} \mathrm{cm}^{2} \mathbf{y r}^{-1}\right)\end{array}$ & $\begin{array}{c}\text { Erosion } \\
\text { rate } \\
\left(\mathrm{m} \mathrm{Myr}^{-1}\right)\end{array}$ & $\begin{array}{c}\text { Internal } \\
\text { uncertainty } \\
\left.(\mathrm{m} \mathrm{Myr})^{-1}\right)\end{array}$ & $\begin{array}{c}\text { External } \\
\text { uncertainty } \\
\left.(\mathrm{m} \mathrm{Myr})^{-1}\right)\end{array}$ & $\begin{array}{c}\text { Erosion rate } \\
\left(\mathrm{g} \mathrm{cm}^{2} \mathrm{yr}^{-1}\right)\end{array}$ & $\begin{array}{c}\text { Erosion } \\
\text { rate } \\
\left(\mathrm{m} \mathrm{Myr}^{-1}\right)\end{array}$ & $\begin{array}{c}\text { Internal } \\
\text { uncertainty } \\
\left(\mathbf{m} \mathbf{M y r}^{-1}\right)\end{array}$ & $\begin{array}{c}\text { External } \\
\text { uncertainty } \\
(\mathrm{m} \mathrm{Myr})\end{array}$ & $\begin{array}{l}\text { Erosion rate } \\
\left(\mathrm{g} \mathrm{cm}^{2} \mathrm{yr}^{-1}\right)\end{array}$ & $\begin{array}{c}\text { Erosion } \\
\text { rate } \\
\left(\mathrm{m} \mathrm{Myr}^{-1}\right)\end{array}$ & $\begin{array}{c}\text { Internal } \\
\text { uncertainty } \\
\left.(\mathbf{m ~ M y r})^{-1}\right)\end{array}$ & $\begin{array}{c}\text { External } \\
\text { uncertainty } \\
\left.(\mathbf{m ~ M y r})^{-1}\right)\end{array}$ & \\
\hline DOB19-02 & 1.22 & 4610 & 400 & 541 & 1.28 & 4830 & 420 & 555 & 1.25 & 4700 & 409 & 494 & 13.51 \\
\hline DOB19-08_1 & 2.01 & 7570 & 726 & 941 & 2.11 & 7950 & 762 & 968 & 2.03 & 7660 & 734 & 862 & 16.57 \\
\hline DOB19-08_2 & 0.80 & 3000 & 162 & 287 & 0.83 & 3140 & 169 & 290 & 0.84 & 3150 & 170 & 252 & 16.57 \\
\hline DOB19-08_3 & 0.82 & 3110 & 199 & 316 & 0.86 & 3250 & 209 & 321 & 0.86 & 3260 & 209 & 284 & 16.57 \\
\hline DOB19-08_4 & 1.62 & 6100 & 768 & 906 & 1.70 & 6400 & 806 & 938 & 1.65 & 6230 & 784 & 866 & 16.57 \\
\hline DOB19-16_1 & 0.32 & 1210 & 48 & 107 & 0.33 & 1240 & 49 & 105 & 0.33 & 1260 & 50 & 89 & 15.20 \\
\hline DOB19-16_2 & 0.29 & 1100 & 40 & 96 & 0.30 & 1140 & 41 & 95 & 0.31 & 1150 & 42 & 80 & 15.20 \\
\hline DOB19-20 & 0.13 & 474 & 15 & 40 & 0.13 & 483 & 15 & 39 & 0.13 & 487 & 15 & 32 & 15.57 \\
\hline DOB19-24 & 0.72 & 2700 & 121 & 246 & 0.75 & 2820 & 127 & 247 & 0.75 & 2820 & 127 & 209 & 14.72 \\
\hline Dobson & 0.44 & 1660 & 67 & 148 & 0.46 & 1720 & 69 & 147 & 0.46 & 1720 & 69 & 123 & 12.91 \\
\hline Hopkins & 0.89 & 3340 & 204 & 334 & 0.93 & 3500 & 214 & 338 & 0.91 & 3440 & 211 & 293 & 13.00 \\
\hline
\end{tabular}


๙ Table 5.4. Results for DOB19-04 catchment-averaged denudation rate. Results are calculated using the Lal/Stone scaling scheme (Lal, 1991;

Stone, 2000).

\begin{tabular}{|c|c|c|c|c|c|c|}
\hline \multirow[b]{2}{*}{ Sample ID } & \multicolumn{6}{|c|}{ Lal/St } \\
\hline & $\begin{array}{c}\text { Erosion rate } \\
\left(\mathrm{g} \mathrm{cm}^{2} \mathbf{y r}^{-1}\right)\end{array}$ & $\begin{array}{c}\text { Erosion rate } \\
\left(\mathbf{m ~ M y r} \mathbf{r}^{-1}\right)\end{array}$ & $\begin{array}{c}\text { Internal } \\
\text { uncertainty } \\
\left(\mathbf{m ~ M y r} \mathbf{M}^{-1}\right)\end{array}$ & $\begin{array}{c}\text { External } \\
\text { uncertainty } \\
\left(\mathbf{m} \mathbf{M y r}^{-1}\right)\end{array}$ & $\begin{array}{c}\text { Production rate } \\
\text { (spallation) } \\
\left(\text { at g }^{-1} \mathbf{y r}^{-1}\right)\end{array}$ & $\begin{array}{c}\text { Production rate } \\
\text { (muons) } \\
\left(\text { at g }^{-1} \mathbf{y r}^{-1}\right)\end{array}$ \\
\hline DOB19-04 & 3.22 & 12142 & 6561 & 6627 & 14.85 & 0.128 \\
\hline
\end{tabular}




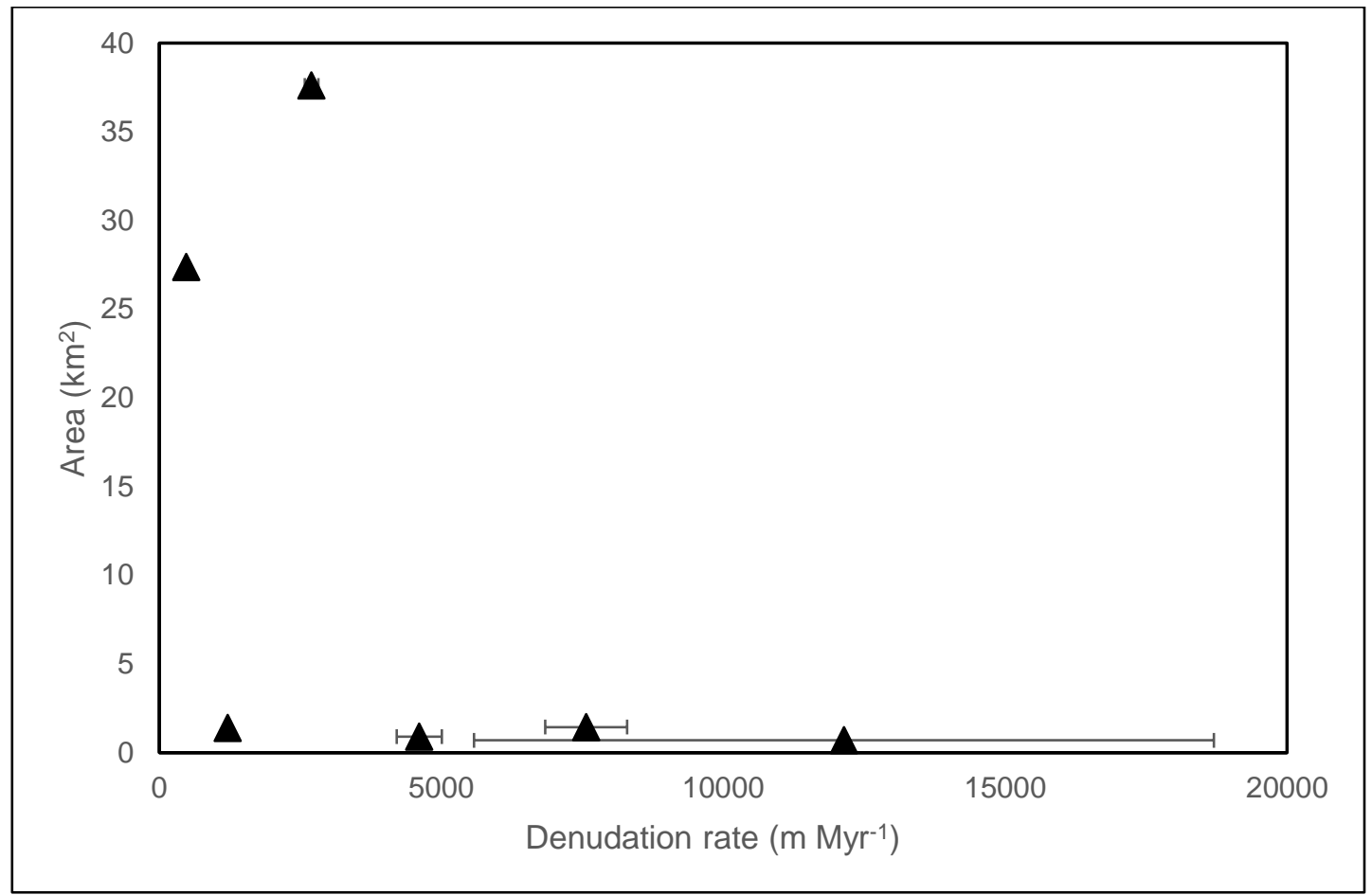

Figure 5.3 Catchment area $\left(\mathrm{km}^{2}\right)$ plotted against denudation rate $\left(m \mathrm{Myr}^{-1}\right)$ for subcatchments in the Dobson Valley..

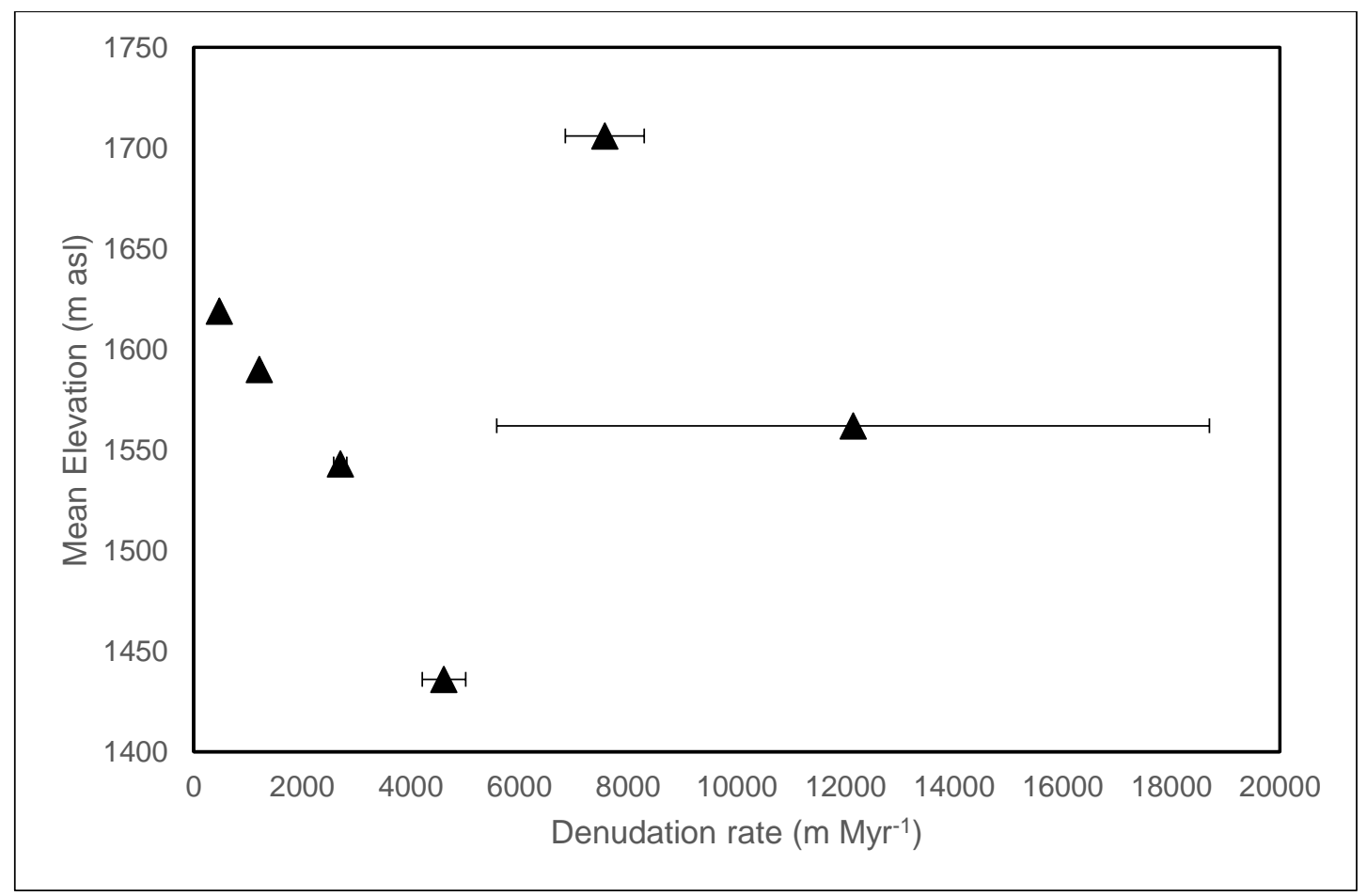

Figure 5.4. Mean elevation ( $m$ asl) plotted against denudation rate $\left(m M^{-1}\right)$ for subcatchments in the Dobson Valley.. 


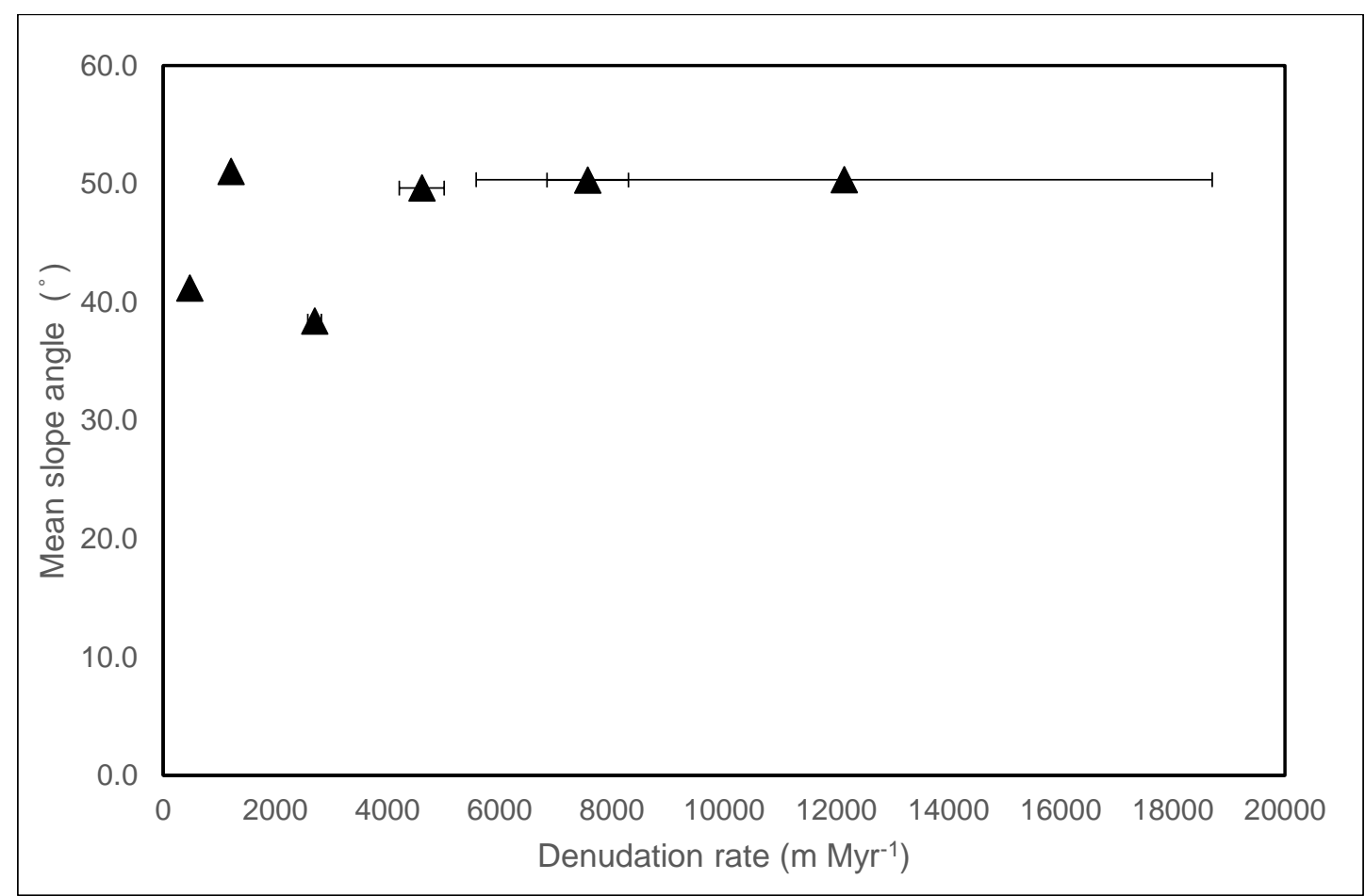

Figure 5.5. Mean slope angle $\left(^{\circ}\right)$ plotted against denudation rate $\left(m \mathrm{Myr}^{-1}\right)$ for subcatchments in the Dobson Valley.

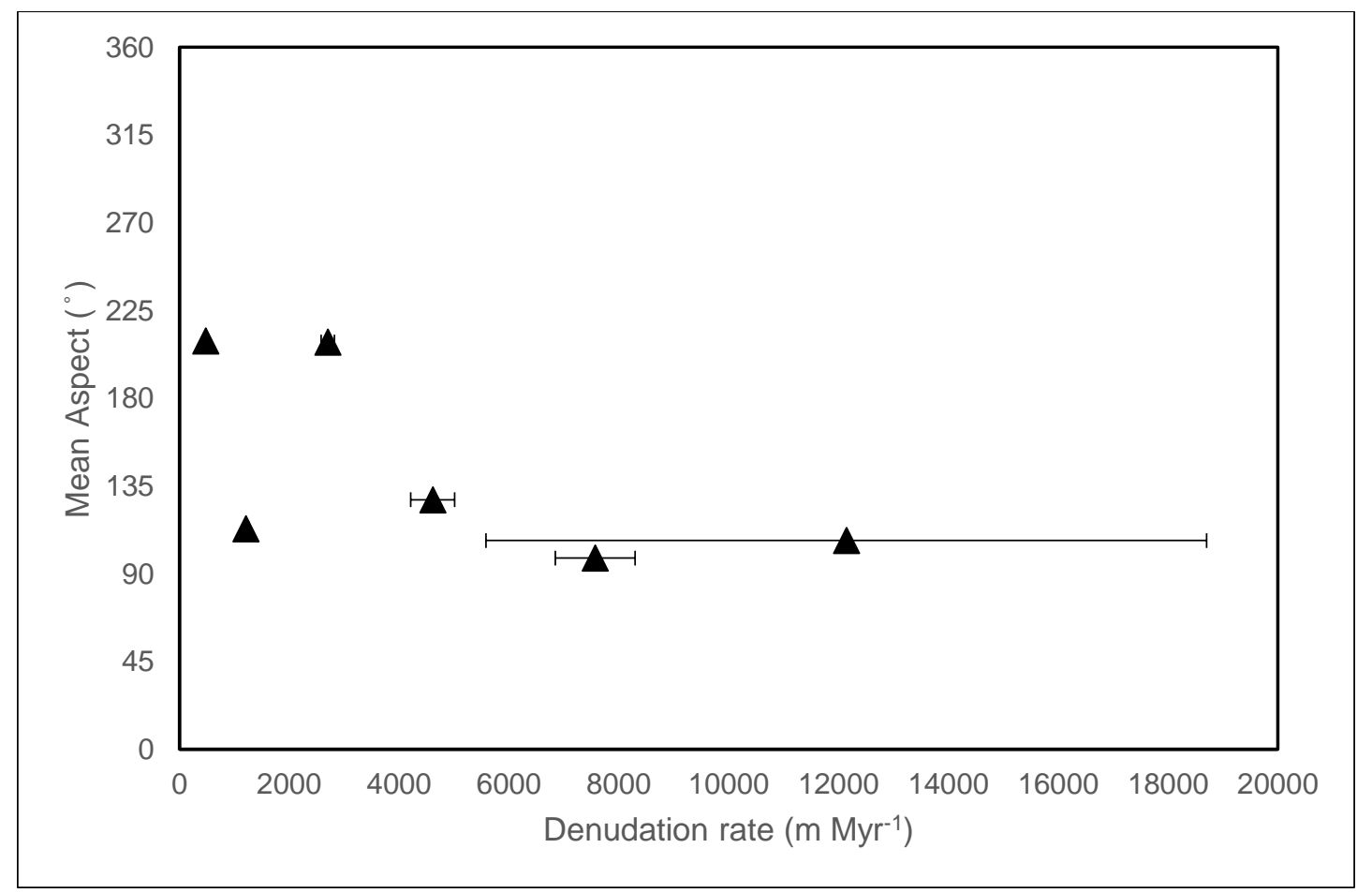

Figure 5.6. Mean aspect $\left({ }^{\circ}\right)$ plotted against denudation rate $\left(m M^{-1}\right)$ for sub-catchments in the Dobson Valley. 


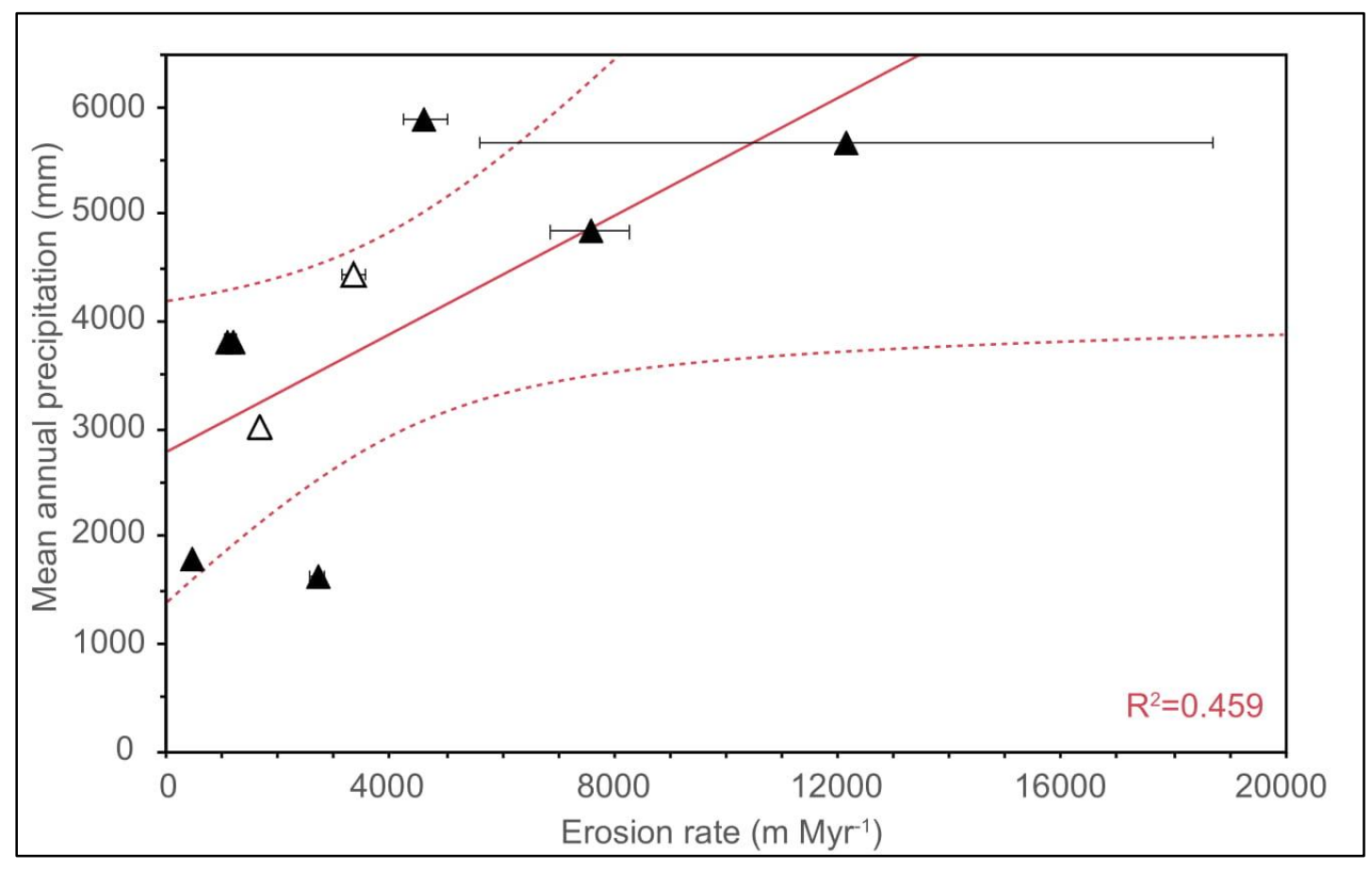

Figure 5.7. Mean annual precipitation $(\mathrm{mm})$ plotted against denudation rate (erosion rate) (m Myr $\left.{ }^{-1}\right)$ for sub-catchments in the Dobson Valley (black triangles) and main Dobson and Hopkins Rivers (white triangles). Regression shows a moderate correlation, $R 2=0.459$.

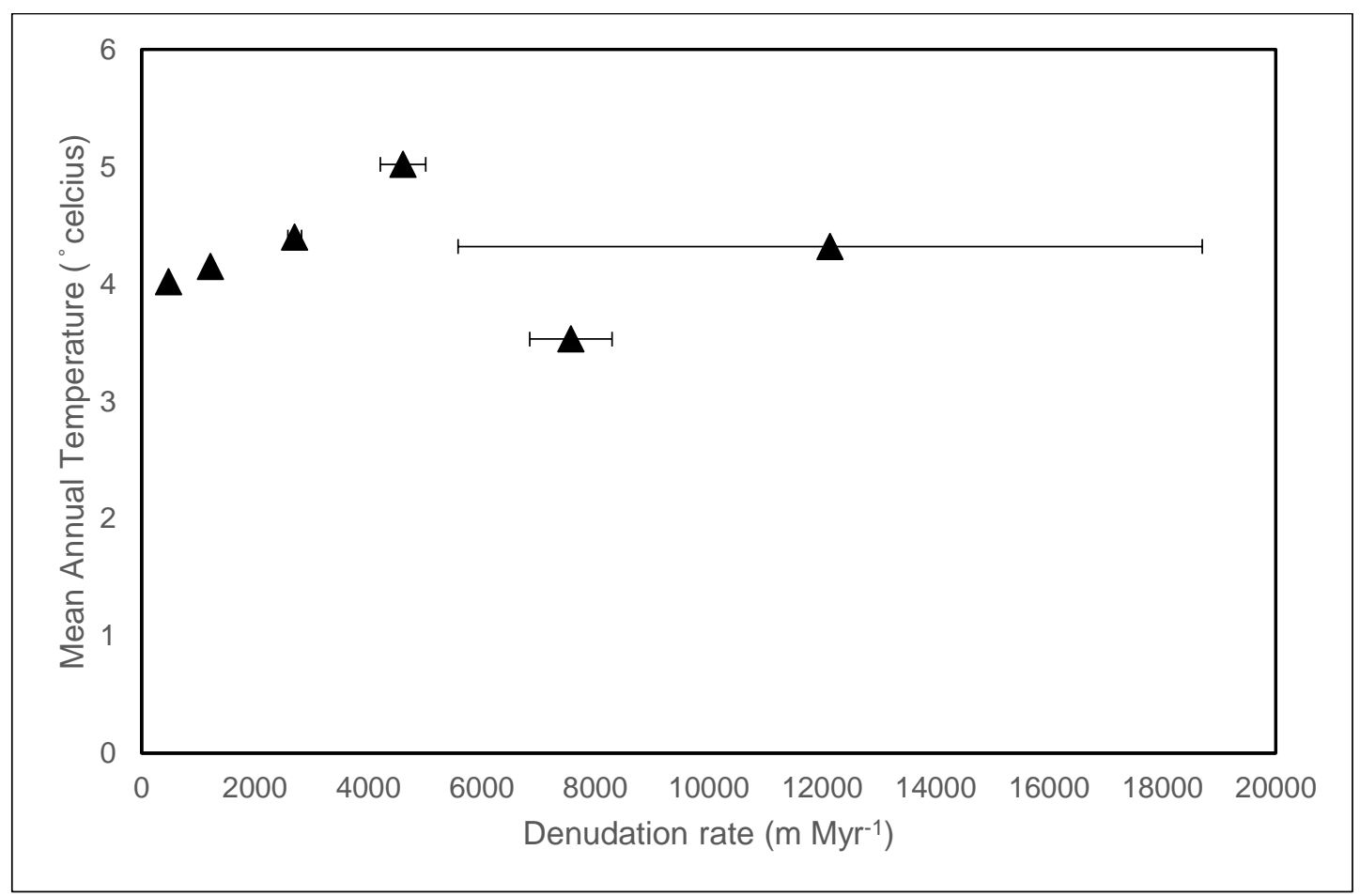

Figure 5.8. Mean annual temperature $\left({ }^{\circ} \mathrm{C}\right)$ plotted against denudation rate $\left(\mathrm{m} \mathrm{Myr}^{-1}\right)$ for sub-catchments in the Dobson Valley. 


\section{2. Zirconium concentrations from $X$-ray Fluorescence}

Zirconium concentrations were measured through X-ray fluorescence (see Section 4. 3). Zirconium concentrations ranged from $324 \mathrm{ppm}$ to $145 \mathrm{ppm}$ throughout the range of soils and saprolites sampled (Table 5. 5). Concentrations were highest for soil samples at the surface and decreased in concentration with depth. Zirconium concentrations were calibrated from known zirconium concentrations of a series of standards. The handheld X-ray Fluorescence equipment does not have in built calibration. The linear calibration curve constructed using a series of known concentrations had an intercept of -19.019 , a slope of 1.122 and a $R^{2}$ value of 0.997 (see Appendix. B).

\section{2. 1. Chemical depletion fractions}

Chemical depletion fractions (CDF) represents the chemical weathering fraction of total denudation (Riebe et al., 2004b). CDF were calculated using Eq. 1. 3, using Zirconium concentrations of soil $\left(\mathrm{Zr}_{\text {soil }}\right)$ from each major soil horizon and from the parent rock $\left(\mathrm{Zr}_{\text {rock }}\right)$ which is the saprolite at the bottom of each pit. Soils in each pit (DOB19-11, DOB19-12 and DOB19-15) had CDF varying from 0.465 to 0.102 (Table 5. 6). All three soil pits showed a consistent trend of being most weathered at the surface then decreasing gradually down to the saprolite (Fig. 5. 9, Fig. 5. $10 \&$ Fig. 5. 11). The soil pit at the highest elevation DOB19-11 showed the highest chemical depletion fraction. The other two soil pits further downslope DOB19-12 and DOB19-15 showed similar chemical depletion fractions throughout the soil horizons. 
Table 5.5. Zirconium concentration results from XRF for soils and saprolites within pits along the soil transect. Average Zr concentration and associated error are the average from each of the replicates and here report the standard deviation from the replicates and here report the standard deviation from the replicates and the instrument error. Total error is the instrument error and standard deviation of the replicates add in quadrature.

\begin{tabular}{|c|c|c|c|c|c|c|}
\hline Sample ID & $\begin{array}{c}\text { Sample Depth } \\
(\mathrm{cm})\end{array}$ & $\begin{array}{c}\text { Average } \mathbf{Z r} \\
\text { Concentration } \\
(\mathbf{p p m})\end{array}$ & $\begin{array}{c}\text { Average } \mathbf{Z r} \\
\text { Concentration } \\
\text { Error } \\
\text { (ppm) }\end{array}$ & $\begin{array}{c}\text { Instrument } \\
\text { error } \\
\text { (ppm) }\end{array}$ & $\begin{array}{c}\text { Total } \mathbf{Z r} \\
\text { error } \\
\text { (ppm) }\end{array}$ & $\begin{array}{c}\text { Total } \mathrm{Zr} \text { error } \\
(\%)\end{array}$ \\
\hline $11-\mathrm{A}$ & $0-4$ & 274 & 4 & 5 & 6 & 2.4 \\
\hline $11-B$ & $10-15$ & 163 & 3 & 3 & 4 & 2.9 \\
\hline $11-\mathrm{C}$ & $26-32$ & 146 & 3 & 3 & 4 & 3.2 \\
\hline $12-\mathrm{A}$ & $0-5$ & 302 & 5 & 5 & 8 & 2.7 \\
\hline $12-B$ & $7-9$ & 324 & 3 & 5 & 6 & 2.1 \\
\hline $12-\mathrm{C}$ & $19-22$ & 265 & 9 & 4 & 11 & 4.1 \\
\hline $15-\mathrm{A}$ & $6-11$ & 299 & 1 & 5 & 5 & 1.9 \\
\hline $15-B$ & $18-23$ & 291 & 6 & 5 & 8 & 2.9 \\
\hline $15-\mathrm{C}$ & $37-42$ & 261 & 4 & 4 & 5 & 2.0 \\
\hline $15-\mathrm{D}$ & 60 & 209 & 3 & 4 & 5 & 2.5 \\
\hline 11-Soil & 0 & 148 & 3 & 3 & 4 & 3.2 \\
\hline 11-Sap & 35 & 145 & 3 & 3 & 4 & 3.2 \\
\hline 12-Soil & 0 & 314 & 5 & 5 & 8 & 2.5 \\
\hline 12-Sap & 16.25 & 204 & 4 & 4 & 5 & 2.8 \\
\hline 13-Soil & 0 & 283 & 5 & 5 & 7 & 2.6 \\
\hline 13-Sap & 50 & 195 & 3 & 3 & 5 & 2.8 \\
\hline
\end{tabular}


Table 5.6. Chemical depletion fraction results calculated using zirconium concentrations of soils and saprolites.

\begin{tabular}{lcccc}
\hline Sample ID & $\begin{array}{c}\text { Sample } \\
\text { Depth } \\
\text { (cm) }\end{array}$ & $\begin{array}{c}\text { Chemical } \\
\text { Depletion } \\
\text { Fraction }\end{array}$ & $\begin{array}{c}\text { Chemical } \\
\text { Depletion } \\
\text { Fraction } \\
\text { Error }\end{array}$ & $\begin{array}{c}\text { Chemical } \\
\text { Depletion } \\
\text { Fraction } \\
\text { Error (\%) }\end{array}$ \\
\hline 11-A & $0-4$ & 0.465 & 0.026 & 5 \\
11-B & $10-15$ & 0.102 & 0.027 & 26 \\
11-C & $26-32$ & 0.000 & 0.000 & 0 \\
12-A & $0-5$ & 0.122 & 0.035 & 28 \\
12-B & $7-9$ & 0.180 & 0.028 & 15 \\
12-C & $19-22$ & 0.000 & 0.000 & 0 \\
15-A & $6-11$ & 0.300 & 0.008 & 3 \\
15-B & $18-23$ & 0.281 & 0.024 & 9 \\
15-C & $37-42$ & 0.198 & 0.018 & 9 \\
15-D & 60 & 0.000 & 0.000 & 0 \\
11-Soil & 0 & 0.018 & 0.031 & 176 \\
11-Sap & 35 & 0.000 & 0.000 & 0 \\
12-Soil & 0 & 0.349 & 0.020 & 6 \\
12-Sap & 16.25 & 0.000 & 0.000 & 0 \\
13-Soil & 0 & 0.309 & 0.021 & 7 \\
13-Sap & 50 & 0.000 & 0.000 & 0 \\
& & & &
\end{tabular}




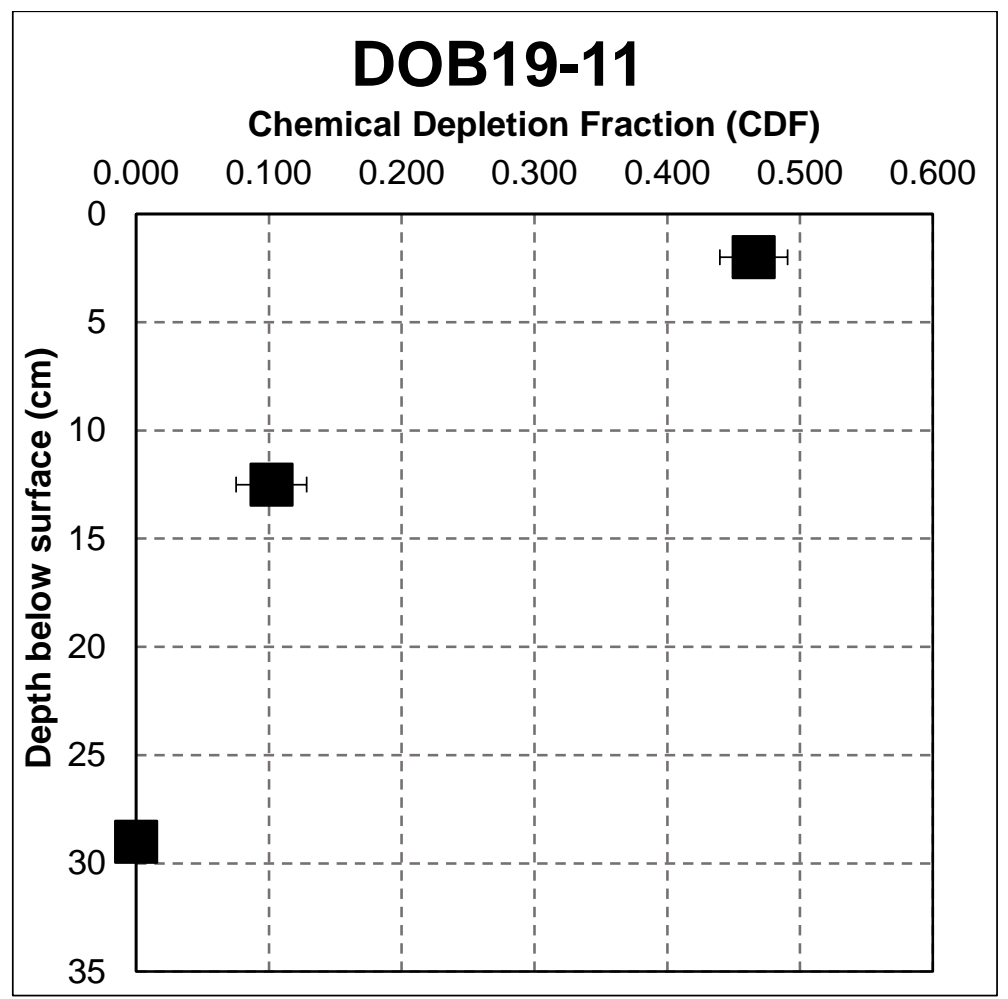

Figure 5.9. DOB19-11 chemical depletion fraction (CDF) plotted against depth below surface $(\mathrm{cm})$.

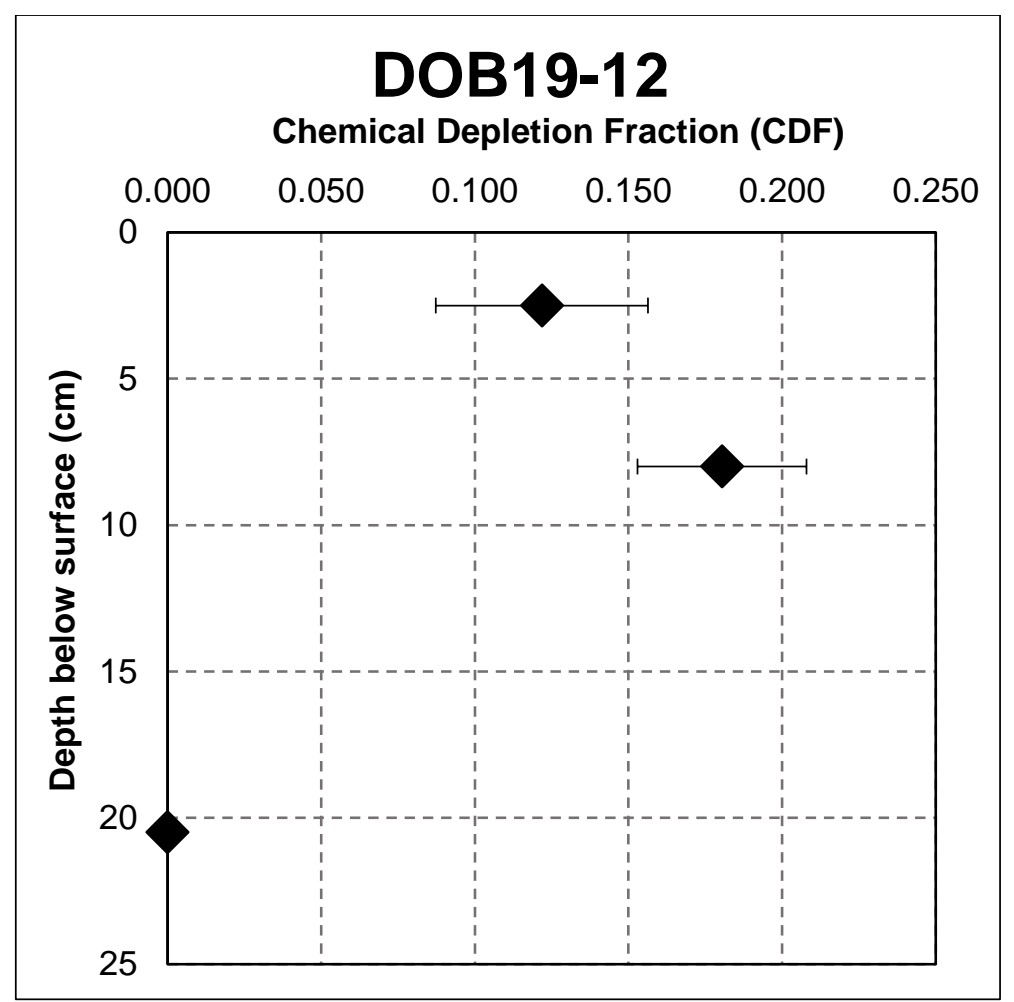

Figure 5.10. DOB19-12 chemical depletion fraction (CDF) plotted against depth below surface $(\mathrm{cm})$. 


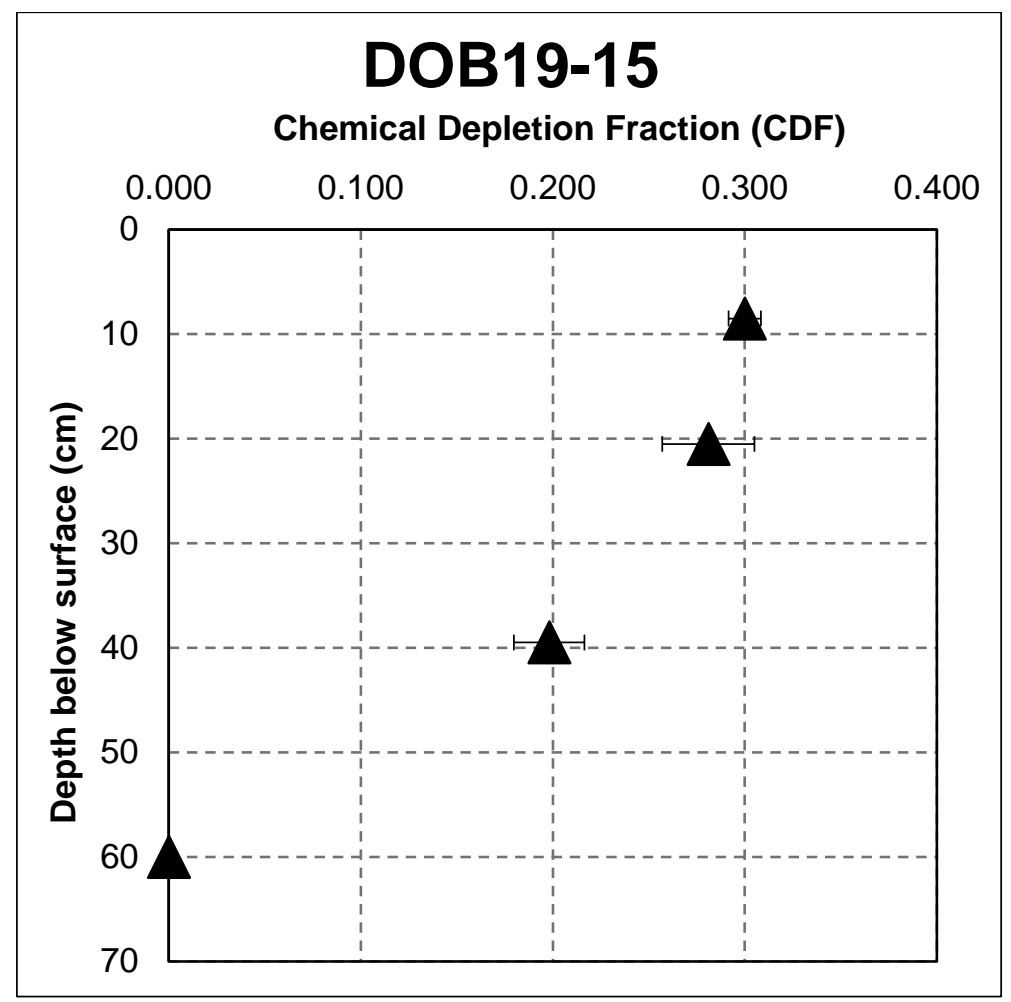

Figure 5.11. DOB19-15 chemical depletion fraction (CDF) plotted against depth below surface $(\mathrm{cm})$. 


\section{Chapter 6. Discussion}

Catchment-averaged denudation rates have been successfully calculated from in situ ${ }^{10} \mathrm{Be}$ analysis in the Dobson and Hopkins Rivers, Canterbury. Denudation rates were calculated in six sub-catchments in the Dobson Valley and from the main river channel in the Dobson and Hopkins Rivers. Quantifying denudation rates in the Dobson Valley and the Hopkins River adds to limited research in rapidly eroding settings such as the Southern Alps, New Zealand. The impact of tectonic and climatic variables such as lithology and precipitation can be assessed across the six sub-catchments in the Dobson Valley. Further results from the main Dobson and Hopkins Rivers allows for comparison to measured long-term sedimentation rates in Lake Ōhau and erosion estimates from annual specific suspended sediment yields.

The six sub-catchments in the Dobson Valley consisted of four from the upper Dobson Valley and two from the lower valley. Denudation rates in the sub-catchments varied from $474 \mathrm{~m} \mathrm{Myr}^{-1}$ to $12,142 \mathrm{~m} \mathrm{Myr}^{-1}$. The main Dobson and Hopkins Rivers had denudation rates of $1,600 \mathrm{~m} \mathrm{Myr}^{-1}$ and 3,340 $\mathrm{m} \mathrm{Myr}^{-1}$ respectively. The calculated denudation rates are comparable to rates from the western Southern Alps that (Larsen et al., 2014) varied from 1,400 $\mathrm{m} \mathrm{Myr}^{-1}$ to $11,650 \mathrm{~m} \mathrm{Myr}^{-1}$.

This chapter is structured around the primary research aim, to quantify denudation rates in the Ōhau catchment, determine any influence of grain size variability on ${ }^{10} \mathrm{Be}$ concentrations and partition chemical weathering and physical erosion rates across climatic gradients in the rapidly eroding Dobson Valley. The following are also discussed in this chapter: limitations and potential sources of error in sampling and measurements of in situ ${ }^{10} \mathrm{Be}$ concentrations, interpretation of denudation rate trends in the Dobson Valley and comparison with other quantified denudation rates in New Zealand. Further to this, the Hopkins and Dobson River denudation rates are compared with Lake Ōhau sedimentation rates. Chemical weathering and physical erosion rates are partitioned from total denudation and the mechanisms driving weathering and erosion will be discussed. Tectonic controls on denudation rates in the Ōhau catchment will be explored and finally, future directions and recommendations for continued research in rapidly eroding settings such as the Southern Alps will be outlined. 


\section{1. Grain size variability}

Stream sediment is widely used in cosmogenic nuclide analysis to determine catchmentaveraged denudation rates. Although sampling stream sediment is common practice, a bias may arise in measured cosmogenic nuclide concentrations depending on the grain size sampled. Sampling stream sediment relies on the key assumption, that the grain size being sampled is representative of denudation throughout the catchment. It is common practice to sample sand-sized grains from streams. The bias this potentially creates varies with geomorphic processes in a catchment and is dependent on systematic changes in grain size across the landscape. Four grain sizes were sampled from the upper Dobson Valley; $125-500 \mu \mathrm{m}, 500 \mu \mathrm{m}-1 \mathrm{~mm}, 1 \mathrm{~mm}-8 \mathrm{~mm}$ and $>8 \mathrm{~mm}$. The grain sizes sampled in the upper Dobson Valley had substantial variability in ${ }^{10} \mathrm{Be}$ concentrations measured between grain sizes, but not in a systematic way.

In order to account for grain size bias within sampled stream sediment, variation in grain size must be understood on a case by case basis. Grain size can vary substantially between catchments, dependent on catchment characteristics including topography and climate. Firstly, there is a need for the cosmogenic nuclide research community to have a consensus on whether a particular grain size is to be sampled to enable comparison of data between landscapes. Secondly, there is great need for future research on how grain size bias is exhibited in individual catchments, building on previous work (Lukens et al., 2016; Riebe et al., 2015; Sklar et al., 2017; van Dongen et al., 2019). Being able to apply criteria to individual catchments to reduce grain size bias will allow for more robust data. This is currently being looked past in research measuring cosmogenic nuclide concentrations for calculating catchment-averaged denudation rates.

A grain size bias will arise in a catchment when parts of a catchment produces sand-sized sediment more rapidly. Concentrations of ${ }^{10} \mathrm{Be}$ in stream sediment depend on controls on grain size, controls on differences in ${ }^{10} \mathrm{Be}$ and catchment characteristics such as relief and area (Lukens et al., 2016; Riebe et al., 2015; van Dongen et al., 2019). Size distribution of sediment changes across a landscape in a predictable fashion with lithology, climate, and topography and erosion rate resulting in variable sediment sizes across landscapes (Sklar et al., 2017). Landslides produce variability in grain size and the rapid formation of small particles through the mixing of sediment during shallow and deep-seated erosional processes. Concentrations of ${ }^{10} \mathrm{Be}$ are effected during landsliding events by the 
mixing of sediment from depth. Variations in ${ }^{10} \mathrm{Be}$ concentrations can result from sediment being transported from different elevations, depths and locations with a range of denudation rates (van Dongen et al., 2019). Given previous research, assessing the three contributions of bias, variable grain size distribution, ${ }^{10} \mathrm{Be}$ concentrations and catchment attributes, it is important when interpreting results to account for any potential bias and natural variability in cosmogenic nuclide research.

The DOB19-08 catchment is small $\left(1.45 \mathrm{~km}^{2}\right)$ and steep (mean slope angle 50.3) with highly variable grain sizes. Although sampling locations in the upper Dobson Valley had no evidence of recent landsliding events, the average slope angle of the catchments exceeded $50^{\circ}$, commonly linked to threshold hillslopes and landsliding (Binnie et al., 2007). The average slope angle and with the surrounding slopes being primarily bare rock with minimal vegetation, frequent rock fall is likely. Steep slope angle combined with very high annual precipitation makes it likely that the area is prone to deep-seated landsliding, particularly on soil-mantled steep ridges, for example the ridge directly north of the sampling site DOB19-08. Once sediment has reached the stream channel, processes such as abrasion and mixing will occur as the sediment travels downstream. The active geomorphic processes in this sub-catchment has led the stream bed to vary in grain size from silt to boulders up to $2 \mathrm{~m}$ diameter. There is permanent ice cover in the headwaters of the stream, above which is bare rock.

Denudation rates measured in the Dobson Valley (DOB19-08) for the grain sizes 125$500 \mu \mathrm{m}, 500 \mu \mathrm{m}-1 \mathrm{~mm}, 1 \mathrm{~mm}-8 \mathrm{~mm}$ and $>8 \mathrm{~mm}$ were 7,580 m/Myr, 3,010 m/Myr, 3,110 $\mathrm{m} / \mathrm{Myr}$ and 6,120 $\mathrm{m} / \mathrm{Myr}$ respectively. The further four sub-catchments samples in the upper Dobson Valley had ${ }^{10} \mathrm{Be}$ analysis for the grain size $125-500 \mu \mathrm{m}$ to compare with the denudation rate of 7,580 $\mathrm{m} / \mathrm{Myr}$. There is a stark contrast in denudation rates across these grain sizes with denudation rates for $500 \mu \mathrm{m}-1 \mathrm{~mm}$ and $1 \mathrm{~mm}-8 \mathrm{~mm}$ being less than half of the higher denudation rates measured for the other grain sizes.

Sampling across the four grain sizes $125-500 \mu \mathrm{m}, 500 \mu \mathrm{m}-1 \mathrm{~mm}, 1 \mathrm{~mm}-8 \mathrm{~mm}$ and $>8 \mathrm{~mm}$ in the upper Dobson Valley (DOB19-08) has identified variability up to a factor of 2.5. Denudation rates measured from the sand sized fraction $(125-500 \mu \mathrm{m})$ were 2.5 times higher than that from the next larger grain size $500 \mu \mathrm{m}-1 \mathrm{~mm}$. The sampled sub-catchment is both steep $\left(>50^{\circ}\right)$ and has high mean annual precipitation $\left(>4,800 \mathrm{~mm} \mathrm{yr}^{-1}\right)$. These 


\section{Discussion}

catchment characteristics make understanding how to account for grain size bias particularly important. Catchment steepness and high mean annual precipitation can create a greater variability (Lukens et al., 2016; van Dongen et al., 2019), this has been shown across measured denudation rates from DOB19-08. Relief of the catchment of $1303 \mathrm{~m}$ also makes this catchment susceptible to bias from under-representation of sediment from higher elevations.

Variability of inferred denudation rates up to 2.5 times exhibits the variations that are present in the landscape. Very low ${ }^{10} \mathrm{Be}$ concentrations in the largest grain size may indicate landsliding and rock fall, compared to the finest grain size which is common in soils and may be most representative of diffusive hillslope processes. Grain size variability in the Dobson Valley is likely a combination of a coarse initial grain size, the influence of climate on weathering and the effect of erosion and soil residence on how sediment can be reduced in size (Sklar et al., 2017). Low fracture density ( 10\%) of lowgrade schist calculated for the Southern Alps (Clarke \& Burbank, 2011) can be applied to the low-grade schist in the Dobson Valley. A low fracture density could result in a coarse initial grain size during erosional processes such as landsliding in the Dobson Valley. High mean annual precipitation $>4500 \mathrm{~mm} \mathrm{yr}^{-1}$ in the DOB19-08 catchment would enhance chemical weathering through increasing biological productivity and intensifying chemical reactions. Enhancement of chemical weathering may increase the breakup of regolith, resulting in fine sediment that creates further variability in grain size. Rapid removal off the landscape through erosional processes such as deep-seated landsliding causes short soil residence. With evidence of previous landslides in the DOB19-08 catchment, it is likely landsliding is common and this may be leading to coarse sediment in the catchment. Conflicting processes in the Dobson Valley creates a large amount of variability between grain sizes varying from silt to boulders. With variability across the grain sizes up to 2.5 times there needs to be caution when interpreting patterns of denudation rates inferred from a single grain size. Denudation rates measured in the Ōhau catchment were all using the $125-500 \mu \mathrm{m}$ fraction as to be consistent and, under the assumption that variability between grain sizes may be as great as variability across catchments. 


\section{2: Laboratory error and limitations}

When processing samples with low concentrations of ${ }^{10} \mathrm{Be}$, consideration must be given to lower the possibility of the addition of beryllium from sources other than the sample. Following the isolation of ${ }^{10} \mathrm{Be}$ (see Section 4. 2), the measured ${ }^{10} \mathrm{Be} /{ }^{9} \mathrm{Be}$ ratios are then corrected using a laboratory blank. This laboratory blank accounts for the addition of any background ${ }^{10} \mathrm{Be}$ introduced during sample processing. Higher process blanks $\left({ }^{10} \mathrm{Be} /{ }^{9} \mathrm{Be}\right.$ ratios on the order of $10^{-14}$ ) lead to increases in uncertainty of sample measurements of ${ }^{10} \mathrm{Be} /{ }^{9} \mathrm{Be}$, particularly in samples with low concentration of ${ }^{10} \mathrm{Be} /{ }^{9} \mathrm{Be}$ (Corbett, Bierman, $\&$ Rood, 2016). Using a fully exhausting fume hood, dedicated lab ware and a ${ }^{9} \mathrm{Be}$ carrier with low additional ${ }^{10} \mathrm{Be}$ can lead to low laboratory blanks (Corbett et al., 2016).

One way of introducing ${ }^{10} \mathrm{Be}$ contamination during laboratory processing is through additional ${ }^{10} \mathrm{Be}$ in the acid used. The VUW Cosmogenic Nuclide Laboratory uses a range of analytical and trace grade acids. Blank experiments at the VUW Cosmogenic Nuclide Laboratory found concentrated hydrofluoric acid (HF) and reused beakers had the highest source of ${ }^{10} \mathrm{Be}$ contamination, accounting for $25 \%$ of ${ }^{10} \mathrm{Be}$ atoms each (Dowling, 2019). Undistilled concentrated analytical grade HF was used throughout sample processing for round one of samples (DOB19-02, DOB19-04, all DOB19-08 and DOB19-16 (1/2 and $2 / 2$ ). Concentrated HF was distilled at $50^{\circ} \mathrm{C}$ for the second round of sample processing (DOB19-20, DOB19-24, Dobson and Hopkins). The ${ }^{10} \mathrm{Be} /{ }^{9} \mathrm{Be}$ laboratory blank for the first round was higher, at $2.56 \times 10^{-14}$ atoms compared to the two from the second round of $8.56 \times 10^{-15}$ and $9.64 \times 10^{-15}$ atoms. The only notable difference between the two rounds of samples was the addition of distilling concentrated HF prior to use.

The differences in laboratory blanks following the use of distilled concentrated acid show how ${ }^{10} \mathrm{Be}$ contamination can affect results of low concentration ${ }^{10} \mathrm{Be}$ measurements. Associated error from samples in the first round were up to $43 \%$ compared to $6 \%$ in the second round of samples. In light of this, further measurements of low concentration ${ }^{10} \mathrm{Be}$ must take careful consideration of ${ }^{10} \mathrm{Be}$ contamination during laboratory procedures. In addition to this, the total mass of quartz used for low concentration ${ }^{10} \mathrm{Be}$ measurements must be taken into account also. In fast eroding catchments such as those in the Dobson Valley, enough stream sediment must be sampled to ensure there can be a measurable result after accounting for the laboratory blank. The low concentration ${ }^{10} \mathrm{Be} /{ }^{9} \mathrm{Be}$ ratio measured for DOB19-04 and the high blank from the second round of samples resulted 
in a very high error margin of $42.9 \%$. A lower laboratory blank would have resulted in lower associated error. Processing at least $60 \mathrm{~g}$ of clean quartz is necessary for these fasteroding landscapes in order to get satisfactory ${ }^{10} \mathrm{Be} /{ }^{9} \mathrm{Be}$ ratios.

\section{3. Trends in Ōhau catchment denudation with topography, lithology and climate}

6. 3. 1. Dobson Valley sub-catchment denudation rate variability

Denudation rates across the six sub-catchments in the Dobson Valley have significant variability. The highest denudation rate measured was 12,142 $\mathrm{m} \mathrm{Myr}^{-1}$ from DOB19-04. This denudation rate is an order of magnitude higher than results from active margins globally, however in a similar range to that measured in the western Southern Alps (Larsen et al., 2014). The catchment DOB19-04 must be taken with careful consideration however, due to the very high error associated (43\%) and is best represented as a minimum estimate of 5,515 $\mathrm{m} \mathrm{Myr}^{-1}$ (measured denudation rate minus error). Even though using the minimum estimate for DOB19-04 the denudation rate is still substantial. When comparing the minimum estimate with the other sub-catchments it remains in the higher end of denudation rates.

Denudation rates decrease further down the main Dobson Valley with the lowest rate from DOB19-20 at $474 \mathrm{~m} \mathrm{Myr}^{-1}$. The furthest catchment down the valley however is higher than the measured denudation rates from DOB19-16 and DOB19-20. Observing a change in the denudation rates from the western to eastern side of the Dobson Valley is reasonable due to variability in catchment characteristics. Variability between DOB1920 and DOB19-24 however, exhibits different natural processes across the subcatchments in the Dobson Valley. Characteristics are similar between the catchments with similar mean elevation, aspect, slope, precipitation, temperature. The catchment area for DOB 19-24 is $37 \mathrm{~km}^{2}$ compared to $27 \mathrm{~km}^{2}$ for DOB19-20. There are more prominent side streams in DOB19-24 and evidence of past glaciation in the headwaters. Given little difference in catchment characteristics there is evidence of how natural variability can affect denudation rates. Rapid tectonic uplift and climate in the Southern Alps cause a highly dynamic natural system. The combination of exceptionally high precipitation and active faulting creates large amounts of variability in lithology and climate across Te Waipounamu. 


\section{3. 2. Controls on denudation rates in the Dobson Valley}

Results from the Dobson Valley, Canterbury show denudation rates have a positive moderate correlation with mean annual precipitation (MAP) $\left(\mathrm{R}^{2}=0.459\right.$; Fig. 5. 6). Precipitation significantly increases further west, closer to the main divide with MAP increasing by $\sim 4,300 \mathrm{~mm} \mathrm{yr}^{-1}$ from the highest (DOB19-02) to lowest (DOB19-24) subcatchment in the valley (Fig. 4. 2). Spatial spread of the sub-catchments sampled in the Dobson Valley covered a precipitation gradient ranging from 1,618 $\mathrm{mm} \mathrm{yr}^{-1}$ to $5,887 \mathrm{~mm}$ $\mathrm{yr}^{-1}$. Results excluding the Dobson and Hopkins Rivers show a moderate positive linear correlation $\left(\mathrm{R}^{2}=0.459\right)$ between MAP and denudation rates across the sub-catchments. Although the addition of the Dobson and Hopkins Rivers lowers the $\mathrm{R}^{2}$ value, both correlations have a reasonable fit.

Sub-catchments from the upper Dobson Valley have significantly higher MAP than the two sub-catchments in the lower Dobson Valley. DOB19-02 and DOB19-04 have the highest MAP at 5,887 $\mathrm{mm} \mathrm{yr}^{-1}$ and 5,665 $\mathrm{mm} \mathrm{yr}^{-1}$, respectively. The headwaters of the

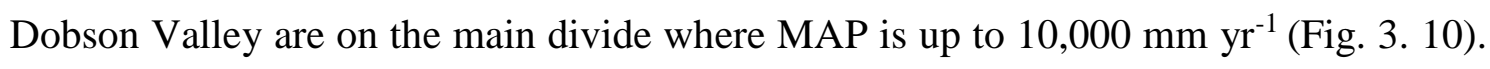
Rainfall decreases rapidly toward the east and MAP in the lower Dobson Valley subcatchments DOB19-20 and DOB19-24 were 1,778 mm $\mathrm{yr}^{-1}$ and 1,618 mm $\mathrm{yr}^{-1}$ respectively. Precipitation in the Dobson Valley is primarily from north-westerly prevailing storms during the summer months that bring intense rainfall. Further north up the Dobson Valley rainfall becomes more intense and results in significant amounts of run-off and movement of material downslope. The denudation rate from DOB19-04 was higher than the other sub-catchment denudation rates in the Dobson Valley. This catchment is facing closer to the north than similar catchments in the upper Dobson. As the prevailing wind direction is from the north-west, precipitation may come as driving rain and have a greater effect on denudation rates. Overall, denudation rates from subcatchments in the Dobson Valley show a positive moderate correlation with precipitation.

Mean annual temperature (MAT) in the sub-catchments vary from $3.5^{\circ} \mathrm{C}$ to $5^{\circ} \mathrm{C}$. Low temperatures and frequent snowfall in winter likely result in MAT having little effect on denudation rates in the Dobson Valley. These results support findings from a global compilation of denudation rates where MAP shows a significant relationship in local and regional catchments compared to MAT that has no significant relationship with denudation rates across local, regional or global scales (Portenga \& Bierman, 2011). 


\section{Discussion}

Lithology can affect denudation rates due to variability in mineralogy, grain size and induration. Lithified, metamorphosed sediment is much more resistant than unmetamorphosed sediment (Clapp et al., 2001; Morel et al., 2003; Palumbo et al., 2010). Crystalline lithologies such as granite and gneiss are additionally less erodible than unmetamorphosed sediments (Morel et al., 2003). Metamorphism increases west toward the Alpine Fault (Cox \& Barrell, 2008) Increasingly metamorphosed schist in the upper Dobson Valley catchments results in a finer grain size with increased bedrock fracturing. Highly fractured bedrock is common across the Southern Alps and is susceptible to landsliding (Clarke \& Burbank, 2011).

Catchments in the upper Dobson Valley are predominately bare rock with mixed shrub and grass vegetation cover below $\sim 1,300 \mathrm{~m}$ asl. In contrast, the lower valley is primarily covered in scree slopes with some tree cover below $\sim 1,000 \mathrm{~m}$ asl. As previously discussed bare bedrock that is highly fractured results in frequent landsliding events and removal of sediment off the landscape (Clarke \& Burbank, 2011). Scree slopes however, have frequent sediment transport downslope, particularly during heavy precipitation. Morphological changes in mountainous landscapes have long been attributed to fluvial or glacial incision or through large landslides (Schmidt \& Montgomery, 1995; Whipple \& Meade, 2006; Whipple \& Tucker, 1999), however in landscapes such as the Southern Alps scree slopes make up a significant amount of eroding slopes (Hales \& Roering, 2005). Scree slopes in the Southern Alps have been linked to climate rather than lithology, seismicity or past glaciation (Hales \& Roering, 2005). Scree slopes are more prevalent in the lower Dobson Valley where precipitation rates are less than 2,000 $\mathrm{mm}$ $\mathrm{yr}^{-1}$. Sub-catchments in the Dobson Valley are at mean elevations of $\sim 1,600 \mathrm{~m}$ asl, consistent with a lower frost-cracking window across the Southern Alps during the last glaciation maximum (Suggate, 1990). Catchments in the upper Dobson Valley have less scree slopes and increased bare bedrock which may indicate landsliding rather than rock fall processes dominate.

Denudation rates measured in sub-catchments within the Dobson Valley show little correlation with slope angle. A lack of correlation between denudation rates and slope angle is likely due to the mean slope angle being $40^{\circ}$ to $50^{\circ}$. Above $\sim 30^{\circ}$ mean slope angle, landsliding becomes dominant and landscapes transition from transport-limited to kinetically-limited regimes (Binnie et al., 2007; Burbank et al., 1996; Montgomery, 2001; 
Montgomery \& Brandon, 2002). Landslide and rockfall processes are likely to be dominant in the Dobson Valley as mean slope angles are $40^{\circ}$ to $50^{\circ}$. Catchment area (Fig. 5. 3), mean elevation (Fig. 5. 4) and mean aspect (Fig. 5. 6) show no trend with increasing denudation rates across the Dobson Valley. Aspect is likely to only have an effect on denudation rates in catchments where the prevailing wind direction is driving precipitation. Previous research suggests catchment area is weakly correlated with denudation rates in research on the controls on denudation in major global rivers (Summerfield \& Hulton, 1994). Elevation is often interrelated with other factors such as temperature, thus in the Dobson Valley where there is no correlation with temperature, it is unsurprising there is also no correlation with elevation. Local catchment relief (maximum minus minimum elevation) exhibits no significant trend with denudation rates in the Dobson Valley. Trends from previous research is highly variable with some finding a strong correlation with local relief (Schaller et al., 2001; Summerfield \& Hulton, 1994) and others finding local relief has little effect on landscape-scale denudation rates (Montgomery \& Brandon, 2002).

Denudation rates measured in the Dobson Valley were derived from ${ }^{10} \mathrm{Be}$ concentrations in $125-500 \mu \mathrm{m}$ sediment. Using a finer grain size gives the assumption sediment is less likely to be derived from landslides and rockfall processes and therefore, ${ }^{10} \mathrm{Be}$ concentrations are representative of all processes eroding the landscape. If sediment is landslide derived ${ }^{10} \mathrm{Be}$ concentrations are still valid to be used for measuring minimum denudation rates. For discussion regarding possible landslide influence on ${ }^{10} \mathrm{Be}$ concentrations, see Section 6. 6. 2.

\section{3. 3. New Zealand cosmogenic nuclide production rates}

Calculated ${ }^{10} \mathrm{Be}$ cosmogenic nuclide production rates for the central Southern Alps, New Zealand show Southern Hemisphere mid-latitude production rates to be $12-14 \%$ lower than the global average (Putnam et al., 2010). Measured ${ }^{10} \mathrm{Be}$ and ${ }^{14} \mathrm{C}$ from the Macaulay Valley, New Zealand showed consistency resulting in a new production rate to be used in dating of features following the last glacial periods, for example the difference between the Younger Dryas and the Antarctic Cold Reversal. For surface exposure dating a 12$14 \%$ difference can cause a remarkable shift between past glacial periods. Calculating erosion rates using the online Earth calculator version 3 the global production rate indicated rates of denudation from the Dobson Valley may be inflated by $\sim 10 \%$. Taking 
into consideration the rapid denudation rates calculated, a $\sim 10 \%$ difference would not make the same impact as a surface exposure date being inflated by $\sim 10 \%$. In addition, natural variability within sub-catchments in the Dobson Valley is likely to be much greater than $\sim 10 \%$, particularly taking into account the $140 \%$ variability between DOB1920 and DOB19-24.

\section{3. 4. Dobson River and Hopkin River denudation rates}

Catchment-averaged denudation rates for the Dobson and Hopkins Rivers were calculated at $4,410 \mathrm{t} \mathrm{km}^{-2} \mathrm{yr}^{-1}$ and $8,850 \mathrm{t} \mathrm{km}^{-2} \mathrm{yr}^{-1}$ respectively. Denudation rates for both catchments fall within the range of denudation rates from sub-catchments within the Dobson Valley. Variability between the Hopkins and Dobson Rivers near the confluence can potentially also be attributed to increased precipitation toward the main divide. The Hopkins Valley has mean annual precipitation of 4,441 $\mathrm{mm} \mathrm{yr}^{-1}$ compared to 3,009 $\mathrm{mm}$ $\mathrm{yr}^{-1}$ in the Dobson Valley. As previously discussed, the Hopkins and Dobson Rivers' denudation rates fit within the trend of increasing denudation with precipitation. Snow and ice cover in the Hopkins Valley is greater than that in the Dobson Valley due to the Richardson Glacier and additional permanent snow cover on the western side of the Hopkins Valley. Increased snow cover, however, makes up less than $10 \%$ of the total catchment and can be disregarded as having a significant impact on denudation rate calculations (Schildgen, Phillips, \& Purves, 2005; Wittmann et al., 2007). Catchment area, aspect, slope angle, elevation, relief and temperature are remarkably similar between the two catchments, allowing for precipitation to be identified as the probable contributor to differences in denudation rates. Mean slope in both catchments is $\sim 37$, above the typical threshold slope angle of $30^{\circ}$. Both catchments are likely to be in kinetically-limited regimes as the threshold angle has been met, thus precipitation may be a driver in rapid denudation rates.

\section{3. 5. Lake Ōhau sedimentation rates}

The Dobson and Hopkins Rivers are the two major tributaries flowing into Lake Ōhau. Lake Ōhau moraines have been studied in context of the last glacial maximum in the Southern Alps (Putnam et al., 2013). Glacial retreat in the Ōhau catchment began at $17 \mathrm{ka}$ as recorded by lateral moraine surrounding Lake Ōhau (Putnam et al., 2013). Geophysical data taken from Lake Ōhau suggests there has been 140m of accumulated sediment since glacial retreat at 17ka (Roop et al., 2015). Sediment cores taken from Lake Ōhau show 
increased sedimentation and coarser material being deposited in summer compared to winter months (Roop et al., 2015). Seasonality plays an important role in sedimentation into Lake Ōhau as during the summer months, storm events from the north-west bring frequent, heavy precipitation that results in flooding. A large flood event in January 2013 was observed to have had an effect on turbidity in Lake Ōhau and increased sedimentation into the lake, contributing $95 \%$ of sediment to the lake inflow that summer, highlighting the importance of precipitation on the erosion system.

Sediment core and geophysical results indicate a sedimentation rate of $12,300 \mathrm{t} \mathrm{km}^{-2} \mathrm{yr}^{-1}$ (assuming sediment density of $1.5 \mathrm{~g} \mathrm{~cm}^{-3}$ ) since $17 \mathrm{ka}$ at the sampling locality in Lake Ōhau. Assuming sediment is depositing evenly in the lake, the sedimentation rate can be

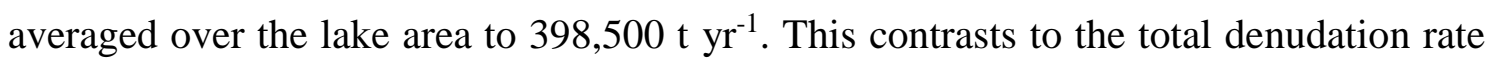

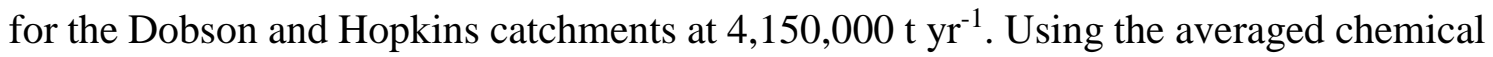
depletion fraction of 0.309 the total physical flux can be estimated as 2,900,000 t $\mathrm{yr}^{-1}$. The physical flux is 7 times greater than that of the sedimentation rate in Lake Ōhau. The discrepancy between the physical flux and sedimentation rate demonstrates how a significant proportion of sediment is by-passing the lake through the chemical flux. Most importantly, it validates how critical bed load yield measurements are in rapidly eroding landscapes. As a significant proportion of sediment being eroded off the landscape is the bed load, it is likely it is being stored in the catchment and not reaching the lake. Alluvial sediment has likely infilled the valley surrounding Lake Ōhau since the beginning of deglaciation at $17 \mathrm{ka}$, transforming the shape of the valley. Extensive alluvial fans throughout the Dobson and Hopkins Valleys and coarse sediment in the river beds are indicative of a substantial bed load component of total sediment yields.

Discrepancy in denudation rates show long-term sedimentation rates may have been decreasing since the last glacial maximum at $17 \mathrm{ka}$. Denudation rates from ${ }^{10} \mathrm{Be}$ concentrations on timescales of $10^{2}-10^{5}$ are 7 times that of sedimentation in Lake Ōhau although deglaciation likely has played a role in the long-term record and could reflect a period of intense paraglacial activity. Evidence of moraines from last glacial maximum show glaciers were widespread throughout the Southern Alps with ice covering the majority of the Ōhau catchment (Putnam et al., 2013). Glacial erosion can induce erosional processes through bedrock erosion (abrasion), plucking and freeze thaw thus increasing rates of sediment removal off the landscape (Hallet, Hunter, \& Bogen, 1996). 


\section{Discussion}

For example, valleys in the Olympic Mountains, Washington were found to have two to four times more sediment removal from glacially incised valleys indicating glacial erosion can have more effective sediment conveyance and export than fluvial valleys (Montgomery, 2002). Evidence of variability in denudation rates from the LGM to today in the Italian Alps show rates have gradually slowed however secondary peaks occur, likely as a result of high amplitude climate change and anthropogenic change (Savi et al., 2014).

In the Ōhau catchment it is likely denudation rates have gradually slowed over the past $17 \mathrm{ka}$ since the last glacial maximum, however there may be a more recent rapid increase in local denudation rates due to climate change and anthropogenic impact in the catchment. Anthropogenic change in the past $~ 800$ years may have created a recent increase in denudation rates. Nothofagus forest dominated the region until Maori arrived in the region 600-800 years ago when indigenous tree cover was cleared through burning (McGlone \& Moar, 1998). Native scrub and grassland covered the landscape until Europeans arrived. Following European settlement $\sim 150$ years ago, the Ōhau catchment has changed again through subsequent burning and the introduction of sheep and beef farming. Burning of indigenous forest cover and the increase in scrub and grassland allowed the Dobson Valley and lower Hopkins Valley to be farmed. Sedimentation rates have likely increased since this change in the catchment. Evidence of burning and the subsequent aggradation can be seen in the confluence of the Hopkins and Dobson Rivers (Fig. 6. 1). Sedimentation into Lake Ōhau may have increased during the past $\sim 800$ years with the increase of anthropogenic activity in the catchment leading to storm events transporting more sediment downstream and increasing landsliding due to the lack of indigenous forest cover. 


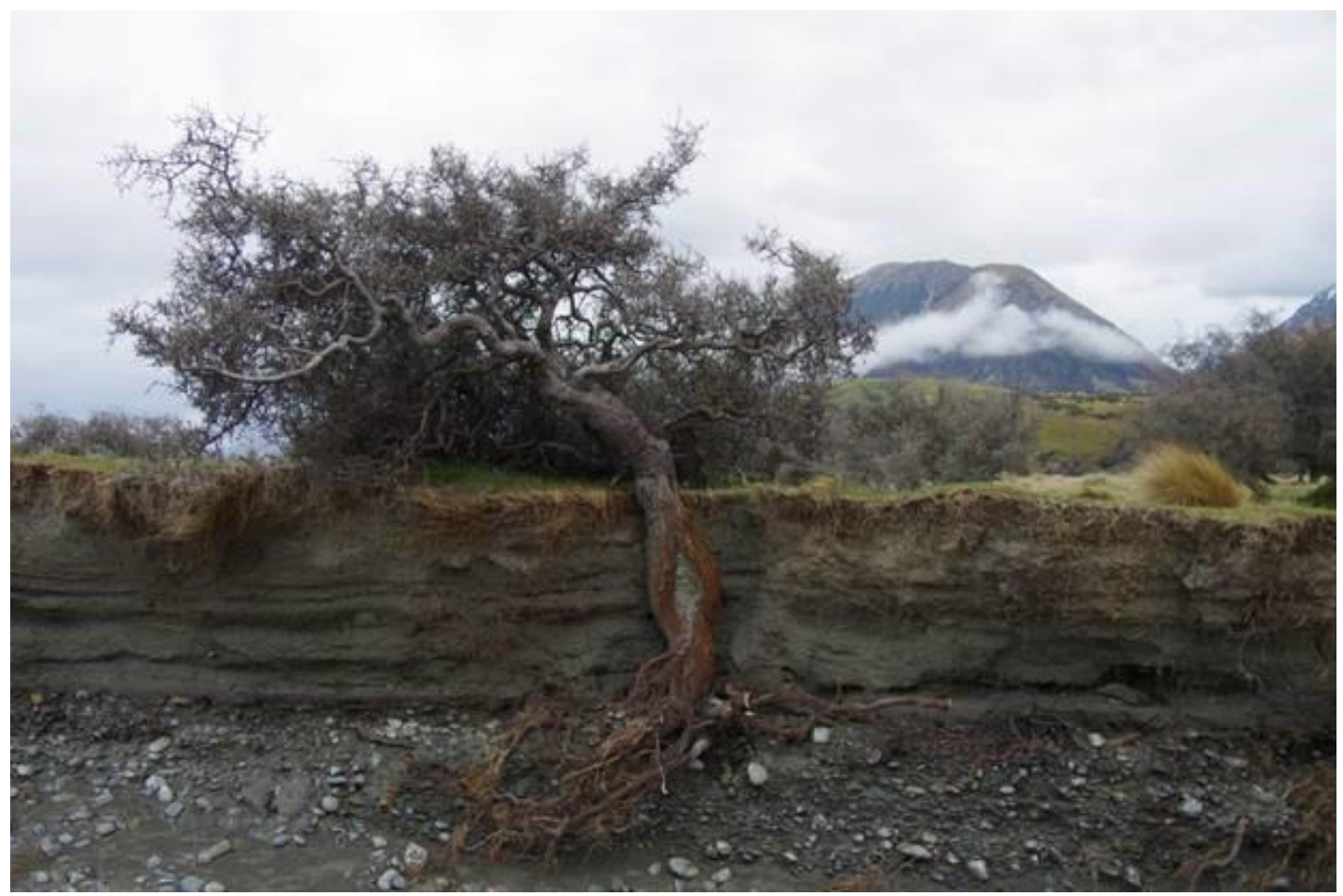

Figure 6.1. Photo of the Hopkins River showing past aggradation of $\sim 1$ m and degradation within the lifetime of a Matagouri tree in the Ōhau catchment, New Zealand. Photo taken by Kevin Norton.

\section{4. Denudation rates across New Zealand}

6. 4. 1. Suspended sediment yields

Methods for measuring denudation rates have developed significantly over past decades. Suspended sediment yield measurements were initially used to determine denudation rates in major rivers, however these estimates span short-term periods that lead to high levels of uncertainty due to potential bias from anthropogenic changes, inability to capture low frequency, high magnitude events and the exclusion of bedload sediment in measurements. The development of cosmogenic nuclide dating has allowed for more reliable long-term denudation measurements. Since the 1970's suspended sediment yield measurements have commonly been used to determine denudation rates for major New Zealand Rivers. Early sediment yield measurements were calculated by integrating suspended sediment rating relationships with flow gauge data (Adams, 1979; Griffiths, 1979; Thompson \& Adams, 1979). More recent estimates have used empirical raster GIS modelling (Hicks et al., 2011). Suspended sediment yield measurements are basinaveraged estimates that make the assumption streams are linked to the hillslope. 
Suspended sediment yield measurements from 40 North Island, New Zealand rivers resulted in specific yields of $35-28,000 \mathrm{t} \mathrm{km}^{-2} \mathrm{yr}^{-1}$ (Adams, 1979). The highest sedimentation yields recorded were from rivers in the East Cape region such as in the Waipaoa catchment (Hicks et al., 2000). Suspended sediment yield estimates from 14 major South Island Rivers found yields from the West Coast to be $170-17,070 \mathrm{t} \mathrm{km}^{-2} \mathrm{yr}^{-}$ ${ }^{1}$ compared to $1,980-3,210 \mathrm{t} \mathrm{km}^{-2} \mathrm{yr}^{-1}$ for the Eastern South Island (Griffiths, 1979). Sediment yields south of the Grey River increased significantly, with Hokitika and Haast River yields at $17,070 \mathrm{t} \mathrm{km}^{-2} \mathrm{yr}^{-1}$ and 12,730 $\mathrm{t} \mathrm{km}^{-2} \mathrm{yr}^{-1}$ respectively (Griffiths, 1979). West Coast yields had lower minimum values than Eastern South Island Rivers, although those draining from the main divide in the Southern Alps had exceptionally high yields. Sediment yields from the East Coast of the South Island were relatively consistent across catchments draining from the main divide. The Waimakariri and Rakaia Rivers had sediment yields at $1,670 \mathrm{t} \mathrm{km}^{-2} \mathrm{yr}^{-1}$ and 1,640 $\mathrm{t} \mathrm{km}^{-2} \mathrm{yr}^{-1}$ respectively (Griffiths, 1979). West Coast river sediment yields are consistently high from Hokitika and Haast (Griffiths, 1979, 1981). Further sediment yield estimates of South Island Rivers were measured at $12-37,000 \mathrm{t} \mathrm{km}^{-2} \mathrm{yr}^{-1}$ (Adams, 1980). Sediment yield estimates from the South Island are highest for those rivers draining off the main divide of the Southern Alps where uplift is greatest and precipitation exceeds 10,000 $\mathrm{mm} \mathrm{yr}^{-1}$ (Adams, 1980; Griffiths, 1981; Griffiths \& Glasby, 1985; Hicks et al., 2011).

Suspended sediment yields of major South Island Rivers from improved estimates using an empirical raster GIS method (Hicks et al., 2011) are comparable in magnitude to denudation rates calculated from the Ōhau catchment. Denudation rates from the Dobson and Hopkins Rivers of 4,410 $\mathrm{t} \mathrm{km}^{-2} \mathrm{yr}^{-1}$ and 8,850 $\mathrm{t} \mathrm{km}^{-2} \mathrm{yr}^{-1}$ respectively are comparable to suspended sediment yield estimates from West Coast Rivers such as Hokitika and Haast. South Island East Coast Rivers, however, even those draining from the main divide, have suspended sediment yield estimates that are substantially less (Fig. 6. 2). The slowest eroding sub-catchments in the lower Dobson Valley are comparable to East Coast draining rivers such as the Waimakariri and Rakaia Rivers (Hicks et al., 2011). 


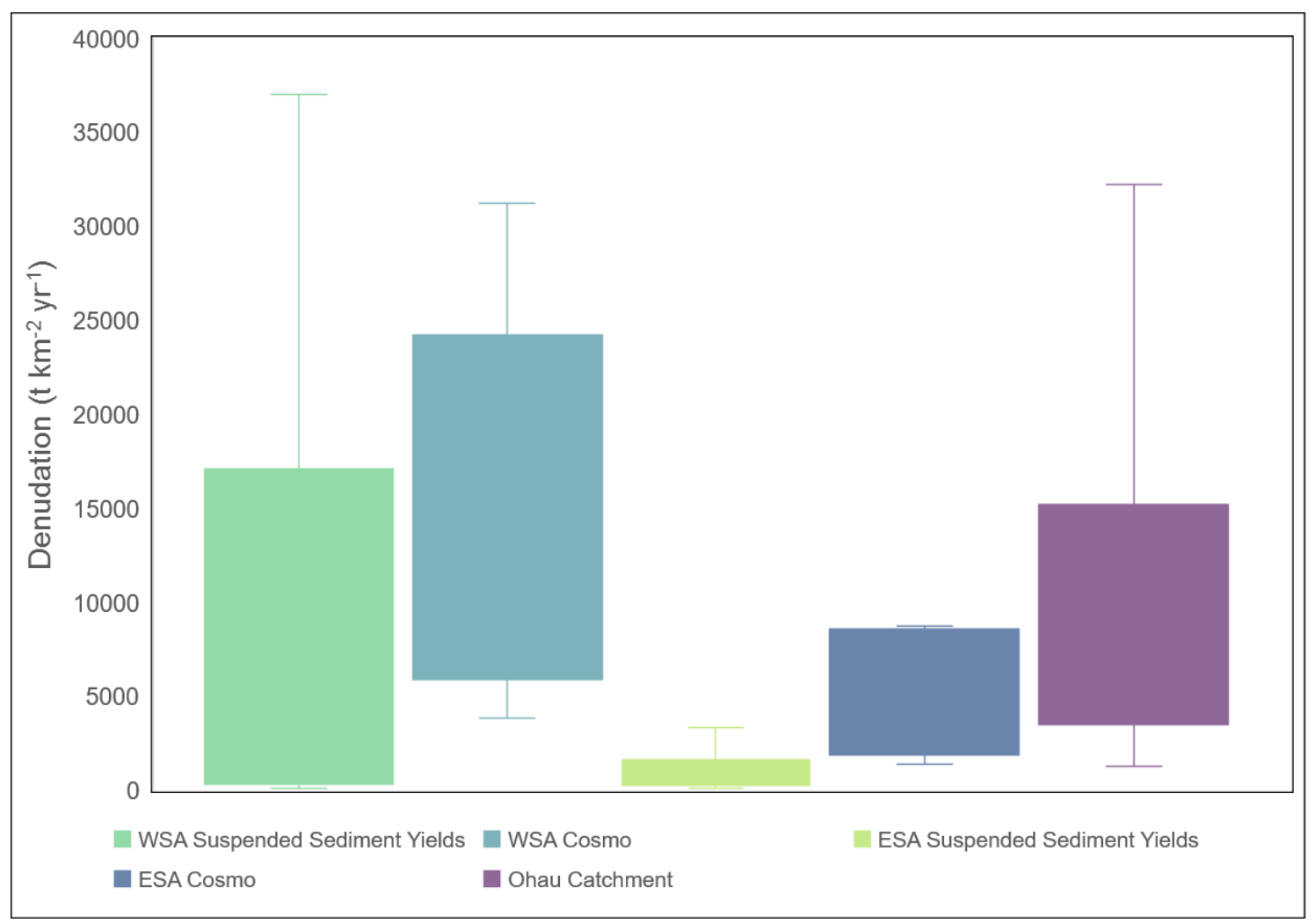

Figure 6.2. Western Southern Alps suspended sediment loads (Adams, 1980; Griffiths, 1979; Griffiths \& Glasby, 1985) and ${ }^{10}$ Be derived denudation rates (Larsen et al., 2014), Eastern Southern Alps suspended sediment yields (Adams, 1980; Griffiths, 1979; Griffiths $\&$ Glasby, 1985) and ${ }^{10}$ Be derived denudation rates (Norton, unpublished data) and, ${ }^{10} \mathrm{Be}$ derived denudation rates from this research in the Ōhau catchment.

\section{4. 2. Cosmogenic nuclide derived long-term denudation rates}

The development of cosmogenic nuclide dating has allowed for long-term catchmentaveraged denudation rates to be calculated (Burdis, 2014; Larsen et al., 2014). The Southern Alps, New Zealand have proven difficult to produce meaningful cosmogenic nuclide dating results due to lithology, climate and accessibility of sampling sites; thus, few published results are available all of which have low ${ }^{10} \mathrm{Be}$ concentrations. Denudation rates were measured in the Nelson/Tasman region of $112-626 \mathrm{t} \mathrm{km}^{-2} \mathrm{yr}^{-1}$ from the Waimea and Motueka catchments (Burdis, 2014). Millennial scale ${ }^{10} \mathrm{Be}$ derived denudation rates are much higher in the Waimea and Motueka catchments than short-term suspended sediment yield estimates (O'Loughlin, Rowe, \& Pearce, 1978). Denudation rates measured from the Waimea and Motueka catchments are an order of magnitude lower than rates from the Ōhau catchment. Mean annual precipitation is $\sim 2,000 \mathrm{~mm} \mathrm{yr}^{-1}$ 
lower than in the Ōhau catchment, tectonic uplift is significantly slower and lithology is highly variable.

Denudation rates measured using ${ }^{10} \mathrm{Be}$ from river sediment in catchments along the western Southern Alps indicate rapid denudation of 3,840 - 31,200 t km $\mathrm{yr}^{-1}$ (Larsen et al., 2014). These rates of denudation are amongst the highest measured worldwide and reinforce why the Southern Alps are an important location to study active orogens. Comparison of suspended sediment yields and ${ }^{10} \mathrm{Be}$ derived denudation rates from rivers along the western Southern Alps find ${ }^{10} \mathrm{Be}$ derived denudation rates to be nearly double that of suspended sediment yields (Hicks et al., 2011; Larsen et al., 2014). Mean denudation rates from the western Southern Alps and the Ōhau catchment are analogous across all sites from both studies (Fig. 6. 2). Rates measured for the main Dobson and Hopkins Rivers are comparable to that of the Fox River $\left(3,840 \mathrm{t} \mathrm{km}^{-2} \mathrm{yr}^{-1}\right)$, Docherty Creek (5,900 t km$\left.{ }^{-2} \mathrm{yr}^{-1}\right)$ and Karangarua River (9,990 t km${ }^{-2} \mathrm{yr}^{-1}$ ) (Larsen et al., 2014). Mean annual precipitation of these catchments are similar to that of the Dobson and

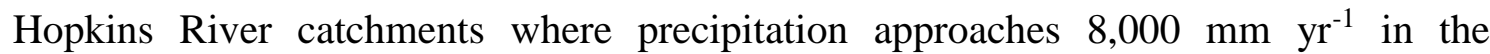
headwaters. As both the sites in the western Southern Alps and in the Ōhau catchment are located on the main divide with similar catchment characteristics such as slope angle, lithology and relief, it is expected these results would be similar. The similarity of denudation rates from Hicks et al (2011) and Larsen et al (2014) confirm on either side of the main divide, the Southern Alps, New Zealand have rapid denudation at rates an order of magnitude higher than elsewhere in the world.

Two North Island rivers and six South Island rivers had denudation rates measured of 454 - 3,290 $\mathrm{m} \mathrm{Myr}^{-1}$ (see Appendix C) (Norton, unpublished data). The two North Island rivers (Akitio and Whareama) are located in the western Wairarapa and had denudation rates measured at 454 and $549 \mathrm{~m} \mathrm{Myr}^{-1}$, respectively. South Island river denudation rates were measured from several major eastern draining rivers and had rates varying from 523 - 3,290 $\mathrm{m} \mathrm{Myr}^{-1}$. Rates from the Awatere and Clarence were measured at 523 and 1,240 $\mathrm{m} \mathrm{Myr}^{-1}$, respectively, which are similar to those from the slower rates from the Dobson Valley (DOB19-20 and DOB19-16).

The Bealey and Rakaia rivers had ${ }^{10} \mathrm{Be}$ concentration error (atoms/gram) greater than $100 \%$; thus, minimum denudation rates were calculated in the online erosion rate 
calculator V. 3 (Balco et al., 2008) were calculated by adding measured ${ }^{10} \mathrm{Be}$ concentrations and ${ }^{10} \mathrm{Be}$ error. Minimum denudation rates of 1,490 and 3,220 $\mathrm{m} \mathrm{Myr}^{-1}$ were measured for the Bealey and Rakaia rivers respectively. Denudation rates were recalculated to measure the 'true' mean estimates (without error) using the initial ${ }^{10} \mathrm{Be}$ concentrations in CRONUS V. 2. 3. Rates calculated for the Bealey and Rakaia were 2,848 and 9,790 $\mathrm{m} \mathrm{Myr}^{-1}$ respectively, which is within the range of denudation rates measured in the Ōhau catchment. The Rangitata and Waimakariri River denudation rates were also measured as minimum estimates as ${ }^{10} \mathrm{Be}$ concentrations were negative after blank corrections, thus ${ }^{10} \mathrm{Be}$ error was added in order to be able to calculate minimum denudation rates in the online Earth calculator V. 3. Minimum denudation rates from the Rangitata and Waimakariri rivers were measured at 3,290 and $796 \mathrm{~m} \mathrm{Myr}^{-1}$ respectively. Rates measured across these eastern South Island Rivers are remarkably consistent with rates from the Ōhau catchment, including the main Hopkins and Dobson Rivers. Notably ${ }^{10} \mathrm{Be}$ concentrations across eastern South Island Rivers are remarkably low, reinforcing the importance of having low concentration laboratory blanks. Although ${ }^{10} \mathrm{Be}$ derived denudation rates are powerful as long-term measurements, careful consideration must be taken when preparing samples when dealing with low concentration samples.

In situ ${ }^{10} \mathrm{Be}$ derived denudation rates provide long-term, averaged results that represents background denudation. Measuring denudation rates over timescales of $10^{2}-10^{5}$ years allows for the effects of climate change, tectonics, topography and lithology to be examined. With anthropogenic climate change becoming an increasing concern, the consumption of $\mathrm{CO}_{2}$ through chemical weathering also becomes progressively important. ${ }^{10} \mathrm{Be}$ derived denudation rates averages across the landscape, including all erosion and weathering processes. In contrast, suspended sediment yields are short-term measurements and do not take into consideration any bedload component of river sediment loads. In tectonically active landscapes such as the Southern Alps, bedload components become increasingly important. Suspended sediment yields and ${ }^{10} \mathrm{Be}$ derived denudation rates in tectonically inactive regions such as Nelson are comparable to each other (Basher et al., 2011; Burdis, 2014). In the tectonically active Southern Alps however, suspended sediment yields are highly variable both between other suspended sediment yield research (Adams, 1980; Griffiths, 1979) and denudation rates measured from in situ ${ }^{10} \mathrm{Be}$ in the western Southern Alps (Larsen et al., 2014) and from this research. Denudation rates measured from in situ ${ }^{10} \mathrm{Be}$ are higher than that measured from 
suspended sediment yields showing a significant portion of total denudation may be missed by not measuring the river bedload. Further research from the Southern Alps using in situ ${ }^{10} \mathrm{Be}$ would average out short-term perturbations. Long-term denudation estimates are a valuable tool for understanding the interactions of climate, tectonics and denudation, and how landscapes may respond in the future.

\section{5. Chemical weathering and physical erosion of total denudation}

\section{5. 1. Partitioned denudation rates}

Denudation rates were partitioned into chemical weathering $\left(\mathrm{m} \mathrm{Myr}^{-1}\right)$ and physical erosion (m $\mathrm{Myr}^{-1}$ ) rates (Table 6. 1) using the Chemical Depletion Fraction from hillslopes (following Riebe et al. (2003)) and catchment-averaged denudation rates. Chemical weathering and physical erosion rates were calculated using the denudation rate from the adjacent sub-catchment to the soil transect (DOB19-08) and the averaged chemical depletion fraction from each top soil along the soil transect (Table 5. 6). The chemical weathering rate was calculated as 2,339 $\mathrm{m} \mathrm{Myr}^{-1}$ and the physical erosion rate as 5,231 $\mathrm{m} \mathrm{Myr}^{-1}$.

Table 6.1. Partitioned chemical weathering ( $m M^{-1}$ ) and physical erosion ( $\left.m \mathrm{Myr}^{-1}\right)$ components of total average denudation using DOB19_08 sub-catchment denudation rate.

\begin{tabular}{cccc}
\hline $\begin{array}{c}\text { Average CDF at } \\
\text { surface }\end{array}$ & $\begin{array}{c}\text { DOB19-08 } \\
\text { Denudation Rate } \\
\left(\mathbf{m ~ M y r}^{-1}\right)\end{array}$ & $\begin{array}{c}\text { Chemical } \\
\text { Weathering Rate } \\
\left(\mathbf{m ~ M y r}^{-\mathbf{1}}\right)\end{array}$ & $\begin{array}{c}\text { Physical Erosion } \\
\text { Rate } \\
\left(\mathbf{m ~ M y r}^{-\mathbf{1}}\right)\end{array}$ \\
\hline 0.309 & 7570 & 2339 & 5231 \\
\hline
\end{tabular}

Chemical weathering and physical erosion rates were then partitioned using the denudation rate measured for the Dobson River (1660 $\left.\mathrm{m} \mathrm{Myr}^{-1}\right)$, assuming that the soil is representative of the entire Dobson Valley, the same approach can be taken to estimate the weathering and erosion fluxes for the whole Dobson catchment. The lower denudation rate for the Dobson, comparatively to the DOB19-08 sub-catchment subsequently resulted in much lower weathering and erosion rates. The chemical weathering rate is 512 $\mathrm{m} \mathrm{Myr}^{-1}$ and the physical erosion rate is $1,147 \mathrm{~m} \mathrm{Myr}^{-1}$. Partitioning of weathering and erosion makes the assumption that hillslopes are broadly representative of the partitioning between chemical and physical fluxes. Given the prevalence of scree slopes and bare- 
rock these estimates are likely an over-estimate of the weathering fluxes and represent maximum estimates of possible weathering fluxes that could contribute to atmospheric $\mathrm{CO}_{2}$ drawdown. Weathering fluxes for the sub-catchment are likely more accurate than those for the entire Dobson catchment as the CDF measured from soils in the upper Dobson Valley likely to not be representative of the CDF across the entire catchment.

Table 6.2. Partitioned chemical weathering $\left(m \mathrm{Myr}^{-1}\right)$ and physical erosion $\left(m \mathrm{Myr}^{-1}\right)$ components of total average denudation for the Dobson River catchment.

\begin{tabular}{cccc}
\hline $\begin{array}{c}\text { Average CDF at } \\
\text { surface }\end{array}$ & $\begin{array}{c}\text { Dobson River } \\
\text { Denudation Rate } \\
\left(\mathbf{m} \mathbf{M y r}^{-\mathbf{1}}\right)\end{array}$ & $\begin{array}{c}\text { Chemical } \\
\text { Weathering Rate } \\
\left(\mathbf{m ~ M y r} \mathbf{~ M y}^{-1}\right)\end{array}$ & $\begin{array}{c}\text { Physical Erosion } \\
\text { Rate } \\
\left(\mathbf{m ~ M y r}^{-\mathbf{1}}\right)\end{array}$ \\
\hline 0.309 & 1660 & 512 & 1147 \\
\hline
\end{tabular}

Even at less than half of physical erosion rates, chemical weathering for the DOB19-08 and Dobson River catchments are $1,356 \mathrm{t} \mathrm{km}^{-2} \mathrm{yr}^{-1}$ and 6,198 $\mathrm{t} \mathrm{km}^{-2} \mathrm{yr}^{-1}$, respectively (assuming rock density of $2.65 \mathrm{~g} / \mathrm{cm}^{-3}$ ). This weathering rate far surpasses the proposed weathering speed limit of $\sim 150 \mathrm{t} \mathrm{km}^{-2} \mathrm{yr}^{-1}$ (Dixon \& von Blanckenburg, 2012). These results are similar to soil chemical weathering rates of $4.4-2,060 \mathrm{t} \mathrm{km}^{-2} \mathrm{yr}^{-1}$ from the western Southern Alps where weathering speed limits are thought to be surpassed (Larsen et al., 2014). This contrasts with chemical weathering rates from western Southern Alps Rivers, measured from dissolved loads in rivers at $59-150 \mathrm{t} \mathrm{km}^{-2} \mathrm{yr}^{-1}$ and for eastern Southern Alps Rivers 9.4 - $36 \mathrm{t} \mathrm{km}^{-2} \mathrm{yr}^{-1}$ (Jacobson \& Blum, 2003). Further chemical weathering rates from the Southern Alps calculated using river geochemical data have been measured at $93-480 \mathrm{t} \mathrm{km}^{-2} \mathrm{yr}^{-1}$ (Lyons et al., 2005) with values from the western Southern Alps Rivers by-passing any proposed weathering speed limit. Since CDF average over the entire lifetime of a soil, instantaneous dissolved river loads from rivers may be more representative of the catchment as a whole.

Chemical weathering rates across the Southern Alps are shown to be closely correlated with precipitation and soil moisture availability (Dixon et al., 2016; Larsen et al., 2014; Lyons et al., 2005). A strong precipitation gradient is evident across the Southern Alps due to orographic rainfall from prevailing westerly winds (Henderson, 1993). Chemical weathering rates are highest in catchments at the highest precipitation rates (Larsen et al., 
2014; Lyons et al., 2005). At high rates of precipitation, leaching intensity increases thus leading to subsequent increases in chemical weathering. The relationship between precipitation and weathering in the Southern Alps is non-linear, with a pedogenic threshold at precipitation rates of $800 \mathrm{~mm} \mathrm{yr}^{-1}$ (Dixon et al., 2016). As precipitation reaches $800 \mathrm{~mm} \mathrm{yr}^{-1}$, rapid changes in soil geochemistry result in increases in chemical weathering; above this threshold, weathering does not appear to be limited by water availability. Precipitation rates across the Southern Alps are up to $10,000 \mathrm{~mm} \mathrm{yr}^{-1}$ therefore it is likely catchments sampled to measure chemical weathering are above this pedogenic threshold. Lithology also plays a role in chemical weathering rates in the Southern Alps with the lowest rates of weathering found in greywacke/argillite compared to the highest rates in schists (Lyons et al., 2005). The underlying lithology in the DOB1908 sub-catchment is schist, compared to the Dobson River catchment which includes a significant amount of greywacke/argillite.

A combination of precipitation, lithology and tectonics result in exceptionally high physical erosion and chemical weathering rates that appear to exceed any proposed weathering speed limit (Dixon \& von Blanckenburg, 2012). Soil production in the Southern Alps is an order of magnitude higher than elsewhere in the world and allows a soil mantle to be maintained across the landscape (Larsen et al., 2014). This soil mantle allows for eco-systems and vegetation cover that encourages the break-up of rock and enhances rates of chemical weathering.

Previous research has found, contrary to initial assumptions, that weathering is linked closely with erosion rates, rather than climatic variables such as temperature and precipitation (Dixon et al., 2016; Dixon \& von Blanckenburg, 2012; Riebe et al., 2004a; West et al., 2005). Further modelling has reinforced that erosion controls weathering rates however, in kinetically limited landscapes climate may in fact play a role controlling weathering rates (Ferrier \& Kirchner, 2008; Gabet \& Mudd, 2009).The Dobson Valley is likely to be a kinetically limited regime particularly high in the catchment where there is high MAP, steep slope angles and an underlying lithology of metamorphosed schist. Characteristics of Dobson Valley are similar to the kinetically limited western Southern Alps (Jacobson et al., 2003). 
In agreement with previous research, my results support the conclusion that the Southern Alps are likely in a kinetically limited regime as the relationship between chemical weathering and physical erosion become non-linear at the highest rates of denudation (Dixon et al., 2016; Larsen et al., 2014). Modelling shows chemical weathering increases with total denudation until denudation rates reach $\sim 100 \mathrm{t} \mathrm{km}^{-2} \mathrm{yr}^{-1}$, above this the relationship becomes non-linear (Gabet \& Mudd, 2009). In the Southern Alps however, rates of total denudation are much higher than this and chemical weathering rates have been found to continue increasing past this point of detachment (Larsen et al., 2014). Findings from the Dobson Valley of exceptionally high total denudation and resulting chemical weathering rates suggest the landscape is likely in a kinetically limited regime. In young, wet, tectonically active landscapes such as the Southern Alps, chemical weathering rates reflect the sheer quantity of overall denudation across the landscape. Mechanisms leading to such high weathering fluxes across the Southern Alps may be a result of linkages between tectonic uplift, climate and biological processes (Fig. 6. 3).

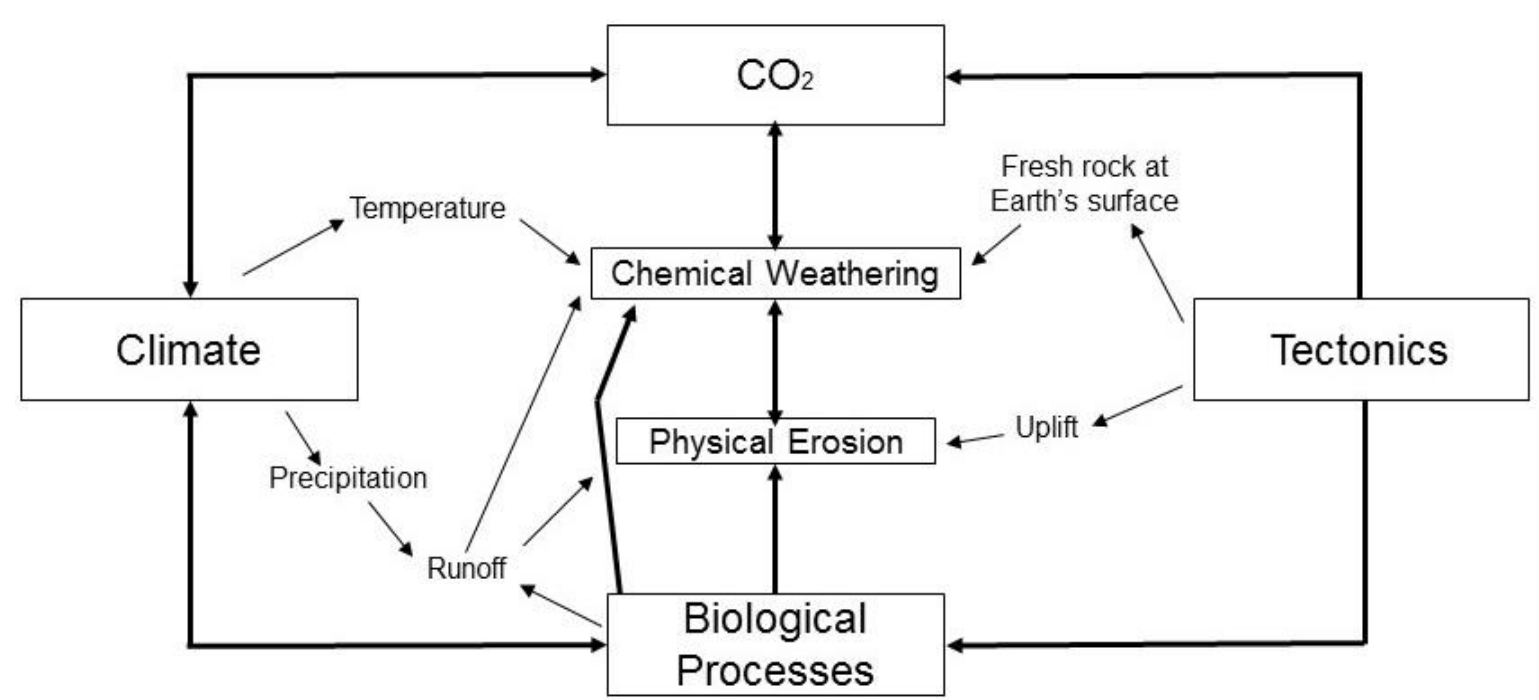

Figure 6.3. Schematic of linkages between climate, tectonics, biological processes, carbon dioxide and weathering fluxes. Adapted from (Goudie \& Viles, 2012).

Rapid tectonic uplift and lithology in the Southern Alps result in fractured bedrock. Fractured bedrock combined with high rates of precipitation leading to extensive runoff, results in rich biological processes thus further enhancing weathering fluxes. Tectonic uplift, lithology and precipitation also lead to frequent landsliding events across the Southern Alps, resulting in short soil residence times that were reflected by low in situ ${ }^{10} \mathrm{Be}$ concentrations. Rates of chemical weathering and physical erosion across the 
Southern Alps affirm the hypothesis that active mountain landscapes are important contributors of efficient weathering leading to increased $\mathrm{CO}_{2}$ consumption.

\section{6. Tectonic controls on denudation}

\section{6. 1. Steady state}

Active convergent mountain landscapes such as the Southern Alps are a depiction of the balance between tectonic uplift and erosional processes. The negative feedback induced through tectonics and erosional processes can result in steady state across a landscape

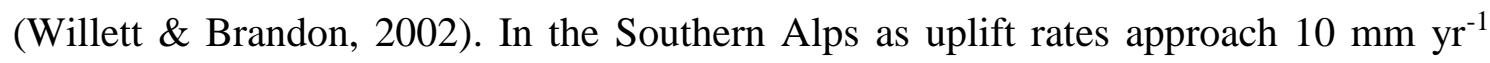
(Little et al., 2005), there is a strong feedback with increasing erosion rates as a result of both orographic rainfall and rapid tectonic uplift.

Topographic steady state describes the state when points across a landscape do not change with time, thus uplift and erosional processes are in balance (Willett \& Brandon, 2002). For topographic steady state to be reached tectonic uplift and erosion must be constant therefore making it unlikely a landscape will ever reach full topographic steady state and is more likely to be ever approaching steady state. The Southern Alps have long been used in modelling of active continental margins as to determine whether a landscape is approaching steady state (Koons, 1989; Montgomery \& Brandon, 2002; Willett \& Brandon, 2002; Willett et al., 2001). Asymmetric topography in the Southern Alps show how horizontal tectonic motion is affecting the geomorphology across the landscape, thus slowing the rate at which topographic steady state can be achieved (Willett et al., 2001). With landslide distribution even across valleys (Meunier, Hovius, \& Haines, 2008) and strong orographic precipitation, rapid denudation rates help to balance uplift rates and reach topographic steady state in the Southern Alps (Willett, 1999). Across the Southern Alps, including in the Ōhau catchment rapid tectonic uplift and strong orographic controls on precipitation mean it is unlikely the landscape is in topographic steady state; however, the landscape may be approaching an overall flux steady state.

\section{6. 2: Threshold hillslopes}

Threshold hillslopes are slopes that are approaching the angle at which bedrock landsliding occurs, which is dependent on rock strength at landscape scale (Schmidt \& Montgomery, 1995). The angle at which denudation rates and slope angle decouple is at $\sim 30^{\circ}$, coinciding with the transition from transport limited to stochastic regimes (Binnie et 
al., 2007). Denudation rates increase with slope angle until the threshold slope angle is reached where rates exponentially increase. Mean slope angle in the Dobson Valley is well above the threshold slope angle at $50^{\circ}$ in the upper sub-catchments and $40^{\circ}$ in lower sub-catchments. Slope angles in the Dobson Valley are therefore well in excess of the threshold angle so that valleys are likely to be dominated by frequent landsliding events, particularly with maximum precipitation rates $>7,000 \mathrm{~mm} \mathrm{yr}^{-1}$. Landslide recurrence intervals across the western Southern Alps are highly variable with estimates of both 300 years (Clarke \& Burbank, 2011) and 1500 - 15000 years (Hilton et al., 2011). Although vastly different landslide intervals are estimated in the western Southern Alps it remains prevalent that landslides are common throughout the landscape and have the potential to influence denudation rates for $\sim 100$ years (Korup, 2005). Soil production rates from the western Southern Alps are rapid enough that at longer landslide recurrence intervals there would be sufficient time for ${ }^{10} \mathrm{Be}$ to re-establish an equilibrium (Larsen et al., 2014).

Landslide events, particularly deep-seated landsliding, have the potential to greatly influence ${ }^{10} \mathrm{Be}$ derived denudation rates. Throughout the Dobson Valley there is strong evidence of past landslide activity. As sediment is brought to the surface, the rate of sediment removal influences the concentration of cosmogenic nuclides such as ${ }^{10} \mathrm{Be}$ at the surface. Deep-seated landsliding $(>5 \mathrm{~m})$ excavates sediment from depths that are not representative of surface sediment ${ }^{10} \mathrm{Be}$ concentrations. Modelling shows as the frequency of landsliding increases, greater the catchment area should be sampled (Niemi et al., 2005). Further modelling found catchments greater than $100 \mathrm{~km}^{2}$ measure consistent ${ }^{10} \mathrm{Be}$ derived denudation rates in landscapes dominated by deep-seated landsliding (Yanites et al., 2009). Given the Dobson and Hopkins catchments are $>300 \mathrm{~km}^{2}$ it is likely both denudation rates accurately represent the long-term averaged denudation rate. The Dobson Valley sub-catchments however, show evidence of both shallow and deep-seated landsliding. In catchments with evidence of landsliding such as DOB19-08 denudation rates are best taken as a maximum estimate as deep-seated landsliding may be lowering ${ }^{10} \mathrm{Be}$ concentrations and resulting in an overestimation in denudation rates. If landsliding in the Dobson Valley sub-catchments is shallow $(0.7-2 \mathrm{~m})$ denudation rates may however produce accurate denudation rates (Yanites et al., 2009). 


\section{6. 3. Tectonic activity on the Alpine Fault, Southern Alps}

The Southern Alps have formed as a result of trans-compressional movement along the Pacific and Australian plate boundary. The Alpine Fault is a continuous $800 \mathrm{~km}$ dextral strike-slip fault that runs the length of Te Waipounamu along the plate boundary, offsetting basement rock by $\sim 470 \mathrm{~km}$ (Norris \& Cooper, 2001; Sutherland et al., 2006; Sutherland et al., 2007; Wellman \& Willett, 1942). Frequent tectonic activity occurs along the Alpine Fault with the last known rupture at $1717 \mathrm{AD}$ resulting in a $7.9 \mathrm{Mw}$ earthquake with a 300-500 km rupture length (Sutherland et al., 2007). Extensive co-seismic landsliding is common in mountainous regions during large earthquakes and contribute to long-term denudation rates. Change in a landscape during tectonic activity creates a disequilibrium and causes perturbations in the overall system including an increase in the sediment flux through erosional processes. Denudation rates in the Flinders Ranges, Australia increased during three large earthquakes since $\sim 67 \mathrm{ka}$, showing a perturbation in the landscape as a response to tectonic activity (Quigley et al., 2007). Earthquakes on the Alpine Fault >7.6 Mw generate a threefold increase in sediment flux in the following 50 year period thus contributing to long-term averaged denudation (Howarth et al., 2012). Denudation rates measured in the Ōhau catchment are likely fast enough to not currently be responding to perturbations from the $1717 \mathrm{AD}$ Alpine Fault rupture although the influence of co-seismic landsliding would be averaged out in long-term denudation rates. Rapid uplift across the Southern Alps (Little et al., 2005; Tippett \& Kamp, 1993) including in the Ōhau catchment has an influence on steep slope angles thus creating tectonic controls on denudation rates.

\section{6. 4. Active and passive margin denudation rates}

A compilation of global denudation rates (Portenga \& Bierman, 2011) show active margins have significantly more rapid denudation rates than that at passive margins (Fig. 6. 4). Active and passive margins were manually selected from the compilation of data by Portenga and Bierman (2011) and active margins include Puerto Rico, Himalaya, western USA and the European Alps. Additional denudation rates from the western Southern Alps, New Zealand (Larsen et al., 2014) and the Ōhau catchment are included. Passive margins include continental settings such as Australia, Namibia and continental USA. The influence of tectonics at active margins is evident as denudation rates from these landscapes being much faster than rates from the passive margins. 


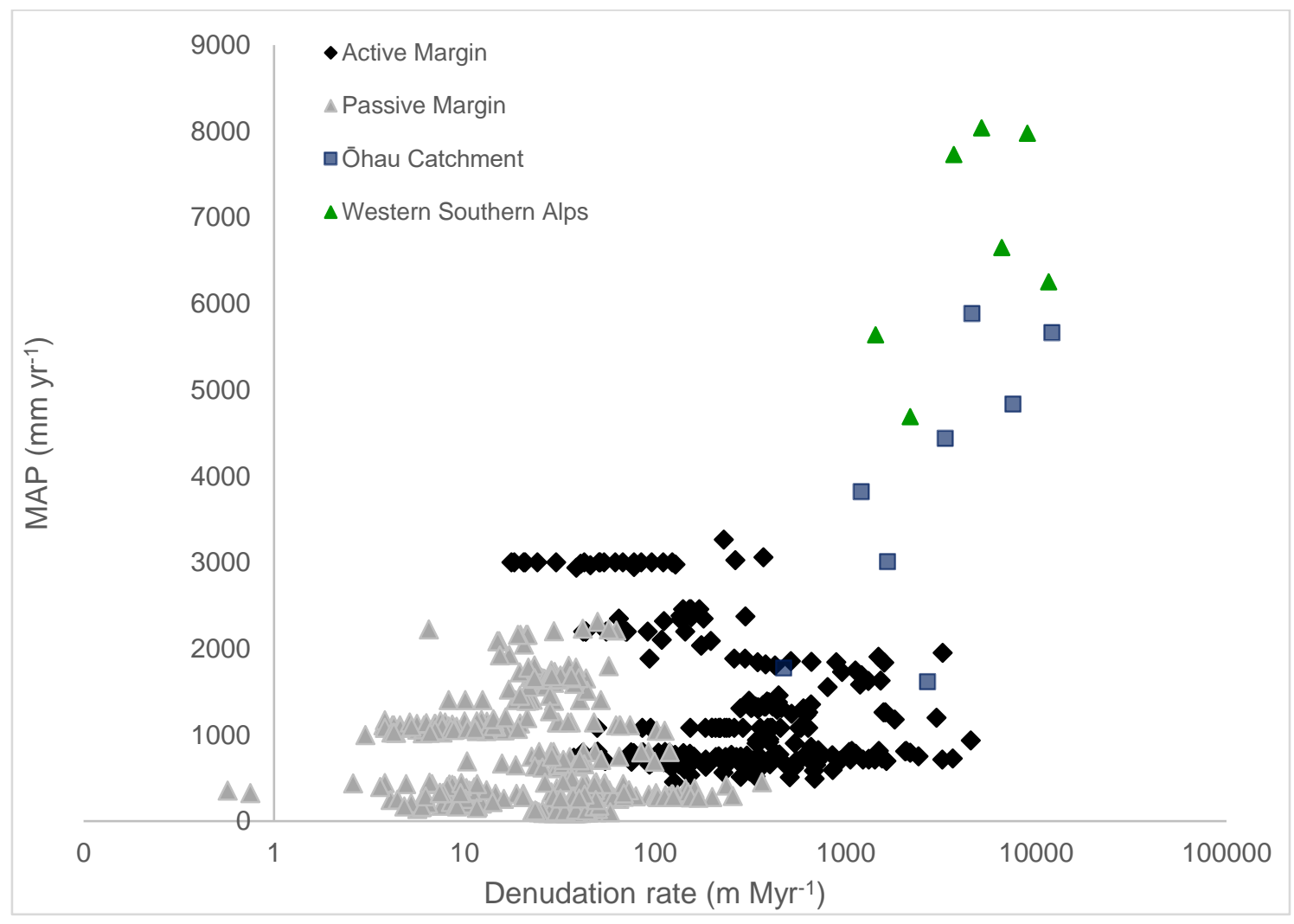

Figure 6.4. Plot of denudation rates and mean annual precipitation for active and passive margins. Data was manually selected as active or passive margins from a compilation by Portenga and Bierman (2011) (therein). additional data from the western Southern Alps (Larsen et al., 2014) and Ōhau catchment, New Zealand from this research. Precipitation rates for the western Southern Alps and Ōhau catchment are calculated for each catchment from annual precipitation data from 1979-2013 from NIWA.

Tectonically active landscapes have high rates of seismicity and uplift that promote rapid denudation through the weakening of rock and base-level lowering (Riebe et al., 2001b). At a global scale, tectonics rather than climate show a stronger relationship with denudation rates (Portenga \& Bierman, 2011). At local and regional scales however, climatic variables such as precipitation begin to show more of a control on denudation rates, as is evident in the Ōhau catchment. Precipitation alone however may have minimal control on denudation rates (Riebe et al., 2001b; von Blanckenburg, 2005). The combination of active tectonics and high precipitation however may result in rapid denudation. At high denudation rates, climate (temperature and runoff) has a greater effect than at low denudation rates (West, 2012). In the Southern Alps the combination of active tectonics and high precipitation may create conditions that evoke denudation rates an order of magnitude higher than the rest of the world. Denudation rates from the 
Southern Alps including from the Ōhau catchment are amongst the highest measured globally, showing active margins may have important implications in physical erosion and chemical weathering at active margins.

\section{7. Erosion, weathering and atmospheric $\mathrm{CO}_{2}$ consumption}

Physical erosion and chemical weathering rates from the Southern Alps support the evolving idea that active mountain landscapes contribute to global $\mathrm{CO}_{2}$ cycling. Silicate weathering plays an important role in the cycling of $\mathrm{CO}_{2}$ by sequestering carbon. Previous theories of a weathering speed limit have shown to be by-passed in the western Southern Alps, demonstrating that even in kinetically limited regimes, chemical weathering intensity increases with physical erosion (Larsen et al., 2014). Denudation rates and partitioned physical erosion and chemical weathering rates from the Ōhau catchment show rapid chemical weathering by-passes any proposed speed limits (Dixon \& von Blanckenburg, 2012). High rates of chemical weathering in active mountain landscapes resulting in increased $\mathrm{CO}_{2}$ consumption relies on rapid physical erosion that promotes weathering processes (Gaillardet et al., 1999; Lyons et al., 2005). Exceptionally high rates of physical erosion in the Southern Alps promote associated high rates of chemical weathering documented using independent methods (Jacobson \& Blum, 2003; Lyons et al., 2005). $\mathrm{CO}_{2}$ consumption across the Southern Alps is at rates 1.5 times that of the global average even taking into consideration low ratios of silicate to carbonate weathering (Jacobson \& Blum, 2003). The western Southern Alps experience chemical weathering rates 5 times that of the eastern Southern Alps (Jacobson \& Blum, 2003), showing the influence from tectonic uplift and orographic rainfall on weathering rates.

In the Southern Alps high-elevation catchments and catchments with underlying greywacke/argillite lithologies have the greatest $\mathrm{CO}_{2}$ consumption (Lyons et al., 2005). These catchments likely have the greatest $\mathrm{CO}_{2}$ consumption due to the prevalence of high precipitation rates at high elevations due to orographic rainfall (Henderson, 1993) and additionally, the erodibility of greywacke/argillite (Clarke \& Burbank, 2011). Catchment characteristics in the Ōhau catchment where denudation rates are greatest are either at high-elevations or have underlying greywacke/argillite. $\mathrm{CO}_{2}$ consumption in the Ōhau catchment is likely similar to rates found on the western Southern Alps at 1.5 times the global average given the very fast weathering rates implied by the CDF from hillslope soils. Rapid overall denudation and high physical erosion and chemical weathering across 
the Southern Alps demonstrates that tectonically active mountain landscapes may play an important role in long-term climate stability.

\section{8: Future directions and recommendations}

This research highlights the importance of quantifying catchment-averaged denudation rates in tectonically active mountain landscapes such as the Southern Alps, New Zealand.

${ }^{10} \mathrm{Be}$ derived catchment-averaged denudation rates from the Ōhau catchment are similar to those from the western Southern Alps (Larsen et al., 2014), and are an order of magnitude higher than elsewhere globally. Analysis of ${ }^{10} \mathrm{Be}$ concentrations across multiple grain-sizes show sampling of particular grain size fractions may result in different denudation rates measured using silt versus pebble sized grains. This possible grain size bias demonstrates the importance of having community agreement on either sampling one particular grain size or mixing several grain size fractions to have consistency across future research. Low concentration ${ }^{10} \mathrm{Be}$ and high rates of error across the denudation rates measured in the Ōhau catchment and previous New Zealand samples highlight the importance of avoiding labware contamination, distilling of acid and careful sample preparation. In the Southern Alps, metamorphosed schist results in a fine grain size that is platy in nature, which created difficulty in sample preparation. The small quantity of quartz in metamorphosed schist in the Southern Alps results in significant amounts of sediment needing to be sampled in order to have enough quartz to measure low-concentrations of ${ }^{10} \mathrm{Be}$ and other potential cosmogenic nuclides.

Trends in denudation rates with mean annual precipitation in the Ōhau catchment are consistent with previous work linking climate and denudation, further research in tectonically active regions and those with exceptionally high precipitation $(>10,000 \mathrm{~mm}$ $\mathrm{yr}^{-1}$ ) would be significant to add to published research. Additional sampling for soils and saprolites along hillslopes in the Dobson Valley would generate additional chemical depletion fraction (CDF) measurements. Additional CDF measurements from the Dobson Valley would increase the accuracy of physical erosion and chemical weathering partitioning and allow the relationship between denudation and precipitation to be tested. Increased certainty of chemical weathering in the Dobson Valley would allow for further inferences on the impact of $\mathrm{CO}_{2}$ consumption in the Southern Alps. The weathering rate calculated here is significantly faster than the proposed kinetic limit. Further work measuring ${ }^{10} \mathrm{Be}$ concentrations and $\mathrm{CDF}$ in wet, tectonically active mountain landscapes 


\section{Discussion}

such as the Southern Alps would allow for a greater understanding as to how these landscapes contribute to global $\mathrm{CO}_{2}$ cycling. 


\section{Conclusions}

In situ ${ }^{10} \mathrm{Be}$ derived denudation rates were measured across six sub-catchments in the Dobson Valley and from the main Dobson and Hopkins Rivers. Denudation rates in the sub-catchments varied from $474 \pm 40-7,570 \pm 941 \mathrm{~m} \mathrm{Myr}^{-1}$ with the exception of one subcatchment that had a denudation rate of $12,142 \pm 6,627 \mathrm{~m} \mathrm{Myr}^{-1}$. For the most rapidly eroding sub-catchment a minimum denudation rate was measured at 5,515 $\mathrm{m} \mathrm{Myr}^{-1}$. The main Dobson and Hopkins rivers had denudation rates measured at 1,660 $\pm 148 \mathrm{~m} \mathrm{Myr}^{-1}$ and 3,340 $\pm 334 \mathrm{~m} \mathrm{Myr}^{-1}$ respectively. Results between the two rounds of ${ }^{10} \mathrm{Be}$ analysis illustrates the importance of careful and precise physical and chemical sample preparation, including the distillation of acids prior to use.

An investigation into a potential grain size variability across the grain size fractions 125 $500 \mu \mathrm{m}, 500 \mu \mathrm{m}-1 \mathrm{~mm}, 1 \mathrm{~mm}-8 \mathrm{~mm}$ and $>8 \mathrm{~mm}$ resulted in denudation rates that varied from $3,000 \pm 287-7,570 \pm 941 \mathrm{~m} \mathrm{Myr}^{-1}$. The discrepancy between grain size fractions most likely represents variable natural processes in the upper Dobson Valley and how this variability can greatly affect denudation rate results. There was a potential grain size variability identified of up to a factor of 2.5 , demonstrating importance of sampling consistent grain sizes in studies.

Correlation between mean annual precipitation (MAP) and denudation rates in the Ōhau catchment showed the only significant relationship amongst catchment characteristics. MAP and denudation rates had a moderate correlation with $\mathrm{R}^{2}=0.459$. These results are similar to trends identified at local and regional scales across other research globally and is likely the result of intense orographic precipitation across the Southern Alps. Denudation rates for the Dobson and Hopkins rivers were less than half that of sedimentation rates measured in Lake Ōhau. Discrepancy in rates may be a result of a slowing of denudation since the last glacial maximum at $17 \mathrm{ka}$, recent anthropogenic change and additional tributaries flowing into Lake Ōhau accumulating sediment.

Immobile element-derived chemical depletion fraction partitioning of physical erosion and chemical weathering from total denudation show rates in the upper Dobson Valley are 5,231 $\mathrm{m} \mathrm{Myr}^{-1}$ and 2,339 $\mathrm{m} \mathrm{Myr}^{-1}$ respectively. Assuming the CDF is valid for a soil in the Dobson catchment is 0.3 , implying that $30 \%$ of total denudation is through chemical weathering. Partitioning for the entire Dobson River catchment resulted in physical 
erosion of 1,147 $\mathrm{m} \mathrm{Myr}^{-1}$ and chemical weathering of $512 \mathrm{~m} \mathrm{Myr}^{-1}$. Chemical weathering rates in the upper Dobson Valley are high due to the remarkably high physical erosion rates measured and is consistent with previous research in the Southern Alps, suggesting that total weathering is not limited by reaction kinetics as previously thought.

Denudation rates and partitioned physical erosion and chemical weathering results from the Dobson River catchment are consistent with previous research in the Southern Alps using ${ }^{10} \mathrm{Be}$. Comparison with suspended sediment yields, however, shows that long-term denudation rates from the Ōhau catchment are much higher. Denudation rates from the Ōhau catchment are likely much higher as a result of the exclusion of river bedloads in suspended sediment yield research, which is an important sediment transport mechanism in tectonically active landscapes. ${ }^{10} \mathrm{Be}$ derived denudation rates may also be higher due to the contribution of high magnitude events such as co-seismic landsliding in long-term denudation rate measurements. Smoothing of low frequency, high magnitude events highlights the importance of using ${ }^{10} \mathrm{Be}$ derived long-term denudation rate measurements.

High denudation rate measurements from the Ōhau catchment, New Zealand highlight the importance of research in wet, tectonically active mountain landscapes. Rapid physical erosion in the Southern Alps results in high chemical weathering rates and, thus rapid consumption of atmospheric $\mathrm{CO}_{2}$. Extreme orographic precipitation, fast tectonic uplift and intense biological processes all result in the Southern Alps having some of the highest denudation rates in the world. Further research in active margins such as the Southern Alps is important for further understanding orogen scale weathering fluxes. 


\section{References}

Adams, J. (1979). Sediment loads of North Island rivers, New Zealand-a reconnaissance. Journal of Hydrology, 36-48.

Adams, J. (1980). Contemporary uplift and erosion of the Southern Alps, New Zealand. Geological Society of America Bulletin, 91. 1-114.

Balco, G. (2017). Production rate calculations for cosmic-ray-muon-produced ${ }^{10} \mathrm{Be}$ and ${ }^{26} \mathrm{Al}$ benchmarked against geological calibration data. Quaternary Geochronology, 39, 150-173.

Balco, G., Stone, J. O., Lifton, N. A., \& Dunai, T. J. (2008). A complete and easily accessible means of calculating surface exposure ages or erosion rates from ${ }^{10} \mathrm{Be}$ and ${ }^{26} \mathrm{Al}$ measurements. Quaternary Geochronology, 3(3), 174-195.

Barrell, D. (2011). Quaternary glaciers of New Zealand. In Developments in Quaternary Sciences (Vol. 15, pp. 1047-1064): Elsevier.

Basher, L., Hicks, D., Clapp, B., \& Hewitt, T. (2011). Sediment yield response to large storm events and forest harvesting, Motueka River, New Zealand. New Zealand Journal of Marine Freshwater Research, 45(3), 333-356.

Basher, L., Tonkin, P., \& McSaveney, M. (1988). Geomorphic history of a rapidly uplifting area on a compressional plate boundary: Cropp River, New Zealand. Zeitschrift für Geomorphologie, 69, 117-131.

Berner, R. A., Lasaga, A. C., \& Garrels, R. M. (1983). The carbonate-silicate geochemical cycle and its effect on atmospheric carbon dioxide over the past 100 million years. American Journal of Science, 283, 641-683.

Berner, R. A., \& Raiswell, R. (1983). Burial of organic carbon and pyrite sulfur in sediments over Phanerozoic time: a new theory. Geochimica et Cosmochimica Acta, 47(5), 855-862.

Bierman, P. R., \& Steig, E. J. (1996). Estimating rates of denudation using cosmogenic isotope abundances in sediment. Earth surface processes landforms, 21(2), 125139.

Binnie, S. A., Phillips, W. M., Summerfield, M. A., \& Fifield, L. K. (2007). Tectonic uplift, threshold hillslopes, and denudation rates in a developing mountain range. Geology, 35(8), 743-746.

Brantley, S. L., \& White, A. F. (2009). Approaches to modeling weathered regolith. Reviews in Mineralogy Geochemistry, Geophysics, Geosystems, 70(1), 435-484.

Brault, M.-O., Matthews, H. D., \& Mysak, L. A. (2017). The importance of terrestrial weathering changes in multimillennial recovery of the global carbon cycle: a twodimensional perspective. Earth System Dynamics, 8(2), 455-475. doi:10.5194/esd-8-455-2017 
Brown, E. T., Stallard, R. F., Larsen, M. C., Raisbeck, G. M., \& Yiou, F. (1995). Denudation rates determined from the accumulation of in situ-produced ${ }^{10} \mathrm{Be}$ in the Luquillo Experimental Forest, Puerto Rico. Earth Planetary Science Letters, 129(1-4), 193-202.

Bull, W. B. (1996). Prehistorical earthquakes on the Alpine fault, New Zealand. Journal of Geophysical Research: Solid Earth, 101(B3), 6037-6050.

Burbank, D. W., Leland, J., Fielding, E., Anderson, R. S., Brozovic, N., Reid, M. R., \& Duncan, C. (1996). Bedrock incision, rock uplift and threshold hillslopes in the northwestern Himalayas. Nature, 379(6565), 505-510.

Burdis, A. J. (2014). Denudation rates derived from spatially-averaged cosmogenic nuclide analysis in Nelson/Tasman catchments, South Island, New Zealand.

Calmels, D., Galy, A., Hovius, N., Bickle, M., West, A. J., Chen, M.-C., \& Chapman, H. (2011). Contribution of deep groundwater to the weathering budget in a rapidly eroding mountain belt, Taiwan. Earth Planetary Science Letters, 303(1-2), 48-58.

Casagli, N., Ermini, L., \& Rosati, G. (2003). Determining grain size distribution of the material composing landslide dams in the Northern Apennines: sampling and processing methods. Engineering geology, 69(1-2), 83-97.

Cerling, T. E., \& Craig, H. (1994a). Cosmogenic 3He production rates from $39 \mathrm{~N}$ to 46 N latitude, western USA and France. Geochimica et Cosmochimica Acta, 58(1), 249-255.

Cerling, T. E., \& Craig, H. (1994b). Geomorphology and in-situ cosmogenic isotopes. Annual Review of Earth and Planetary Sciences, 22(1), 273-317.

Champagnac, J.-D., Molnar, P., Anderson, R., Sue, C., \& Delacou, B. (2007). Quaternary erosion-induced isostatic rebound in the western Alps. Geology, 35(3), 195-198.

Champagnac, J.-D., Schlunegger, F., Norton, K., von Blanckenburg, F., Abbühl, L. M., \& Schwab, M. (2009). Erosion-driven uplift of the modern Central Alps. Tectonophysics, 474(1-2), 236-249.

Chmeleff, J., von Blanckenburg, F., Kossert, K., \& Jakob, D. (2010). Determination of the $10 \mathrm{Be}$ half-life by multicollector ICP-MS and liquid scintillation counting. Nuclear Instruments and Methods in Physics Research Section B: Beam Interactions with Materials and Atoms, 268(2), 192-199.

Clapp, E. M., Bierman, P. R., Nichols, K. K., Pavich, M., \& Caffee, M. (2001). Rates of sediment supply to arroyos from upland erosion determined using in situ produced cosmogenic 10Be and 26Al. Quaternary Research, 55(2), 235-245.

Clarke, B. A., \& Burbank, D. W. (2011). Quantifying bedrock-fracture patterns within the shallow subsurface: Implications for rock mass strength, bedrock landslides, and erodibility. Journal of Geophysical Research: Earth Surface, 116(F4).

Codilean, A. T. (2006). Calculation of the cosmogenic nuclide production topographic shielding scaling factor for large areas using DEMs. Earth Surface Processes and Landforms, 31(6), 785-794. 
Corbett, L. B., Bierman, P. R., \& Rood, D. H. (2016). An approach for optimizing in situ cosmogenic 10Be sample preparation. Quaternary Geochronology, 33, $24-34$.

Cox, S. C., \& Barrell, D. J. A. (2008). Geology of the Aoraki Area: Scale 1: 250000: GNS Science.

Dalai, T., Krishnaswami, S., \& Sarin, M. (2002). Major ion chemistry in the headwaters of the Yamuna river system:: Chemical weathering, its temperature dependence and $\mathrm{CO} 2$ consumption in the Himalaya. Geochimica et Cosmochimica Acta, 66(19), 3397-3416.

Darvill, C. M. (2013). Cosmogenic nuclide analysis. Geomorphological techniques, 125.

Desilets, D., Zreda, M., \& Prabu, T. (2006). Extended scaling factors for in situ cosmogenic nuclides: new measurements at low latitude. Earth and Planetary Science Letters, 246(3-4), 265-276.

DiBiase, R. A., \& Whipple, K. X. (2011). The influence of erosion thresholds and runoff variability on the relationships among topography, climate, and erosion rate. Journal of Geophysical Research: Earth Surface, 116(F4).

Diehl, R., Halloin, H., Kretschmer, K., Lichti, G. G., Schönfelder, V., Strong, A. W., . . Knödlseder, J. (2006). Radioactive 26 Al from massive stars in the Galaxy. Nature, 439(7072), 45-47.

Dietrich, W. E., Reiss, R., Hsu, M. L., \& Montgomery, D. R. (1995). A process-based model for colluvial soil depth and shallow landsliding using digital elevation data. Hydrological processes, 9(3-4), 383-400.

Dixon, J. L., Chadwick, O. A., \& Vitousek, P. M. (2016). Climate-driven thresholds for chemical weathering in postglacial soils of New Zealand. Journal of Geophysical Research: Earth Surface, 121(9), 1619-1634.

Dixon, J. L., Hartshorn, A. S., Heimsath, A. M., DiBiase, R. A., \& Whipple, K. X. (2012). Chemical weathering response to tectonic forcing: A soils perspective from the San Gabriel Mountains, California. Earth Planetary Science Letters, 323, 40-49.

Dixon, J. L., Heimsath, A. M., Kaste, J., \& Amundson, R. (2009). Climate-driven processes of hillslope weathering. Geology, 37(11), 975-978.

Dixon, J. L., \& von Blanckenburg, F. (2012). Soils as pacemakers and limiters of global silicate weathering. Comptes Rendus Geoscience, 344(11-12), 597-609.

Dowling, L. (2019). The Holocene Glacial History of Dart Glacier, Southern Alps, New Zealand. (Master of Science), Victoria University of Wellington,

Dunai, T. J. (2001). Influence of secular variation of the geomagnetic field on production rates of in situ produced cosmogenic nuclides. Earth Planetary Science Letters, 193(1-2), 197-212.

Dunai, T. J. (2010). Cosmogenic Nuclides: Principles, concepts and applications in the Earth surface sciences: Cambridge University Press. 
Dunai, T. J., \& Lifton, N. A. (2014). The nuts and bolts of cosmogenic nuclide production. Elements, 10(5), 347-350.

Ferrier, K. L., \& Kirchner, J. W. (2008). Effects of physical erosion on chemical denudation rates: A numerical modeling study of soil-mantled hillslopes. Earth Planetary Science Letters, 272(3-4), 591-599.

Ferrier, K. L., Riebe, C. S., \& Hahm, J. (2016). Testing for supply-limited and kineticlimited chemical erosion in field measurements of regolith production and chemical depletion. Geochemistry, Geophysics, Geosystems, 17(6), 2270-2285.

Fuller, C. W., Willett, S. D., Hovius, N., \& Slingerland, R. (2003). Erosion rates for Taiwan mountain basins: New determinations from suspended sediment records and a stochastic model of their temporal variation. The Journal of geology, 111(1), 71-87.

Gabet, E. J. (2007). A theoretical model coupling chemical weathering and physical erosion in landslide-dominated landscapes. Earth Planetary Science Letters, 264(1-2), 259-265.

Gabet, E. J., Burbank, D. W., Putkonen, J. K., Pratt-Sitaula, B. A., \& Ojha, T. (2004). Rainfall thresholds for landsliding in the Himalayas of Nepal. Geomorphology, 63(3-4), 131-143.

Gabet, E. J., \& Mudd, S. M. (2009). A theoretical model coupling chemical weathering rates with denudation rates. Geology, 37(2), 151-154. doi:10.1130/g25270a.1

Gaillardet, J., Dupré, B., Louvat, P., \& Allegre, C. (1999). Global silicate weathering and $\mathrm{CO} 2$ consumption rates deduced from the chemistry of large rivers. Chemical geology, 159(1-4), 3-30.

Gaillardet, J., \& Galy, A. (2008). Himalaya-carbon sink or source? Science, 320(5884), 1727.

Galy, A., \& France-Lanord, C. (2001). Higher erosion rates in the Himalaya: Geochemical constraints on riverine fluxes. Geology, 29(1), 23-26.

Gosse, J. C., \& Phillips, F. M. (2001). Terrestrial in situ cosmogenic nuclides: theory and application. Quaternary Science Reviews, 20(14), 1475-1560.

Goudie, A. S., \& Viles, H. A. (2012). Weathering and the global carbon cycle: geomorphological perspectives. Earth-Science Reviews, 113(1-2), 59-71.

Granger, D. E., Kirchner, J. W., \& Finkel, R. (1996). Spatially averaged long-term erosion rates measured from in situ-produced cosmogenic nuclides in alluvial sediment. The Journal of geology, 104(3), 249-257.

Griffiths, G. (1979). High sediment yields from major rivers of the western Southern Alps, New Zealand. Nature, 282(5734), 61-63.

Griffiths, G. (1981). Some Suspended Sediment Yields From South Island Catchments, New Zealand 1. Journal of the American Water Resources Association, 17(4), 662-671. 
Griffiths, G., \& Glasby, G. (1985). Input of river-derived sediment to the New Zealand continental shelf: I. Mass. Estuarine, coastal shelf science, 21(6), 773-787.

Hales, T., \& Roering, J. (2005). Climate-controlled variations in scree production, Southern Alps, New Zealand. Geology, 33(9), 701-704.

Hallet, B., Hunter, L., \& Bogen, J. (1996). Rates of erosion and sediment evacuation by glaciers: A review of field data and their implications. Global Planetary Change, 12(1-4), 213-235.

Heimsath, A. M., DiBiase, R. A., \& Whipple, K. X. (2012). Soil production limits and the transition to bedrock-dominated landscapes. Nature Geoscience, 5(3), 210214.

Heimsath, A. M., Dietrich, W. E., Nishiizumi, K., \& Finkel, R. C. (1997). The soil production function and landscape equilibrium. Nature, 388(6640), 358-361.

Henderson, R. (1993). Extreme storm rainfalls in the southern Alps, New Zealand. 113113.

Herman, F., \& Champagnac, J. D. (2016). Plio-Pleistocene increase of erosion rates in mountain belts in response to climate change. Terra Nova, 28(1), 2-10.

Hewitt, A. E. (2010). New Zealand soil classification. Landcare Research Science Series(No.1), $136 \mathrm{pp}$.

Hicks, D. M., Gomez, B., \& Trustrum, N. A. (2000). Erosion thresholds and suspended sediment yields, Waipaoa River basin, New Zealand. J Water Resources Research, 36(4), 1129-1142.

Hicks, D. M., Shankar, U., McKerchar, A. I., Basher, L., Lynn, I., Page, M., \& Jessen, M. (2011). Suspended sediment yields from New Zealand rivers. Journal of Hydrology, 81-142.

Hilley, G., Chamberlain, C., Moon, S., Porder, S., \& Willett, S. (2010). Competition between erosion and reaction kinetics in controlling silicate-weathering rates. Earth Planetary Science Letters, 293(1-2), 191-199.

Hilton, R. G., Meunier, P., Hovius, N., Bellingham, P. J., \& Galy, A. (2011). Landslide impact on organic carbon cycling in a temperate montane forest. Earth surface processes landforms, 36(12), 1670-1679.

Howarth, J. D., Fitzsimons, S. J., Norris, R. J., \& Jacobsen, G. E. (2012). Lake sediments record cycles of sediment flux driven by large earthquakes on the Alpine fault, New Zealand. Geology, 40(12), 1091-1094.

Ivy-Ochs, S., \& Kober, F. (2008). Surface exposure dating with cosmogenic nuclides. Quaternary Science Journal, 57(1-2), 179-209.

Ivy-Ochs, S., Schäfer, J., Kubik, P. W., Synal, H.-A., \& Schlüchter, C. (2004). Timing of deglaciation on the northern Alpine foreland (Switzerland). Eclogae Geologicae Helvetiae, 97(1), 47-55. 
Jacobson, A. D., \& Blum, J. D. (2003). Relationship between mechanical erosion and atmospheric $\mathrm{CO} 2$ consumption in the New Zealand Southern Alps. Geology, $31(10), 865-868$.

Jacobson, A. D., Blum, J. D., Chamberlain, C. P., Craw, D., \& Koons, P. O. (2003). Climatic and tectonic controls on chemical weathering in the New Zealand Southern Alps. Geochimica et Cosmochimica Acta, 67(1), 29-46.

Kirchner, J., Granger, D., \& Riebe, C. (1997). Cosmogenic isotope methods for measuring catchment erosion and weathering rates. Paper presented at the $\mathrm{J}$. Conf. Abstr.

Koons, P. (1989). The topographic evolution of collisional mountain belts; a numerical look at the Southern Alps, New Zealand. American Journal of Science, 289(9), 1041-1069.

Korschinek, G., Bergmaier, A., Faestermann, T., Gerstmann, U., Knie, K., Rugel, G., . . . Von Gostomski, C. L. (2010). A new value for the half-life of 10Be by heavyion elastic recoil detection and liquid scintillation counting. Nuclear Instruments and Methods in Physics Research Section B: Beam Interactions with Materials and Atoms, 268(2), 187-191.

Korup, O. (2005). Large landslides and their effect on sediment flux in South Westland, New Zealand. Earth Surface Processes Landforms: The Journal of the British Geomorphological Research Group, 30(3), 305-323.

Kump, L. R., Brantley, S. L., \& Arthur, M. A. (2000). Chemical weathering, atmospheric CO2, and climate. Annual Review of Earth Planetary Sciences, 28(1), 611-667.

Lal, D. (1988). In situ-produced cosmogenic isotopes in terrestrial rocks. Annual Review of Earth and Planetary Sciences, 16(1), 355-388.

Lal, D. (1991). Cosmic ray labeling of erosion surfaces: in situ nuclide production. Earth Planetary Science Letters, 104, 424-439.

Larsen, I. J., Almond, P. C., Eger, A., Stone, J. O., Montgomery, D. R., \& Malcolm, B. (2014). Rapid soil production and weathering in the Southern Alps, New Zealand. Science, 343(6171), 637-640.

Lifton, N. A., Bieber, J. W., Clem, J. M., Duldig, M. L., Evenson, P., Humble, J. E., \& Pyle, R. (2005). Addressing solar modulation and long-term uncertainties in scaling secondary cosmic rays for in situ cosmogenic nuclide applications. Earth and Planetary Science Letters, 239(1-2), 140-161.

Lifton, N. A., Sato, T., \& Dunai, T. J. (2014). Scaling in situ cosmogenic nuclide production rates using analytical approximations to atmospheric cosmic-ray fluxes. Earth and Planetary Science Letters, 386, 149-160.

Little, T. A., Cox, S., Vry, J. K., \& Batt, G. (2005). Variations in exhumation level and uplift rate along the obliqu-slip Alpine fault, central Southern Alps, New Zealand. Geological Society of America Bulletin, 117(5-6), 707-723. 
Lukens, C. E., Riebe, C. S., Sklar, L. S., \& Shuster, D. L. (2016). Grain size bias in cosmogenic nuclide studies of stream sediment in steep terrain. Journal of Geophysical Research: Earth Surface, 121(5), 978-999.

Lyons, W. B., Carey, A. E., Hicks, D. M., \& Nezat, C. A. (2005). Chemical weathering in high-sediment-yielding watersheds, New Zealand. Journal of Geophysical Research: Earth Surface, 110(F1).

Macara. (2016a). The climate and weather of Canterbury: NIWA, Taihoro Nukurangi.

Macara. (2016b). The climate and weather of West Coast. NIWA, Taihoro Nukurangi.

Marrero, S. M., Phillips, F. M., Borchers, B., Lifton, N., Aumer, R., \& Balco, G. (2016). Cosmogenic nuclide systematics and the CRONUScalc program. Quaternary Geochronology, 31, 160-187.

Masarik, J., \& Reedy, R. C. (1995). Terrestrial cosmogenic-nuclide production systematics calculated. Earth and Planetary Science Letters, 136, 381-395.

Matmon, A., Bierman, P. R., Larsen, J., Southworth, S., Pavich, M., Finkel, R., \& Caffee, M. (2005). Grain size dependency of 10 Be concentrations in alluvial sediments in the Great Smoky mountains. Geochmica et Cosmochimica Acta, 69(10), A160.

McGlone, M., \& Moar, N. (1998). Dryland Holocene vegetation history, Central Otago and the Mackenzie Basin, South Island, New Zealand. New Zealand Journal of Botany, 36(1), 91-111.

Meunier, P., Hovius, N., \& Haines, J. A. (2008). Topographic site effects and the location of earthquake induced landslides. Earth Planetary Science Letters, 275(3-4), 221232.

Milliman, J. D., \& Syvitski, J. P. (1992). Geomorphic/tectonic control of sediment discharge to the ocean: the importance of small mountainous rivers. Geology, $100(5), 525-544$.

Molnar, P. (2004a). Late Cenozoic increase in accumulation rates of terrestrial sediment: How might climate change have affected erosion rates? Annu. Rev. Earth Planet. Sci., 32, 67-89.

Molnar, P. (2004b). Late Cenozoic increase in accumulation rates of terrestrial sediment: How might climate change have affected erosion rates? , 32, 67-89.

Molnar, P., \& England, P. (1990). Late Cenozoic uplift of mountain ranges and global climate change: chicken or egg? Nature, 346(6279), 29-34.

Montgomery, D. R. (2001). Slope distributions, threshold hillslopes, and steady-state topography. American Journal of Science, 301(4-5), 432-454.

Montgomery, D. R. (2002). Valley formation by fluvial and glacial erosion. Geology American Journal of science, 30(11), 1047-1050. 
Montgomery, D. R., \& Brandon, M. T. (2002). Topographic controls on erosion rates in tectonically active mountain ranges. Earth Planetary Science Letters, 201(3-4), 481-489.

Morel, P., Von Blanckenburg, F., Schaller, M., Kubik, P. W., \& Hinderer, M. (2003). Lithology, landscape dissection and glaciation controls on catchment erosion as determined by cosmogenic nuclides in river sediment (the Wutach Gorge, Black Forest). Terra Nova, 15(6), 398-404.

Mudd, S. M., Harel, M.-A., Hurst, M. D., Grieve, S. W., \& Marrero, S. M. (2016). The CAIRN method: automated, reproducible calculation of catchment-averaged denudation rates from cosmogenic nuclide concentrations. Earth Surface Dynamics, 4(3), 655-674.

Niemi, N. A., Oskin, M., Burbank, D. W., Heimsath, A. M., \& Gabet, E. J. (2005). Effects of bedrock landslides on cosmogenically determined erosion rates. Earth Planetary Science Letters, 237(3-4), 480-498.

Nishiizumi, K., Imamura, M., Caffee, M. W., Southon, J. R., Finkel, R. C., \& McAninch, J. (2007). Absolute calibration of 10Be AMS standards. 258(2), 403-413.

Nishiizumi, K., Winterer, E., Kohl, C., Klein, J., Middleton, R., Lal, D., \& Arnold, J. (1989). Cosmic ray production rates of $10 \mathrm{Be}$ and $26 \mathrm{Al}$ in quartz from glacially polished rocks. Journal of Geophysical Research: Solid Earth, 94(B12), 1790717915.

Norris, R. J., \& Cooper, A. F. (2001). Late Quaternary slip rates and slip partitioning on the Alpine Fault, New Zealand. Journal of Structural Geology, 23(2-3), 507-520.

Norton, K. P. (unpublished data). NZ River Denudation Rates. Unpublished Work.

Norton, K. P., \& Schlunegger, F. (2017). Lack of a weathering signal with increased Cenozoic erosion? Terra Nova, 29(5), 265-272.

Norton, K. P., \& von Blanckenburg, F. (2010). Silicate weathering of soil-mantled slopes in an active Alpine landscape. Geochimica et Cosmochimica Acta, 74(18), 52435258. doi:10.1016/j.gca.2010.06.019

Norton, K. P., von Blanckenburg, F., \& Kubik, P. W. (2010). Cosmogenic nuclidederived rates of diffusive and episodic erosion in the glacially sculpted upper Rhone Valley, Swiss Alps. Earth Surface Processes and Landforms: The Journal of the British Geomorphological Research Group, 35(6), 651-662.

Norton, K. P., von Blanckenburg, F., Schlunegger, F., Schwab, M., \& Kubik, P. W. (2008). Cosmogenic nuclide-based investigation of spatial erosion and hillslope channel coupling in the transient foreland of the Swiss Alps. Geomorphology, 95(3-4), 474-486.

O'Loughlin, C. L., Rowe, L. K., \& Pearce, A. J. (1978). Sediment yields from small forested catchments north Westland-Nelson, New Zealand. Journal of Hydrology, 1-15. 
Palumbo, L., Hetzel, R., Tao, M., \& Li, X. (2010). Topographic and lithologic control on catchment-wide denudation rates derived from cosmogenic 10Be in two mountain ranges at the margin of NE Tibet. Geomorphology, 117(1-2), 130-142.

Portenga, E. W., \& Bierman, P. R. (2011). Understanding Earth's eroding surface with 10 Be. GSA today, 21(8), 4-10.

Puchol, N., Lavé, J., Lupker, M., Blard, P.-H., Gallo, F., France-Lanord, C., \& Team, A. (2014). Grain-size dependent concentration of cosmogenic 10Be and erosion dynamics in a landslide-dominated Himalayan watershed. Geomorphology, 224, $55-68$.

Putnam, A. E., Schaefer, J., Barrell, D., Vandergoes, M., Denton, G., Kaplan, M., . . . Kelley, S. (2010). In situ cosmogenic 10Be production-rate calibration from the Southern Alps, New Zealand. Quaternary Geochronology, 5(4), 392-409.

Putnam, A. E., Schaefer, J. M., Denton, G. H., Barrell, D. J., Birkel, S. D., Andersen, B. G., .. Doughty, A. M. (2013). The last glacial maximum at $44 \mathrm{~S}$ documented by a 10Be moraine chronology at Lake Ohau, Southern Alps of New Zealand. Quaternary Science Reviews, 62, 114-141.

Quigley, M., Sandiford, M., Fifield, L. K., \& Alimanovic, A. (2007). Landscape responses to intraplate tectonism: Quantitative constraints from $10 \mathrm{Be}$ nuclide abundances. Earth Planetary Science Letters, 261(1-2), 120-133.

Rasmussen, C., Brantley, S., Richter, D. d., Blum, A., Dixon, J., \& White, A. F. (2011). Strong climate and tectonic control on plagioclase weathering in granitic terrain. Earth Planetary Science Letters, 301(3-4), 521-530.

Raymo, M. E., \& Ruddiman, W. F. (1992). Tectonic forcing of late Cenozoic climate. Nature, 359(6391), 117-122.

Raymo, M. E., Ruddiman, W. F., \& Froelich, P. N. (1988). Influence of late Cenozoic mountain building on ocean geochemical cycles. Geology, 16(7), 649-653.

Riebe, C. S., Kirchner, J. W., \& Finkel, R. C. (2003). Long-term rates of chemical weathering and physical erosion from cosmogenic nuclides and geochemical mass balance. Geochimica et Cosmochimica Acta, 67(22), 4411-4427.

Riebe, C. S., Kirchner, J. W., \& Finkel, R. C. (2004a). Erosional and climatic effects on long-term chemical weathering rates in granitic landscapes spanning diverse climate regimes. Earth Planetary Science Letters, 224(3-4), 547-562.

Riebe, C. S., Kirchner, J. W., \& Finkel, R. C. (2004b). Sharp decrease in long-term chemical weathering rates along an altitudinal transect. Earth Planetary Science Letters, 218(3-4), 421-434.

Riebe, C. S., Kirchner, J. W., Granger, D. E., \& Finkel, R. C. (2001a). Minimal climatic control on erosion rates in the Sierra Nevada, California. Geology, 29(5), 447450 . 
Riebe, C. S., Kirchner, J. W., Granger, D. E., \& Finkel, R. C. (2001b). Strong tectonic and weak climatic control of long-term chemical weathering rates. Geology, 29(6), 511-514.

Riebe, C. S., Sklar, L. S., Lukens, C. E., \& Shuster, D. L. (2015). Climate and topography control the size and flux of sediment produced on steep mountain slopes. Proceedings of the National Academy of Sciences, 112(51), 15574-15579.

Roering, J. J. (2008). How well can hillslope evolution models "explain" topography? Simulating soil transport and production with high-resolution topographic data. Geological Society of America Bulletin, 120(9-10), 1248-1262.

Roering, J. J., Almond, P., Tonkin, P., \& McKean, J. (2004). Constraining climatic controls on hillslope dynamics using a coupled model for the transport of soil and tracers: Application to loess-mantled hillslopes, South Island, New Zealand. Journal of Geophysical Research: Earth Surface, 109(F1).

Roering, J. J., Kirchner, J. W., \& Dietrich, W. E. (1999). Evidence for nonlinear, diffusive sediment transport on hillslopes and implications for landscape morphology. Water Resources Research, 35(3), 853-870.

Roering, J. J., Kirchner, J. W., \& Dietrich, W. E. (2001). Hillslope evolution by nonlinear, slope-dependent transport: Steady state morphology and equilibrium adjustment timescales. Journal of Geophysical Research: Solid Earth, 106(B8), 1649916513.

Roering, J. J., Marshall, J., Booth, A. M., Mort, M., \& Jin, Q. (2010). Evidence for biotic controls on topography and soil production. Earth Planetary Science Letters, 298(1-2), 183-190.

Roop, H. A., Dunbar, G. B., Levy, R., Vandergoes, M. J., Forrest, A. L., Walker, S. L., . . Whinney, J. (2015). Seasonal controls on sediment transport and deposition in Lake Ohau, South Island, New Zealand: Implications for a high-resolution Holocene palaeoclimate reconstruction. Sedimentology, 62(3), 826-844.

Ruddiman, W. F. (2010). A paleoclimatic enigma? Science, 328(5980), 838-839.

Sadler, P. (1999). The influence of hiatuses on sediment accumulation rates. Paper presented at the GeoResearch Forum.

Savi, S., Norton, K. P., Picotti, V., Akçar, N., Delunel, R., Brardinoni, F., . . Schlunegger, F. (2014). Quantifying sediment supply at the end of the last glaciation: Dynamic reconstruction of an alpine debris-flow fan. Geological Society of America Bulletin, 126(5-6), 773-790.

Savi, S., Tofelde, S., Wittmann, H., Castino, F., \& Schildgen, T. F. (2017). Determination limits for cosmogenic $10 \mathrm{Be}$ and their importance for geomorphic applications.

Schaller, M., von Blanckenburg, F., Hovius, N., \& Kubik, P. (2001). Large-scale erosion rates from in situ-produced cosmogenic nuclides in European river sediments. Earth Planetary Science Letters, 188(3-4), 441-458. 
Schildgen, T., Phillips, W., \& Purves, R. (2005). Simulation of snow shielding corrections for cosmogenic nuclide surface exposure studies. Geomorphology, 64(1-2), 6785 .

Schmidt, K. M., \& Montgomery, D. R. (1995). Limits to relief. Science, 270(5236), 617620.

Siame, L., Angelier, J., Chen, R.-F., Godard, V., Derrieux, F., Bourlès, D., . . Lee, J.-C. (2011). Erosion rates in an active orogen (NE-Taiwan): A confrontation of cosmogenic measurements with river suspended loads. Quaternary Geochronology, 6(2), 246-260.

Sklar, L. S., Riebe, C. S., Marshall, J. A., Genetti, J., Leclere, S., Lukens, C. L., \& Merces, V. (2017). The problem of predicting the size distribution of sediment supplied by hillslopes to rivers. Geomorphology, 277, 31-49. doi:10.1016/j.geomorph.2016.05.005

Smart, D., Shea, M., \& Flückiger, E. (2000). Magnetospheric models and trajectory computations. In Cosmic Rays and Earth (pp. 305-333): Springer.

Stallard, R. F. (1998). Terrestrial sedimentation and the carbon cycle: Coupling weathering and erosion to carbon burial. Global biogeochemical cycles, 12(2), 231-257.

Stallard, R. F., \& Edmond, J. (1983). Geochemistry of the Amazon: 2. The influence of geology and weathering environment on the dissolved load. Journal of Geophysical Research: Oceans, 88(C14), 9671-9688.

Stone, J. O. (2000). Air pressure and cosmogenic isotope production. Journal of Geophysical Research: Solid Earth, 105(B10), 23753-23759.

Suggate, R. (1978). The Geology of New Zealand (Vol. 2): EC Keating, Government Printer.

Suggate, R. (1990). Late pliocene and quaternary glaciations of New Zealand. Quaternary Science Reviews, 9(2-3), 175-197.

Summerfield, M., \& Hulton, N. (1994). Natural controls of fluvial denudation rates in major world drainage basins. Journal of Geophysical Research: Solid Earth, 99(B7), 13871-13883.

Sutherland, R., Berryman, K., \& Norris, R. (2006). Quaternary slip rate and geomorphology of the Alpine fault: Implications for kinematics and seismic hazard in southwest New Zealand. Geological Society of America Bulletin, 118(34), 464-474.

Sutherland, R., Eberhart-Phillips, D., Harris, R., Stern, T., Beavan, J., Ellis, S., . . . Berryman, K. (2007). Do great earthquakes occur on the Alpine fault in central South Island, New Zealand? GEOPHYSICAL MONOGRAPH-AMERICAN GEOPHYSICAL UNION, 175, 237. 
Tait, A., Henderson, R., Turner, R., \& Zheng, X. (2006). Thin plate smoothing spline interpolation of daily rainfall for New Zealand using a climatological rainfall surface. International Journal of Climatology: A Journal of the Royal Meteorological Society, 26(14), 2097-2115.

Thompson, S., \& Adams, J. (1979). Suspended load in some major rivers of New Zealand. Physical Hydrology.

Tippett, J. M., \& Kamp, P. J. (1993). Fission track analysis of the late Cenozoic vertical kinematics of continental Pacific crust, South Island, New Zealand. Journal of Geophysical Research: Solid Earth, 98(B9), 16119-16148.

van Dongen, R., Scherler, D., Wittmann, H., \& von Blanckenburg, F. (2019). Cosmogenic $10 \mathrm{Be}$ in river sediment: where grain size matters and why. Earth Surface Dynamics, 7, 393-410.

von Blanckenburg, F. (2005). The control mechanisms of erosion and weathering at basin scale from cosmogenic nuclides in river sediment. Earth Planetary Science Letters, 237(3-4), 462-479.

von Blanckenburg, F., Belshaw, N., \& O'Nions, R. (1996). Separation of ${ }^{9} \mathrm{Be}$ and cosmogenic ${ }^{10} \mathrm{Be}$ from environmental materials and SIMS isotope dilution analysis. Chemical geology, 129(1-2), 93-99.

Von Blanckenburg, F., Hewawasam, T., \& Kubik, P. W. (2004). Cosmogenic nuclide evidence for low weathering and denudation in the wet, tropical highlands of Sri Lanka. Journal of Geophysical Research: Earth Surface, 109(F3).

Wang, Q., Zhang, P.-Z., Freymueller, J. T., Bilham, R., Larson, K. M., You, X., . . Liu, J. (2001). Present-day crustal deformation in China constrained by global positioning system measurements. Science, 294(5542), 574-577.

Wellman, H., \& Willett, R. W. (1942). The geology of the west coast from Abut Head to Milford Sound.

West, A. J. (2012). Thickness of the chemical weathering zone and implications for erosional and climatic drivers of weathering and for carbon-cycle feedbacks. Geology, 40(9), 811-814.

West, A. J., Galy, A., \& Bickle, M. (2005). Tectonic and climatic controls on silicate weathering. Earth Planetary Science Letters, 235(1-2), 211-228.

Whipple, K. X., \& Meade, B. (2006). Orogen response to changes in climatic and tectonic forcing. Earth and Planetary Science Letters, 243(1-2), 218-228. doi:10.1016/j.epsl.2005.12.022

Whipple, K. X., \& Tucker, G. E. (1999). Dynamics of the stream-power river incision model: Implications for height limits of mountain ranges, landscape response timescales, and research needs. 104(B8), 17661-17674.

White, A. F., \& Blum, A. E. (1995). Effects of climate on chemical weathering in watersheds. Geochimica et Cosmochimica Acta, 59(9), 1729-1747. 
White, A. F., \& Brantley, S. L. (2003). The effect of time on the weathering of silicate minerals: why do weathering rates differ in the laboratory and field? Chemical geology, 202(3-4), 479-506.

Whitehouse, I. E. (1988). Geomorphology of the central Southern Alps, New Zealand: the interaction of plate collision and atmospheric circulation. Zeitschrift für Geomorphologie. Supplementband, 69, 105-116.

Willenbring, J. K., Codilean, A. T., Ferrier, K., McElroy, B., \& Kirchner, J. (2014). Earth is (mostly) flat, but mountains dominate global denudation: apportionment of the continental mass flux over millennial time scales, revisited.

Willenbring, J. K., \& Jerolmack, D. J. (2016). The null hypothesis: globally steady rates of erosion, weathering fluxes and shelf sediment accumulation during Late Cenozoic mountain uplift and glaciation. Terra Nova, 28(1), 11-18.

Willenbring, J. K., \& von Blanckenburg, F. (2010a). Long-term stability of global erosion rates and weathering during late-Cenozoic cooling. Nature, 465(7295), 211-214.

Willenbring, J. K., \& von Blanckenburg, F. (2010b). Meteoric cosmogenic Beryllium-10 adsorbed to river sediment and soil: Applications for Earth-surface dynamics. Earth-Science Reviews, 98(1-2), 105-122.

Willett, S. D. (1999). Orogeny and orography: The effects of erosion on the structure of mountain belts. Journal of Geophysical Research: Solid Earth, 104(B12), 2895728981.

Willett, S. D., \& Brandon, M. T. (2002). On steady states in mountain belts. 30(2), 175178.

Willett, S. D., Fisher, D., Fuller, C., En-Chao, Y., \& Chia-Yu, L. (2003). Erosion rates and orogenic-wedge kinematics in Taiwan inferred from fission-track thermochronometry. Geology, 31(11), 945-948.

Willett, S. D., Slingerland, R., \& Hovius, N. (2001). Uplift, Shortening, and Steady State Topography in Active Mountain Belts. American Journal of Science, 301(4-5), 455-485. doi:10.2475/ajs.301.4-5.455

Wittmann, H., von Blanckenburg, F., Kruesmann, T., Norton, K. P., \& Kubik, P. W. (2007). Relation between rock uplift and denudation from cosmogenic nuclides in river sediment in the Central Alps of Switzerland. Journal of Geophysical Research: Earth Surface, 112(F4).

Yanites, B. J., Tucker, G. E., \& Anderson, R. S. (2009). Numerical and analytical models of cosmogenic radionuclide dynamics in landslide-dominated drainage basins. Journal of Geophysical Research: Earth Surface, 114(F1).

Zachos, Pagani, M., Sloan, L., Thomas, E., \& Billups, K. (2001a). Trends, rhythms, and aberrations in global climate $65 \mathrm{Ma}$ to present. 292(5517), 686-693. 
Zachos, Shackleton, N. J., Revenaugh, J. S., Pälike, H., \& Flower, B. P. (2001b). Climate response to orbital forcing across the Oligocene-Miocene boundary. 292(5515), 274-278. 
Appendix A. 1. Results of catchment-averaged denudation rates (erosion rate) calculated by the online earth calculator (version 2.3) (Balco et al., 2008) using the Lal/St scaling scheme (D. Lal, 1991; Stone, 2000). The process blank DOB19-B01 was used for DOB19-02, DOB19-04, all DOB19-08 and both DOB19-16 samples. The DOB19-B02 process blank was used for DOB1924, Dobson and Hopkins and the DOB19-B03 process blank was used for DOB19-20.

\begin{tabular}{|c|c|c|c|c|c|c|c|c|}
\hline Sample ID & $\begin{array}{l}{ }^{10} \mathrm{Be} \\
\text { conc. } \\
\left(10^{3}\right)\end{array}$ & $\begin{array}{l}{ }^{10} \mathrm{Be} \\
\text { conc. } \\
\left(10^{3}\right)\end{array}$ & $\begin{array}{c}\text { Internal } \\
\text { uncertainty } \\
\left(\mathrm{m} \mathrm{Myr}^{-1}\right)\end{array}$ & $\begin{array}{l}\text { Erosion rate } \\
\left(\mathrm{g} \mathrm{cm}^{2} \mathrm{yr}^{-1}\right)\end{array}$ & $\begin{array}{c}\text { Erosion rate } \\
\left(\mathrm{m} \mathrm{Myr}^{-1}\right)\end{array}$ & $\begin{array}{c}\text { External } \\
\text { uncertainty } \\
\left(\mathrm{m} \mathrm{Myr}^{-1}\right)\end{array}$ & $\begin{array}{l}\text { Production } \\
\text { rate } \\
\text { (spallation) } \\
\left(\text { at g }^{-1} \mathrm{yr}^{-1}\right)\end{array}$ & $\begin{array}{c}\text { Production } \\
\text { rate } \\
\text { (muons) } \\
\left(\text { at g }^{-1} \mathrm{yr}^{-1}\right)\end{array}$ \\
\hline DOB19-02 & 3.041 & 0.265 & 291.38 & 0.87898 & 3316.92 & 386.78 & 13.51 & 0.123 \\
\hline DOB19-04 & 0.906 & 0.396 & 6571.34 & 3.22056 & 12153.05 & 6638.04 & 14.85 & 0.128 \\
\hline DOB19-08_1 & 2.586 & 0.248 & 456 & 1.24696 & 4705.49 & 585.02 & 16.57 & 0.134 \\
\hline DOB19-08_2 & 4.797 & 0.258 & 136.86 & 0.67197 & 2535.73 & 240.33 & 16.57 & 0.134 \\
\hline DOB19-08_3 & 4.675 & 0.3 & 168.16 & 0.68945 & 2601.69 & 263.37 & 16.57 & 0.134 \\
\hline DOB19-08_4 & 2.938 & 0.37 & 531.66 & 1.09902 & 4147.24 & 622.09 & 16.57 & 0.134 \\
\hline DOB19-16_1 & 9.483 & 0.373 & 46.79 & 0.31408 & 1185.21 & 103.06 & 15.2 & 0.129 \\
\hline DOB19-16_2 & 10.261 & 0.373 & 39.84 & 0.28985 & 1093.78 & 93.66 & 15.2 & 0.129 \\
\hline DOB19-20 & 24.241 & 0.748 & 14.61 & 0.12517 & 472.36 & 39.55 & 15.57 & 0.131 \\
\hline DOB19-24 & 4.729 & 0.212 & 103.6 & 0.61103 & 2305.77 & 206.03 & 14.72 & 0.127 \\
\hline DOBSON & 6.244 & 0.251 & 62.41 & 0.41055 & 1549.26 & 133.88 & 12.91 & 0.121 \\
\hline HOPKINS & 3.677 & 0.225 & 162.68 & 0.70171 & 2647.95 & 259.71 & 13 & 0.121 \\
\hline
\end{tabular}



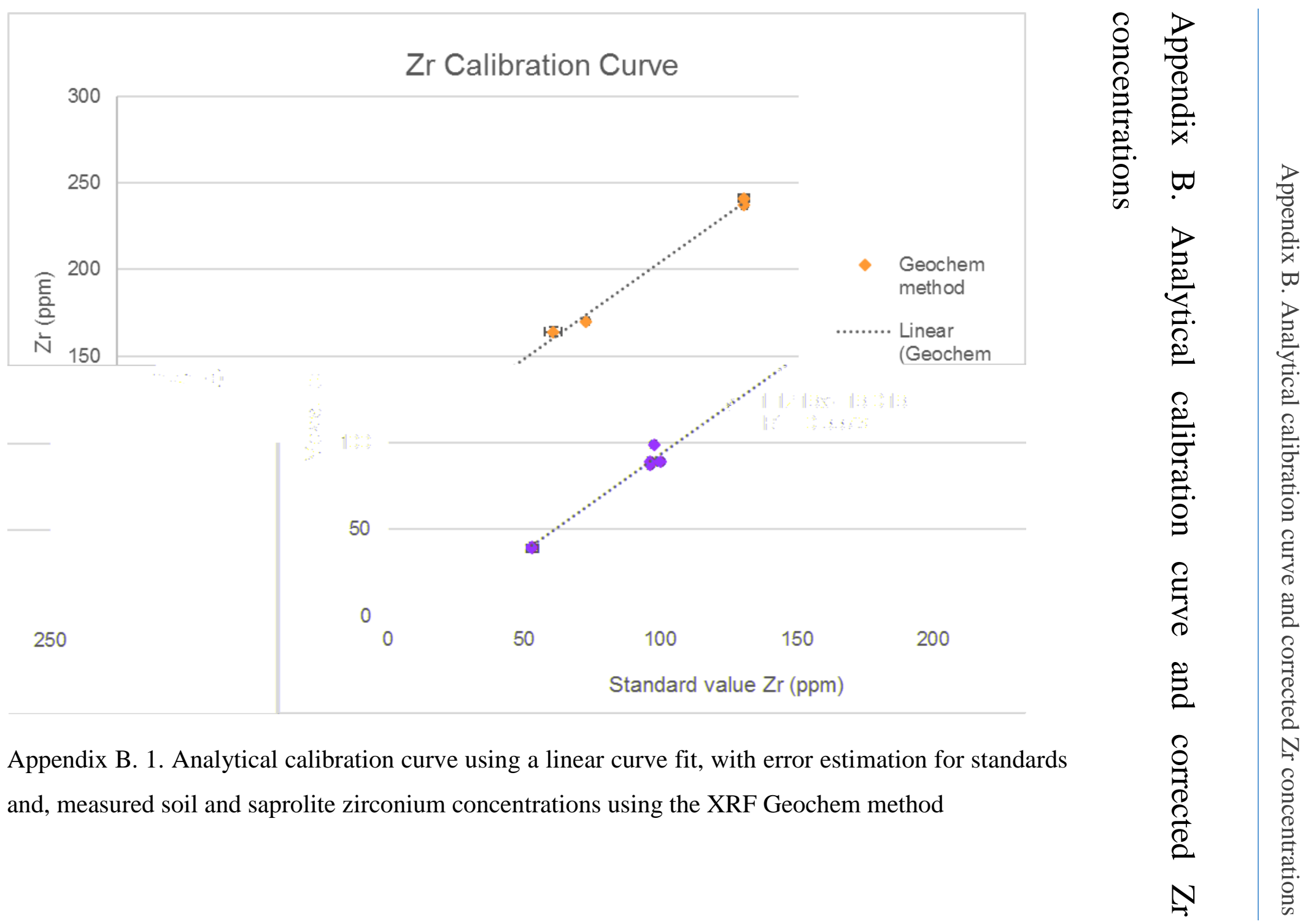

Appendix B. 1. Analytical calibration curve using a linear curve fit, with error estimation for standards and, measured soil and saprolite zirconium concentrations using the XRF Geochem method 
Appendix B. Analytical calibration curve and corrected $\mathrm{Zr}$ concentrations

Appendix B. 2. Table of corrected zirconium concentrations for soil and saprolite subsamples.

\begin{tabular}{|c|c|}
\hline Sample ID & $\begin{array}{l}\text { Corrected Zr } \\
\text { concentration }\end{array}$ \\
\hline 11-A1 & 269 \\
\hline $11-\mathrm{A} 2$ & 283 \\
\hline $11-\mathrm{A} 3$ & 273 \\
\hline 11-B1 & 157 \\
\hline 11-B2 & 167 \\
\hline 11-B3 & 167 \\
\hline $11-\mathrm{C} 1$ & 140 \\
\hline $11-\mathrm{C} 2$ & 151 \\
\hline $11-\mathrm{C} 3$ & 149 \\
\hline $12-\mathrm{A} 1$ & 297 \\
\hline $12-\mathrm{A} 2$ & 296 \\
\hline $12-\mathrm{A} 3$ & 314 \\
\hline 12-B1 & 318 \\
\hline 12-B2 & 324 \\
\hline 12-B3 & 331 \\
\hline $12-\mathrm{C} 1$ & 262 \\
\hline $12-\mathrm{C} 2$ & 251 \\
\hline $12-\mathrm{C} 3$ & 284 \\
\hline $15-\mathrm{A} 1$ & 298 \\
\hline $15-\mathrm{A} 2$ & 297 \\
\hline $15-\mathrm{A} 3$ & 302 \\
\hline 15-B1 & 304 \\
\hline $15-\mathrm{B} 2$ & 290 \\
\hline 15-B3 & 281 \\
\hline $15-\mathrm{C} 1$ & 258 \\
\hline $15-\mathrm{C} 2$ & 269 \\
\hline $15-\mathrm{C} 3$ & 256 \\
\hline 15-D1 & 209 \\
\hline 15-D2 & 204 \\
\hline 15-D3 & 215 \\
\hline 11-Soil & 148 \\
\hline 11-Sap & 146 \\
\hline 12-Soil & 314 \\
\hline 12-Sap & 204 \\
\hline 13-Soil & 283 \\
\hline 13-Sap & 196 \\
\hline
\end{tabular}


Appendix C. 1. ${ }^{10}$ Bef Be ratios, ${ }^{10}$ Be concentrations and additional information associated with calculating catchmentaveraged denudation rates. Catchment-averaged denudation rates were calculated using both version 2.3 and version 3 of the online erosion rate calculator (Balco et al., 2008). Further values needed for calculation included sample density of 2.65 $\mathrm{g} \mathrm{cm}^{-3}$, elevation/pressure flag 'std', thickness of $0.1 \mathrm{~cm}$ (surface concentrations) and the AMS standard for Be KNSTD (Nishiizumi et al., 2007).

\begin{tabular}{|c|c|c|c|c|c|c|c|c|}
\hline Sample & Latitude & Longitude & $\begin{array}{c}\text { Elevation } \\
\text { (m asl) }\end{array}$ & $\begin{array}{l}\text { Shielding } \\
\text { correction }\end{array}$ & $\begin{array}{c}\text { Quartz } \\
\text { mass (g) }\end{array}$ & $\begin{array}{c}{ }^{9} \text { Be mass } \\
(\mu \mathrm{g})\end{array}$ & $\begin{array}{c}{ }^{10} \text { Be conc. } \\
\left(10^{3} \text { at }\right)\end{array}$ & $\begin{array}{c}{ }^{10} \text { Be conc } \\
(1 \sigma) \\
\left(10^{3} \text { at }\right)\end{array}$ \\
\hline Akitio & -40.549 & -176.397 & 211 & 1 & 32.4204 & 396.954 & 8.9750 & 2.7651 \\
\hline Awatere & -41.667 & -174.04 & 927 & 1 & 24.7644 & 396.695 & 13.0717 & 3.6482 \\
\hline Bealey & -43.003 & -171.591 & 1283 & 1 & 26.4764 & 397.139 & 3.1332 & 3.1987 \\
\hline Clarence & -42.158 & -173.898 & 1089 & 1 & 23.5168 & 395.476 & 6.3910 & 3.6253 \\
\hline Rakaia & -43.515 & -171.637 & 1082 & 1 & 34.474 & 394.737 & 0.7995 & 2.3595 \\
\hline Rangitata & -44.169 & -171.468 & 1065 & 1 & 22.7808 & 395.032 & -0.4695 & 3.5778 \\
\hline Waimakariri & -43.017 & -171.59 & 1282 & 1 & 7.0157 & 395.254 & -0.3014 & 11.5552 \\
\hline Whareama & -40.997 & -176.082 & 174 & 1 & 24.6914 & 395.956 & 7.2751 & 3.5733 \\
\hline
\end{tabular}


${ }^{10} \mathrm{Be} /{ }^{9} \mathrm{Be} \quad{ }^{10} \mathrm{Be} /{ }^{9} \mathrm{Be}$

$\left(10^{-15}\right) \quad(1 \sigma)\left(10^{-15}\right)$


Appendix C. 3. Results of catchment-averaged denudation rates calculated by the online earth calculator (V. 3 \& V. 2.3) (Balco, 2017; Balco et al., 2008) for three scaling scheme; St (Stone, 2000), Lm (Balco et al., 2008) and LSDn (Lifton, Sato, \& Dunai, 2014). Italicised and single-asterisk results are 'true' mean estimates calculated using only ${ }^{10}$ Be concentrations (atoms $\left.g^{-1}\right)$ in V. 2.3 of the calculator, thus results are using only the Lal/St scaling scheme (D. Lal, 1991; Stone, 2000), uncertainty could not be calculated as the confidence interval includes zero. Double-asterisk results are minimum estimates calculated using V. 3 of the calculator by adding ${ }^{10}$ Be concentrations (atoms $\left.g^{-1}\right)$ and ${ }^{10}$ Be error (atoms $g^{-1}$ ).

\begin{tabular}{|c|c|c|c|c|c|c|c|c|c|c|c|c|}
\hline \multirow[b]{2}{*}{ Sample } & \multicolumn{4}{|c|}{ St } & \multicolumn{4}{|c|}{$\mathrm{Lm}$} & \multicolumn{4}{|c|}{ LSDn } \\
\hline & $\begin{array}{l}\text { Erosion rate } \\
\left(\mathrm{g} \mathrm{cm}^{2} \mathrm{yr}^{-1}\right)\end{array}$ & $\begin{array}{c}\text { Erosion } \\
\text { rate } \\
\left(\mathrm{m} \mathrm{Myr}^{-1}\right)\end{array}$ & $\begin{array}{c}\text { Internal } \\
\text { uncertainty } \\
\left(\mathrm{m} \mathrm{Myr} \mathbf{r}^{-1}\right)\end{array}$ & $\begin{array}{c}\text { External } \\
\text { uncertainty } \\
\left(\mathrm{m} \mathrm{Myr} \mathrm{r}^{-1}\right)\end{array}$ & $\begin{array}{c}\text { Erosion rate } \\
\left(\mathrm{g} \mathrm{cm}^{2} \mathrm{yr}^{-1}\right)\end{array}$ & $\begin{array}{c}\text { Erosion } \\
\text { rate } \\
\left(\mathrm{m} \mathrm{Myr}^{-1}\right)\end{array}$ & $\begin{array}{c}\text { Internal } \\
\text { uncertainty } \\
\left(\mathrm{m} \mathrm{Myr} \mathbf{r}^{-1}\right)\end{array}$ & $\begin{array}{c}\text { External } \\
\text { uncertainty } \\
\left(\mathrm{m} \mathrm{Myr} \mathbf{~ M y ~}^{-1}\right)\end{array}$ & $\begin{array}{c}\text { Erosion rate } \\
\left(\mathrm{g} \mathrm{cm}^{2} \mathrm{yr}^{-1}\right)\end{array}$ & $\begin{array}{c}\text { Erosion } \\
\text { rate } \\
\left(\mathrm{m} \mathrm{Myr} \mathrm{r}^{-1}\right)\end{array}$ & $\begin{array}{c}\text { Internal } \\
\text { uncertainty } \\
\left(\mathrm{m} \mathrm{Myr} \mathrm{r}^{-1}\right)\end{array}$ & $\begin{array}{c}\text { External } \\
\text { uncertainty } \\
\left(\mathrm{m} \mathrm{Myr} \mathbf{r}^{-1}\right)\end{array}$ \\
\hline Akitio & 0.12 & 454 & 140 & 145 & 0.122 & 461 & 142 & 146 & 0.113 & 427 & 131 & 134 \\
\hline Awatere & 0.139 & 523 & 146 & 152 & 0.141 & 532 & 149 & 154 & 0.135 & 510 & 143 & 146 \\
\hline Bealey* & 0.755 & 2848 & - & - & - & - & - & - & - & - & - & - \\
\hline Bealey** & 0.396 & 1490 & - & - & 0.409 & 1540 & - & - & 0.405 & 1530 & - & - \\
\hline Clarence & 0.329 & 1240 & 705 & 712 & 0.34 & 1280 & 727 & 734 & 0.331 & 1250 & 708 & 712 \\
\hline Rakaia* & 2.594 & 9790 & - & - & - & - & - & - & - & - & - & - \\
\hline Rakaia** & 0.852 & 3220 & - & - & 0.894 & 3370 & - & - & 0.868 & 3280 & - & - \\
\hline Rangitata** & 0.872 & 3290 & - & - & 0.914 & 3450 & - & - & 0.89 & 3360 & - & - \\
\hline Waimakariri** & 0.211 & 796 & - & - & 0.216 & 814 & - & - & 0.213 & 805 & - & - \\
\hline Whareama & 0.146 & 549 & 270 & 273 & 0.148 & 558 & 274 & 277 & 0.138 & 522 & 256 & 258 \\
\hline
\end{tabular}

